\title{
Petr Stolypin: The making of a cultural memory
}

\section{Wijermars, Marielle}

Routledge

2018

Wijermars , M 2018 , Petr Stolypin: The making of a cultural memory . in MEMORY POLITICS IN CONTEMPORARY RUSSIA: TELEVISION, CINEMA AND THE STATE .

Studies in Contemporary Russia, Routledge , OXFORD, ENGLAND , pp. 41-83 . https://doi.org/10.4324/978135100

http://hdl.handle.net/10138/324769

https://doi.org/10.4324/9781351007207

cc_by_nc_nd

publishedVersion

Downloaded from Helda, University of Helsinki institutional repository.

This is an electronic reprint of the original article.

This reprint may differ from the original in pagination and typographic detail.

Please cite the original version. 


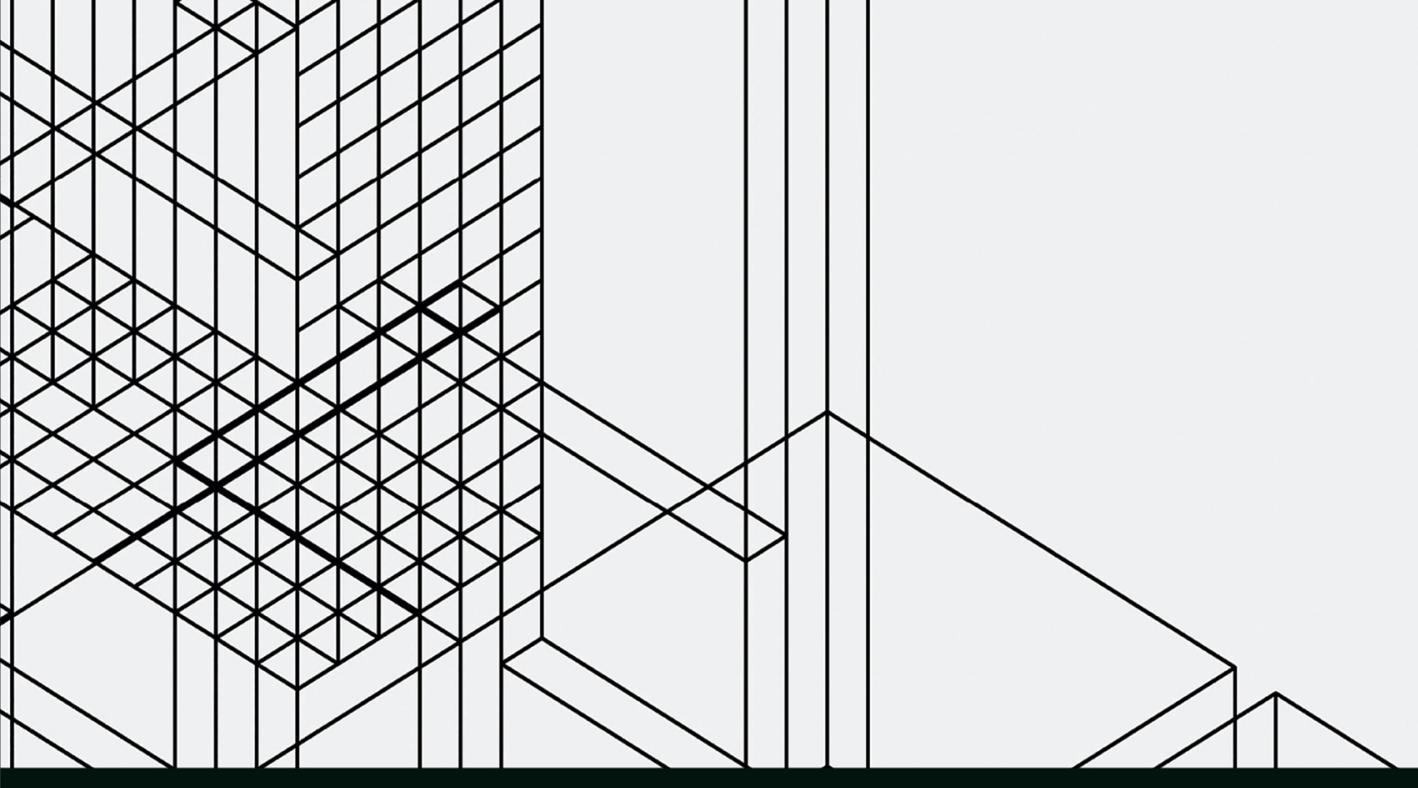

\section{Studies in Contemporary Russia}

\section{MEMORY POLITICS IN CONTEMPORARY RUSSIA \\ TELEVISION, CINEMA AND THE STATE}

Mariëlle Wijermars

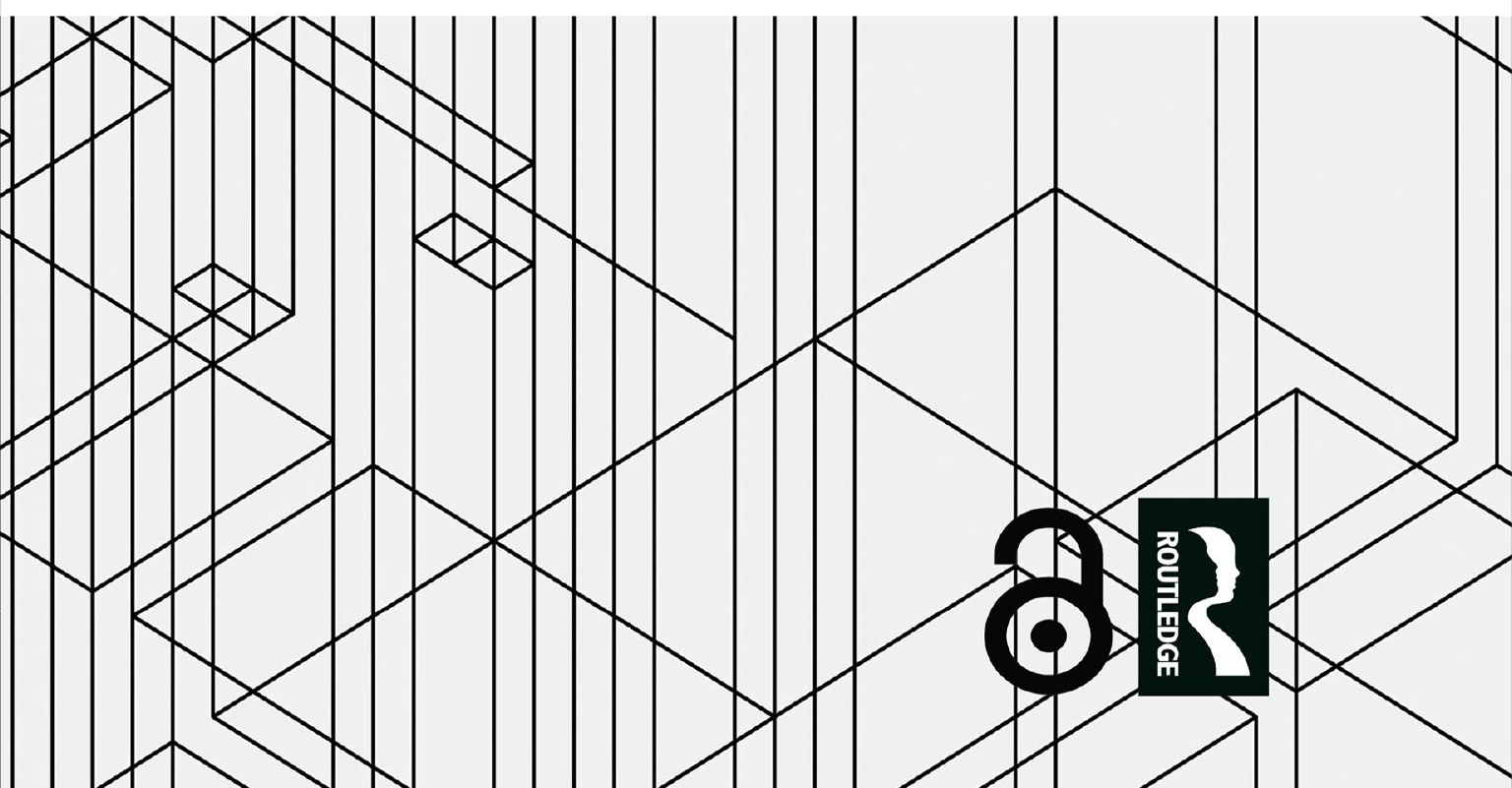




\section{Memory Politics in Contemporary Russia}

This book examines the societal dynamics of memory politics in Russia. Since Vladimir Putin became president, the Russian central government has increasingly actively employed cultural memory to claim political legitimacy and discredit all forms of political opposition. The rhetorical use of the past has become a defining characteristic of Russian politics, creating a historical foundation for the regime's emphasis on a strong state and centralised leadership.

Exploring memory politics, this book analyses a wide range of actors, from the central government and the Russian Orthodox Church to filmmaker and cultural heavyweight Nikita Mikhalkov and radical thinkers such as Aleksandr Dugin. In addition, in view of the steady decline in media freedom since 2000, it critically examines the role of cinema and television in shaping and spreading these narratives. Thus, this book aims to promote a better understanding of the various means through which the Russian government practices its memory politics (e.g. the role of state media) while at the same time pointing to the existence of alternative and critical voices and criticism that existing studies tend to overlook.

Contributing to current debates in the field of memory studies and of current affairs in Russia and Eastern Europe, this book will be of interest to scholars working in the fields of Russian studies, cultural memory studies, nationalism and national identity, political communication, film, television and media studies.

Mariëlle Wijermars is a postdoctoral researcher at the Aleksanteri Institute, University of Helsinki. 


\section{Studies in Contemporary Russia}

Series Editor: Markku Kivinen

Studies in Contemporary Russia is a series of cutting-edge, contemporary studies. These monographs, joint publications and edited volumes branch out into various disciplines, innovatively combining research methods and theories to approach the core questions of Russian modernisation; how do the dynamics of resources and rules affect the Russian economy and what are the prospects and needs of diversification? What is the impact of the changing state-society relationship? How does the emerging welfare regime work? What is the role of Russia in contemporary international relations? How should we understand the present Russian political system? What is the philosophical background of modernisation as a whole and its Russian version in particular?

The variety of opinions on these issues is vast. Some see increasingly less difference between contemporary Russia and the Soviet Union while, at the other extreme, prominent experts regard Russia as a 'more or less' normal European state. At the same time new variants of modernisation are espoused as a result of Russian membership of the global BRIC powers. Combining aspects of Western and Soviet modernisation with some anti-modern or traditional tendencies the Russian case is ideal for probing deeper into the evolving nature of modernisation. Which of the available courses Russia will follow remains an open question, but these trajectories provide the alternatives available for discussion in this ground-breaking and authoritative series.

The editor and the editorial board of the series represent the Finnish Centre of Excellence in Russian Studies: Choices of Russian Modernisation.

For more information about this series, please visit: www.routledge.com/ series/ASHSER-1421

\section{Russia and the EU}

Spaces of Interaction

Edited by Thomas Hoffmann and Andrey Makarychev

\section{Memory Politics in Contemporary Russia}

Television, Cinema and the State

Mariëlle Wijermars 


\section{Memory Politics in Contemporary Russia}

Television, cinema and the state

\section{Mariëlle Wijermars}


First published 2019

by Routledge

2 Park Square, Milton Park, Abingdon, Oxon OX14 4RN

and by Routledge

711 Third Avenue, New York, NY 10017

Routledge is an imprint of the Taylor \& Francis Group, an informa business

(c) 2019 Mariëlle Wijermars

The right of Mariëlle Wijermars to be identified as author of this work has been asserted by her in accordance with sections 77 and 78 of the Copyright, Designs and Patents Act 1988.

The Open Access version of this book, available at www.taylorfrancis.com, has been made available under a Creative Commons Attribution-Non Commercial-No Derivatives 4.0 license.

Trademark notice: Product or corporate names may be trademarks or registered trademarks, and are used only for identification and explanation without intent to infringe.

British Library Cataloguing in Publication Data

A catalogue record for this book is available from the British Library

Library of Congress Cataloging in Publication Data

A catalog record has been requested for this book

ISBN: 9781138543195 (hbk)

ISBN: 9781351007207 (ebk)

Typeset in Times New Roman

by Taylor \& Francis Books 


\section{Contents}

Acknowledgements vii

1 Introduction 1

Memory politics beyond the Kremlin walls 2

Governmental memory politics in post-Soviet Russia 5

History on the small and big screens 9

Methodology 13

2 Memory politics and the remediation of cultural memory

Cultural memory and political legitimacy 19

The politics of memory: conformity and contestation 21

Memory politics on screen 23

Remediation 30

Case studies

3 Petr Stolypin: The making of a cultural memory

Stolypin in the Russian historical and political imagination 41 Institutionalisation of Stolypin's memory 44

Film and television analyses 51

Petr Stolypin ... The Undrawn Lessons (2006) 52

The Name is Russia (2008): Petr Stolypin 65

Petr Stolypin: A Shot at Russia (2012) 72

Conclusion 79

4 Aleksandr Nevskii: The saviour of Orthodox civilisation

Nevskii in the Russian historical and political imagination 84 $A$ beacon of Orthodox morality in the face of globalisation 88

The Russian Orthodox Church and cultural memory 91 Nevskii as the founding father of Russian foreign policy 97 
vi Contents

Film and television analyses 100

Aleksandr: The Neva Battle (2008) 100

The Name is Russia (2008) 107

Conclusion 118

5 The Time of Troubles: The cyclical return of chaos

122

The Time of Troubles in the Russian political and cultural imagination 124

Institutionalisation of the memory: the Day of National Unity 129

Memory chains 136

Film and television analyses 140

TV documentaries on the occasion of the Day of National Unity (2005-2006) 140

1612: Chronicles of the Time of Troubles (2007) 148

Boris Godunov (2011) 153

Conclusion 159

6 Ivan the Terrible and the Oprichnina: Subversive histories

164

Ivan the Terrible in the Russian historical and political imagination 165

The concept of 'Novaia Oprichnina' 171

Ivan the Terrible and Orthodox fundamentalism 179

Film and television analyses 183

Ivan the Terrible (2009) 184

Tsar (2009) 192

The Trial of Time (2010) 199

Conclusion 204

7 The Trial of Time

The trial of The Trial of Time 209

Cancellation and reappearance 212

8 Conclusion

List of interviews 


\section{Acknowledgements}

There are many people who, in various ways, helped me complete this study and to whom I owe my heartfelt gratitude. First of all, to Sander Brouwer, whose contribution to the project from initial idea to completion has been invaluable. Thank you, Sander, for your friendship and your unfailing trust in my potential. I also wish to express my heartfelt gratitude to Joost van Baak for his sincere enthusiasm for the project and encouraging nudges along the way. Finally, a thank you is in order to Boris Noordenbos for his feedback on the initial project idea. The research for this book was conducted at the University of Groningen, where the first version of the book was completed in the summer of 2016. I am grateful to the Aleksanteri Institute of the University of Helsinki for the institutional support I have received while preparing the manuscript for publication.

With regard to my research stay in Moscow, I wish to thank Galina Zvereva for hosting me at the Russian State University for the Humanities and for offering me advice. I owe gratitude to Andrei Shemiakin, Il'ia Kukulin and Ekaterina Lapina-Kratasiuk who consulted with me during my stay. I also wish to thank Marina Frolova-Walker for offering me a home-away-from-home in Moscow as well as first-class companionship. A special thank you goes to Natal'ia Iakovlevna Venzher for sharing her extensive knowledge of Russian cinema and television production and state financing, for allowing me to make use of her personal database of television broadcasts and, above all, for her heartfelt hospitality. To the members of the Foreign Historians Club (you know who you are) who provided me with company during the long winter months. Finally, I wish to thank my interviewees as well as the other people I met during my stay in Moscow for their kindness, generosity and trust. Despite increasing socio-political tensions and evident pressure on those working in cinema and television at the time when I did my fieldwork in autumn and winter 2014, they welcomed me with incredible openness and generosity.

Earlier versions of several chapters were presented at conferences and workshops in Belgium, Denmark, Japan, the Netherlands, Russia, the United Kingdom and the United States; I wish to thank the audiences and discussants for their valuable remarks and encouragements. A personal thank you is in order to Otto Boele, Graeme Gill and Yngvar Steinholt for reading 
and commenting on parts of the manuscript. To Hanna Stähle, for commenting on parts of the manuscript and advising me on translation matters. And to Kseniia Rovinskaia for helping me wrestle with untranslatable Russian slang.

Finally, a very special thank you goes out to Niké Wentholt, the best office mate in the world, who generously offered me the key to her vacant home for the final stretch of the research for this book. And, of course, to Richard, for keeping me sane along the way and for always pushing me to dream bigger.

Part of my research was facilitated by a European Union Erasmus Mundus Action 2: Aurora mobility grant, which allowed me to spend six months as a visiting doctoral researcher at the Russian State University for the Humanities in Moscow. Parts of chapter 3, in their earlier versions, appeared in Problems of Post-Communism and The Ideology and Politics Journal. I am grateful to the publishers for their permission to include these materials here.

The transliteration of Russian names and terms is based on the modified Library of Congress system. Most place names are transliterated according to English common usage. The same applies to proper names in those cases where an English equivalent is more generally accepted (for example, Yeltsin instead of El'tsin and Peter the Great instead of Petr I). All translations are mine, unless stated otherwise. 


\section{Introduction}

In the Alexander Gardens in Moscow, next to the Kremlin walls, stands a granite memorial obelisk. It was erected in 1914 to commemorate the 300th anniversary of the Romanov dynasty, but its intended eternal endurance proved short-lived. In 1918, as the Civil War raged across the territory of the former Russian Empire, the obelisk received a makeover. It was refashioned to correspond to the idols of the fledgling socialist state: the Imperial doubleheaded eagle at its crown was removed, and the inscribed names of the Romanov tsars were replaced with those of socialist revolutionaries and philosophers. Then, in 1966, it was relocated to the centre of the gardens to make room for the Tomb of the Unknown Soldier - a symbolic affirmation of the then emerging myth of the Soviet victory in the Second World War. And thus the obelisk stood, as the politically and socially revered idols of the Soviet state ceased to be worshipped and eventually that very state ceased to exist. By then, the names inscribed on the obelisk sounded foreign to the average person's ear; indeed, many belonged to Western European thinkers and proponents of the socialist cause. ${ }^{1}$

On the occasion of the 400th anniversary of the Romanov dynasty in 2013 - a manifestly artificial anniversary that was nonetheless extensively marked - the obelisk was restored to its original state. ${ }^{2}$ On 4 November, the Day of National Unity, the monument was unveiled and blessed by the patriarch of Moscow and All Russia Kirill (Gundiaev). In his speech, the patriarch emphasised the symbolic significance of the restoration for the consolidation of national unity and, by extension, the future existence of the Russian state:

We cannot live divorced from our history, we cannot think that our state is little more than 80 years old or, as is sometimes said, little more than 20 years. We are heirs to a thousand-year history, and if we acknowledge this linkage to history, to times past, if we acknowledge our connection with the heroes of the past, then we are imbued with national consciousness and a sense of dignity, without which a nation [narod] cannot exist. 


\section{Introduction}

A similar sentiment was expressed by Sergei Ivanov, chief of staff of the presidential administration. He commented: 'In commemorating this date today, and in unveiling this stele, we pay tribute to the Romanov dynasty and return to our roots ... . It is the continuity of history' (Mel'nikov \& Mal'tsev 2013).

The history of the obelisk and the significance attributed to its restoration in the statements quoted here is one of countless examples of how, in contemporary Russia, the state has sought to turn the past into a powerful symbolic resource. In the period since Vladimir Putin first became president in 2000 , the Russian central government has increasingly actively engaged in such memory politics ${ }^{3}$ : employing cultural memory to claim the political legitimacy of those in power, as well as discredit all forms of political opposition (e.g. Laruelle 2009; Miller 2012; Sherlock 2007; Sherlock 2011; Vázquez Liñán 2010). The rhetorical use of the past has since become a defining characteristic of Russian politics. ${ }^{4}$ The government's strategy of memory politics has aimed to create a continuous narrative of a Great Russia (velikaia Rossiia) that has been under constant threat from domestic and foreign enemies. Drawing upon both the recent and distant past, it aimed to create a historical foundation for the regime's emphasis on a strong state and centralised leadership. The Soviet past has become an integral part of this overarching narrative, in which the Putin era is presented as the logical next episode.

\section{Memory politics beyond the Kremlin walls}

Yet the Russian government is not the only one who has used cultural memory to spread its ideas about how the Russian state 'traditionally' should be governed. Various societal, cultural and religious groups and organisations have put forward their own historically framed visions on Russian statehood. This book examines this societal dynamics of memory politics in contemporary Russia in the period 2000-2012. I analyse a wide range of actors, from the central government and the Russian Orthodox Church we already came across above, to filmmaker and cultural heavyweight Nikita Mikhalkov and radical thinkers such as Aleksandr Dugin. In addition, in view of the steady decline in media freedom since 2000 (Hutchings \& Tolz 2015), I critically examine the role of cinema and television in shaping and spreading these narratives. Thus, this book aims to, on the one hand, gain a better understanding of the various means through which the Russian government practises its memory politics (e.g. the role of state-aligned media) and, on the other hand, sufficiently value the existence of alternative and critical voices that existing studies tend to overlook.

In this book I aim to answer the following set of interrelated research questions:

1 In what way have various actors in Russian society, as well as the state, mobilised cultural memory to legitimise, question or challenge the political regime? 
2 Which cultural memories have been employed, by whom and to what end?

3 How have these actors drawn upon existing interpretations and representations of the respective cultural memories to shape their contributions to the debate on history and political legitimacy?

The way that scholars typically approach Russian memory politics - that is, through analysis of how the state employs references to history to support its legitimacy and frame its political course - suggests that the state is a proactive and dominant player in these 'memory games' (Mink \& Neumayer 2013). These studies allow the impression to persist that there has been no societal, political or cultural resistance to the regime's claims. However, in every society, state and non-state actors at various levels contest with one another in efforts to provide that society with meaning in the present through representations of the past, and thus, with guidance to determine its political and ideological orientation towards the future. The same applies to twenty-firstcentury Russia. The state does not act in isolation. It is part of a complex socio-political process of negotiating the contemporary meaning of history and the political implications resulting from that meaning. The role played by non-state actors at the national level, both as accomplices in and as opponents to official memory politics, has thus far been insufficiently addressed. The differentiation between state and non-state actors in today's Russia is notoriously murky: within the intricate maze of interactions between state officials, state-sponsored and 'state-aligned' persons and organisations, drawing a definite line between these two spheres is a near impossible task. In my usage of the terms, state actor should therefore be understood in its most concrete sense as referring to the actions and statements of the Russian government, state officials and so on. Non-state actor, then, refers to the grey zone beyond the state's official structures and ranges from the 'state-loyal' to the outspokenly oppositional. It is the complexity of this grey zone and its manifold connections to and interactions with the state that I aim to explore.

In view of the decline since 2000 in the freedom granted to the media including television (Hutchings \& Rulyova 2009; Hutchings \& Tolz 2015) - it is imperative to also examine how memory politics extends into the domain of mass media and popular culture. It is here, in television and cinema, that state efforts to control public opinion are most pronounced; they have been much less stringent, for instance, in relation to literature. To avoid oversimplifying the means through which (authoritarian) political regimes mediate their views, it is essential to critically examine cultural productions about history aimed at a mass audience. To gain strength, an interpretation of history has to be mediated at multiple levels of society. It is precisely the interplay between these levels, official and unofficial, that influences the potential effect of government-supported cultural memories. In this study I seek to address these gaps. My analysis covers the years 2000 through 2012, a turning point after which the state's memory politics changed substantially (as I will 


\section{Introduction}

elaborate on shortly), and refers to earlier and subsequent developments wherever relevant.

To accommodate the inclusion of non-governmental actors and the sphere of popular culture, I develop an alternative approach to memory politics. Here, I define the latter concept as the mobilisation of cultural memory to put forward political claims and, in particular, to propagate historically informed visions of what constitutes 'traditional Russian' state governance. Memory politics is thus conceived as not just a political but also a social process of negotiating the meaning of the past - a process in which the state, one must add, has a disproportionately large stake. I seek to move away from static conceptualisations of memory politics - such as those guiding studies that chronicle acts of memory politics and explain their meanings - towards a dynamic model: a conceptualisation that includes other societal and cultural actors operating at the national level and that can shed light on the dynamic development of memory politics over time and across the political and sociocultural spectrum. I offer an alternative approach that, looking beyond the Russian state's apparent hegemony on memory in the public domain, can uncover divergent or competing voices in the national public discourse.

On the basis of four extensive thematic case studies and one smaller case study, I demonstrate, first, how the state has relied on memories with rich histories of cultural representation and political instrumentalisation to portray itself as traditional. Yet the accumulated meanings of these constellations of memory greatly increase their subversive potential by providing access points for the formulation of a historically framed political critique. Second, I argue that non-state actors have played a highly significant role in memory politics during this period. Moreover, the behaviour of the government in this respect should in some cases be characterised as reactive rather than proactive and shows clear signs of continuous re-evaluation and adaptation.

The history of the memorial obelisk and the framing of its recent renovation exemplify the three aspects of contemporary Russian memory politics that are central to my argument in this study. The first aspect is the emphasis on the continuity of Russian history. In direct response to the definite break with the past favoured by Boris Yeltsin's regime during the 1990s, to which I will return shortly, Putin's memory politics in the new millennium has sought to reintegrate the Russian Federation into an extended historical narrative. Second, the memorial obelisk illustrates the palimpsestic layering of this memory politics - how contemporary memory culture (implicitly and explicitly) engages with and builds upon previous symbolic practices and their visual, narrative and material traces. In this particular case, the act of restoration was actually presented as an 'un-layering' of memory, as a correction of the (supposedly unrighteous) Soviet appropriation of the monument. In the words of Patriarch Kirill, by restoring the names of the Russian tsars to the obelisk, 'the most historically unjust action [was] corrected' (Samsonova 2013). The patriarch's phrasing brings me to the third aspect, namely that, in contemporary Russia, memory politics goes beyond claiming 
the existence of a state-oriented tradition to legitimise the current political regime. It is equally preoccupied with reclaiming lost traditions of remembrance. By framing essentially new symbolic acts as the continuation of commemorative practices that were forcibly abolished in Soviet and postSoviet times, the state pretends to undo past damages rather than impose its own memory regime.

Two important media domains fall beyond the scope of my investigation. With regard to television, I have chosen to exclude television journalism. Journalistic coverage of historical topics, for instance concerning exhibits or special events, or around commemorative dates, is controlled from the top down to a fairly large extent. Therefore, I only note when coverage deviates in important ways from the state-supported narrative. Moreover, the relation between the Kremlin and national media outlets during this period is extensively covered in the literature (e.g. Oates 2006; Arutunyan 2009; Beumers et al. 2009; Hutchings \& Rulyova 2009; Burrett 2011; Schimpfossl \& Yablokov 2014; Hutchings \& Tolz 2015). The role of non-journalistic television in memory politics, such as the television series and documentaries analysed in this study, has largely been neglected. Yet these programmes' characteristics their longer playing time, which allows for the development of an argument, their rich associations of genre, their extensive use of stylistic devices and an emotionally persuasive soundtrack to support particular interpretations of historical events, and so on - make them particularly adept at creating lasting memory images. At the same time, these precise characteristics can introduce ambiguities and make it difficult to control the exact meaning of their messages. This merits in-depth examination. Second, my analysis of online memory discourses is limited. I use online forums to (retrospectively) assess audience reception of the cinema and TV productions that I am analysing. Yet since my research is focused on the competition between the state and the various non-state actors that operate at the national level - the political and cultural elite, if you will - rather than with local or grassroots developments, a comprehensive examination of these online memory discourses lies beyond the scope of this study.

In what follows I will first sketch the development of memory politics as the Russian state has practised it since 1991. This brief discussion of the main trends in governmental policy serves as a necessary introduction and background to the multi-actor analyses in the case studies. Then, I will summarise the most important trends in historical programming for both the big and small screens, as well as key developments in state policy regarding television and film production. The final section describes this study's methodology and outlines the book's structure.

\section{Governmental memory politics in post-Soviet Russia}

The dissolution of the Soviet Union made suddenly obsolete the Communist meta-narrative that had previously guided all aspects of political, economic, 


\section{Introduction}

cultural and personal life. State collapse created a rupture between the Soviet past and the still unknown path to the future. The historic events that the population had commemorated and the Soviet myths that had guided their interpretation of the world and themselves were rejected, but the search for viable substitutes proved a complicated process. For many Russians, their newly acquired democratic freedoms were scant consolation for the loss of state-sponsored services, overall stability and societal solidarity. Having lost its Soviet empire, Russia found itself still at the beginning of the process of building a nation. That the Communist meta-narrative was essentially a historical narrative, based on the assumption that communism was the final stage of historical development, intensified the cultural impact of its being disavowed (Yurchak 2006). The loss of Communist teleology occasioned an acute search 'for its substitute, for another convincing plot of Russian development that will help make sense of the chaotic present' (Boym 2001: 59). During the 1990s, political and cultural elites proved unable to fill this void with new coherent narratives of national identity (Tolz 2001; Smith 2002). The regime of Yeltsin, in fact, based its political legitimacy on historical discontinuity by rejecting the Soviet period in its entirety. With a lack of historical examples to draw on (the autocratic tradition represented by tsarist Russia was thought to be as unsuitable as Soviet communism), the government framed the extensive reforms of the 1990s within a narrative of Western ideals of capitalism and democracy.

Only in response to the increasing popularity of the Communist Party of the Russian Federation, which actively mobilised the Soviet past in its campaigns, did the state reluctantly become involved in memory politics. The 50th anniversary of the victory in World War II was publicly commemorated in 1995, albeit modestly in comparison to similar celebrations staged more recently. ${ }^{5}$ Following Yeltsin's re-election in 1996, the government took more concrete steps. Acknowledging that social cohesion needed a 'national idea' to compensate for a lack of ideology, the government established a commission to formulate an 'idea for Russia'. The initiative, which was unable to produce a viable result, is indicative of the overall failure of the state to coherently and effectively engage history to its advantage (Smith 2002: 178).

As Kathleen Smith notes, 'toward the end of his second term [...] Yeltsin wanted to promote stability and reconciliation, but without encouraging historical amnesia' (idem: 179). His successor, Vladimir Putin, held on to the former of these elements, but took a far more permissive stance towards the latter. Cherry-picking his way through recent and distant history alike, he set as the main goal of governmental memory politics the restoration of national pride. Tapping into, on the one hand, persistent popular sentiments of uncertainty and national inferiority (Oushakine 2009) and, on the other, increasing nostalgic tendencies with regard to both Soviet and imperial pasts, the regime now showed itself to be acutely aware of the political usefulness of historical symbolism. Within Putin's first year in office, he settled all the major disputes over state symbolism, which had dragged on for most of the 
1990s. Most significantly, the Soviet national anthem was reinstated. Its new lyrics were written by Sergei Mikhalkov, who also composed the original lines dating to the 1940s, as well as their de-Stalinised version from the 1970s. This symbolic act set the tone: rather than harking back to one particular period in history, the various and seemingly incompatible stages of the development of Russian statehood - tsarist, Soviet and post-Soviet - were reconceived as integral parts of its history. As Marlène Laruelle rightly points out,

[w]hile the desire to regain the geopolitical power lost in 1991 is obvious, these symbols have not been restored purely and simply for their ideological value - communism itself has not been rehabilitated - but because they are part of a cultural background common to the entire population and are seen as an indication of normalcy.

(Laruelle 2009: 155)

In other words, the recognisability of the constitutive elements of state symbolism is key.

Memory politics intensified especially around 2005 (Horvath 2013; Miller 2012). This was part of the state's response to the colour revolutions that ended in several regime changes in and beyond the post-Soviet region, including in neighbouring Georgia and Ukraine. The Kremlin took notice as a wave of peaceful protest swept across the former Soviet space and, fearing that something similar would happen in Russia, responded accordingly. It initiated a 'preventive counter-revolution' that repressed societal groups that could potentially form a support base for revolution (most notably, nongovernmental organisations) and, at the same time, engaged in proactive mobilisation - for instance, by means of patriotically oriented youth movements (Horvath 2013: 5-7). ${ }^{6}$ The campaign's ideological underpinning was the idea that 'Russia's sovereignty was menaced by Western efforts to foment a revolution and impose "external rule" (idem: 6). In this narrative, opposition groups were branded as cat's paws of foreign forces seeking to undermine and destroy the Russian state. The intensity of this wave of official memory politics peaked between 2007 and 2010. Among other measures, the government supported the 2007 textbook History of Russia: 1945-2006 written by Aleksandr Danilov and Aleksandr Filippov, which caused an international scandal for referring to Stalin as an 'effective manager', and, in 2009, Medvedev signed a decree to set up a Presidential Commission to Counter Attempts to Falsify History (Miller 2012; Sherlock 2016). This commission was dissolved in early 2012. During this period, conflicts concerning the interpretation of history regularly flared up between Russia and neighbouring countries in Eastern Europe. ${ }^{7}$

Nikolay Koposov correctly points out that, as relations with the West improved, 'aggressive memory politics [became] inappropriate' (Koposov 2011b). President Medvedev now 'unambiguously condemned Stalin's crimes, declared the memory of the repressions to be as "sacred" as that of the heroic 


\section{Introduction}

exploits during the Second World War, and attempted to liberate the story of the war from the taint of neo-Stalinism' (ibid.). The repositioning with regard to Stalin did not mean, however, that there was an abandonment of memory politics. Quite the contrary. The 2010 Victory Day Parade in Moscow, marking the 65th anniversary of the end of World War II, was the largest parade held in Russia since the dissolution of the Soviet Union. While the format of the parade changes somewhat from year to year, ${ }^{8}$ it has since retained its symbolic importance as (one of) the principle patriotic events of the year (Lutz-Auras 2012; Malinova 2017). In addition, with several convenient memorial dates to draw from in 2012 and signs of brewing societal unrest becoming ever more evident, the Kremlin again turned to history to underpin its legitimacy, as I will address in chapters 3 and 5.

Although this study covers the years 2000-2012, it should be emphasised that the intensity of memory politics has not abated since then. On the contrary, the state has stepped up its mobilisation of history, in particular the memory of the Second World War, in the context of the conflict in Ukraine. Putin's return to the presidential office in 2012 also signalled a shift towards a more ethnonationalist interpretation of Russian national identity. The Russian government started to 'deliberately blur the boundaries between the civic rossiiskii and the ethnic russkii identities. The civic identity has become more explicitly Russian, with the Kremlin holding up the Russian language, culture and traditional values as the core of this identity' (Blakkisrud 2016: 267. Italics in original). This marked departure in the state's identity politics and mobilisation of memory substantiates my decision to view the start of Putin's third presidential term as a turning point in the development of memory politics and to limit my analysis to the years 2000-2012.

If we look more closely at which narrative frameworks have been employed, it becomes clear that a variety of historical references have been used to demonstrate both the historical necessity and the traditionally Russian character of what has come to be known as 'managed democracy', the 'vertical of power', and so on. To some extent, politically useful cultural memories have been employed interchangeably; different historical images or narrative frameworks were employed to deliver more or less the same political message. Still, as will become clear from the case studies (in particular, those of chapters 3 and 5), one can discern significant shifts in preference for certain cultural memories. Moreover, the state's use of history can be categorised according to two (at times interconnected) core ideas. The first constellation of narratives aimed to promote the concept that, under the new president, political order and stability had been restored following a period of intense political, economic, social and spiritual turmoil. The promise of (continued) economic prosperity and the return of Russia as a great power in the international arena complemented this narrative of Russia's rebirth from its ashes.

A second group of narratives established a lineage of 'great Russian reformers'. This lineage includes familiar faces such as Peter the Great and Aleksandr II, but also newcomers such as the prerevolutionary prime minister Petr 
Stolypin (see chapter 3). Connected to the latter trend is the much wider debate concerning 'Russian' models for modernisation. The paradoxical central claim of the state's memory politics can thus be summarised as modernisation through restoration and preservation. Despite the apparent simplicity and appeal of such an aim, it is by no means self-evident what it actually means to reform and modernise the state in a way true to Russia's 'natural' predisposition to a certain type of governance. However much the Kremlin would prefer it to be otherwise, it has not been the only one to put forward its views on how Russia can be modernised 'in a Russian way'. Competing views abound, albeit with differing measures of sophistication, leverage and general political and societal impact (see chapter 4 and, in particular, chapter 6).

The understandings of the development of Russian history underlying official memory politics on the one hand and oppositional narratives about the (predestined) nature of governance in Russia on the other are predicated on different dichotomies. While the state interprets the dramatic turns in history to be alternations of periods of chaos and order, its opponents view them as cycles of relative freedom (e.g. the Thaw, Perestroika) and repression (e.g. Stalinism, Stagnation and, by extension, 'Putinism'). ${ }^{9}$ The tension resulting from these diametrically opposed interpretations of historical development lies at the heart of the debates I discuss in the case studies: order and repression appear to be two sides of the same coin. The fragile balance between the two is what is at stake in virtually all discussions about current and future Russian politics.

\section{History on the small and big screens}

As was already noted, from the beginning of Putin's first presidential term, the state has steadily expanded its control over the media (Beumers et al. 2009; Hutchings \& Tolz 2015). While journalism remains the primary target of such restrictive measures, historical fiction and nonfiction have also been affected as the state's efforts to promote patriotism have intensified. Indeed, as Stephen Hutchings and Vera Tolz argue,

One of the Kremlin's key motivations for imposing its grip on television broadcasting was to promote its own vision of a powerful Russian state with a unity of patriotic purpose and an enviable cultural history spanning the imperial and the Soviet periods.

The reason why television in particular was chosen to serve 'as the propaganda tool of a powerful, centralizing state' (idem: 73) is self-evident: for an overwhelming majority of Russians, television continues to be the main source of information. According to polls conducted by the Levada Centre, 71 per cent of respondents listed state TV channels as their primary news source in 2012, while an additional 7 per cent relied on private TV channels, 


\section{0}

\section{Introduction}

including NTV, a channel loyal to the state (Levada Centre 2015: 123). ${ }^{10}$ When respondents were permitted to mention multiple sources of information, the percentage is even higher: 94 per cent mentioned television among their primary sources in 2009 (Levada Centre 2016: 166). This figure has since decreased somewhat yet remains high at 86 per cent in December 2016 (Volkov \& Goncharov 2017). During the period covered by this study, the influence of the Internet was still limited. In 2011, only 6 per cent of respondents listed the internet as their primary source of information, a share that increased to 15 per cent by 2012 (Levada Centre 2015: 123). Although state efforts to influence film production have long tended to be more covert and indirect, a marked tendency towards establishing far-reaching control over the industry can be observed (I will return to this point shortly).

State-aligned TV channels and the Russian film industry have been prolific suppliers of historical narratives. ${ }^{11}$ Driven by the popularity of historically themed productions with the Russian audience, this development was facilitated by increasing budgets - in part attributable to advertising revenue - and the rapid professionalisation of the industry. Various formats and genres have been used to delve into the Russian past: from blockbusters and art house films, documentaries and docudramas to TV series, documentary series and talk shows. While a significant portion of these productions concern the Soviet period, other periods of Russian history have been far from neglected. With regard to television, the genre of the historical documentary series deserves specific mention. Some of these series ran for several years. Historical Chronicles with Nikolai Svanidze (Istoricheskie khroniki c Nikolaem Svanidze, 2003-2013), for instance, was broadcast by the Rossiia channel for over a decade. Each episode was dedicated to one year in Russian history, covering the years 1900-1993. The historical investigation series The Searchers (Iskateli) has been running weekly episodes on the Kul'tura channel since 2010 . Until he was dismissed from NTV, the journalist Leonid Parfenov produced a popular and influential documentary series called The Other Day 1961-2003: Our Era (Namedni 1961-2003: Nasha era, 1997-2003). Finally, the historical talk shows The Trial of Time (Sud vremeni, 2010) and its successor The Historical Trial (Istoricheskii protsess, 2011-2012) were as controversial as they were popular (and, for that reason, will be discussed in chapter 6 and, as a case in their own right, chapter 7).

Opinion polls conducted by the Levada Centre give us insights into the popularity of the different genres of history television and film in the years 2000-2012, and their potential impact on popular opinion. Respondents were asked what types of shows they watched 'often/most often'. Comparing the results from, respectively, 2002 and 2011, 81 (61) per cent of Russian viewers often watched TV films; ${ }^{12} 68$ (37) per cent regularly tuned into Russianproduced TV series; and 24 (14) per cent of viewers frequently watched shows about history (Levada Centre 2012: 262). ${ }^{13}$ Among the Russian TV series, historical topics were quite popular: in 2011, 17 per cent of respondents enjoyed watching 'historical/historical-action/costume melodrama', 15 per 
cent regularly watched melodramas set in the recent Soviet past, while another 12 per cent turned on their televisions for historical series about Russian history, historical events and personalities. TV series set in the past were still surpassed in popularity, though, by police detective shows $(32 \%)$, contemporary melodramas $(21 \%)$ and criminal dramas (20\%) (Levada Centre 2012: 264). Regarding film, in 2009 and 2011 respectively, 20 (21) per cent of respondents indicated a preference for historical and costume films, 9 (7) per cent enjoyed films about heroes and important individuals, while 9 (10) per cent indicated that they watched scholarly/educational films about history, culture or art. By comparison, 35 (36) per cent of respondents expressed their liking for detective movies and action films, 32 (34) per cent for romantic films or melodramas, while 37 (33) per cent mentioned comedy among their favourites (Levada Centre 2012: 252).

The ways the state has tried to promote the output of historical film and television productions, as well as to influence the particular interpretations of the historical events they depict, roughly fall into two categories: measures aimed to stimulate and measures aimed to restrict. For both strategies, controlling the flow of funds is the most evident and efficient means to achieve their aims. Yet changes to the institutional conditions of production (e.g. measures that impact distribution and broadcasting) can also greatly influence the types of projects that make it onto the big screen. Jasmijn van Gorp has analysed the correlation between the government's film policy, which includes state subsidies, and the production of 'national' films - that is, films that contribute to nation-building - between 1991 and 2005 (Van Gorp 2011). She demonstrates that in the period $2000-2005$, the state actively tried to stimulate the production of such national films through a five-year plan issued by the Ministry of Culture. On occasion, the ministry organised competitions to solicit films on particular topics (a type of goszakaz). Van Gorp argues that these measures were effective primarily through how they influenced filmmakers' 'common sense'. Provided with an economic incentive, they were tempted to make films that would satisfy the ministry's criteria and therefore be eligible for state support. Paradoxically, the direct calls did not always result in the actual production of a film. For example, as Van Gorp illustrates, while during the years 2001-2005, 11 films were produced about the Second World War (of which seven received state support), an advertised commission for a film on the same topic in 2004 failed to produce a result. The availability of state funding, she concludes, therefore appears to have worked as an indirect system of state commission.

The voluntary pragmatic conformity to governmental preferences identified by Van Gorp persisted after 2005 and indicates how state control over film production during these years can be difficult to prove. Indeed, as Greg Dolgopolov asserts,

[a]lthough the attraction of conspiracy theories is undeniable, it would be wrong to consider that all these positive subjects are 'ordered' from the 
top as the outcomes tend to be authorially messy and 'dirty'. [...] Putinera cinema and television drama is best defined by a heterogeneous 'dirty' base that supports broad genre variety, an indigenization of Western formats, a decline in experimental art house cinema, and a resurgent populism based on retro-oriented blockbusters and a banal, domesticated national consciousness in tele-serials and soap operas.

(Dolgopolov 2008)

My analyses of a wide variety of TV and cinema productions in the case studies support Dolgopolov's assertion.

In 2009, the system of financial support for the film industry was drastically reformed. The newly established Federal Fund for Social and Economic Support to National Cinematography, or Fond Kino, was assigned the allocation of most of the available funds. The remainder is allocated by the ministry itself in support of the so-called leaders of national film production (whose criteria determining ranking is unclear) and through competitive thematic calls (Ziborova 2013). In both 2010 and 2011, the call mentioned, for instance, 'films of historical, military and patriotic content, developing a sense of pride in one's country,' as well as a similar theme regarding documentary film (Ministry of Culture of the Russian Federation 2010; Ministry of Culture of the Russian Federation 2011). The structural reorganisation involved a significant change in the composition of the councils overseeing the distribution of funds. After the restructuring only a few film professionals were left among their ranks, their places now occupied by bankers, vice-ministers, chairmen of the boards of directors for major media holdings and other people 'wielding substantial financial and political leverage' (Ziborova 2013: 74). The council at the Ministry of Culture responsible for the allocation of funds was headed by (then) Prime Minister Vladimir Putin, leaving little doubt about the direct correspondence between political preferences and subsidised projects. For a film to be completely free from the implicit and explicit restrictions that are now connected to these streams of state funding, it has to be produced with exclusively private funds (Ziborova 2013: 75). ${ }^{14}$

In addition to direct funding and the stimulation of pragmatic self-censorship, the state has also exerted indirect control, for instance by placing individuals loyal to the Kremlin as heads of significant production and distribution companies (Pomerantsev 2014: 43-45). ${ }^{15}$ Moreover, film and television production are increasingly mutually interdependent in Russia. Major historical films, in particular, are often released (in extended versions) as TV miniseries, premiering on TV not long after their cinematic releases. By producing and financing such productions, state TV channels have become yet another means to promote the release of films on certain topics. Simultaneous release on the big and small screens dramatically increases the audience reached by such productions. Stylistically, their impact has been exceedingly important. As Il'ia Kalinin correctly argues, Channel One and the All-Russia State Television and Radio Broadcasting Company (VGTRK, owner of, e.g., Rossiia 1 and 2 and Kul'tura) have 
'shaped the commercial format of patriotic cinema that now dominates domestic screens' (Kalinin 2013).

The lack of alternative sources of funding (that is, of funds not connected in any way to state-aligned production companies, TV channels and other sources of direct and indirect governmental support) seriously restricts the number of independent productions. In chapter $5 \mathrm{I}$ analyse one such independent film, Boris Godunov (Mirzoev, 2011). For now, it suffices to say that the person who sponsored this politically sensitive film funded it on the condition that his name would not be disclosed. The film also encountered some difficulties with distribution. The system of financing has thus acted as a restrictive tool within Russia's increasingly state-owned media landscape in this period.

There has, though, been some opposition to the evident loyalty to the Kremlin shown by key individuals in the industry. The most significant development in this respect is the decision of a group of filmmakers to leave the Union of Cinematographers of the Russian Federation and establish their own independent union, Kinosoiuz, in 2010. In their founding statement 'We don't like it', which collected more than 150 signatories, the protesting filmmakers explicitly oppose the Union of Cinematographers' 'imposed agreement of opinion, official patriotism and lackey-ness' ('Istoriia Kinosoiuza' n.d.). Their discontent was directed mainly at the Union's long-serving chairman, Nikita Mikhalkov, an Academy Award winner and a personal friend of Putin (on Mikhalkov, see also chapter 3). Among Kinosoiuz's founders are the (internationally) acclaimed directors Aleksei German, Aleksandr Sokurov and Boris Khlebnikov. ${ }^{16}$ While this split among filmmakers created a stir at the time it emerged, its overall effect upon the industry appears to be limited. ${ }^{17}$

\section{Methodology}

In order to be able to study memory politics as a socio-cultural process involving governmental politics, societal actors of national importance and the sphere of cultural production, I adopt a case-study approach. Each case is dedicated to the remediation and political instrumentalisation of a particular cultural memory across the three domains. As will be described in detail in the next chapter, I depart from the theoretical conceptualisation of cultural memory developed by Jan and Aleida Assmann to frame and analyse the interdisciplinary subject at hand. In addition, I build upon the concept of remediation as it has been adapted for the study of cultural memory by Astrid Erll and Ann Rigney (see chapter 2). The selection of the cases is motivated, first, by the aspects of memory dynamics they allow me to explore. Taken together, the four major case studies represent as wide a variety of political, social and cultural actors as possible. The memory of the Time of Troubles formed the central narrative of state memory politics and has a particularly rich history. Putin himself advocated that the figure of Petr Stolypin be regarded as an exemplary political figure, but did so only after television 


\section{Introduction}

productions had prepared the ground. Stolypin's case is particularly revealing since, unlike other historical references used by the regime, there were no previous memory texts to build upon. The case of Aleksandr Nevskii provides insights into the memory politics of the Russian Orthodox Church (ROC), as well as the coinciding interests of the ROC and the Ministry of Foreign Affairs in favouring the medieval prince. Finally, the memory of Ivan the Terrible and the oprichnina offers a case that allows an exploration of how ultranationalist and fundamentalist Orthodox groups use cultural memory to put forth visions of Russian statehood that undermine current political structures.

My selection of cultural productions includes documentary and feature films, television series and TV shows. They were each chosen on the basis of one or more of the following criteria: 1) the example is a major project that involved substantial investment and/or was presented as an important event; 2) the persons and/or organisations involved warrant particular attention; and/or 3) the production had significant societal impact or sparked controversy. Consequently, my research is limited to TV channels with national coverage.

Since this study is also an investigation of the balance between the political arena on the one hand and television and cinema production on the other, I have selected cases that were sufficiently prominent in both domains. As a result, some important names did not make the cut. Catherine the Great has largely been absent on the cultural front, though this lack has recently been addressed with two major television series in the wake of the annexation of Crimea. ${ }^{18}$ From time to time, political statements made reference to Peter the Great, but his memory was never as explicitly instrumentalised as, for instance, Petr Stolypin's. ${ }^{19}$ One major TV series was broadcast about Peter in 2011, but this should be seen as the exception that proves the rule, as it were, of a further lack of symbolic investment. ${ }^{20}$ Since my main objective is to gain insight into the various actors involved in memory politics and their interaction with one another, an examination of the reasons why these and other specific cultural memories were for the most part absent in this period is beyond the scope of this study.

The attentive reader will have noticed that the selected case studies all concern prerevolutionary Russian history. Obvious case studies, on Stalin or the memory of the Second World War, are missing. This decision, as well as being informed by my overarching aim of achieving a diverse sample of governmental, nongovernmental and cultural actors, results from the following considerations. First, the existing literature on Russian memory politics in the new millennium somewhat overstates the importance of these memories in this particular timeframe and often fails to place the regime's attitude towards the Soviet past in the context of other instrumentalised periods in history. The evidence provided by my case studies challenges the argument made by, for instance, Graeme Gill, that 'the pre-Soviet past has not been a major source of either symbolism or enthusiasm in post-Soviet Russian discourse (Gill 2013: 143). Contrary to Gill's assertion that, '[w]hile it may be an era of 
general interest, pre-Soviet Russia has not generally been seen as a relevant model or guide for contemporary or future development' (Gill 2013: 143), I have found a pronounced political interest in the pre-revolutionary period both for framing policy decisions and for informing future policy. Second, the various episodes of Soviet rule tend to be conflated in order to argue that the Putin regime has taken an overall justificatory stance towards the Soviet past. While, indeed, the memory of the Second World War makes up one of the primary elements of patriotic symbolism (as Ludmila Lutz-Auras explores in her excellent study of its politicisation), ${ }^{21}$ the state has been much more hesitant in associating itself with Stalin. ${ }^{22}$ Moreover, I would argue that the prominence awarded to the victory of 1945 represents a revival of memory culture from the Brezhnev era, when the myth first came to serve this purpose (see Gill 2011), rather than sincere praise for Stalinism. Triumphs in war have proved to be particularly useful in serving as the basis for patriotic celebrations, and the victory in the Second World War just so happens to be the one that Russians were used to celebrating. The memory was 'the most 'politically usable' element of the collective past due to its previous institutionalization and its uncontested positive meaning', as Olga Malinova has pointed out (Malinova 2017: 65).

The regime's failure to come to terms with the crimes committed by the Soviet state continues to be a cause for concern (one that many excellent scholars have addressed). While I do not directly address this issue, the question of the permissibility of state violence against its own people occupies centre stage in the chapters on Ivan the Terrible and Stolypin. The legacy of the Soviet past features indirectly in yet another way. Indeed, one of my main arguments is that the rationale behind the recirculation of pre-revolutionary memory, e.g. by the Russian state, lies in the fact that these historical narratives had been actively used during the Soviet period (see chapter 2). Thereby, this study also sheds light on a particular aspect of the reworking of the Soviet past that has not received enough attention: the reappropriation of elements of Soviet history propaganda. Three of the cultural memories that I examine in the case studies had been instrumentalised by the Soviet state, and yet, as will become clear, contemporary memory politics engages differently with this legacy in each case. But with regard to the memory of Stolypin, the opposite is true. Lacking pre-existing symbolic representation, his political actions were, in fact, almost unanimously evaluated negatively by Soviet historians and politicians (see chapter 3). The contrasts between the cases therefore allow me to reflect on the importance of Soviet-era prefiguration.

Because this book is an interdisciplinary study, I use a wide variety of primary sources that fall roughly into the following categories: official governmental documents (including presidential decrees, policy documents and public statements); newspaper and journal publications accessed via the websites of their respective media outlets and the Integrum World Wide database; radio transcripts from Ekho Moskvy; documentary and feature films; various genres of television production; and online forums. My assumptions about the 
television and film industry and, in particular, the ways the state influences them have also been informed by a number of interviews I conducted in Moscow in late 2014 and early 2015 (see List of interviews). The multidisciplinary and cross-media methodology of this study enables me to accommodate both conformity to and contestation of official memory politics. This study thereby makes a contribution to the understanding of memory politics and, in particular, how governmental memory politics relates to societal and cultural memory practices and, to a certain extent, is constrained by them.

The structure of the book is straightforward. Chapter 2 lays out the theoretical and conceptual framework of the research. The subsequent chapters present the four main case studies, each governed by a similar structure. The first part of each case study provides an overview of the historical development of the particular memory under consideration, including its representation in the arts, before turning to the analysis of the political, social and cultural actors involved in its contemporary mobilisation. The second part is dedicated to a discussion of key television and cinema productions, encompassing their production history and reception. Chapter 7 presents an additional small case study about the talk show The Trial of Time, used as a prism to examine the politics of television programming. Building upon the thematic case studies that precede it, this final chapter employs an analysis of the societal debate generated by the show as a stepping stone for a reflection on the interaction between the different levels of memory politics: the state and media and non-state actors, on the one hand, and the general audience whose perceptions they aim to influence, on the other. Finally, the Conclusion sums up my main findings and places them within the context of more recent developments in Russian memory politics.

\section{Notes}

1 The names inscribed were the following: Karl Marx, Friedrich Engels, Wilhelm Liebknecht, Ferdinand Lassalle, August Bebel, Tommaso Campanella, Jean Meslier, Gerrard Winstanley, Thomas More, Henri de Saint-Simon, Édouard Vaillant, Charles Fourier, Jean Jaurès, Pierre-Joseph Proudhon, Mikhail Bakunin, Nikolai Chernyshevskii, Petr Lavrov, Nikolai Mikhailovskii, and Georgii Plekhanov.

2 I would like to thank Marina Frolova-Walker for drawing my attention to the obelisk's refurbishing.

3 Scholars have proposed various concepts to describe the political practice of engaging with history, such as politics of history, history politics and historical politics. Within the context this study, however, I feel it is most appropriate to speak of memory politics (see also chapter 2).

4 Russia is not unique in this respect, however. A similar revival of memory politics can be observed across Eastern Europe. See, e.g., Miller \& Lipman (2012); Mink \& Neumayer (2013).

5 On the memory of the October Revolution, the 'Great Patriotic War' and Stalinism in the public discourse of the 1990s, see Koposov (2011a), Langenohl (2000), Lutz-Auras (2012).

6 On state-sponsored youth movements and the promotion of state patriotism, see Hemment (2015); Lassila (2014); Mijnsen (2014). 
7 See, e.g., Torbakov (2011), Etkind et al. (2012), Brouwer (2016a).

8 See, e.g., Oushakine (2013).

9 For an example of the latter opinion, see Beard (2015).

10 The Levada Centre uses the following categorisation of TV channels. State TV channels: Channel One, Rossiia, Kul'tura, and regional channels that are part of VGTRK. Private channels: NTV, Ren-TV and other non-state-owned and commercial channels, including local and regional channels.

11 Books have also been a particularly prolific medium. Bookstores abound with (non-specialist) historical works of varying academic quality as well as historical fiction. A number of fiction writers, most notably Boris Akunin, are extremely popular and have gained significant social status and influence. Several of Akunin's works have been adapted to the screen, for instance Turkish Gambit [Turetskii gambit] (Faiziev, 2005) and The State Counsellor [Statskii sovetnik] (Iankovskii, 2005).

12 This figure includes both domestic and foreign film productions. On the basis of one of the follow-up questions, the proportion of domestic films appears to be greater than of foreign films. Comparing results from 2002 and 2011, 69 (59) per cent of respondents indicated a preference for Soviet films shown on television, while Russian films were similarly preferred by 66 (59) per cent. Foreign TV films were less popular: 37 (29) per cent of respondents indicated a preference for American films, 21 (10) per cent for Western European productions, 9 (6) per cent for Arabic and Indian films and 3 (2) per cent for Eastern European films (Levada Centre 2012: 263).

13 Although these percentages show a marked decrease between 2002 and 2011, this does not appear to be related to the particular genres: with the notable exception of the news (similar percentage) and genres that were not listed in 2002 (e.g. court shows and 'Dancing with the Stars' types of programmes) all genres show a significant to dramatic drop in percentage. A possible explanation for this fact could be the diversification of television programming since 2002 .

14 Until recently, the restructuring of the system did not necessarily preclude the production of state critical films, as is evidenced by the case of Andrei Zviagintsev's Leviathan (Leviafan, 2014) about the pervasiveness of corruption within the Russian bureaucracy, legislature and Russian Orthodox Church. Minister of Culture Vladimir Medinskii has made it very clear, however, that such 'anti-Russian' films will no longer be supported by state funds, regardless of the potential international success of a given project (promoting the international competitiveness of the Russia film industry is one of the explicit aims of film policy). See 'Vladimir Medinskii: “Leviafan” zapredel'no kon'iunkturen' (2015).

15 Peter Pomerantsev's widely discussed journalistic account about the structure of (in)direct control of media was confirmed by several of my interviewees.

16 The remaining founding members are: El'dar Riazanov, Iurii Norshtein, Daniil Dondurei, Aleksandr Gel'man, Vladimir Dostal', Vitalii Manskii, Andrei Proshkin and Aleksei German Jr. The current number of members exceeds 200.

17 This conclusion was supported by two of the persons I interviewed (Interviewee A; Interviewee D). Still, signing the petition was a highly symbolic act that, in turn, could translate into real-world consequences. Interviewee $G$, for example, related the story of a film director who was supposed to take part in the Moscow Film Festival as a special guest. However, when his name appeared among the signatories, the invitation was withdrawn; someone who is openly defiant of Nikita Mikhalkov cannot appear as a special guest at the festival of which Mikhalkov is the director. The tragedy of the situation was that the film director claimed his name was included erroneously: he had not signed the petition.

18 Catherine [Ekaterina] (Baranov \& Sabitov, 2014); The Great [Velikaia] (Zaitsev, 2015). Catherine the Great is typically included in the manifold TV documentary 


\section{Introduction}

series about the Russian tsars, yet since she is not singled out among them in any particular way this does not warrant a case study. Moreover, while she did make it to the finals of the TV show The Name Is Russia, her memory did not prove popular (see chapter 4).

19 The traditional image of Peter the Great as the ruler who sought to integrate Russia into Europe and modernise the country in emulation of the West is the most likely obstacle in this case. The way that his legacy is commonly perceived was too pro-Western to be of use to the Putin regime's narrative of Russia's 'unique path' of historical development.

20 Peter the Great: The Testament [Petr Pervyi. Zaveshchanie] (Bortko, 2011). During this period, Peter the Great appeared in a small number of films, including The Sovereign's Servant [Sluga gosudarev] (Riaskov, 2011) and Russian Ark [Russkii kovcheg] (Sokurov, 2002), but was never featured as their main subject.

21 Lutz-Auras (2012); see also Malinova (2017). On the symbolic meaning of Putin's personal involvement (or, 'performance') in the celebrations connected to the memory of the Second World War, see Wood (2011).

22 For an analysis of films about World War II, see, e.g., Liderman (2007). 


\section{Memory politics and the remediation of cultural memory}

\section{Cultural memory and political legitimacy}

In contemporary Russia the past is omnipresent. Traces of history and narratives describing its events and main characters permeate all spheres of society and cultural life: politics, holidays, traditions, education, popular culture, arts, architecture, the blogosphere ${ }^{1}$ and so on. The everyday presence of the past finds expression through a wide range of media and in divergent contexts - from the tangible remnants of periods long gone (the Muscovite Kremlin, the architectural splendour of tsarist Saint Petersburg, the high-rise main building of Moscow State University) to vehement television debates on national history between politically opposed individuals (for example, The Trial of Time that will be discussed in chapters 6 and 7) and nostalgic marketing strategies ('Alenka' chocolate bars). These historical traces are part of acts and processes of remembering in multiple ways. Some historical references are closely connected to the memory of individuals, evoking memories of lived experience or orally transferred life stories of relatives and friends. Such, for instance, is the case with the Soviet past and the turbulent events following the disintegration of the Soviet Union in 1991. The majority of historical references, however, pertain to areas of common knowledge, culture or education. One has come to know what they represent and how their contemporary relevance should be viewed via a learning process, a transfer of knowledge. In other words, they are evidence of collective remembrance.

To conceptualise the ways that individuals 'remember' collectively, Jan and Aleida Assmann distinguish between communicative and cultural memory. Communicative memory refers to shared memories that exist in embodied form, literally in someone's memory:

Communicative memory is non-institutional; it is not supported by any institutions of learning, transmission, and interpretation; it is not cultivated by specialists and is not summoned or celebrated on special occasions; it is not formalized and stabilized by any forms of material symbolization; it lives in everyday interaction and communication and, for this very reason, has only a limited time depth which normally 
reaches no farther back than eighty years, the time span of three interacting generations.

(J. Assmann 2008: 111)

Cultural memory, on the other hand, is the part of collective remembering that exists in disembodied form and is mediated by carriers of memory such as novels, monuments and pictures.

Cultural memory is a kind of institution. It is exteriorized, objectified, and stored away in symbolic forms that, unlike the sounds of words or the sight of gestures, are stable and situation-transcendent: They may be transferred from one situation to another and transmitted from one generation to another.

(J. Assmann 2008: 110-111)

The line separating communicative from cultural memory is not absolute. Shared memories of lived experience can coexist with institutionalised, symbolic representations of related events, as will be discussed in greater detail towards the end of this chapter.

Cultural memory can further be divided into two domains that, through their interaction, shape the dynamics of the memory process (A. Assmann 2008). The first is the active cultural memory of a society or its canon. These are those memories that are in circulation in a society at a given moment. The archive, on the other hand, refers, in both the literal and metaphorical senses, to those memories no longer in active circulation that have been preserved in an inert state. Consider, for example, memories captured in novels that are no longer read or in statues of no-longer-revered heroes. That these memories have been embodied in an artefact or text means that they can be rediscovered and brought back into active cultural memory. Such re-activation is very much a deliberate process, governed by the question of which images of the past have been chosen to bolster or complement a present condition:

At the other end of the spectrum, there is the storehouse for cultural relicts. These are not unmediated; they have only lost their immediate addressees; they are de-contextualized and disconnected from their former frames which had authorized them or determined their meaning. As part of the archive, they are now open to new contexts and lend themselves to new interpretations.

(A. Assmann 2008: 99)

The history of the Romanov memorial obelisk, described in the previous chapter, illustrates well how memory artefacts can be repurposed and endowed with new meanings.

The basic premise that memory is shaped to fit the needs of the present (Rigney 2005: 14) implies that memory practices provide us with insights into 
present-day cultural, political and social developments; indeed, they function in this fashion to an extent far greater than the way they may shed light on a 'factual' past. Therefore, what is of interest in this study is the move from archive to canon, the selection, reworking and circulation of narratives about the past that aim to relate such narratives to the Russia of today. What exactly happens to memory when it is moved from the archive to the canon? How can we conceptualise the re-activation of memory and the (possible) changes that occur in the process of re-activation? And how do we define the relation between the 'new' (version of the) memory and its 'original(s)'? The second part of this chapter will put forward the conceptual framework that will guide the case-study analyses in order to answer these questions. Before proceeding, however, it is necessary to consider how cultural memory is linked to political legitimacy, and what (groups of) actors are involved in the process of political memory-making.

\section{The politics of memory: conformity and contestation}

For politicians and political movements, history can be an important source of framing devices. The rhetorical use of historical references can establish a line of tradition - an evident aim of the politics of memory of the Putin regime, which, as mentioned in the Introduction, has focused on creating a historical foundation for its emphasis on a strong state and centralised leadership. Political actors can contextualise their connection to the political entity they seek to represent by indicating a historical analogy between the present and a given historical occurrence (including appeals to tradition and collective identity); alternately, they can place themselves in opposition to a set of characteristics embodied by a historical individual, event or movement. Simultaneously, historical framing helps stress their singularity, the leadership qualities or policy objectives that set them apart from competing political groups. Scholars apply diverse concepts to describe this political practice: the politics of history, history politics, historical politics, memory politics, and so on. To speak of history politics or historical politics is somewhat problematic, at least within the terms of this study, since it implies that political historical framing is about history and consequently is aimed towards truth-finding and the establishment of facts (or maybe the refutation of accepted historical facts). I would argue that, on the contrary, political uses of historical references are symbolic in aim and therefore about not history, but memory. To paraphrase Alexander Etkind, it is not a question of validity, but of relevance (Etkind 2017: vii). Therefore, I will speak of memory politics and the politics of memory (phrases I use interchangeably), and will do so in instances when political actors purport to be speaking about historical facts or the distortion of history by others.

Since the aim of the politics of memory is to orient notions about the shared past towards the endorsement of current policies, a regime may seek to exert as much control as possible over public expressions of collective 


\section{2}

Memory politics

remembrance. Political statements, state symbols and holidays are the most salient form of such endeavours, but state control over memory practices, depending on the degree of state centrism, can extend to all spheres of society: education, academic research, museum exhibitions and journalism, but also, and this is the sphere under consideration in this research, television and cinema. Russian memory politics and the influence of the state on cultural production are often interpreted in an unequivocal way by journalists and scholars alike. The state is seen as promoting a monolithic, unchanging interpretation of Russian cultural identity, fixated on sustaining its power and eliminating domestic opposition, while non-state actors are depicted as seeking to undermine and tarnish that power. However, state control over cultural memory in the public sphere was, and continues to be, by no means comprehensive. Nor is it univocal. First, the politics of memory takes part in a larger cultural dynamic of meaning-making. 'Memory texts' involve not only senders (who shape the message to their advantage) but also the circulation of their messages in a medium (which leaves a trace on the message) and a recipient (who interprets the messages and decides whether to adopt new interpretations). Any analysis of the political elite's pragmatic motivations to express certain views on history in isolation would not sufficiently reflect the complexity of cultural meaning-making that occurs through memory practices. By choosing a certain political myth to valorise, the regime reveals its belief that the public will associate itself with it. But the regime may be mistaken and, consequently, the myth may lose its legitimating power.

Moreover, the dynamics of memory incorporates a wide range of actors, both within and outside the government, each having their own interests and objectives, each exercising a different measure of influence. Therefore, as already indicated, this study extends its sources beyond official speeches, texts and policies to avoid oversimplifying the means through which political regimes mediate their views. This is also the reason why the source material is not limited to either cinema or television, as might be more usual scholarly practice, and why the case studies are defined thematically. As a result, the scope is broadened to assess the dissemination of connected narratives in different media and place the analysed audiovisual memory products in their societal context. To exclude non-official texts would also be to overlook or insufficiently value challenges to the dominant actor in the process of cultural memory formation. Especially within the context of democratisation and underdeveloped civil society structures in contemporary Russia, such signs can provide additional insights into the development of Russian society and politics. Conversely, this decision also helps to avoid conceptualising a strict opposition between the state and the so-called cultural elite. While the central government may indeed exercise a certain degree of hegemony on memory claims, cultural memory should not restrictively be seen as the product of manipulation and deception. In their memory practices, political and cultural elites are to a certain extent limited and influenced by the socio-cultural environment. Non-state actors are motivated by a multitude of different 
considerations to act and express themselves in ways that support the state, ranging from actual support of the state - or the belief that there is no political alternative to the current regime - to a desire to maintain social status or reap financial gains.

Roughly sketched, the (groups of) actors specifically involved in shaping historical representation in television and cinema include cultural policymakers (involved in the legal framework of cultural policy, state financing and the official structure of production/distribution), the Union of Cinematographers, production and distribution companies (including state TV channels), scriptwriters, directors, historical advisors, societal actors and private parties involved on the commissioning side or with funding (e.g. foundations and religious organisations). Furthermore, the participation of a certain host (in case of a TV show or documentary) or actor (in case of fictional dramatisations) can lend authority to the interpretation of history presented or increase the popularity of a production (and hence augment its societal reach and potential impact). This study aims to provide insights into the complexities of the interactions among these actors and also examine the dynamics of contestation of and conformity to the state-supported line. TV and cinema are thus approached simultaneously as extensions of the political sphere and a space of (restricted) dialogue, the outcomes of which are determined by the interplay of political, cultural and societal actors.

Finally, it has to be stressed that memory politics is not static. Historical narratives deemed politically relevant have to be repeatedly circulated and are continuously subject to redefinition in response to challenges (for instance, the circulation of competing memories) or societal changes. If a narrative appears to be losing its rhetorical power and risks becoming obsolete, it can be altered, recontextualised or abandoned. As a result, memory culture is in continual flux, and for a memory construct to gain dominance - that is, societal acceptance as a relevant frame of interpretation - or maintain the dominance it already enjoys, it has to be actively supported and promoted by one or more of the actors named above. We can try to identify 'memory sponsors', a variation on the concept 'frame sponsor' (Van Gorp 2007: 64). Who is working to popularise a given memory, a particular interpretation of events, and why?

\section{Memory politics on screen}

How can we define the position and importance of TV and cinema in the process of creating a politically 'useful past', described above? In his introduction to the seminal work Television Histories: Shaping Collective Memory in the Media Age (2001), Gary Edgerton outlines seven assumptions about the role played by television in shaping (collective) notions about history. While Edgerton formulated his views about the role of 'television as a historian' some time ago and with the American television system in mind, the greater part of his insights also applies to the contemporary Russian context. 


\section{Memory politics}

First, he emphasises the importance of recognising television as 'the primary way that children and adults form their understanding of the past' and foregrounds the medium as 'the principal means by which most people learn about history today' (Edgerton 2001: 1). Because historically oriented nonfiction programming is often as popular as fictional television programmes, while being 'relatively cost-effective to produce', historical programmes had already then become 'big business' (idem: 2). This second assumption would not entirely hold if we were to include historical fiction (as this study does). While period dramas, for example, may indeed be very popular with television audiences, they are not necessarily cheaper to produce. A similar exception can be made for screenings or television adaptations of full-length historical feature films. Third, Edgerton argues that such historical productions are strongly influenced by the 'technical and stylistic features of television as a medium', most notably the emphasis on narrative ('well-constructed plot structure') and biography ('personalizing all [...] historical matters' and 'viewer-involving' in the presentation of the events) (ibid.).

The fourth assumption adheres to one of the premises of this study, namely television's 'affinity and ability to embody current concerns and priorities within the stories it telecasts about the past' (Edgerton 2001: 3). Indeed, according to Edgerton, the producers of history on screen 'tacitly embrace presentism through the back door by concentrating only on those people, events, and issues that are most relevant to themselves and their target audiences' (ibid.). They allow contemporary values to determine what image of the past is rendered, rather than seeking to establish a (more) truthful reconstruction of a past reality. This tendency underscores the difference between this form of popular history and the works of academic historians. Building upon the previous assumption, Edgerton states that this merging of past and present happens in almost a methodological fashion and flows from TV producers and audiences being "similarly preoccupied with creating a "usable past," a long standing tenet of popular history, where stories involving historical figures and events are used to clarify the present and discover the future' (Edgerton 2001: 4). Sixth, 'collective memory is the site of mediation where professional history must ultimately share space with popular history' (idem: 5). And, finally, while popular historians may be accused of engaging in presentism, the opposite may be said about professional historians when they fail to acknowledge the place of popular history and 'declare the past off limits to nonscholars' (Edgerton 2001: 6).

As I indicated in the Introduction, historical subjects are quite prevalent in Russian TV programming, ranging from talk shows to documentaries and fictional TV series. Different formats can be discerned, each with their own stylistic characteristics (Zvereva, 2004): academic presentations, in which experts elucidate detailed accounts of history to their uninformed or underinformed audience; documentaries akin to sensational journalism, filled with scandals, intrigues and secrets; investigations of history that explain the origins of current (political) events and present a political argument; or simply 
the staging of history as entertainment, where an abundance of visual trickeries and rapid editing ensures that the viewer remains engaged. Yet another type is exemplified by The Name Is Russia, aired in 2008 by the Rossiia TV channel in imitation of foreign examples such as the BBC's 100 Great Britons. Through multiple online and telephone voting rounds, leading up to $12 \mathrm{TV}$ shows presenting the finalists, the Russian public could vote for their favourite Russian of all time. The interactivity of the project and the way it engaged several media platforms set it apart from the kinds of historical programmes described above (for a detailed analysis of The Name Is Russia, see chapters 4 and 5).

While television is often disregarded for being a medium for mere popular culture and therefore an inferior type of cultural production, or for being simply the mouthpiece of the Russian government, its importance and societal influence remains significant. For most of the period examined in this study, the 'post-Soviet television genre [was] the supreme locus for the negotiation of control over cultural meaning' (Hutchings \& Rulyova 2009: 219220). Although internet access has proliferated rapidly in Russia and is now widespread, achieving a penetration of 71 per cent of the adult population in 2017 (Mediascope 2017), opinion polls conducted by the Levada Centre show that television continues, by far, to be the most important source of information for Russians, although there is a growing generational discrepancy as the younger generation increasingly relies on online sources (Volkov \& Goncharov 2017). This is not to say, of course, that the audience accepts or agrees with everything it is told. Ellen Mickiewicz has shown that Russian viewers are exceptionally adept at extracting information from television; they are critical viewers who scrutinise television coverage in a way that goes beyond reading between the lines. As a result of their 'particularly effortful engagement with the news to extract the maximum amount of data in an environment of limited information', Russian viewers are able to, for example, recognise TV channels by their 'content, tone, or approach' (Mickiewicz 2008: 33). Their characteristically sceptical attitude of viewing, Mickiewicz suggests, is partly attributable to the 'Soviet legacy' that 'has shaped the repertoire of methods of extraction of news unintended and uncued from broadcast' (Mickiewicz 2008: 104). This sceptical viewing strategy enables viewers to differentiate among the constitutive elements of a narrative, to appreciate the influence of the narrative's source on its representation and to be aware of the possibility of multiple 'truths'.

Vera Zvereva notes a particular, rather drastic shift in the representation of history on Russian TV since the 1990s drew to a close. Historical programming in the late 1980s and for most of the 1990s was preoccupied with disclosing previously unknown facts and hosting heated debates about topics that had been off limits to public inquiry before Perestroika. As the turn of the millennium approached, the public appeared to have grown tired with the disclosure of yet more archival documents about the (Soviet) past, and its enthusiasm for new interpretations waned. Also, since the late 1990s, 'Russian media are increasingly turning to the forms and rhetorics of Soviet culture' 
(Zvereva 2004). Simpler, more comprehensible and, moreover, familiar explanations appeared to better suit the shifting preferences of the viewing audience, who had grown tired of the negativities and uncertainties of the first post-Soviet decade.

Where exactly such a shift originates is difficult to pinpoint, as is also evident from Edgerton's seven assumptions: The type of programmes that are aired and the way their contents are presented derive from the professional and economic considerations of those involved in their production and distribution, even as these actors simultaneously attempt to sense viewer preferences and anticipate and respond to any changes among them. Even with a 'big player' such as the state involved, as is the case with the state-owned TV channels, it would be mistaken to assume direct or complete control over TV's content. Anna Novikova, for example, puts forward the following explanation when she comments on the tendency to positively re-evaluate Soviet practices noted by Zvereva:

By the end of the 1990s people were disillusioned and critical of government
policies that were aimed at shaping pro-European identity. This enabled the
new Russian government (V. Putin in particular) to change the state's strategy
at the beginning of a new century and to return to the model of a paternalist
state. Russia's state channels - never free from state pressure - supported new
government policies. As a result, various television shows began to rehabili-
tate the Soviet past through the use of recycled Soviet myths.

(Novikova 2014: 282)

Several studies have shown, however, that state control over the Russian media in this period, and television in particular, is a complex matter and should not be overestimated. Stephen Hutchings and Natalia Rulyova aptly speak of 'remote control' (2009: 3). Although media freedom has declined and 'government control over the content and style of television programmes' has increased since Putin took office in 2000, effective control is restricted by the drastically altered environment in which the Russia media system now operates. Indeed, 'precisely because of the recent changes wrought upon Russian society, a blanket return to the totalitarianism of the Soviet media has not occurred' (Hutchings \& Rulyova 2009: 3 ). ${ }^{3}$ Efforts to exert control over television broadcasting, on both the production and reception sides, were impeded in the 2000s in several ways:

1 The disjunction between official pronouncements emanating from central government and the confused interpretation of those pronouncements by national television channels

2 The global media environment in which national television now operates

3 The fickle tendencies of television audiences, aided by new media forms less supine in their relationships with state government, to ignore officially preferred meanings.

(Beumers et al. 2009: 7) 
It should also be noted that Novikova appears to (incorrectly) assume that 'pro-European identity' and 'a paternalistic state' act as opposite poles, which allow little space for alternative modes of political organisation between them.

In line with Hutchings and Rulyova's analysis, Anna Amelina argues that the relationship between state and television during Putin's first two presidencies can be characterised as one of asymmetrical interdependence. She formulates her 'These der asymmetrischen Interdependenz' (Amelina 2008) as follows:

Von Interdependenz kann gesprochen werden, weil in der Tat Massenmedien auch in Russland auf neue politische Themen, auf politische Skandale und auf heiße Diskussionen angewiesen sind. Auch die politischen Instanzen sind gezwungen, besondere Formen medialer Funktionsweise $\mathrm{zu}$ übernehmen, um vom medialen Popularitätsbonus zu profitieren. Doch dieses Interdependenzverhältnis ist asymmetrisch, weil das politische Bedürfnis nach Anpassung an die mediale Logik von partieller Einschränkung massenmedialer Thematisierungsleistungen begleitet wird und sich zum Teil in Eingriffen in die redaktionelle Entscheidungsfreiheit niederschlägt,

(Idem: 31-32)

Amelina emphasises the importance of self-censorship to state control over TV journalism:

Die Entwicklung der journalistischen Selbstzensur im neuen russische Fernsehen deutet darauf hin, dass die Aktualisierung der staatlichen Kontrollmechanismen nicht direkt die von 'Neophilie' geprägte mediale Logik auflöst. Stattdessen werden die Kontrollversuche der politischen Instanzen in der medialen Kommunikation transformiert: Sie werden zwar als Störung wahrgenommen, jedoch in der redaktionellen Entscheidungspraxis durch Selbstzensur verarbeitet.

(Idem: 41)

The issue of self-censorship, I would add, is of equal significance with respect to historical programming. Amelina indeed signals that TV fiction can also be affected by considerations determined by current politics: 'Dabei muss die Selbstzensur im Fernsehen nicht unbedingt nur die Nachrichtensparte betreffen. Auch Fernsehfilme oder -serien, die auf den Tschetschenien-Konflikt verweisen, können entsprechend 'umgestaltet' werden' (idem: 41). More recent research, as well as the interviews I have conducted, support these findings (Kalinina 2017; Schimpfossl \& Yablokov 2014).

Cinema's influence in shaping people's knowledge and beliefs about history has also become a subject of scholarly scrutiny, as has the use of cinema as a means of political propaganda. ${ }^{4}$ The degree of historical accuracy adhered to by films set in the past varies greatly, as do opinions about whether accurate 
reconstruction - or, to use an even more objectionable term, representation ${ }^{5}-$ is a valid criterion by which to judge the merit of this cinematic genre. ${ }^{6}$ Both the meticulously recreated, fetishised historical 'real' of a period piece based on true events - often with a recapitulation before the closing titles informing the viewer what has become of its characters 'after the film ended' - and the romantic drama recounting the lives of fictional characters loosely framed in a historical context endeavour to make the past, or at least some elements of it, accessible to its viewer who is located in the present (recall Roland Barthes' amazement at the use of a signature haircut - fringes - as 'the label of Romanness' in Mankiewicz's Julius Caesar [Barthes 1973]). It is fair to argue that Edgerton's assumption that television is 'the primary way that children and adults form their understanding of the past' (Edgerton 2001: 1) to a large extent holds true for cinema as well. The popularity of a film may well tell us more about its potential societal impact than a reviewer's evaluation of its quality as a historical document. Even in those cases where a film's principle aim is to keep its audience entertained, its effect can nonetheless be educational via its contribution to the individual viewer's memory repertoire of stock images, phrases and other associations connected to the historical figure, event or period portrayed.

In addition to political coverage on TV, history education and the use of historical references in political statements, Russian cinema in particular has been recognised as an important means of popularising and consolidating public support for the strengthening of the power vertical since the turn of the millennium (Laruelle 2009; Vázquez Liñán 2010). Historical fiction has provided a suitable vehicle for quasi-nationalist narratives instilling a sense of state patriotism in their viewers. Stephen Norris argues that there is a clear link between the political line of the Putin regime and the messages spread through historical feature films, especially those of the Hollywood-style Russian historical blockbuster that has emerged:

The birth of blockbuster history - or the way American cultural practices could be adapted to make Russian historical epics - parallels the rise of Putin and the resurgence of Russian political nationalism. These links and processes $[\ldots]$ are far from coincidental but not always connected $[\ldots]$ : patriotism and the past sell.

(Norris 2012: 5)

Commenters often explain the popularity of many of the historical feature films released since 2000, especially those related to the Second World War, by framing it as a response to the total rejection of history by political elites in the 1990s and the troublesome process of redefining Russian collective identity. Re-envisionings of the past filled the void of Russians' 'negative identity' (Gudkov 2000):

Russian blockbuster history offered a chance for audiences to escape into alternative histories: the tsarist era to the Russia we lost, Great Patriotic 
War films to the patriotism displayed by their parents' generation, late socialism to the values of stable socialism and a lost childhood, and fantasy history to an invented past with clear values.

(Norris 2012: 17)

Despite the parallel rise of state-sponsored nationalism and the boom in (politically relevant) historical feature films, this tendency to search for political guidance in the national past should not be attributed wholly to the state, as Norris also suggests. As already argued above, the process of cultural production involves a multitude of actors, notwithstanding limited media freedom. Furthermore, filmmakers explored cinematic genres other than the Hollywoodinspired blockbuster to pursue historical themes as well. For instance, Vladimir Mirzoev's Boris Godunov (2011), a screen adaptation of Pushkin's eponymous play set in twenty-first century Moscow, appeals more to an 'art-house' audience (see chapter 5). Perhaps it is more productive to approach nationalist feature films produced after 2000 as 'an expression of a prevailing common sense whereby filmmakers and other stakeholders were preoccupied with a national identity' (Van Gorp 2011: 243) rather than as a 'light' version of state propaganda. The equivocality or ambiguity that tends to characterise historical productions (evident in their implicit meanings and irony) renders it even more difficult for complete control to be exerted over the end product.

To conclude, it should be emphasised that in the Russian case, much more so than elsewhere, TV and cinema are overlapping spheres of cultural production (as was briefly mentioned in the Introduction) and are thus best analysed together:

Because of the way television came to dominate Russian cinema in the zero years - the largest producers of feature films are television stations blockbuster history played out on both large and small screens. The people behind this production of the past and its subsequent screening of memory were not just film directors - television producers, businessmen, and even popular authors all played a role in the behind-the-scenes development of the historical blockbuster.

(Norris 2012: 15)

Moreover, as will be discussed in more detail below, cultural memory has to be actively and repeatedly circulated for a given interpretation of history to gain or maintain dominance. When similar narratives are expressed in multiple media simultaneously, they can reach a larger audience and compound their signifying potential. Increased exposure can lend credibility to historically framed claims and help them gain acceptance as relevant signposts for the present and future. Therefore, when either TV or cinema is categorically excluded from our analyses, we may fail to appreciate the importance of these intermedial memory dynamics. Now, let us move on the concept of remediation and see what role it plays in the processes that were outlined above. 


\section{Memory politics}

\section{Remediation}

In the introduction to the volume Mediation, Remediation, and the Dynamics of Cultural Memory (2009), Astrid Erll and Ann Rigney adapt the concept of remediation, which had been introduced for the study of new media by David Jay Bolter and Richard Grusin (1999), to the study of cultural memory. They chose to adapt this concept out of a specific concern about the conceptualisation and analysis of memory practices:

the dynamics of cultural memory can only be fully understood if we take into account, not just the social factors at work, but also the "medial framework' of remembering and the specifically medial processes through which memories come into the public arena and become collective.

(Erll \& Rigney 2009: 2. Italics in original)

The concept of remediation highlights the 'mediatedness' of collective memories that is central to the authors' 'dynamic' concept of cultural memory, in which texts and artefacts function as media of circulation rather than as 'static' lieux de mémoire (cf. Pierre Nora). Furthermore, it draws attention to relations between media and to the reshaping of memory in the process of remediation. Central to the concept of remediation is its underlying 'double logic,' based on the fact that '[our] culture wants to multiply its media and erase all traces of mediation; ideally it wants to erase its media in the very act of multiplying them' (Bolter \& Grusin 1999: 5). Remediation, then, is determined simultaneously by the opposed tensions of immediacy, which provides a mediation that is somehow more 'real', and hypermediacy, which highlights the fact of its mediation through its embedded recognition of its precursor(s):

Although each medium promises to reform its predecessors by offering a more immediate or authentic experience, the promise of reform inevitably leads us to become aware of the new medium as a medium.

(Idem: 19)

According to Bolter and Grusin, media can exist only in relation to other media. Consequently, remediation creates complex intertextual (or intermedial) webs as each new medium 'responds to, redeploys, competes with, and reforms other media' (Bolter \& Grusin 1999: 55). The relation between subsequent mediations, between the new mediation and the medium it 'borrowed' its content from, depends on the perception and interpretation of its receiver:

With reuse comes a necessary redefinition, but there may be no conscious interplay between media. The interplay happens, if at all, only for the reader or viewer who happens to know both versions and can compare them. 
Consequently, the audience's viewing attitudes and pre-existing knowledge are of great significance.

Erll and Rigney argue that remediation is a central characteristic of the creation and circulation of cultural memory:

Just as there is no cultural memory prior to mediation there is no mediation without remediation: all representations of the past draw on available media technologies, on existing media products, on patterns of representation and medial aesthetics.

(Erll \& Rigney 2009: 4)

The 'double logic' of immediacy and hypermediacy described by Bolter and Grusin equally applies to the way that memories are mediated:

On the one hand, most memorial media strive for ever greater 'immediacy'. The goal is to provide a seemingly transparent window on the past, to make us forget the presence of the medium and instead present us with an 'unmediated memory'. On the other hand, this effect is usually achieved by the recycling and multiplication of media.

(Ibid.)

The emphasis on remediation, rather than mediation as such, highlights another aspect of the dynamic concept of cultural memory proposed in this study, which I assume as one of its premises: cultural memory does not exist in isolated texts or carriers of memory but, rather, is the result of repeated mediations that disperse particular cultural memories among the members of a society and allow them to perceive these memories as part of their shared past and (collective) identity. The object of analysis, then, is texts not in isolation but rather in their function as media of circulation, as part of a cloud of media touching upon the same memory theme and together constituting the constantly evolving cultural memory itself.

When we look at the emergence and 'life' of memory sites, it becomes clear that these are based on repeated media representations, on a host of remediated versions of the past which 'converge and coalesce' into a lieu de mémoire, which create, stabilize and consolidate, but then also critically reflect upon and renew these sites.

(Erll \& Rigney 2009: 5. Italics in original)

This makes it possible to reconstruct a genealogy of cultural memories that can also encompass those periods when the memory retreats into the archive, to be rediscovered and remediated at a later time.

As the above discussion already suggests, the social frameworks of collective remembering (which Maurice Halbwachs has called attention to) are as important as its media forms. Indeed, '[it] is the public arena which turns 
some remediations into relevant media versions of the past, while it ignores and censors others' (ibid.). A study of cultural memory 'at the intersection of both social and medial processes' (ibid.), as the authors propose, affords insights into the genealogy of a given memory by mapping available remediations (both synchronically and diachronically) and their respective similarities and differences. In addition, by embedding these same media in their socio-cultural and historical contexts, one can discern which 'versions' gained a hegemonic meaning and which were ignored and attempt to explain the varying societal responses to them. Through this process, one can gain a greater understanding of the memory practices of a society within a given timeframe.

Before proceeding, let us briefly consider the different ways that memory can be re-activated. First, an existing memory text can be recirculated via, for example, a rerun of a television series or the republication of a novel. While the text is circulated integrally and appears to remain intact, the meaning attributed to it by its readers can change substantially. A film from the 1930s (e.g. Sergei Eisenstein's Aleksandr Nevskii [1938]) will most likely elicit substantially different interpretations from its audience today than it did from its contemporaries. Apart from such a temporal displacement, we could also imagine the possible implications of a geographical displacement (a screening of the same Eisenstein film in the United States in the 1930s) and even further social displacements (the 1930s American audience consisting either of proponents for or opponents of communism).

Another possibility is quotation, the use of (an element from) an original text within a new (con)text. Apart from the literary quotation of text, this would also apply to the use of film footage (historical and fictional), images, music and so on. The result is a new memory text that makes explicit reference to another memory text (thus creating an intertextual reference), in which case certain qualities of the quoted original are retained. Quotations can amount to the reproduction of a mere fragment of the original (a film scene or melody) or of an integral original (for images in particular). As suggested above, such quotations establish intertextual links that (can) influence the meaning of the new text. The possible intermediality of quotation should be noted, since memory cultures encompass not just texts and visuals but also memory artefacts, such as buildings and monuments, and performances of memory, such as national holidays, celebrations and memorials. Quotation, then, can become quite complex. Consider, for example, a documentary that uses a scene from a historical feature film that shows an actual statue of a national hero. Such intermedial 'double quotations', in this instance a statue quoted in a feature film quoted in a documentary, can pose a serious challenge for describing and interpreting the respective meanings of these different layers within a memory text.

Finally, an existing memory (a historical person or event, story or myth) can be used to create a new, original memory text. Aleksandr: The Neva Battle (2008, see chapter 4), to create its historical epic, drew upon the same 
national mythology as Eisenstein, but this recent film is an independent memory text. Nevertheless, by using the same memory it becomes part of an intertextual web consisting of other memory texts and artefacts that refer to the same myth. It is this kind of 're-make' or 're-cycling' of memory that scholars often appear to have in mind when discussing the re-activation of cultural memory.

Most of the historical figures, periods and phenomena that have been brought into active circulation in Russian memory culture since 2000 and that were, in the process, adapted to suit their contemporary target audiences can boast rich genealogies of cultural representations and political appropriations alike. Invoking pre-revolutionary memory images in particular involves the creation of intricate intertextual webs, and, depending on the knowledge and interpretation of the viewer, invests the historical narrative that is presented with additional meaning. In this study, the concept of cultural memory remediation as described above is further developed and used in two complementary ways to describe how history is employed to discuss issues pertaining to contemporary politics. The first way concerns the remediation of existing stories about the past and the extent to which they are reinterpreted. This understanding of the concept largely overlaps with the definition of remediation as 'the act of reworking a story [...] with an eye toward calibrating it for its new historical moment and audience' (Figge \& Ward 2010: 10). The second way this concept is understood involves the remediation of existing images or (feature) film footage about particular historical figures and events.

When we connect these two aspects of remediation to the topics of our case studies, the analysed cultural productions and the dynamics of cultural memory in contemporary Russia in general, two characteristics become apparent. First, manifestations of cultural memory do not exist independently of each other but rather behave as if they form a constellation. These memory clusters are shaped by synchronic connections and composed of associated memories or narratives. For example, the memory of Stolypin belongs to a memory cluster that comprises, among other figures and events, Tsar Nicholas II and his family, Rasputin, the Socialist Revolutionaries, Russian terrorism in the early twentieth century in general and Lenin. Historical factors (persons and events from a given time period) and topical factors (the end of empire, revolutionary tensions, [failed] attempts at reform) - in short, the cultural-historical timeframe that dominates the cluster and forms the tissue connecting its constituent elements - define which narratives belong to a memory cluster.

The existence of such clusters has implications for the dynamics of remediation. It means that a reinterpretation of or even a challenge to an established memory can occur not only via an altered version of a particular narrative. Such revisions can also take the form of a shift in focus from one person or event to another within the same cluster, which then has its own connotations, associations and mediation history. In addition, the cultural or 


\section{Memory politics}

political prevalence of one narrative can help 'prepare the ground' for the introduction of another narrative associated with it, thereby increasing the likelihood it will gain in popularity. For example, the memory of Stolypin was a relatively new addition to the Russian symbolic vocabulary. Yet, at the moment of its introduction, it benefited potentially from not one but two supporting lines of narration that had recently become quite popular among the public: narratives about early-twentieth-century terrorists and the police detectives who pursued them (including the detectives' present-day equivalent of anti-terrorist special forces working for the secret police), and often nostalgically inclined tales about the last Romanov family and the fall of the tsarist empire (see chapter 3).

The second characteristic involves the layered nature or even the explicit layering of memory. These diachronic connections can manifest themselves in a way very similar to the concept of remediation described above, namely in the repeated mediation of the same memory (cluster) over a long period of time - for example, when a given memory has been revisited and circulated under several tsars, in the Soviet period and again in the post-Soviet period. What results is 'akin to a snowball that gathers layers over time as it rolls across historical terrain, without losing its original core' (Figge \& Ward 2010: $10){ }^{7}$ The act of repetition establishes a certain connection among these periods, since it forces a positioning against previous interpretations. This form of layered memory can be implicit or explicit, conscious or unconscious. But what is striking about the materials that underlie this study is their widespread tendency to create links binding different periods in time, in an attempt to actively create a chain of memory in a rather explicit way. This layering of memory often takes the shape of cyclical historical parallels or analogies that extend through the present and thereby embed present-day reality in a diverse yet coherent and extensive history. Therefore, the genealogies of remediation and the layered meanings invested in these cultural memories are not just hypothetical. Their interconnectedness is frequently made explicit; memories can actually be presented as being layered. For instance, the historical linkage of the years 1612-1812-2012 has become common enough to have even made it onto a banner carried during the protest march on Manezhnaia Square on 18 December 2011 ('Luchshie lozungi narodnogo protesta na Manezhke' 2011; Brouwer 2016b).

The prevalence of memory chains appears to be connected to the complex reworking of the Soviet past in post-Soviet Russia. Memory chains do not seek to work around and exclude the Soviet period from the history of Russia being constructed, as was prevalent during most of the 1990s. Rather, by combining the pre-revolutionary and Soviet periods into one narrative, or enclosing it within a larger historical analogy - such as the 1612-1812-2012 chain mentioned above - the memory of the Soviet past is neutralised to a certain extent and presented as a 'natural' occurrence in the cyclical development of Russian history. The creation of a memory chain makes it possible to reintegrate the memory of the Soviet past, in its positive and negative 
elements, into narratives of national belonging (see also Brouwer 2016b). It remedies anxieties flowing from the perception of the Soviet era as a disruption of historical development and, consequently, of historical time. As such, pre-revolutionary memories, and the layered way they are represented, in fact forms an integral part of how contemporary Russia seeks to come to terms with its more recent past.

While repetition is essential for memory to be consolidated and therefore to be able to fulfil its potential as a political frame of reference, the product of remediation is necessarily complex and to a certain extent ambiguous. The implicit meanings of historical representations, resulting from their repeated mediations and reworkings, are hard to control. With regard to Nazi Germany, Linda Hutcheon explains:

Like parody, adaptation is politically versatile - or, perhaps more accurately, politically ambivalent. It can be used to subvert or to contain the power of its adapted work; it can exploit that power to new or nostalgic ends. The National Socialists were adept at using adaptations to tame or even remedy/rehabilitate what they saw as dangerous or threatening in Weimar culture; what they couldn't control, they discovered, was the continuing power of the evoked work, persisting through any of their deliberate modifications. The past is never fully erased even in an adaptation that consciously aims to construct a new and dominant normalcy; it lingers on, for better or worse.

(Hutcheon 2010: vii-viii)

What is relevant to this study is that remediation appears to be just as important for challenging the dominant line of interpretation as it is for consolidating it. The product of remediation already contains in itself the potential for questioning or undermining the official line of interpretation. Referring to Rachel Epp Buller's study of Weimar-era women photomontage artists included in the edited volume Reworking the German Past, Hutcheon states that their 'counter-narratives of resistance, like those of the various experimental documentary and fictional filmmakers [...], were made possible specifically by the act of adapting a prior narrative loaded with historical meaning' (Hutcheon 2010: viii). The photomontages by artists Marianne Brandt and Alice Lex analysed by Buller employ the meanings invested in their source material - news images from printed media - to create contrasts and tension in their montages. By drawing upon familiar visual imagery, they were able to visually formulate a powerful societal and political critique that was nevertheless understandable to the general public (Buller 2010).

The dual concept of remediation, as it has been outlined above, draws attention to a key distinctive feature of Russian memory politics: the fact that the selection of cultural memories has been motivated by the potential of such memories to establish a connection to early periods in Russian history; they have been chosen because of their long reach and accumulated meanings. 
Within these remediation genealogies, (political) historical narratives and cultural productions from the Soviet era are of particular significance for two reasons. When drawn upon, they have the potential to directly connect to a person's existing knowledge about history and also to what that individual learned at a young age (via formal education, but also through the transfer of knowledge and traditions within the family sphere). This pre-established knowledge, and possibly also a personal appreciation of particular stories, films and imagery, make the (re)introduction of latent cultural memories easier to accept. This effect is, of course, limited by the turn of generations.

In addition, the Soviet era exerts influence over contemporary representations of pre-revolutionary Russian history through the abundance of intertextual references to Soviet-era interpretations of these cultural memories and the inclusion of (audio-)visual materials in contemporary productions. Irina Shcherbakova aptly points out the inconspicuous way that Soviet-era historical representations continue to influence, for instance, contemporary (fictional) historical television programming:

What we see in television series [...] resembles an onion, where each of its layers reminds one of something the authors have seen on [the television] screen in their childhood or teens. You could peel off layer after layer, but still fail to uncover anything that is actually related to the depicted historical era. You have to keep in mind that the Soviet examples were created under conditions of censorship - this concerned everything, including the stage properties. Therefore it is highly amusing to hear contemporary creators of historical TV films remark that they have carefully watched feature films from the '60s.

(Shcherbakova 2014)

Many who today are making TV programming received their historical education during the Soviet era, which (literally) formed an image of their national past. But this is only one of the ways that Soviet historiography lives on in contemporary Russian TV and cinema. The frequent use and recontextualisation of excerpts from Soviet historical productions, and the (indirect) influence of Soviet-era historical productions on the way topics have been conceptualised by contemporary figures, has received little scholarly attention (except for those instances where the object of analysis is a contemporary remake of a Soviet production). Given the exceptionally complex dealings with the memory of the Soviet Union and the various periods and aspects of its existence, attitudes towards Soviet interpretations and representations of Russian history merit particular notice. I will return to this question in chapter 5 , where I provide a brief consideration of the hermeneutic effect of the remediation of visual representations of history on the basis of a sample of television documentaries on the Time of Troubles. Yet when assessing the impact of remediation of Soviet audiovisual materials on the interpretation of history, one should always be aware of the viewing strategies of the audience. As mentioned 
earlier, it is never a given that viewers accept as valid what they are shown. While Mickiewicz's findings concern viewer engagement with television news, I would argue that the Russian audience applies these same sceptical viewing strategies to other television genres and to cinema as well, albeit to a greater or lesser extent in each case. An ability to recognise the likely origin of a given story, and the possible interests involved in portraying a topic in this or that way, most certainly shapes how Russian viewers engage with other types of media as well. We must account for this critical, at times even cynical, viewing attitude when we make assumptions about the effect of television discourse on political views held by the general public.

\section{Notes}

1 Blogosphere is an umbrella term referring to the network of online communities, blogs and social media. On the Russian-language Internet, or Runet, blog platform LiveJournal (Zhivoi Zhurnal) has been particularly popular and influential.

2 The concept refers to those, actively advocating a particular framework for interpretation such as politicians and interest groups.

3 Hutchings and Rulyova go on to name the precise factors that determine this development: 'The fact that television now operated in a global 'infosphere'; the inherently porous boundaries between television texts and their contexts; the growing 'conversationalisation' of media discourse; the influence of the market imperative; television's twin, and contradictory, national-centripetal and local-centrifugal emphases; the lack in post-Soviet Russia of an established mechanism for mediating between public and private spheres; and the persistently low cultural status that the medium enjoys in Russia all conspire to ensure that the control that Putin nominally exercises remains remote and less than wholly effective' (2009: 3. Italics in original).

4 With regard to Russian and Soviet cinema, see, e.g., Youngblood (2007), Dobrenko (2008), Taylor \& Spring (1993), Roberts (1999), Norris (2012).

5 Jean Baudrillard's description of the relation between history and its representation in historical film is illuminating here: 'Today, the history that is 'given back' to us [...] has no more of a relation to a 'historical real' than neofiguration in painting does to the classical figuration of the real. Neofiguration is an invocation of resemblance, but at the same time the flagrant proof of the disappearance of objects in their very representation: hyperreal. Therein objects shine in a sort of hyperresemblance (like history in contemporary cinema) that makes it so that fundamentally they no longer resemble anything, except the empty figure of resemblance, the empty form of representation' (Baudrillard 1998. Italics in original. Quoted in Hughes-Warrington 2009: 190).

6 In its effort to immerse the viewer in a historical 'reality', historical cinema in fact adds yet another layer of fictionality to the fiction film: 'In an ordinary fiction film the actor portrays a character who he or she is not, but that character never existed; in a historical film, the actor portrays a referential figure who he or she is not. Therefore, although the historical film may claim to deal with real events, it is actually more artificial with respect to a spectator's desire to believe in the reality of the image' (Rosen 2001: 180. Italics in original).

7 Serguei Oushakine has noted something similar with regard to the St. George Ribbon that has become one of the most potent symbols of patriotism and remembrance of the Second World War in recent years: 'The St. George Ribbon is [...] a mnemonic object that has little known history of its own but helps to 


\section{Memory politics}

manifest a certain link with history. It presents a very particular trajectory of remembering whose structure is fundamentally rooted in various operations of dedifferentiation, historical blurring, temporal amalgamation, and semantic ambiguity. The familiar sequential order of the linear narrative is replaced [...] by the logic of palimpsest, which allows the retention of incompatible or contradictory meanings within one framework. The layered - "laminated" - history of the ribbon helps one to refrain from any resolute political or historical differentiation' (Oushakine 2013: 286). 


\section{Case studies}


$\Longrightarrow$ Taylor \& Francis

Taylor \& Francis Group

http://taylorandfrancis.com 


\section{Petr Stolypin: The making of a cultural memory}

\section{Stolypin in the Russian historical and political imagination}

On 27 December 2012, President Vladimir Putin and Prime Minister Dmitrii Medvedev unveiled a 4.6-metre-high bronze statue of Petr Stolypin in downtown Moscow. ${ }^{1}$ The statue, by sculptor Salavat Shcherbakov, was placed at the intersection of Novy Arbat and Koniushkovskaia ulitsa in sight of the House of Government of the Russian Federation. The unveiling marked the end of the year-long commemoration of the 150th anniversary of the prerevolutionary politician's birth. Stolypin served as minister of the interior and subsequently as prime minister from 1906 until his assassination in Kiev by Socialist Revolutionary and secret police agent Dmitrii Bogrov in 1911. Stolypin's name is generally associated with his agrarian reforms and his efforts to repress the terrorist movement in the wake of the 1905 revolution. He is also noted for his rhetorical skills. Stolypin's speeches before the Duma have become a frequently mined source of political one-liners, most popularly among them 'They are in need of great upheavals, but we are in need of a Great Russia' and 'Give the state twenty years of internal and external peace, and you will not recognise present-day Russia.' Stolypin has come to symbolise a political system characterised by top-down reform and the suppression of the opposition, combined with the aims of creating stability and stimulating economic growth. The degree of authoritarianism this system implies is portrayed as a necessary evil in achieving the higher goal of restoring and maintaining Russia's greatness. In addition, it is often justified by pointing out Stolypin's unique visionary leadership, a tendency that bears resemblance to the personification of state power in the figure of Putin over the ongoing period of his rule as president and prime minister. This chapter will analyse the making and meaning of the myth of 'stability Stolypin-style' (stabil'nost po-Stolypinski) (Nadein 2012a) under Putin, and the interplay among different actors in the political, societal and cultural spheres and, more specifically, between politics and television in the process of this cultural memory's creation and dissemination.

The memory of Stolypin and its institutionalisation as an exemplary image for Russian politics has emerged relatively recently. Contrary to the cultural 
memories that will be discussed in the later case studies, this particular memory had not been actively used by a previous political regime. In fact, the image of Stolypin in Soviet historiography was explicitly negative. In their appraisals, historians followed Lenin, who 'denounced the prime minister as the "hangman-in-chief," or simply as a hangman, tyrant, reactionary, or "pogrom-maker"” (Ascher 2001: 3). The statue of Stolypin in Kiev, erected in 1913, was taken down following the 1917 revolution and, quite symbolically, replaced by one of Karl Marx. The bust of Stolypin in present-day Ulianovsk met a similar fate. Stolypin's name became associated especially with two images: 'Stolypin's necktie' (Stolypinskii galstuk) and the 'Stolypin carriages' (Stolypinskie vagony). The first phrase refers to a quote by Cadet Duma member Fedor Rodichev, who coined the term in 1907 to criticise the field courts-martial established under Stolypin to put terrorist revolutionaries on trial (idem: 218). In Soviet historiography, and consequently history education, the expression came to symbolise the cruel, repressive character of Stolypin's politics. As for the second term, referring to the railway carriages used to transport peasant migrants to Siberia, it also acquired a negative connotation in later years. Although the colonisation of the Far East was actively promoted and supported by the tsarist state under Stolypin, people moved there on a voluntary basis, and the migrants were transported on newly built, ordinary trains (idem: 323). In the Stalinist era, however, the same route was traversed by trains equipped with bars that transported convicts to the region's prison camps. Today, the term 'Stolypin carriage' is still used to refer to trains specially equipped to transport convicts.

The Perestroika period saw renewed interest in pre-revolutionary Russia and a positive reappraisal of Stolypin's politics. Abraham Ascher speaks of 'an avalanche of publications' about the era when Stolypin held his position of power (Ascher 2001: 4). In 1991 the publishing house Molodaia Gvardiia, for example, released a complete collection of Stolypin's speeches in the Duma and State Council, subtitled 'We are in need of a Great Russia' (Nam nuzhna Velikaia Rossiia), the second half of his famous quote and a telling indication why the volume was published in the Soviet Union's final days. The preface outlines the radically opposed interpretations of the tsarist prime minister's importance and the 'myths and legends' associated with his name, and expresses hope that this volume of collected speeches will provide professional historians with material for them to reconsider and correct prevalent views (Stolypin 1991: 7-8). In essence, the Soviet argument was turned inside out: during the late 1980s and continuing into the 1990s, advocates of his memory re-framed Stolypin, who now came to be seen as 'a farsighted statesman whose policies were precisely the ones Russia needed to develop into a prosperous, stable, and powerful country' (Ascher 2001: 5). This position was often accompanied by the belief that had Stolypin not been assassinated, the implementation of his reforms in full would have averted the revolution. The two seemingly irreconcilable assessments of Stolypin as a statesman - one Soviet, the other counter-Soviet - mark the inherent complexity of the 
memory: the man was at once a despotic tyrant and a visionary leader who would have saved Russia from the horrors of revolution and war, had it not been for his tragic death. Vladimir Nadein aptly summarises how proponents of Stolypin have attempted to merge both aspects into a positive image:

Cruel, but far-sighted. For the good of the country. For the sake of a radiant future. He hanged [convicts], but also raised [the country] from its knees. He hanged, but also gave the country [a higher] GDP. All of Great Britain spread our Siberian butter onto their sandwiches in the morning. The rouble became heavier than gold. The export of grain increased several-fold.

(Nadein 2012a)

It is hard to miss how much these arguments echo those heard in contemporary Russia in defence of Stalin's reign.

Historians and politicians may have 'rediscovered' the legacy of Stolypin as the Soviet Union disintegrated, but indicators of public opinion in Russia paint a rather different picture emerging over the past twenty years. Polls conducted by the Levada Centre over this period indicate that Stolypin was never especially popular (Gudkov 2010: 39). When asked to give the names of five to ten names individuals from all nations whom they believed to be the most outstanding persons of all time, less than 1 per cent of the respondents named Stolypin in both the 1989 and 1991 surveys. In 1994, the figure rose to 8 per cent, then dropped back to 1 per cent in 1999 and rose to 4 per cent in 2008. Considering these figures, it is surprising that Stolypin was selected as the second most popular Russian of all time in 2008 in the nationally televised competition The Name Is Russia (Imia - Rossiia, to be discussed in detail below). This chapter aims to reconstruct how the memory of Stolypin was mediated in this recent period and, in this process, was continually reinterpreted to such an extent that the government felt confident enough to officially endorse it. I will also reflect on the particularities of the Stolypin myth that contributed to its popularisation and institutionalisation in this particular period, compared to earlier periods. The chapter is structured as follows. The first section analyses the myth's political appropriation and institutionalisation and considers earlier indicators of political interest in this image. Then I discuss the appearance of Stolypin in Russian cultural productions, on television in particular. Here I also point out certain precursors to the Stolypin myth, closely connected historical narratives that nevertheless do not feature him (or in which he plays a subsidiary part). The mediation of such narratives from the same memory cluster (see chapter 2) helped facilitate the emergence of our central myth; instead of the introduction of a brand-new memory, what transpired was rather a shift in focus and perspective. The chapter discusses three productions in detail: the TV series Stolypin ... The Undrawn Lessons (Stolypin ... Nevyuchennye uroki, 2006), the above-mentioned televised competition The 
Name Is Russia (2008), and the television documentary Petr Stolypin: A Shot at Russia (Petr Stolypin: Vystrel v Rossiiu, 2012).

\section{Institutionalisation of Stolypin's memory}

Stolypin has been part of Putin's political vocabulary from the very beginning of his presidency. In his first Annual Address to the Federal Assembly of the Russian Federation in 2000, Putin referred to Stolypin while discussing the difficulty in striking a balance between state interests and the rights of the individual. He stated:

Over the past decade, fundamental changes have taken place in the country - rights and freedoms of the individual are guaranteed by the Constitution, a democratic political system has formed, and a multi-party system has become reality. [...]

However, the letter of the law and real life are often quite different things. Only the framework of a civil society has been formed in Russia. Collective, patient work is now required for it to become a full partner of the state. We are not always able to combine patriotic responsibility for the destiny of our country with what Stolypin once called 'civil liberties'. So it is still hard to find a way out of a false conflict between the values of personal freedom and the interests of the state.

(Putin 2000)

Other commentators have also indicated a connection between the challenges faced by Putin at the start of the new millennium and those confronting Stolypin in the wake of the 1905 revolution. In discussions from the early 2000s of Stolypin's reforms, and more specifically in the appraisal of why Stolypin would have been exceptionally adept at carrying them through, we can even trace parallels to the characterisation of Putin himself. V. Loginov, for example, notes the following four characteristics: first, Stolypin "came, as it were, "out of nowhere"; second, "he was young - fortyfour years old'; third, 'he gave the impression of being a tough and decisive individual, a "strong personality" capable of imposing "order"; and finally, 'he was able to express his thoughts in a precise and laconic manner' (Loginov 2004 [2001]: 22). In the concluding paragraph of his essay Loginov embeds the discussions on Stolypin in the context of contemporary Russian politics. He states:

In today's discussions of the mature, overblown, but still-unresolved problems of national life, the most frequently expressed fears are of a 'new dictatorship'. This is not what we should fear. It is, rather, the unwillingness to take into account popular sentiments and the people's will that marks the high road to sweeping grass-roots upheavals. 
In other words, the establishment of a strong state should not be judged negatively, as (Western) observers of the process of democratisation in Russia have done for most of Putin's and Medvedev's presidencies, as long as the dominant political line does not conflict with the sentiments of the general public.

If we consider societal actors beyond the ruling elite who sponsored the emergence of the memory of Stolypin early on, we should note the Petr Stolypin National Prize for the Agrarian Elite (Natsional'naia premiia imeni Petra Stolypina 'Agrarnaia elita Rossii'). The award was established in 2002 as a private initiative ('Istoriia premii' n.d.), and the first awards given in 2003. Its purpose is to honour those who are successful in the agricultural sector along with those who "with their work revive Russian traditions, help our rural areas' (ibid.). In 2012, the awards ceremony was included in the official programme of festivities connected to the Stolypin commemorative year and thereby implicitly adopted by the state. The foundation behind the Petr Stolypin National Prize for the Agrarian Elite had already been one of the main initiators responsible for the celebration of a previous Stolypin year in 2006 (ibid.); marking the 100th anniversary of the beginning of Stolypin's reforms, the commemoration was supported by the Russian government. On 20 October 2006, Prime Minister Mikhail Fradkov signed a directive establishing an organising committee, chaired by Dmitrii Medvedev (Russian Government 2006). While the government thus endorsed the 2006 Stolypin year, it did not allocate funds to the activities that had been organised. Another organisation involved was the Fund for the Study of P.A. Stolypin's Legacy (Fond Izucheniia Naslediia P.A. Stolypina 2006a). This fund was established in 2001 by historian Pavel Pozhigailo, who held the position of state secretary of culture and mass communication between 2006 and 2008 (Fond Izucheniia Naslediia P.A. Stolypina n.d.), which may well have contributed to the government's decision to support the anniversary festivities. The program consisted of, amongst other things, a requiem in Stolypin's honour at the Church of Christ the Saviour in Moscow and the scholarly conference, 'The Stolypin model of the modernisation of Russia, 1906-2006'.

During the final meeting of the organising committee, Medvedev highlighted the parallels between the Stolypin era and the present: 'Today, Russia is faced by similar problems. Therefore, the general interest in Stolypin as a figure is no coincidence. Many of his ideas and plans are indeed as relevant as before' (Fond Izucheniia Naslediia P.A. Stolypina 2006b). It is important to note that the basis for the link between the two eras, as expressed by Medvedev, lies in the question of agricultural reform. The use of Stolypin's image is principally connected to specific policy issues rather than personal characteristics, a particular type of leadership that he represents or an autocratic style of governance, as we will see later on. This emphasis is consistent with the function of the historical analogy made between Stolypin and Putin that Caroline Humphrey has described with regard to agricultural reform and the efforts to 'deconstruct' the remains of Soviet collectivities in the post-Soviet period: 
What historical analogy does is to draw a parallel between Stolypin's attempt to get more independent-minded peasants to leave their communes and set up as private farmers and Yeltsin's and Putin's policies of disbanding collective farms and promoting 'fermery' today. Stolypin, in a famous phrase, said that Russia must now 'place a wager on the strong'. In brief, since both Stolypin and Putin attempted to impose private individual ownership of agricultural land, what they both represent is the destruction of the commune.

(Humphrey 2009: 234. Italics in original)

According to Humphrey, the generally accepted basis for the analogy is that Stolypin and Putin represent 'strong proponents of centralized state power'; each was 'in charge of the secret police' and 'pushed through, against fierce opposition, a series of reforms introducing private property in agricultural land in Russia' (idem: 235). While the importance of these elements cannot be denied, and indeed continue to inform the use of Stolypin's image, I will argue that since the time of Humphrey's writing the relevance of Stolypin has undergone a shift - from indicating parallels in policy to serving as a symbolic personification of autocratic leadership.

Humphrey, in fact, would have been surprised to see the Stolypin memory become institutionalised in 2012: she notes that 'the Stolypin-Putin analogy has died away in the last few years' (idem: 240), which she attributes to unresolved contradictions implicit in his remembrance, such as the alleged involvement of the secret police and the tsar in his death and the contradictory appraisals of his repressive policies. She argues that Putin and Stolypin might be too similar in this respect, which makes it difficult for Stolypin to be shaped into the sort of historical image that would allow his contemporary incarnation to be seen in a positive light:

[T] he whole personalized tangle (the rigid Stolypin, the jealous Tsar, the corrupt secret police, the double-dealing revolutionary) is reminiscent of the environment of secret police 'provocations' that also surround Putin. It is another layer of meaning hovering around the historical analogy one, like the assassination itself, of course, that the present Russian executive would have to eliminate from public consciousness if the analogy is to work in a positive way for the leader.

(Humphrey 2009: 239-240)

Already in 2008 we can see Stolypin's memory shifting away from historical analogy and moving towards the assumption of a more symbolic function. In his first Address to the Federal Assembly as president in 2008, Medvedev referred to Stolypin in his plea for constitutional democracy and increased respect for individual freedoms. He stated: 
The Constitution paves the way for Russia's renewal as a free nation and a society that holds law and the dignity of each individual as its highest values.

The cult of the state and the illusory wisdom of the administrative apparatus have prevailed in Russia over many centuries. Individuals with their rights and freedoms, personal interests and problems, have been seen as at best a means and at worst an obstacle for strengthening the state's might. This view endured throughout many centuries. I would like to quote Pyotr Stolypin, who said, 'What we need to do first is create citizens, and once this has been achieved civic spirit will prevail of its own accord in Russia. First comes the citizen and then the civic spirit, but we have usually preached the other way round.'

(Medvedev 2008)

Here, the Stolypin era comes to represent the development of a young democracy undergoing a process of stabilisation following a period of severe turmoil, paralleling the process of democratisation that has taken place in post-Soviet Russia. It points to the difficulties involved in establishing a representative system of government, as well as the issues that can arise when the government and the Duma are forced to engage in constructive cooperation as they try to implement necessary reforms. The balance between the collective and the rights of the individual, implicit in this discussion, tends to tilt towards the individual, which corresponds to the hope that Russia would take important steps toward democratisation under Medvedev.

In May of that year, the Russian government issued a decree that created the Stolypin medal. Divided into first and second degrees, the medal was first awarded in 2009 by Prime Minister Putin. In the decree, the purpose of the medal is outlined as follows:

The P.A. Stolypin medal is an encouragement for the contribution to solving strategic problems connected to the social-economic development of the country, including the realisation of long-term projects of the government of the Russian Federation in the fields of industry, agriculture, construction, transportation, science, education, healthcare, culture and other fields of work.

(Russian Government 2008)

The medal features a relief portrait of Stolypin and the inscription 'To the glory of Russia, for the good of the Russians'. Recipients have included the former minister of finance Aleksei Kudrin (1st degree, 2010), former minister of defence Sergei Ivanov (2nd degree, 2011) and Vladimir Zhirinovskii, leader of the ultranationalist Liberal Democratic Party of Russia (2nd degree, 2012).

During his period as prime minister, Putin has quoted and paraphrased well-known statements by Stolypin. The elements of Stolypin's legacy connected to democratisation found at the beginning of Medvedev's presidency quickly lost ground, replaced by a symbolic charge similar to that of the 
memory of the end of the Time of Troubles, discussed in chapter 5. Stolypin has become yet another wrapper, as it were, to enclose the promise of stability and economic prosperity that the Putin regime has been selling the Russian electorate for over a decade. Consider, for instance, the statement Putin made during a session of the Duma on 20 April 2011 - evidently, as Pavel Aptekar' points out, an echo of Stolypin's assertion that he needed twenty years of peace to transform Russia beyond recognition: 'The country needs a decade of stable, peaceful development without various kinds of rushing, [and] thoughtless experiments, entangled in, at times unwarranted, liberalism or, on the other hand, in social demagogy' (Aptekar' 2011). On the investment forum 'Russia calling!' Putin quoted Stolypin to substantiate his claim that Russia was an 'island of stability' and 'safe haven' for foreign investors. Putin's remark, 'We do not need great upheavals, we need a great Russia', altering the first words of the original Stolypin quote only slightly, made headlines in the Russian media ('Putin zagovoril iazykom Stolypina' 2011). The main difference between the 'end of the Time of Troubles' wrapper and the Stolypin wrapper lies in how each defines the purported threat that Russia continues to face. While the Time of Troubles narrative places its enemies outside of Russia, as we will see later on, the Stolypin narrative shifts attention to enemies within the country.

Putin defended the choice of Stolypin as a role model at the All-Russian forum of the agricultural professional class in November 2011 ('Putin otvetil na kritiku Stolypinu i ego reform' 2011). One of the participants challenged the political endorsement of Stolypin's legacy by arguing that Stolypin's reforms were, in fact, unsuccessful, which naturally cast doubt on whether someone like him should be made into a guiding figure for contemporary politics. In his reply, Putin addressed in particular the criticism of Stolypin's repressive measures by claiming that such actions had been necessitated by the tumultuous situation following the 1905 revolution. Paraphrasing Stolypin, he added: 'I hope that [his] descendants can distinguish between the blood on the hands of a doctor and the blood on the hands of a hangman' (ibid.). Putin also contradicted the allegation that a one-sided picture of the great reformer was being painted. He stated: 'We do not want to idealize the figure of Stolypin, but we want history to know all sides of this process [of reform] and all sides of this individual' (ibid.).

The decree establishing the Stolypin year was signed by President Medvedev on 10 May 2010 (President of the Russian Federation 2010). The organising committee was headed by Putin himself and consisted of several members of the government ('Putin vozglavil komitet po podgatovke prazdnovaniia iubileia Stolypina' 2011). While the year of commemoration comprised numerous events, the erection of the statue was its most public manifestation. This monument was the subject of extensive commentary in the press from its announcement in mid-2011 up through its unveiling in December 2012. It would not, it was decided, receive state financing; rather, the necessary funds would be collected from Russian businesses and 
individuals. Putin, for his part, encouraged all members of the government to follow his example and donate a share of their salaries towards its financing ('Putin predlozhil chlenam kabmina vnesti den'gi na pamiatnik Stolypinu' 2011), thereby urging them to buy into the memory of Stolypin not only symbolically, by endorsing the decision in their capacity as politicians, but also literally, through financial support. About the relevance of Stolypin, Putin offered the following comment during one of the organising committee's meetings:

As a true patriot and wise politician, [Stolypin] understood that different kinds of radicalism are equally dangerous for the country as standing still, [as] refusing reorganisation [and] necessary reforms; [he understood] that only a strong, capable state power, supported by the private, civic initiative of millions of people, can provide for the development, [can] guarantee the order and stability of a vast, multinational power, [can] guarantee the inviolability of its borders.

('Putin predlozhil chlenam kabmina vnesti den'gi na pamiatnik

Stolypinu' 2011)

The design for the statue was subject to a competition in which both established and young artists took part (Krasnov 2011). The final decision was based on popular voting and the judgement of a professional jury. ${ }^{2}$ Pavel Pozhigailo, the director of the Fund for the Study of P.A. Stolypin's Legacy mentioned above and a man who was involved in the organisation of the Stolypin year, has commented on how they managed to raise the required funds ('V Moskve ustanovili pamiatnik Petru Stolypinu' 2012). He revealed that more than 1,500 people in total, from all over the country, made contributions. This group of donors consisted of about one hundred politicians, political representatives and businessmen, with the rest being average citizens 'of modest means' such as pensioners and teachers, who, Pozhigailo claims, donated on average half their monthly income. Pozhigailo emphasised that the fundraising was not actively propagated, so the influx of donations demonstrates that the memory of Stolypin is very much cherished by the Russian population as a whole. This latter claim can be questioned, however, since all the traditional media outlets had picked up on the plans to erect the statue and on Putin's call to follow his example and make a donation. Even so, the idea of employing popular fundraising instead of allocating state funds has highly symbolic import, of course, as it suggests that the statue was erected by the Russian people rather than being imposed from above by the state. Its location next to the House of Government is no less symbolic, emphasising the close connection between the public display of honour for Stolypin and the ruling political regime.

Erecting a statue of Stolypin in central Moscow was not in fact a completely new idea. It had been proposed in 2001 by none other than Nikita Mikhalkov, a renowned film director and a highly influential figure in Russian 
cultural affairs. He is also a personal friend and supporter of Putin, and one of the main sponsors of the memory of Stolypin, as will become clear from the remainder of this chapter. Mikhalkov suggested placing Stolypin on Lubianka Square to replace the highly controversial statue of Feliks Dzerzhinskii that had been taken down in 1991 ('Kto dolzhen stoiat' na Lublianke?' 2011). The city of Moscow's commission on monumental art considered the suggestion in 2002 but decided not to endorse it because they believed 'one monument of the reformer in St. Petersburg was sufficient' ('V Moskve ustanoviat pamiatnik Stolypinu' 2011). That same year the city of Saratov, where Stolypin served as governor before being appointed minister of the interior, erected its statue of the reformer to mark the 140th anniversary of his birth ('V Saratove otkryt pamiatnik P.A. Stolypinu' 2002). The square that is home to the monument was named in his honour as well. Several years later, in 2011, the city of Krasnodar also unveiled a statue ('V Krasnodare otkryli pamiatnik Stolypinu' 2011). This time, the occasion was the 100th anniversary of Stolypin's assassination rather than his year of birth, as had been the case with the other celebrations.

The largest number of Stolypin-related events and commemorations so far, however, occurred in 2012. On 26 September 2012, a statue of Stolypin was unveiled at the State Agrarian Academy near Ulianovsk, which had borne Stolypin's name since February of that same year ('Zurab Tsereteli otkryvaet v Ul'ianovske vystavku i pamiatnik Petru Stolypinu' 2012). Its sculptor, Zurab Tsereteli, is one of Russia's best-known artists, a figure who, on account of his close relationship with the former Moscow mayor Iurii Luzhkov, has left a (severely criticised) mark on the post-Soviet transformation of the Russian capital (Goscilo 2011). Indicative of Tsereteli's favourable position vis-à-vis the Kremlin is his immortalisation of Putin via a larger-thanlife-size bronze sculpture of the Russian leader dressed in a judo outfit. Tsereteli actually submitted a design for the Moscow monument, corresponding to that of his statue of Stolypin in Ulianovsk. Several sources have suggested that Tsereteli, after failing to win the bid for Moscow, offered the statue of a seated Stolypin to Kiev, whose officials declined it, stating that the memorial plaque on the building where Stolypin drew his last breath was sufficient ('Tsereteli podaril Ul'ianovsku pamiatnik Stolypinu, ot kotorogo otkazalis' v Kieve' 2012; 'Kiev ne khochet prinimat' ot RF v dar pamiatnik Stolypinu' 2012). For that reason, the statue ended up at the academy that then made Tsereteli honorary professor in return for his generous gift ('V Ul'ianovskoi oblasti otkryli pamiatnik, izgotovlennyi Zurabom Tsereteli' 2012). In addition, there were plans to place a bust of Stolypin, again by Tsereteli, in the city centre of Ulianovsk (Chilikova 2012; 'Tsereteli poobeshchal produblirovat' Stolypina' 2012), but the selected location proved administratively problematic. The bust is a remake of a monument to Stolypin that was unveiled in 1913 and then torn down soon afterwards. However, the plan to 'return' Stolypin to its original location in the centre of Ulianovsk required the relocation of the statue of writer Ivan Goncharov now occupying that space. As 
the bust was gathering dust in a municipal storehouse, a public vote was finally organised in February 2017 to decide on the statue's future location (Ul'ianovsk Public Chamber 2017). Other events connected with the celebration of the Stolypin year included an exhibition in the State Historical Museum entitled 'The last knight of the empire'; renamings of the Moscow city university of management, a street, and a vessel of the Russian navy; a silver two-rouble coin bearing Stolypin's image (Russian Central Bank 2012); and a special commemorative stamp (Filaticheskii Obzor 2012). Furthermore, the Ministry of Education provided suggestions on how to dedicate a class to the theme of 'the lesson of Stolypin' in secondary schools (Ministry of Education and Science of the Russian Federation 2012).

How can we explain this political institutionalisation of the Stolypin memory as sketched above? Russian historian Igor' Froianov asserts that the process of 'Stolypinisation' (stolypinizatsiia) should be seen in parallel to the renewed efforts at de-Stalinisation (Froianov 2011). While I do not endorse Froianov's views (he goes on to argue how, in fact, the memory of Stolypin can never measure up to the memory of Stalin and how he is a mere 'pigmy' when compared to the Soviet 'giant'), the parallel development he points out is an interesting observation. The peak in attention for Stolypin (2011/12) did indeed come after the greatest leniency shown by the state towards a positive re-evaluation of Stalin's legacy abated (for a more detailed discussion on the figure of Stalin in Russian memory politics, see the Introduction). However, as the previous discussion has shown, and as will become clear from the analyses that follow, it would be a mistake to see the Stolypin myth as, first, a new phenomenon and, second, a mere consequence of the need to fill the void left by the memory of Stalin. It is also more fruitful to consider the myth of Stolypin together with the memory of the Time of Troubles rather than focus on the limited number of characteristics shared by Stolypin and Stalin.

\section{Film and television analyses}

During the 1990s and the 2000s, Russian cinema and television showed a lively interest in the pre-revolutionary period and, in particular, the first two decades of the twentieth century. Two themes connected to this period cleared the way for the emergence of productions about Stolypin. The first theme concerns reflections on the period leading up to the 1917 revolutions in relation to the last Romanovs. This imperial theme, often tinged with a hint of nostalgia, was very much present in the 1990s (Govurukhin's The Russia That We Lost [Rossiia, kotoruiu my poteriali, 1992] is an obvious example) and continued into the 2000s with, for example, The Romanovs: An Imperial Family (Romanovy: Ventsenosnaia sem'ia, 2000), directed by Gleb Panfilov. Because of Stolypin's position close to the tsar, it was possible to insert a narrative about him into this established narrative framework. His allegedly tense relationship with the monarch, and the claims that Stolypin could have saved the empire and thereby the lives of the royal family, increased the appeal of this combination. 


\section{Case studies}

Yet the second theme into which the Stolypin memory could have been fitted - and indeed has been - appears to be more significant: TV series and films about the Combat Organisation of the Socialist Revolutionary Party (the members of which were the terrorists whom Stolypin came down on) and the efforts of the Okhrana, the secret police, to repress it. This group of productions should be seen in the context of the general popularity of TV series on the police and secret services in the 2000s. Examples include the film The Rider Named Death (Vsadnik po imeni smert', 2004), directed by Karen Shakhnazarov $^{3}$ and the TV series Empire under Fire (Imperiia pod udarom, 2000) and The Sins of Our Fathers (Grekhi ottsov, 2004). Whenever Stolypin makes an appearance in such a production, he is but one of many historical characters and receives little particular attention. Moreover, he is a person in need of protection, rather than someone who takes positive action to protect others from harm. The single focus on Stolypin in the TV series under discussion in the next section, therefore, was unusual, a marked departure from previously existing representations.

\section{Petr Stolypin ... The Undrawn Lessons (2006)}

The historical dramatisation Stolypin ... The Undrawn Lessons, a series broadcast in 2006 by NTV, was the first fiction feature to have Stolypin as its leading character. ${ }^{4}$ Consisting of 14 episodes, the series covers the period from when Stolypin was governor in Saratov up until his assassination in Kiev in 1911. The scenario was written by Eduard Volodarskii, who also wrote a historical novel, published in 2007, with the same title to accompany the series. Drawing extensively on detective series' tropes, it depicts the constant struggle between, on the one hand, the Russian state as it attempts to accommodate the outcomes of the 1905 revolution while preserving the tsarist empire and, on the other hand, the Socialist Revolutionaries (SR) who continue to attack the state's representatives with the aim of undermining the empire's stability. However, as will be discussed in greater detail below, the state is not conceived of as a unitary actor. Rather, it is an intricate political maze of conflicting interests among the tsar, the State Council, the Duma and the Okhrana, through which Stolypin struggles to find his way in order to implement his vision of what Russia should be.

The series' timing was significant: it aired in the wake of the colour revolutions in neighbouring Georgia and Ukraine, among other states. As was explained in the Introduction, the Kremlin initiated a "preventive counterrevolution' to prevent a similar scenario unfolding in Russia. The TV series reflects elements of this discourse, which intimated close cooperation between Western states and Russian opposition groups in an effort to undermine the Russian state. In many ways, the series laid the groundwork for the thematic constructions that have since become associated with Stolypin's memory. The narrative's central aim is to demonstrate Stolypin's personal and political superiority and the tragedy of his untimely death, which, it is implied, had 
consequences equally tragic for Russia itself. According to the series' director, Iurii Kuzin, Stolypin ... The Undrawn Lessons is about 'a person, who was killed by mistake' (Epanchina 2006). He explains: 'Stolypin was killed by [Dmitrii] Bogrov, who was the son of a Kievan petty bourgeois, a Jew by the way. But Stolypin actually defended the rights of minority groups, including Jews. Therefore, Bogrov was mistaken. He killed the wrong person' (Epanchina 2006). It would have been better if Bogrov had shot the tsar, who was also present in the Kiev theatre, instead of Stolypin. It is quite remarkable how the series, which advocates an exemplary role for Stolypin for contemporary Russia, portrays those involved in the attacks. Their characters, especially those of Evno Azef, his right-hand man Boris Savinkov ${ }^{5}$ and Bogrov, have considerable depth and are sometimes depicted even more emphatically than several of Stolypin's political adversaries. While their actions are not endorsed, these characters are endowed with complex emotions of anger, love, remorse and spite and are shown to be passionate in the pursuit of their ideals.

The central leitmotiv of the series is that Stolypin had been the single figure capable of leading Russia, the one man who could have prevented its political and social crises on the eve of the revolution and, ultimately, the revolution itself; but adversaries on multiple fronts prevented him from fully implementing his reforms. The argument is well summarised in the words of Empress Mariia Fedorovna, the mother of the tsar, when she presses her son not to accept Stolypin's resignation. She argues that Stolypin is genuine, while other high-ranking politicians (such as his predecessor Vitte) are hypocritical. The empress warns her son: 'If you lose Stolypin, revolution will break out in two years' time and all those who surround you now will betray you'. A few scenes later in this episode, Stolypin has an audience with the empress and she stresses her point once more: 'only you can save Russia from times of troubles and poverty, and set her on the right path'. The series emphasises the idea that had Stolypin's political adversaries not been focused on their personal gains and ambitions but, instead, conceded that Stolypin's policies were correct, the state would not have collapsed. This is not to say that the series completely ignores the political and societal problems existing in late tsarist Russia. It acknowledges the tensions between the governing elite and the majority of the agrarian population that culminated in the socialist revolution. But Stolypin's reforms are presented as the unacknowledged alternative that could have addressed these issues along more gradualist lines; they represented the golden mean between (extreme) conservatism and revolutionary tendencies.

\section{Stolypin the reformer and his (political) opponents}

Petr Stolypin, played by Oleg Klishin, is a Janus-faced figure. On the one hand he is the confident statesman, endowed with persuasive rhetorical skills. On the other hand he is the dedicated family man, revealing a tender and 
sensitive character hidden behind his stern outward appearance. In each of these roles Stolypin excels. His superiority emphasises how the opposition towards his reforms, as well as his assassination, should be interpreted as a tragedy for Russia, and underlines Stolypin's exemplary function for contemporary Russia, a role suggested by the series' title. Kuzin describes his Stolypin as 'a Renaissance man': 'he is a reformer, like Luther, like Peter the First ... . Therefore he has different faces: with enemies he is severe, with friends he is gentle, with his wife and children he is childlike and mischievous' (Epanchina 2006).

Stolypin's introduction in the very first scene is crucial for his establishment as a person of noble character. A young Stolypin rushes to a field where his brother lies dying as a result of a duel. To uphold his brother's honour, he then challenges his brother's murderer to another duel. Stolypin is shot in the arm but, when his turn comes to fire, he deliberately misses his target. The duelling motif is later repeated and again signifies Stolypin's noble personality. One of the members of the Duma, the constitutional democrat (Kadet) Fedor Rodichev, criticises the field courts-martial that the prime minister has authorised to counter the revolutionaries. Rodichev gives the hangman's rope the nickname 'Stolypin's necktie', mentioned earlier, an expression that has stuck to the memory of Stolypin ever since. Stolypin takes offence and challenges him to a duel. After repeated public apologies by Rodichev, Stolypin eventually forgives his opponent for the offence. In another scene from the first episode, Stolypin singlehandedly disperses a revolutionary uprising in Saratov, which demonstrates his natural ability to exercise authority over people. Outpacing his security guards, Stolypin walks into a square where a young man is inciting a crowd to revolt against the monarchy. He climbs the platform to join the revolutionary and, after taking off his coat, he summons the now confused agitator to hold it for him. Not in the least intimidated, Stolypin proceeds to declare his achievements as governor and, slowly but surely, wins over the crowd. While the assembled people are on his side, the insulted revolutionary takes revenge by throwing a bomb that misses the governor but injures some of the spectators. The outcome of the scene adumbrates the challenges that Stolypin will face in the rest of the series when dealing with the terrorist movement on the national level as prime minister. At the same time, the scene establishes him as a resolute and fearless leader.

Explicit criticism can also be heard, mainly from the side of Stolypin's political adversaries. He is repeatedly accused of being a dictator, of concentrating power in his own hands and of bypassing the State Council and the Duma in order to implement his reforms. Their criticism is undermined by the constant idealisation of Stolypin already indicated above and by the expressly negative portrayal of those expressing these reproaches. Their hostility towards Stolypin is motivated not by a sincere renunciation of his policies, it is suggested, but rather by the fear of losing political influence and privileges. Because they lust for power and behave in ways that show indifference to the people's needs, these reproaches are cast as hollow and self- 
serving accusations. Furthermore, some government officials, most notably General Vladimir Trepov, a member of the State Council, attempt to undermine the tsar's confidence in Stolypin by deliberately misrepresenting the accomplishments of his reforms, such as the level of economic growth in their aftermath. During one of Trepov's audiences with the tsar, Nicholas II dismisses the State Council's proposal to discharge Stolypin on these very grounds, stating that the recommendation is not based on sincerely held views but rather derive from a personal feud against the reformist prime minister.

There is a grain of truth, however, in the claim that Stolypin transgressed the powers invested in his position as prime minister. Taking advantage of article 87 of the Fundamental Laws of the Empire, Stolypin, with the cooperation of the tsar, twice dissolved the State Council and the Duma for a period of three days, thus allowing the tsar to directly approve his reform measures. ${ }^{6}$ Bending the law and circumventing the state's representative bodies are justified on two grounds in the series. First, it is claimed that Stolypin is the only person who is not guided by his personal ambitions and desire for gain and who knows precisely how Russia must be reformed in order to prevent social upheaval and state collapse. Second, it is justified since the State Council and the Duma continue to obstruct all proposals for reform without offering any vision of an alternative path, despite Stolypin's efforts to cooperate with the members of these bodies. Thus, the series appears to justify a high measure of autocracy in carrying out reforms. Opposition within the political system, and especially that of the popularly elected members of the Duma, is renounced as being self-centred, short-sighted and obstructive.

It should be noted that Stolypin's reforms are rejected both by conservative monarchists in the State Council and the Duma and by liberals and socialists. The former fear the undermining of the Russian Empire, while the latter find the reforms insufficiently far-reaching. Stolypin's vision therefore comes across as a middle course, the golden mean between (extreme) conservatism and revolutionary tendencies. The idea that far-reaching reforms can be implemented while maintaining political stability is very attractive to the contemporary viewer. Indeed, it sounds familiar. Numerous elements of the programme's outlook can be interpreted as drawing parallels with Putin's Russia. First and foremost, the series presents an intransigent Duma, whose lack of cooperation with the prime minister is attributed to the former's obstructiveness, not the latter's lust for power. What is more, it justifies a certain degree of authoritarianism via the claim that autocratic rule is necessary in order to revive the country. In addition, the way Stolypin addresses the Duma - using blunt language and much expressiveness and making jokes at the expense of Duma members - is reminiscent of Putin's appearances before parliament.

The way the series' writers have rewritten, combined and added to wellknown passages from Stolypin's speeches to construct arguments that carry particular resonance with contemporary Russia provides important clues 
about the political programme promoted by the production. Consider, for example, Stolypin's address to the Duma towards the end of the third episode:

\begin{abstract}
A weak Russia - that is what our enemies dream of. We, among other strong and powerful nations, are advised to turn Russia into a wreck. In order to then build on these ruins a Fatherland that is unfamiliar to us (1). The Russian state developed on its own yeast [drozhzha] (2): The Scythians, Byzantium with its emperors, the Horde and Europe ... . Who did not knead the dough from which the coarse rye bread of Russian history was baked? But our path, gentlemen, is still different from the path of Western democracies. Their fate is eternal movement, our fate is eternal repose. You, gentlemen of the SR and Social Democrats, are in need of great upheavals, but we, gentlemen, are in need of a great Russia! (3).
\end{abstract}

Most of what is delivered here can be traced back to actual speeches given by Stolypin in 1907 and 1908 (printed in italics in the quote above). Extract 1 has been incorporated with minor adaptations but is placed in a new context. The original passage is taken from a speech on the structure of agrarian life and the farmers' right to property and, thus, concerns explicitly internal matters (Stolypin 1991: 90). However, in its new context, the word 'enemies' in the first line, which extract 1 refers back to, appears to refer to foreigners. This is confirmed by the sentence on the Russian path being different from that of the Western democracies. The direct address to the SR and SD in the final sentence draws attention to the claim that there are also internal enemies who threaten to undermine the stability of the Russian state. Hereby, the impersonal construction 'we are advised' (predlagaiut nam) takes on a different connotation and is connected to the strong notion of 'enemies' lurking within and outside Russia.

In the second extract, the final words have been changed, though the sentence retains its tenor. Again, the context has shifted. In the original, the idea of Russia's own unique roots is linked to the argument that Russia is predisposed to be a monarchy (Stolypin 1991: 107). The roots of the Russian state are traced back to the autocracy of the Muscovite rulers, to Peter I, Catherine II and Aleksandr II, each of whom represents a different stage in the development of supreme imperial power. Stolypin's speech in the series lifts just one sentence from the original and then invokes a quite different definition of Russia's roots, derived from the Scythians, Byzantium, the Golden Horde and European influences. This conception makes explicit appeals to such ideas as Eurasianism, Russia as the Third Rome and the Europeanisation of Russia by Peter I. The subsequent passage goes on to appeal to the idea that Russia's historical path is unique. Stolypin indeed expressed a similar position in a speech from 1908, when he stated:

Our eagle, an inheritance of Byzantium, is a double-headed eagle. Of course, single-headed eagles are also strong and powerful, but by cutting 
off the head of our Russian eagle that is directed towards the east you will not turn it into a single-headed eagle; you will only make it bleed.

(Stolypin 1991: 129)

The speech ends with Stolypin's most famous statement (extract 3). The often quoted and paraphrased sentence is taken from the speech on agrarian reform, just like extract 1 . The sentences that precede it are markedly different than the original speech, but the two texts are largely comparable in meaning (Stolypin 1991: 96). The elements that cannot be retraced to Stolypin's actual words are explicit references to the discourse on what or who constitutes a threat to Russia in contemporary politics. Russia's enemies, it is intimated, fear the country's return to strength. Through obstruction and criticism they attempt to keep the state weak. The sentence arguing that Russia's path is very different from that of the Western democracies explicitly responds to the Western critique of the stalled process of democratisation and the centralisation of power in Russia under Putin.

It is not wholly tenable, however, to assert a direct correspondence between the two periods and make Stolypin a stand-in for Putin: Stolypin functioned as a prime minister subject to the will of the tsar, whereas Putin was president at the time the series aired. More generally speaking, it is to be doubted whether it is productive to search for such one-to-one analogies with the aim of understanding the political relevance of (fictional) television productions. And even if direct correspondence (which would allow us to pinpoint which character has been shaped to resemble which contemporary politician) is lacking, this by no means forecloses the possibility that a historical narrative can put forth a message about governance. In this particular case, the incompleteness of the analogy between Stolypin and Putin does not undo the fact that the leadership qualities that the series puts forward can be transferred onto the Russia of the twenty-first century, even more so since Nicholas II is portrayed as an indecisive ruler who, in fact, depends on Stolypin to steer Russia towards salvation from revolutionary harm. But though the Tsar is hardly Stolypin's equal when it comes to leadership abilities, Stolypin remains loyal and subservient, placing himself in the service of the state.

The series depicts the process of 'democratisation' following the 1905 revolution, a movement towards a system where governmental powers are to some extent restricted by representative bodies. Yet the government is still allowed to set aside the opinion of these bodies in order to directly implement reforms. The argument that justifies this (increased) level of autocracy stems from the pressing need to counter subversive actions by oppositional forces both within and outside the state apparatus, in order to preserve the condition of stability that has been achieved and to prevent the weakening of the state.

Before delving into the depiction of Stolypin's political adversaries and, more specifically, their ties with foreign enemies, the second group of opponents has to be introduced, the bombisty. The Combat Organisation (Boevaia Organizatsiia), hereafter CO, the branch of the Party of Socialist 
Revolutionaries involved in terrorist attacks against state officials, is presented as Stolypin's main opponent. One of the policies most readily associated with Stolypin, both in Soviet times and today, is indeed his harsh repression of terrorist revolutionaries and the field courts-martial he established to more quickly put individuals suspected of revolutionary activities on trial (thus 'Stolypin's necktie', referred to above). The series follows the CO extensively in its preparation and execution of several attacks, among others on Prime Minister Von Pleve, Grand Duke Sergei Aleksandrovich and Stolypin himself. Its members meet in smoke-filled, dimly lit drinking cellars, in private apartments and in luxury restaurants where they indulge in champagne and decadent suppers. The organisation consists mostly of young, idealistic men inspired by nihilist, socialist or maximalist ideologies. They argue passionately about who should be assassinated next, but are far removed from the ordinary people whose interests they purportedly seek to defend. While their ideals and motivation for joining the $\mathrm{CO}$ vary, they agree that terrorism is a legitimate means of political action - indeed, the only effective means of challenging the tsarist state and bringing about substantial social change. Fatal attacks are political deeds, not murders. They regard the loss of innocent lives a necessary price to pay for the achievement of their goals. At the same time, the series includes several episodes that argue that the revolutionaries are mostly opportunists who will not stand by their ideals when faced with resistance or offered financial benefits. The recruiting of terrorists as informers was a customary practice in the fight against the revolutionary movement. The series includes several such double agents, including one of the main characters, Evno Azef.

The case of Evno Azef has become legendary. In the period covered by the series, Azef headed the $\mathrm{CO}$ and was deeply involved in the planning and execution of attacks. But he simultaneously leaked information about the $\mathrm{CO}$ to the Okhrana. The pay he received in return for his inside information allowed him to enjoy a lavish lifestyle. Furthermore, his links to the police enabled him to eliminate enemies within the $\mathrm{CO}$ and maintain his position. Azef, played by Aleksandr Stroev, is first and foremost a person of excess. $\mathrm{He}$ is smartly dressed, extroverted, engaging - a smooth talker who can turn every situation to his advantage. He is a selfish opportunist who does not care whether his actions inflict damage on Russia or on the terrorist movement he claims to believe in. Despite Azef's confident appearance, his way of life, which requires him to play two opposing roles at the same time and run the imminent risk of being unmasked, does not leave him unaffected. He is tormented by an inner struggle that manifests itself through severe drinking and frequent nightmares. He wakes up crying out to his imagined opponents to let him go, begging his internal fiends to leave him in peace. The revolutionaries who share an apartment in Moscow with him are driven to sleep-deprived desperation, unable to rest because of Azef's nocturnal screaming. To the outside world and especially to his contacts within the Okhrana he conceals his anxiety, claiming to actually enjoy his double role: 'I love to play games'. 
Most of what we learn about Azef's motives and his opinions about terrorism is expressed in his discussions with Bogrov. He repeatedly emphasises Bogrov's Jewish background, linking it to his terrorist ambitions, and even philosophises about the difference between Russians and Jews. Jews are too sceptical, he thinks, while Russian have too much faith in Orthodoxy and the tsar. Quite unexpectedly, Azef offers up Stolypin as an example of this 'weakness' found in Russians. Whereas Bogrov speaks degradingly about Stolypin (since he is only a governor at that time), Azef is more impressed with him and even foresees that Stolypin will soon become a minister. But he also predicts that if indeed Stolypin rises to power, terrorism will be done for. In another discussion we learn that Azef is critical towards traditional religions and the materialist ideology of the Social Democrats (the future Bolsheviks) alike, and believes only in fate and death. This view is also expressed in the way he speaks about the victims of terrorist acts. He ridicules Bogrov's scruples about trying to ensure that no innocent bystanders lose their lives in the attacks; he sees their deaths as the necessary evil of terror. Indeed, the absolutist state cannot be changed without the killing of innocents.

The motif of Jewishness is strongly expressed throughout the series. Indeed, in the first episode, not only is Bogrov's religious background emphasised, but Interior Minister Von Pleve actually calls upon a group of rabbis to stop their youth from committing terrorist attacks. He dismisses their suggestion that the situation can change only when Jews are given rights equal to those of Russians (as Stolypin later attempts to do), and he warns that there will be nationwide pogroms if they fail to control their followers. The anti-Semitic undercurrent that intimates a direct relation between Judaism and revolutionary inclinations has been discussed and criticised (Tsyrkun 2006; Kachkaeva 2006) by, among others, the writer of the original script, Eduard Volodarskii. In an interview in the renowned journal Iskusstvo kino (Balandina 2007), Volodarskii distances himself from the series' anti-Semitism via a direct offensive against Kuzin, whom he claims heavily rewrote the script without consulting him, to such an extent that he can no longer agree with its content (ibid.). Kuzin has responded angrily to this interview in several posts on his LiveJournal blog. He denies having excluded Volodarskii from the project. Quite the contrary: he claims that Volodarskii himself failed to comment on the extensive adaptation of the script he proposed (Kuzin 2007a; Kuzin 2007b). Kuzin describes the script in exclusively negative terms, calling it a 'scenario that fell into a fainting fit, swollen like a case of dropsy' (Kuzin 2007b). Kuzin's defence makes it clear that Volodarskii might have been correct in claiming that he did not recognise his writing in the end result:

The scenario E.R. Volodarskii wrote was incoherent and wordy and it was impossible to fit it to the format of 15 episodes. For starters, I cut it in half. After substituting the official jargon with words from the contemporary lexicon, I reworked the sluggish and archaic monologues; I gave the scenes taken from Savinkov's book an original look, placing 
emphasis on the characters of the historical personalities, their personal lives. And all I have done was not out of a desire to annoy Eduard Volodarskii, but because of the reluctance of the latter to cooperate with the director.

(Kuzin 2007a)

Kuzin avoids the issue of Judaism and fails to address the accusation that he added an 'anti-Semite subtext'.

Azef's right-hand man Savinkov is, unlike Azef himself, truly committed to the revolutionary cause and to terrorism. He is emotionally involved in his mission and considers Azef to be his close friend: together they will shake the foundations of the monarchy. The accusations against his boss lead him to endure much anguished doubt, and he is unwilling to accept the unmasking of Azef as a double agent for quite some time. According to Kuzin, Savinkov is 'conscientious. He is tormented with doubt, he feels the urge to get even with himself' (Epanchina 2006). When Vladimir Burtsev mounts his accusations against Azef and the SR decides to investigate the case, Savinkov is repeatedly shown taking a shower in an attempt to clear his head. The voiceover of Azef reading a letter to Savinkov, in which he declares that he is loyal to the state and not the revolution, ${ }^{7}$ and the intersecting shots of the proceedings of the SR trial demonstrate how he cannot shake off his doubts about the loyalty of his purported friend. While the family background of Bogrov is made explicit and, to a certain extent, presented as an explanation for his revolutionary tendencies, Savinkov is not given a past. That Boris Savinkov was actually Polish never comes up, even though the proposed law on zemstvos in the Western provinces, aiming to decrease the political influence of the Polish elite, features extensively in the conflicts between Stolypin and the parliament. So while the overrepresentation of Poles is seen as a threat to the position of ethnic Russians in the empire, they are not linked to the revolutionaries. The possibility that the Polish region might secede nevertheless returns explicitly in the political testament dictated by Stolypin in the final episode (to which I will return shortly).

\section{Enemies of the state as 'foreign agents'}

The CO's foreign financing and the terrorists' frequent travels to Western Europe are instrumental for the representation of their activities as a threat to the Russian state. Indications of the links between foes abroad and domestic enemies (the revolutionaries) can be found in almost every episode. Azef frequently boards trains with their destinations explicitly shown, and the live music played in the restaurants indicates which country they find themselves in. Berlin, Zurich, and Paris are favourite hideouts as they plan future attacks beyond the reach of the Okhrana, so the series tells us. Finland is another case in point. At the time, it was a Grand Duchy in the Russian Empire and therefore enjoyed a considerable level of autonomy. In the series, the $\mathrm{CO}$ uses 
Finland as a safe haven for dynamite workshops and as a retreat to evade the police. Because of Finland's autonomous status, the imperial police forces were not allowed to perform their duties on Finnish territory. In response to successful attacks, the $\mathrm{CO}$ receives sizeable donations from (foreign) sympathisers with the struggle against the Russian monarchy. The series indicates two more sources of funding: attacks on money transports and funds received from Western Freemasons.

Freemasonry, a classic bogeyman in Russian culture, not only finances terrorist actions from the West. It turns out the organisation threatens the state from inside its governmental apparatus as well. Indeed, Stolypin's starkest political adversaries are exposed as Freemasons. The masonic conspiracy among high-profile government representatives is introduced in a scene in which a group of men, seated around a large oval glass table, roll a crystal ball across the tabletop to call upon someone to speak. For the duration of the entire scene, the camera follows the crystal ball as it passes from speaker to speaker, showing the distorted reflections of the speakers' faces in the glass. Close-ups of the silver ring worn by one of the speakers indicate whom we are dealing with here. Similar scenes follow in subsequent episodes and, eventually, the faces of the speakers are revealed. Among those involved in the conspiracy are General Trepov and Pavel Kurlov, the head of the police department. These men are also shown to be conspiring against Stolypin during a church mass in the presence of the royal family and of Stolypin himself, testifying to their audacity. In their final meeting around the glass table, the group reaches the decision that Stolypin has to be eliminated, and Kurlov introduces his plan (see below).

The significance of the Freemasons as an enemy of the state is underlined by the efforts of both the tsar and Stolypin to investigate the extent to which Freemasonry is active in Russia, as well as masonic involvement in the revolutionary movement and its threat to the Russian state. Stolypin sends his close friend Ivan Alekseev, who is state counsellor with the Ministry of Foreign Affairs, to Western Europe to investigate the threat of war and the link between domestic and foreign Freemasons. In France, Alekseev discusses Freemasonry with a professor at the Sorbonne. He intimates that there might be a link to Russians who have lived abroad in France and England, and mentions the names of Herzen and Chernyshevskii. When his interlocutor questions his claim that Chernyshevskii has lived abroad, Alekseev accuses him of knowing nothing about Russian Freemasons. An interesting twist follows when the Frenchman subsequently ('A propos ...') introduces Alekseev to Lev Trotskii who has just wandered past, thus subtly reiterating linkages between Freemasonry, revolutionaries and émigré Russians. In Germany Alekseev is told that France is planning to go to war against Germany, but England is reluctant to join the effort without the involvement of Russia. If they are successful in their concerted provocation, Russia would be forced to clash with the German army. A meeting in a masonic lodge in Berlin supports Alekseev's impression that the threat of war on Russia is imminent. 


\section{2}

Case studies

Furthermore, he has discovered that Russian Freemasons keep in contact with their foreign counterparts through international organisations.

Stolypin reports Alekseev's findings to the tsar. For whom, the tsar asks, would drawing Russia into war be beneficial? 'The revolutionary parties,' Stolypin replies. 'They need war like oxygen'. Thus, again, internal and external enemies of the Russian state are presented as working in tandem. If we place the series in the context of the year it was broadcast, it can be argued that for the Russian viewer the argument described above would bring to mind the law on non-commercial organisations that was adopted on 10 January 2006. The law required the majority of NGOs active in Russia, including both domestic and foreign organisations, to re-register. This process involved the submission of extensive information about their activities, financial sources and the organisations they had cooperated with, thereby giving the state the opportunity to directly curtail the activities of human rights organisations (Human Rights Watch 2008). In a similar fashion, the Freemasons and the revolutionaries are presented as part of a complex network of groups who seek to undermine the state; having permeated society, this network must now be subjected to state control.

\section{Enemies of Stolypin as enemies of the state}

The scenes in Stolypin's office introduce the viewer to a scale model of a palace that Stolypin is building. This motif can be interpreted as offering an indication of Stolypin's enemies and allies within the government. The model is located in Stolypin's office and, depending on the person he is receiving there, the interaction with the model differs. Some visitors (Kurlov, Azef) do not interact with it at all. With others (Kokovtsev), the scene ends when Stolypin walks over to the model and the visitor joins him. Alekseev is somewhat more interested and either shakes hands with Stolypin above the model or follows Stolypin's example of kneeling beside it to take a closer look at its details. The only person actually involved in building the model is Aleksandr Gerasimov, head of the Okhrana in St Petersburg and the contact person for Azef. The scale model makes its final appearance after Stolypin's death, when a group of clerks is shown carefully documenting and archiving the possessions left in his office. Still unfinished, the model is stacked away without special notice. The way that the motif of the scale model recurs suggests that it symbolises Stolypin's vision for Russia. Over the course of several episodes, he continues carefully and meticulously to work on it, and only a select few support him in this process. His death means that the project of constructing a new Russia has been halted prematurely - and, as with the scale model, his plans were discarded by his successors. Stolypin's palace under construction can be contrasted with the model of a high tower kept by Nicholas II in a bell jar, reflecting his conservative attitude towards the Russian state.

The series has the two groups of Stolypin's enemies, the $\mathrm{CO}$ and the masonic conspiracy within the Russian government, unite to commit their 
fatal attack on the prime minister. Although Bogrov has intended to kill Stolypin for most of his time as a member of the $\mathrm{CO}$, for reasons that never fully become evident, only when he comes into contact with Kurlov does the perfect opportunity arise. Kurlov has come up with an intricate scheme in which Bogrov will pretend to infiltrate a group of terrorists planning to assassinate Stolypin. In response to his claim to prevent the bogus attack, Bogrov will be given access to the theatre to point out the terrorists. On the basis of this scheme, Bogrov is provided with a ticket in the capacity of an Okhrana agent. During the first act of the opera being performed in the theatre, Bogrov leaves the hall in evident distress. He paces up and down the hallway, puts his hands on his head and retreats to the bathroom to wash his face. When the bell rings signalling the commencement of the second act, Bogrov returns to the hall as audience members return to their seats. He walks up to Stolypin, who is standing near the stage with his back turned to him. Bogrov takes a first shot that misses and injures a member of the orchestra. His second shot hits Stolypin in the chest. Bogrov is seized by members of the audience while the tsar disbelievingly watches the events unfold from his loge. In the midst of the tumult, Stolypin looks up to the tsar and crosses himself as a final testimony of his loyalty. The audience starts to sing the national anthem as Stolypin is carried out of the theatre. He dies in hospital a few days later.

Throughout the series Stolypin is given numerous warnings about the personal danger his political actions expose him to. Rasputin even twice foretells his death in Kiev. Despite all this, Stolypin refuses to allow the Okhrana to guard him and seems determined not to let himself become intimidated. But the scene where he says goodbye to his family before departing on his fateful journey to Kiev suggests that he sensed he would not return. This premonition is confirmed by the fact that, while in Kiev, he orders his servant to write down his political testament, to be given to the tsar in case of his assassination. His perseverance in issuing reforms in the face of these explicit threats emphasises the idea that he has (literally) dedicated his life to safeguarding Russia from imminent collapse.

The closing scene of the final episode, and thus of the series as a whole, vividly shows the consequences of Stolypin's death for Russia. It reiterates the frequently uttered claim that had Stolypin not been killed, Russia would not have become involved in the First World War and the Bolshevik revolution and subsequent civil war would not have happened. At several points in the series such an outcome is predicted by, among others, Rasputin and Empress Mariia Fedorovna. In the concluding scene, the royal family and Rasputin are watching a film screening. The fragments show military parades, religious processions and images of the royal family. Then, the sound of a church mass signals a shift in the images from those of peaceful Russia to those of the First World War. As the tsar continues to watch the projection, it displays images of warfare: explosions, trenches, cannons, tanks, zeppelins, crashing airplanes and funerals. The intersecting close-ups of the face of the tsar show emotions of confusion and distress. At the image of a sinking ship he closes 
his eyes. The subsequent images are evidently meant to indicate the destruction wrought by the revolutions of 1917 and the civil war. They show a series of Orthodox churches as their cupolas are being pulled down. The succession of images argues that Russia became involved in the First World War as a consequence of the death of Stolypin. Moreover, it suggests his death entailed the destruction of the monarchy and the Orthodox foundations of the Russian state.

What, then, are the undrawn lessons of Stolypin? Several questions addressed in the series, either in the parliamentary discussions or through the representation of the revolutionaries, remain relevant today. Consider, for example, the (political) relations between Russians and other ethnic groups within the empire and the justification of Russian political supremacy, and the attempts to develop and populate Siberia. The apparent need for effective governmental control over the entire territory of the empire to prevent subversive or secessionist movements, exemplified by Finland, finds overt parallels with contemporary Russia and the terrorist threats from within the country's territory. The two most telling lessons the series puts forward, however, are the following. First, there is its characterisation of visionary leadership combined with a high level of authoritarianism, which are asserted as being essential to the proper governance of the new 'democracy'. The negative representation of the Duma as being first and foremost an obstruction to the implementation of much-needed reforms, instead of an indispensable representative of the people's interests, is a further critique of the superiority of a democratic system for Russia. Second, the series reiterates the argument that the state's domestic enemies, either within or outside the government, are facilitated or even guided by enemies in the West who envy or fear the strength and potential of Russia. To counter these threats the state is allowed to take strong measures. As Stolypin states in his defence of the Azef affair: a surgeon, to heal a sick person, must sometimes pick up a scalpel and draw blood. While it is difficult to prove that the representation of the $\mathrm{CO}$ in Stolypin ... The Undrawn Lessons was intentionally shaped to correspond to and consolidate the notion that 'foreign agents' are insidiously working against Russia's interests, it is fair to argue that the portrayal of Stolypin's (and by extension, the Russian state's) enemies resonates with political issues dominating the public debate at the time when the series was first broadcast. Furthermore, this portrayal was the result of deliberate choices by those involved in the production: it is quite possible to entertain other interpretations of the historical material in question.

Apart from these implicit lessons, the final episode also presents the viewer with Stolypin's political testament. In Kiev, as noted, Stolypin orders his servant, Kazimir, to transcribe a message to the tsar about how Russia should be reformed should he be assassinated. From the scene in which Stolypin's possessions are archived, we learn that this political testament has mysteriously disappeared. The letter to the tsar was in Stolypin's briefcase, which was collected from the Okhrana. But its contents have gone missing. One of the men 
remarks tellingly that someone must have gotten there before them. The scene also implies that, although early twentieth-century Russia was not spared the tragedies that Stolypin's visionary leadership would have prevented, twentyfirst-century Russia can learn from the memory of Stolypin and thus should not make the same mistakes. The way that state power (or at least the sensible assertion of it for the benefit of Russia) becomes personalised in the figure of Stolypin in the series is very similar to the personalisation of power under Putin. Therefore, the series appears to subscribe to the view that proper state leadership is not dependent on a type of government or group of statesmen, but rather is connected to a singular extraordinary leader.

In a discussion programme on Radio Svoboda commenting on the TV series, the journalist and television critic Sergei Varshavchik concluded that its director had a single idea in mind, namely 'that the strengthening of the vertical of power is impossible without intelligent, talented reformers' (Kachkaeva 2006), an idea that was evidently aimed to draw a parallel with contemporary politics. This linkage ties in with the genealogy of great Russian reformers that was introduced earlier. Historian Nikita Sokolov, also taking part in the discussion, added in a similar vein that the modern style of language used in the series, not at all faithful to that of the time period portrayed, was explicitly chosen to encourage the viewer to connect past and present:

I [...] believe that this [the simplification of the language in the dialogue, M.W.] was done completely intentionally in order to pull it together with the external situation as much as possible, and to embed a certain ideology in the mind of the viewer: that this represents a strong power, and that it should not be interfered with in any way but, rather, be allowed to operate. The TV series [...] The Undrawn Lessons of Stolypin [sic] appears to say that one should not interfere with a great reformer. Not interfere with a great man who assumes responsibility.

(Kachkaeva 2006)

There is little need to clarify whom Varshavchik's immediate reply, 'Even for a third term in office', refers to.

The TV series was broadcast on state television well before President Putin began to refer to Stolypin as an exemplary figure on a regular basis, which started around 2008. While a significant number of the thematic constructions developed in the series continued to be associated with Stolypin's memory (as will become clear below), certain connotations did not. The more extreme, conspiratorial elements, especially those implicating Freemasonry, did not carry over into subsequent TV portrayals or into the official political discourse.

\section{The Name is Russia (2008): Petr Stolypin}

The cross-media project The Name Is Russia, which set out to elect the greatest Russian of all time, prompted much Russian and even international 
discussion in 2008, as is explored in depth in chapter 4 . While it came as a surprise to many when Nevskii was crowned the winner, the runner-up may have raised even more eyebrows. Before the project, Petr Stolypin was a familiar name among historians and politicians, but his political legacy was little known beyond these professional circles. As noted earlier, opinion polls indicate that Stolypin has never been very popular (Gudkov 2010: 39), which makes it all the more surprising that Stolypin was elected the second most popular Russian of all time by the programme's vote. The following analysis limits itself to the arguments that were put forward in the live show about Stolypin concerning his candidacy and to the way the project contributed to the discursive and visual consolidation of his memory image (see chapter 4 for a comprehensive analysis of the project). The broadcast exemplifies the crucial role of remediation in the construction of new cultural memories. In this case, the TV series examined above provided the visually appealing material needed to boost the public's familiarity with the long-dead politician.

It is fair to assume, though, that the TV series about Stolypin reached only a limited audience when it was broadcast. ${ }^{8}$ Stolypin's candidacy on The Name Is Russia was therefore an important event in the efforts to popularise his memory, one that had the potential to decisively shape the public's perception of his political legacy. How the politician was characterised and portrayed in the opening statement and clip is particularly significant because of the authoritative tone adopted by the programme: the introductory clip, a recurring feature in all episodes, comes across as a more or less factual summary of what is known about the person and what has shaped our understanding of his or her acts (e.g. films). It also outlines the themes and parameters for the subsequent discussion. The introduction of host Aleksandr Liubimov reiterates the frequently heard argument that Stolypin's reforms might well have averted Russia's involvement in the First World War and the 1917 revolutions: Stolypin was the person 'about whom it was often said and continues to be said: if he had lived, [...] three or four years would have sufficed and our country would have would taken a completely different path'.

The clip argues that Russia was in a state of crisis following the 1905 revolution and that times of crisis require a special type of leader: someone who possesses a thorough understanding of urgent problems and is always ready to act vigorously, someone who does not allow himself to be intimidated by any kind of resistance. Tsar Nicholas II recognised these capacities in Stolypin and appointed him minister, overruling Stolypin's initial rejection of the offer. The state of affairs when he took office is characterised as a moment of political deadlock. Social unrest (high levels of unemployment, revolutionary tendencies, strikes, pogroms) was severe enough to warrant drastic measures, yet neither the tsar nor the (democratic) opposition was willing to grant the population civil rights and both tended instead towards the dictatorship of the state. Only Stolypin, it is claimed, acknowledged that dictatorship was a dead end (tupik) and reform was necessary to resolve the crisis; this, it is claimed, was also why he refused to cooperate with the 
opposition. Stolypin implements his reforms in the face of fierce political resistance and several attempts on his life, and the country starts to reap the rewards of his bold action. As we see archival footage of streets bustling with activity, railways, industry and long lines of women working efficiently, the voice-over enumerates the excellent results of Stolypin's reform package: agricultural production increased dramatically and Russia's economic position as well as its industrial production improved significantly. In fact, it is claimed, the brief period under Stolypin was the most productive period of the entire twentieth century in Russia.

His policies' evident success was nevertheless insufficient to stifle adverse criticism or halt terrorism. Failure to recognise the efficiency of his reforms came from all directions, the clip asserts: Stolypin was portrayed as the oppressor of revolution by forces on the left, the destroyer of the privileged position of the nobility in state structures by those on the political right, and the empress, for her part, felt that Stolypin undeservedly overshadowed the tsar. As the camera slowly zooms in on a photograph of Stolypin as he lies in state, his phrase that twenty years of stability would transform Russia beyond recognition is reiterated with the addition that he was given less than five. It is concluded, somewhat spitefully, that Stolypin did not receive the posthumous honour he deserved, neither in the final years of the tsarist empire nor thereafter. A modest monument, it is stated, was erected with funds raised by Altai farmers, but destroyed soon after in 1917. As the voice-over summarises: 'The new Russia did not need Stolypin'.

The introduction incorporates extensive clips from the TV series: scenes of Stolypin before the Duma and the State Council, his fearless confrontation with revolutionaries in Saratov and the subsequent attempt on his life, Bogrov aiming his pistol at the prime minister in the Kiev opera house and Stolypin looking at his bloodstained hand after he has been shot. The scenes are played in slow motion, without the original sound and with two scenes superimposed onto each other. The theme of the scale model under construction as a visual metaphor of Stolypin's efforts to (re)build Russia returns. But whereas in the TV series the model was left unfinished and forgotten, here it is effectively destroyed. The narrative telling of Stolypin's political acts is interspersed with close-up shots of a hand piling up wooden blocks, placing a knight to protect it and showing a toy train effortlessly weaving its way through the newly built fortress of wooden houses, symbolising the beneficence of Stolypin's reforms. Following his assassination, however, the train derails. The knight-figure is tipped over and brings down several towers in its fall. A panning shot shows the model built by Stolypin as it lies in ruins. As we return to the studio, Liubimov mentions the Fund for the Study of P.A. Stolypin's Legacy, whose activities were discussed above. He holds up one of their publications on Stolypin and discloses that the Fund was closely involved in the production of the show.

In his plea for Stolypin, Mikhalkov emphasises four elements: first, he addresses how the opinion of most viewers about the prime minister was 
shaped by Soviet education and was currently, therefore, pronouncedly negative. Here, he emphasises Russia's dire situation at the beginning of the twentieth century, the extensive threat posed by terrorists and the fact that the number of people tried by the field courts-martial is small compared with the many that endured Soviet repression. Second, Stolypin was a visionary who foresaw the rapid rise of China and completed the agrarian reforms initiated by Aleksandr II (e.g. the actual transfer of land to farmers). The effect of these reforms was far-reaching since, according to Mikhalkov, the population growth achieved under Stolypin of some thirty million people over the course of a decade resulted from a renewal of faith among the people in their potential and their future prospects. Finally, only Stolypin took action to strengthen the Russian state instead of engaging in liberal talk or arousing an insurgency among the population. Mikhalkov concludes by stating that Stolypin surpasses other great heads of state, such as Aleksandr Nevskii, Aleksandr II, Catherine the Great and even Peter the Great, in his ability to combine a visionary capacity with decisiveness: 'He foresaw and was able [to correct the country's course] and for that he paid with his life'.

Mikhalkov explicitly calls for reading the turmoil of 1905 in parallel to that of the Russia of the 1990s. After outlining the ailments of state and society and summarising the time when Stolypin took office as the 'roaring 1900s' in clear analogy to the common catchphrase 'the roaring 1990s' (likhie 90-e), he points out how this era was very similar to the Russian experience of the preceding twenty years. The statement is met with applause. The argument about population growth is paired with the statement that, from 1994 to 2004, there was zero population growth in Russia. According to Mikhalkov, the solution to overcome such a state of crisis, both then and now, is first to stabilise the country and then to implement extensive reforms: firm action against crime and corruption should be paired with a systemic reform package.

(Then) Metropolitan Kirill endorses Mikhalkov's plea and provides a religious and spiritual rephrasing of its main points. He mentions that Stolypin's efforts at religious reform, in parallel to European examples, was grounded in the notion of freedom of religion. At the same time, however, he continues, Stolypin understood the importance of Russian Orthodoxy to the Russian people and the nation's future, and regarded it as the first among religions (we will come across this argument again in chapter 4). Metropolitan Kirill reiterates the idea that Stolypin was, anachronistically, a highly contemporary politician. In fact, he states, his reforms should have been the foundation for Russia's restructuring following the disintegration of the Soviet Union, in particular with regard to its spirit $(d u k h)$ : reforms that fail to take into account the needs and wishes of the people will not succeed, because the national character the nation's 'thousand-year old form' - cannot be altered.

Viktor Chernomyrdin, the late politician who served as prime minister from 1992 to 1998 , echoes the claim that no other historical figure suits the current era as well as Stolypin, who, he states, uniquely combined being a reformer and a patriot (on par with Peter the Great and Aleksandr II). 
Stolypin's reforms, he adds, continue to be relevant to all aspects of economics and governance, yet their implementation requires courage. Their effects could be drastic. Indeed, the implementation of Stolypin's reforms in full would have averted not just the revolutions of 1917 but the First World War as well. Poet Iurii Kublanovskii goes so far as to say that if Pushkin is considered the zenith of Russian literature, Stolypin occupies this position in politics. The tragedy of his death, he continues, equals that of the great poet. Renowned painter Il'ia Glazunov praises the agrarian reforms and Stolypin's measures seeking to stimulate migration to Siberia. To underpin his views, he recounts an anecdote from his visit to a village in Siberia founded around that time. A local granny, he asserts, recalled how farmers had received as much land as they could farm.

A recurrent theme is how, in Russian history, reformers tend to be misunderstood by their contemporaries. The late physicist and television host Sergei Kapitsa argues that in Russian history, reformers are tragic figures and the occupation of prime minister is a dangerous one. The lesson to take away from the memory of Stolypin, he concludes, is how urgently the relation between reformers and the state apparatus needs to change. Andrei Sakharov, the director of the Institute of Russian History, relates how opinion polls demonstrate continued societal dissensus about reformers such as Stolypin. This, he adds, is part of the 'grievous path' they are fated to follow: reformers occupy the vanguard and have concrete ideas about addressing pressing matters, yet their actions are more rapidly transformative and far-reaching than society and the establishment are willing to accept - a fact that many had to pay for with their lives. According to Dmitrii Rogozin, the then representative of the Russian Federation to NATO, Stolypin exemplifies the certain failure of reforms in the absence of public support. As a direct result of his policies, which simultaneously advanced liberalisation and 'crushed' the political elite, Stolypin lacked the political and societal backing he needed. For those viewers who failed to notice that the discussion about Stolypin and the fate of reformers in general is to be understood in reference to Putin, host Liubimov at one point reminds the viewer that there is a link between the two men. Somewhat out of place and without evident relevance to the ongoing discussion, he points out that Putin used to work and live in Dresden, the German city where Stolypin was born.

In the discussion, there are remarkably few arguments opposed to Stolypin. One person who disagrees with the general sentiment of approval is Ziuganov, who, as chairman of the Communist Party of the Russian Federation, upholds Lenin's assessment of Stolypin as the hangman-in-chief. This is not so surprising since, within the format of the show, there is an obvious need for a dissenting voice to make the discussion interesting. Ziuganov is the obvious candidate for this role. Yet his criticism is relatively mild. He contradicts the claim that the revolutionaries caused more bloodshed than Stolypin's repressive measures and quotes Lev Tolstoi's negative appraisal of him. He also argues that Stolypin should not have dismantled the obshchina - the 
traditional peasant communes - but should rather have taken its form to be the foundation for a new structuring of the state, since it constituted a genuinely Russian type of societal organisation. But Ziuganov actually praises Stolypin on several points, notably his recognition of the necessity of addressing the agrarian population's living conditions and actively developing Siberia. Dmitrii Rogozin cites the example of Sergei Vitte, Stolypin's predecessor, to frame his argument that there is indeed occasion for criticism. In the opinion of Vitte, Stolypin's liberal reputation by no means corresponded to the reality of his actions. Mikhalkov objects to Rogozin's remark on the grounds that Vitte harboured a grudge against his successor and therefore does not constitute a neutral source of information. Sergei Kapitsa voices another reservation. He points out that Mikhalkov mistakenly idealises the economic progress achieved under Stolypin: in the twenty-first century, he states, the most successful economies are structured in a fundamentally different way, with an emphasis on service industries, not agriculture. To imitate Stolypin's reforms in any way would therefore be erroneous.

Despite these instances of criticism, Mikhalkov takes advantage of his position as chair to summarise the discussion in a positive light. He asserts that of all the contenders, the discussion regarding Stolypin was most concerned with debating the state of contemporary Russia and the problems it faces. This is the case, he asserts, because Stolypin 'concretely' (real'no) demonstrated the country's potential for rapid development. He repeats the claim that had Stolypin been given fifteen or twenty years in power, Russia would have become an entirely different country. Therefore, he concludes, Russia needs the memory of Stolypin 'like oxygen' ( $k a k$ vozdukh). The significance of Mikhalkov's sponsorship of the Stolypin memory should not be underestimated. According to a 2008 poll commissioned by Kommersant and conducted by the independent Levada Centre and VTsIOM, Mikhalkov ranked seventh in the top 100 of the Russian elite, a list topped by Putin, Medvedev and singer Alla Pugachova (Alekseev 2008). Polls by the Levada Centre have shown that Mikhalkov was considered to be the most influential person of the societal and cultural elite of Russia in 2010 and 2011, ranking above Patriarch Kirill ('Rossiiane nazvali predstavitelei elity strany' 2012). In the overall list, which includes politicians, businessmen, cultural figures, journalists, stars of popular culture and high-profile athletes, Mikhalkov has been ranked the eighth (2010) and seventh (2011) most influential person in Russia ('Rossiiane nazvali predstavitelei elity strany' 2012). Moreover, his position as chair of the jury allowed Mikhalkov to significantly influence the course of the discussions and authoritatively summarise the meaning and relevance of the candidates at the end of each episode. There is, however, reason to suspect that Mikhalkov had a say in the production of the show in ways that go beyond what is customary for a panellist. When, in the first show, Mikhalkov is instituted as chairman by unanimous vote, the host substantiates his capacity to occupy the position by referring to the role Mikhalkov played in his 
film 12 (2007). Incongruously, given the flow of the show, a clip from the film is shown: an obvious case of improper advertising.

In an interview published on the project's website, Mikhalkov answers questions from viewers and again emphasises that 'Petr Arkadevich stood before the exact same problems we face today' ('Rezhisser Nikita Mikhalkov otvechaet na voprosy zritelei proekta "Imia Rossiia", 2008). Here it becomes clear that Mikhalkov's perception of the nature of Russian politics and culture is more closely interwoven with religious elements than had been apparent in the TV show. One of the questions concerns how to form highly educated individuals with high moral standards in today's religiously and nationally multifaceted world. The answer, Mikhalkov claims, lies in an 'Orthodox upbringing': 'Not in the sense of a parish school, but in the sense of attachment to those cultural traditions, roots, and moral criteria familiar to a Russian person' ('Rezhisser Nikita Mikhalkov otvechaet na voprosy zritelei proekta "Imia Rossiia" 2008). This Orthodox upbringing should have as its aim the fostering of resilience, a kind of 'national immunity' (natsional'nyi immunitet) that enables one to act and think freely. This national immunity, he continues, consists of

grandmother's fairytales, of all that is absorbed together with the mother's milk, including the words of the Divine Liturgy on Sunday that children and also adults do not always understand. But in this lies a mystical connection across the centuries, because Aleksandr Nevskii and Dmitrii Donskoi heard those exact same words. It is a sacred connection! It is the bond [underlying] our national genetic code.

(Ibid.)

This 'national genetic code' view closely resembles the 'civilisational code' argument frequently used by (then) Metropolitan Kirill, including during The Name Is Russia broadcasts. Mikhalkov invests great significance in The Name Is Russia and what a vote for Stolypin and, as is evident from his choice of words, Putin would signify:

I believe that, in order to prevent such a disaster, we need enlightened conservatism and armed evolution - and Stolypin is exactly that. Therefore I vote for him and I advise you to do the same if you want to live a normal life.

(Ibid.)

On 26 December 2008, in the final days of voting, a discussion appeared on the project's LiveJournal blog on the likelihood of Stolypin winning the competition. The author of the initial post firmly believed this would happen: the Russian people, he proclaimed, have understood the importance of Stolypin and will cast their votes for him, despite the efforts of provocateurs to meddle with the results to have Stalin win (ratnik07 2008. See also chapter 


\section{Case studies}

4). One of the users responding to the post (0987655 2008) is equally convinced Stolypin will be chosen, but for entirely different reasons. He summarises:

1 N.S. Mikhalkov is used to being first (whenever possible) and would not have agreed to take part in the project The Name Is Russia if he had doubts about 'the success' of his 'defendant'.

2 The voting results of this project are a peculiar 'New Year's present and parting words' for a person we all know.

If this project had taken place in, say, 2006 then, I assume, N.S. Mikhalkov would have 'defended' Peter I or Aleksandr II for reasons clear to all.

(0987655 2008)

In the end, however, Stolypin failed to secure the victory. Whether the outcome of the project was rigged and the project was indeed a New Year's present for Putin remains difficult to prove (we will return to allegations of falsification in chapter 4). What is certain, however, is that the project's producers did their utmost to support the candidacy of Stolypin - the outsider who was evidently meant to be associated with the (then) prime minister. Stolypin's surprise appearance among the 12 finalists, along with his highprofile representative and unexpected (supposedly popular) success, serves as an indication that, in 2008, a high-level effort was underway to popularise Stolypin's memory among the general public. To do so, the project built upon the previous TV series to shape and consolidate a visual and moving image of the great reformer. The Name Is Russia demonstrates a definitive reorientation of popularisation efforts from the intellectual and political elites, who were to take direct inspiration from Stolypin's policies and ideas, to the mass audience, for whom the symbolic representation of exceptional leadership in times of crisis took precedence. The shift from the policy to the symbolic domain both necessitated and was facilitated by the creation of sufficient historical and visual literacy concerning Stolypin: a clear, accessible and relatable set of images, catchphrases and explicit analogies with current issues. The Name Is Russia catered to this need.

\section{Petr Stolypin: A Shot at Russia (2012)}

The documentary Petr Stolypin: A Shot at Russia, narrated and directed by Nikita Mikhalkov, was broadcast by Russia 1 in 2012. Many of the themes introduced in the 2006 TV series and via Mikhalkov's plea for him on The Name Is Russia reappear in the documentary. Two years before, Mikhalkov had explicitly mentioned Stolypin in his political manifesto propagating 'enlightened conservatism' as one of the politicians who abided by its principles (Mikhalkov 2010). The documentary reiterates the main tenets of the 
manifesto, which emphasised the importance of a strong vertical of power, gradual and state-guided reform, and the centrality of tradition and the Orthodox faith in safeguarding the Russian nation. The documentary was produced on the occasion of the Stolypin commemorative year and was broadcast in prime time on 14 April, Stolypin's birthday. ${ }^{9}$ As might be expected of Mikhalkov, it is aesthetically pleasing and carries an emotionally persuasive soundtrack. To increase its credentials, the documentary employs multiple experts. ${ }^{10}$ While the production had most likely been initiated at an earlier time (the plans for the Stolypin year were first announced in 2010), the concurrence of its premiere with the Russian protest movement of 2011/12 gives it particular relevance. As will become clear below, Mikhalkov has in fact commented directly on the link between the protesters and the power struggles faced by the pre-revolutionary politician. Therefore, the documentary should be viewed in the context of the state's response to the growing social unrest that culminated in street protests during the winter of 2011.

The documentary describes Stolypin's life from birth until death and comes close to presenting him as a martyr. It is argued that after becoming minister of the interior, Stolypin sought to cooperate with the Duma but all attempts at collaboration were thwarted by the unwillingness of (several of) the representative parties. Mikhalkov personally acts out several of the prime minister's signature speeches in front of the Duma - that is, considerably abbreviated and edited versions of them, as had also been the case in the TV series. The image presented of Stolypin is an idealised one: apart from being a political visionary, Stolypin is modest, economical, pious, generous, dedicated to his country and the tsar, and a loving family man to boot. Repeated here is the idea, which we saw in the TV series, that an affectionate character is hidden behind an outwardly stern appearance. The documentary by extension implies that the same holds for Putin, who is commonly characterised by his stern posture in public appearances. Meanwhile, while Stolypin is dedicating his life to reforming his country, his future assassin, Dmitrii Bogrov, is pursuing his studies in Europe, eagerly reading anarchist literature - and, as it turns out, he is not alone. According to Mikhalkov, cities like Munich and Paris were inhabited by extensive groups of high-born Russians who enjoyed criticising the state of Russian politics from a safe distance ('It was fashionable'). To provide Bogrov's character with some depth and explain how such a fortunate young man might be capable of committing political murder, the viewer is informed that he was Jewish, liked to gamble, and had the slightly morbid hobby of collecting insects (an actor playing Bogrov emotionlessly drives a pin through a beetle to attach it to a display board). Mikhalkov's reasoning is at times flawed and based on hindsight - for instance, when he explains that Bogrov chose to kill Stolypin instead of the tsar 'because Stolypin was more dangerous than the emperor. Because precisely he represented what could have saved Russia from terrible revolution and bloody civil war.'

Implicitly and at times quite explicitly the documentary constructs the political opposition to be enemies of the state. As a result, it provides 


\section{Case studies}

justification for repressive measures and the limitation of democratic rights. Members of the opposition are portrayed as materialistic, selfish individuals who lack a real or viable vision for Russia, block the leadership's attempts at constructive reform and steer a path that will result in bloody revolution (again viewed retrospectively). But in particular, and this is where direct parallels with the contemporary political discourse come to the fore, members of the opposition are again depicted as 'foreign agents' who receive funds from abroad and spend a lot of time in the West. In this sense, they are put on a par with those fortunate Russian youth with anarchist inclinations who have been educated in the West, such as Bogrov. Moreover, it is intimated that they are willing to abandon the country as soon as they get the chance. In other words, all forms of opposition are equated with treason towards the national cause. This bears a striking similarity to the arguments used in some propagandistic non-historical TV programmes of the time. For instance, there are clear analogies between the representation of the early twentieth-century opposition and terrorist groups and the discursive strategies used to negatively depict the leaders of the Russian protest movement in the two documentaries broadcast by NTV in 2012 under the title Anatomy of a Protest (Anatomiia protesta). Consider, for instance, the claim that Sergei Udal'tsov received funding from the Georgian state official Givi Targamadze, who allegedly was also behind the Orange Revolution in Ukraine, to attempt to overthrow the current regime in Russia. Furthermore, the documentary about Stolypin echoes the opinions expressed in one of the articles by Putin published in the run-up to the 2012 presidential elections, in which he argues in favour of 'stable development'. In addition to an exposition of the benefits of such a strategy, the article offers a character sketch of its main adversary:

A constantly recurring problem in Russian history is the pursuit of part of its elite of rupture, of revolution instead of consistent development. Meanwhile, not just the Russian experience, but also the overall global experience demonstrates the malignancy of historical bursts: of rushing forward and subversion without creation.

(Putin 2012a)

It is intimated that such 'revolutionaries' do not represent the will of the majority of the population and, as a result, can rule only by making deceptive promises of a brighter future. Such a situation, Putin claimed, is untenable, even undemocratic:

There can be no real democracy without the acceptance of politics by the majority of the population, without it reflecting the interests of this majority. Yes, it is possible to capture a significant part of society with ringing slogans [and] images of a wonderful future for a short period. But when people do not see themselves in that future afterwards they will 
turn away from politics and societal challenges for a long time. This has occurred multiple times in our history.

(Ibid.)

Any kind of broad popular support for non-incremental change, even if achieved in a democratic setting, should thus be seen as the result of the public being deceived.

Despite Mikhalkov's reputation as a monarchist, his depiction of Tsar Nicholas II is markedly negative. ${ }^{11}$ The tsar is characterised as an alienated ruler who has lost touch with his people and with the overall socio-political reality that surrounds him. Unlike Stolypin, he fails to recognise the severity and imminence of the revolutionary threat and its potential to disrupt the very foundations of the Russian Empire. As proof, Mikhalkov reads an inscription on one of the walls in the Winter Palace. Using Nicholas's nickname, it reads: 'Niki 1902. Looking at the Hussars. 7 March.' As he stands at the exact place where the tsar looked out from the palace window, Mikhalkov fantasises about how it would have been that day, some two years before the birth of Aleksei, the heir to the throne. The inscription was made sixty days before the fatal attack on Interior Minister Dmitrii Sipiagin, when, as Mikhalkov emphasises, 'the terror' begins. As the soundtrack takes on a threatening tone and the viewer is presented with feature-film excerpts of terrorist attacks manipulated to appear aged, he claims that the inscription demonstrates how the tsar was unaware of or blind to the impending upheavals. Melancholically, he sketches the years leading up to the 1905 revolution as the calm before the storm. Referring to Nicholas's diaries, he claims that the tsar lacked any interest in political matters, conservatively prioritised the maintenance of stability and valued family life first and foremost. Following the attack on Stolypin's dacha on Aptekarskii Island in 1906, the family moved to the Winter Palace where, Mikhalkov asserts, the imperial family was effectively 'in hiding'. At that time, he continues, the palace closely resembled a crypt for the Romanov family. The tsar's withdrawal from the people stood in direct contrast to Stolypin's drive to continue to engage with the ordinary man, despite the risks this posed to his life.

To enliven and underpin its argument, the documentary draws upon documents of various types, visuals and material objects, making extensive use of archival film and photographs as well as feature-film excerpts. ${ }^{12}$ Many of these visual materials have been manipulated in some way: feature film is shown in black and white, photographs are altered to simulate depth. Mikhalkov follows in Stolypin's footsteps and visits all the significant locations relating to his life and legacy (among others, the family estate, Saratov, the Kiev opera and the Kiev-Pechersk Lavra). Letters from Stolypin and the tsar are read aloud and, repeatedly, material links between past and present are highlighted: Mikhalkov touches the very desk at which Stolypin sat when the attack on the dacha occurred and shows the family mansion that has since become a ruin, the (now) empty grand ballrooms of the Winter Palace; the 
camera zooms in on the very chair in the Kiev opera where Stolypin was sitting moments before he was shot. The documentary continues to build upon the visual image of Stolypin that was first established in the TV series and remediated in the introductory clip on The Name Is Russia. Instead of using fragments from the TV series, however, Mikhalkov shot new scenes in which the same actor, Oleg Klishin, plays Stolypin. What is striking about these scenes is Stolypin's silence. In a way, they function as the moving versions of the photographs that are shown, as an animation of memory images or evocations of the past. This effectively establishes and affirms temporal distance. The only occasions when Stolypin's 'voice' can be heard occur through the intermediary of Mikhalkov. In a metaphorical sense, then, there are two Stolypins in the documentary: a historical figure (in photographic images and silent impersonation) and an anachronistic presence who literally speaks to and from the present as Mikhalkov acts out key speeches. The high degree of adaptation in the speeches affirms the split of 'Stolypin' into a past (historical) and current (memory) image: the original appearance is left intact (photographs, the static impersonation by Klishin, the showing of the pedestal from which he delivered his speeches) even as its content is made more malleable (in the rephrasing of statements and how they speak about the present). Mikhalkov was not the first to climb onto the Duma's pedestal and read a Stolypin speech on camera. In his historical TV series The Russian Empire (Rossiiskaia imperiia, 2000-2003), Leonid Parfenov opted for the same set-up. Yet Mikhalkov's performance - his theatricality in acting out the speeches as well as his personal political ambitions create a potent association between him and the historical figure he is reanimating.

Compared to Mikhalkov's defence of Stolypin on The Name Is Russia, the documentary places far greater emphasis on the prime minister's noble birth and religiosity. In fact, the documentary's portrayal of Stolypin suggests that Mikhalkov strongly identifies with the politician on a personal level, as it echoes important aspects of the image Mikhalkov has created of himself: both are of noble descent, both are intelligent and ostensibly good-intentioned men who, through circumstance and hard work, find themselves close to the powers that be. They use their privileged position in society to support and strengthen the state instead of acting in opposition to it. It is intimated that, in this respect, Stolypin, and by analogy Mikhalkov, differs from those members of the so-called intelligentsia who manoeuvre against state leadership as if by default. They represent a 'serious' type of intellectual whose actions are truly beneficial to the nation as they balance rubbing shoulders with those in power with maintaining a constructive critical stance on political matters. A type of intellectual who is sympathetic to the well-being of the people and also has a clear vision for the future development of the state and the nation. Mikhalkov has commented on the connection between himself and the prime minister in a local news item shot in Saratov, where he was recording scenes for the documentary ('Mikhalkov "zamakhnulsia" na gubernatora' 2012). In the interview he states that he has recently learnt that he is directly related to 
Stolypin on his father's side. When exactly and in what context this discovery was made (and whether he deliberately searched for this information) remain unclear. In the interview, Mikhalkov reiterates the lesson to be drawn from Stolypin's tragic fate, namely that it should be acknowledged that, in Russia, a strong power vertical is a necessary protective condition, without which the country will slide into chaos. In apparent response to a direct question, Mikhalkov asserts that Putin is the leader who comes closest to Stolypin.

On multiple occasions, Mikhalkov has demonstrated that his interest in the memory of Stolypin is not so much historical as symbolic. According to Mikhalkov, developments in contemporary Russia in many ways mirror those of Stolypin's time; if we fail to recognise and learn from the mistakes made a century ago, history might well repeat itself. In a short article advocating the contemporary relevance of Stolypin, Mikhalkov vividly sums up the condition the Russian state was in when 'the great reformer' took up office as prime minister in 1906:

Corroded by the poison of Nechaev's radicalism and liberal nihilism, Russian society was falling apart. It could and would not unite out of love for something. It united around hatred.

A weak power without authority that enabled a monstrous wave of terrorism. A state system eroded by corruption. The disgraceful defeat of the Russian army in the war with Japan. And even more disgraceful was the attitude of the Russian liberal intelligentsia towards this defeat, sending congratulatory telegrams to the Mikado.

An immense budgetary deficit, impending financial collapse, halting business, outflow of capital abroad. Authorities are begging Western governments and bankers for loans.

Separatism in the borderlands. Suppression of the peasants. Societal feelings of hopelessness and disbelief, spiritual crisis, mass alcoholism, a decreasing birth rate.

The tumultuous 1900 s ... . It rings familiar, doesn't it?

(Mikhalkov 2012)

The choice of words in the final sentence makes it abundantly clear that the characterisation of the first decade of the twentieth century is meant to refer to the 'tumultuous 1990s' in equal measure. In Mikhalkov's subsequent praise for how the prime minister managed to 'save the country' from this state of despair in a mere five years, the name of Stolypin appears to be interchangeable with that of Putin. Furthermore, what Stolypin would have wanted for Russia in the twenty-first century is what Mikhalkov symbolically calls 'the Russian cross': 'the organically connected vertical axis of state power and horizontal axis of culture and civil society' (ibid.).

In this vision of Russia, inspired by Stolypin's legacy, there is no place for an independent opposition. At this point in the argument, Mikhalkov abandons the metaphorical intermediary of Stolypin and voices direct criticism of 
the Russian protest movement, whose members he condescendingly refers to as 'mink fur collars' and 'our satiated, glamorous "revolutionaries", (Mikhalkov 2012):

The self-appointed leaders of our cashmere opposition employ the affronted sense of justice felt by ordinary people for their own PR. But, when they return from the raving rallies and get back behind the tall fences of their Rublevskie dachas ${ }^{13}$ and London mansions, they are unlikely to ever give thought to how they themselves could help their not-asloudmouthed and considerably less fortunate compatriots.

(Ibid.)

Paraphrasing one of Stolypin's most famous quotes, Mikhalkov drives home the point of his dislike of persons such as Aleksei Naval'nyi and Kseniia Sobchak: 'Only they, who have somewhere else to go, are in need of great upheavals. But they, who want to live here, are in need of a great Russia' (ibid.). Interestingly, in the Saratov interview referred to earlier, he differentiates between the leaders of the protest movement ('loudmouths and [...] political weathercocks and prostitutes') and the majority of protesters, who, he asserts, were simply demanding answers about certain issues and want to cooperate with the state ('Mikhalkov 'zamakhnulsia' na gubernatora' 2012). While the views of the first group should be dismissed outright, Putin should seriously reckon with the concerns of the latter body. Vladimir Nadein has aptly summarised the collapse of historical time that Mikhalkov seeks to achieve through the memory of Stolypin as follows:

This is why Mikhalkov needed Stolypin. To make it appear as if we inherited identical legacies from the past and are therefore equally obliged to cherish them. To stir up [our] historical experience with nonsystemic opposition: as if to say, Stolypin already cautioned the people about [Boris] Nemtsov and [Valeriia] Novodvorskaia. But the premier was shot and where are our two-three bedroom apartments, fur coats and 'zhiguli' [type of car, M.W.] now? Watch out, well-behaved, genuine Russians, do not miss [the target] again.

(Nadein 2012b)

The message that Mikhalkov seeks to put across to the viewer in his documentary deviates little from his other statements about Stolypin and Russian politics in general made around the same time, although he does attempt to stay close to the historical parallel. In the final scene, he comes close to spelling out the contemporary political relevance of Stolypin's legacy. In the scene, we see Mikhalkov standing in the Kiev-Pechersk Lavra, where Stolypin lies buried. He explains how the Russian state collapsed and civil war ensued after Stolypin's death. Millions died and millions more were displaced, leaving everything behind. Mikhalkov asks rhetorically: 'Did these people think 
about how terribly their lives would change, all because they failed to listen to the one person who knew what to do and was capable of stopping this destruction?' He cites examples of politicians who challenged Stolypin, only to die 'in poverty' in exile, far from Russia. After a long, meaningful pause, Mikhalkov continues:

But it was too late. And now, when we look back at that time, the feeling arises that, maybe, today we need to remember Stolypin more than ever before. It makes sense to remember this situation where everything was on the brink [of collapse] but could still be saved. [...] I believe it makes sense to think about this and especially for those, who disdainfully, ironically, spit upon their past, their present, without considering what the future might hold for them after that. It is time to learn how to learn from the past.

The message here is unspoken but clear: for Mikhalkov, learning from the past means that the power and position of Putin - Stolypin's contemporary counterpart - should not be challenged. The memory of Stolypin provides him with the narrative material he needs to shape and spread his view of proper Russian governance.

Given Mikhalkov's longstanding admiration for Stolypin, as well as his reputation and his position in the film industry - for example, the director of the major production company TriTe, the chairman of the Union of Cinematographers of the Russian Federation - it comes as no surprise that he was the person to give shape to the principle documentary on Russian television that marked the government-backed celebrations of the Stolypin commemorative year. ${ }^{14}$ The political message put forward through his interpretation of Stolypin's policies and personal characteristics is first and foremost a propagation of Mikhalkov's own political manifesto. And while his ideas about 'enlightened conservatism' are, to a large extent, compatible with the current government line - and the official interpretation of Stolypin as an exemplary political figure - they are not the same thing.

\section{Conclusion}

With the incorporation of the memory of Stolypin into its symbolic repertoire, the Russian government deviated from the logic underpinning its memory politics in two ways. First, it put forth a new cultural memory with little remediation history or developed symbolism. Even the historical figure of Stolypin was hardly known among the general public. Second, it exalted a person who had been perceived negatively in Soviet historiography. This negative appraisal of Stolypin had been disseminated via the history education of the Soviet period, and for a large part of the adult population constituted their only knowledge of the politician. Why, then, did the Kremlin embrace the memory of Stolypin? The explanation lies beyond the Kremlin's 
walls. The appropriation of the memory of Stolypin, in fact, demonstrates how the Russian government's memory politics is, in essence, opportunistic and reactive. It simply jumped on the Stolypin bandwagon, riding the societal momentum that other actors were creating. In this case, the momentum can be attributed to two memory sponsors. First, the efforts of the Foundation for the Study of the Legacy of P.A. Stolypin contributed significantly towards stimulating (scholarly) interest in Stolypin and made resources available to the general public in the form of, for example, publications. The foundation actively lobbied the government to commemorate Stolypin's achievements long before the latter demonstrated serious interest in them. Second and more decisive was the sponsorship by Nikita Mikhalkov. As one of the most influential figures in contemporary Russia, he consistently and continuously pushed the memory. Drawing upon his considerable network, societal standing and influence in the television industry, he explored several platforms to reach a wide audience with his message. Some of these attempts turned out to be dead ends, at least temporarily. The plan to erect a statue, for instance, was only realised in an actual monument more than a decade after it had been proposed. Other efforts had great societal effect. Mikhalkov's appearance as the representative of Stolypin on The Name Is Russia should be regarded as a watershed moment in the development of the memory of Stolypin as a 'political myth'.

Stolypin's success in The Name of Russia, I would argue, gave the government its final push to develop a public, state-sponsored image of the prerevolutionary politician in earnest. The establishment of the P.A. Stolypin Medal in spring 2008, as the initial online voting for the project had only just begun, as well as earlier references to Stolypin in speeches by both Putin and Medvedev, point to a pre-existing intention to move in this direction. Yet, even the medal was closely linked to specific policy areas. The initiative is likely to have been part of the liberal reorientation under Medvedev as he took office as president. That is, it acknowledged the appreciation for Stolypin in political circles. There is little to suggest that the medal aimed for wide societal resonance. After The Name Is Russia, however, references to Stolypin in a symbolic rather than historical sense became ever more frequent. This was especially the case in statements by Putin. It was only then that the memory of Stolypin acquired a more broadly defined meaning: Stolypin as 'the great reformer'. The main tenets of this memory image were not developed by the Russian government. They were taken from the cultural memory image of Stolypin as it had been shaped on the television screen. This memory image, with its roots in the immediate post-colour revolutions period, contained all the ingredients necessary for its use as an anti-opposition narrative.

While the narrative of post-revolution, implicit in the myth of the End of the Time of Troubles (to be discussed later), suited the political circumstances of Putin's first and second presidential terms, the shift from consolidating to maintaining political power required a reconfiguration of the regime's historical vocabulary. The figure of Petr Stolypin, constructed here as the great but 
unrecognised visionary leader of his time, has filled this gap in memory symbolism. Stability 'Stolypin-style' became the new brand of stability-oriented state patriotism, which taps into the societal fears and insecurities that are connected to memories of the 1990s but is geared to fit a situation in which recent achievements have to be safeguarded against the perceived or imagined threat posed by domestic rather than foreign enemies. Indeed, for the Russian government, '[t]he constant threats of chaos and an internal 'war of all against all' were intended to curb its own intrinsic contradictions' (Penzin \& Budraitskis 2013: 122). It formed the core of its raison d'être, namely 'stability based on catastrophes' (ibid.). Instead of promising a stable and prosperous future, the Stolypin memory cautions that recent achievements can all too easily be lost again. In this sense, the adoption of the memory of Stolypin, and the particular way it was shaped, indicates that the regime correctly anticipated that its next challenge would come from within in the form of increasing societal opposition - which, indeed, culminated in the street protests of $2011 / 12$.

The Stolypin case study provides a significant example of how television preceded official memory politics in the process of shaping a new political memory figure in response to current political challenges. The remediation among the three TV productions analysed above demonstrates how they all recognised the importance of visual and narrative repetition for shaping and consolidation a cultural memory where none had existed previously. If we look at the political arguments that can be derived from the productions, we can note that they (also) introduce arguments and associations that differ from the state-endorsed interpretation of the memory (both at the time and afterwards). The TV series Stolypin ... The Undrawn Lessons draws upon the popular tropes of conspiracy theories and the detective genre to keep its audience engaged. Mikhalkov's documentary Petr Stolypin. A Shot at Russia echoes the filmmaker's own political manifesto of 'enlightened conservatism'. These productions nevertheless support and propagate its central tenets: the importance of strengthening the vertical of power and implementing topdown reform to maintain stability and prevent revolution, paired with a justification of the (temporary) suspension of certain civic rights. In the case of the memory of Stolypin, memory politics indeed extended beyond the political domain and onto the television screen, yet the actual shape taken by the narratives was not as strictly regulated as is often assumed. A measure of deviation from the official line was allowed, albeit within a - constantly shifting and largely implicit - bandwidth of what is deemed permissible.

\section{Notes}

1 Earlier versions of parts of this chapter have previously been published as $\mathbf{M}$. Wijermars, 'Memory Politics beyond the Political Domain: Historical Legitimation of the Power Vertical in Contemporary Russian Television,' Problems of PostCommunism 63, no. 2 (2016): 83-94. Published online 14 January 2016, publisher 
Taylor \& Francis, www.tandfonline.com, reprinted by permission of the publisher; and, M. Wijermars, 'The Making of a Political Myth: Stability 'Po-Stolypinski', The Ideology and Politics Journal 5, no. 1 (2015): 37-56. Reprinted with permission.

2 The committee on architecture and city planning of Moscow (Moskomarkhitektura) hosted an exhibition of the 42 competing designs where visitors could cast their votes for their favourites. The Ministry of Culture rewarded the three most popular designs with a prize of 400,000 roubles. A jury of experts had the final say in selecting the winning design.

3 The scenario of the film was based on Boris Savinkov's loosely autobiographical novel The Pale Horse (Kon' blednyi, 1909). For an analysis of the film and its production history, see Norris (2012): 251-68.

4 In the years preceding 2006, several minor TV documentaries on this topic were broadcast, e.g., The Life and Death of Petr Arkadevich Stolypin [Zhizn' i smert' Petra Arkad'evicha] (Khotulev, 2002); Historical Chronicles with Nikolai Svanidze: 1911. Petr Stolypin [Istoricheskie khroniki s Nikolaem Svanidze: 1911. Petr Stolypin] (Gusev, 2003); The Searchers: The Murder of Stolypin [Iskateli: Ubiistvo Stolypina] (Nikolaev, 2004). The 2006 TV series, however, was the first production in which Stolypin's life took centre stage and that was aimed at entertainment instead of historical enquiry (and could therefore potentially appeal to a much wider audience).

5 Contrary to Stolypin, Boris Savinkov was featured in several Soviet films, both as member of the CO and in his capacity as member of the Provisional Government. For example: The Vyborg Side [Vyborgskaia storona] (Kozintsev \& Trauberg, 1938); Extraordinary Assignment [Chrezvychainoe poruchenie] (Kevorkov \& Karamian, 1965); The Collapse [Krakh] (Chebotarev, 1968) and its television remake Sindicate 2 [Sindikat 2] (Orlov, 1981); No Distinguishing Features [Osobykh primet net] (Bobrovskii, 1978) and its sequel The Collapse of Operation 'Terror' [Krakh operatsii 'Terror'] (Bobrovskii, 1980).

6 Officially, laws implemented by the tsar under article 87 (when the Duma was not in session) had to be submitted to the Duma within two months. Because of the failure to act accordingly, the dissolution of the Second Duma in 1907 is also referred to as the Coup of 3 June.

7 The letter is not included in the published compilation of Azef's letters (Pavlov \& Peregudova 1994). It therefore appears to be a fiction that was most likely added to the scenario to support the claim that Stolypin judged Azef's loyalty correctly and successfully persuaded him to choose the side of the law.

8 The actual reach of the series is difficult to estimate but may well be greater since the episodes were, and continue to be (as of 30 June 2016) widely available online for download or streaming on websites such as Youtube and Vkontakte. On the basis of the comments on download websites, it appears The Name Is Russia project actually provided an impetus to watch the $2006 \mathrm{TV}$ series.

9 Reruns of the documentary aired on 3 and 4 July 2014.

10 The experts are historians Valentin Shelokhaev (associated with the Fund for the Study of P.A. Stolypin's Legacy), Aleksandr Logunov (Dean of the Faculty of History, Politology and Law at the Russian State University for the Humanities, RGGU), Natal'ia Shatina (RGGU) and Kirill Solov'ev (RGGU). The latter has published extensively on Stolypin and also appeared on the talkshow The Trial of Time (discussed in chapters 6 and 7) as an expert on Tsar Nicholas II and his contemporaries.

11 Mikhalkov appears to particularly admire Tsar Aleksandr III, whom he impersonated in his film Barber of Siberia [Sibirskii Tsiriul'nik] (1998).

12 E.g. taken from A Rider Named Death [Vsadnik po imeni smert'] (Shakhnazarov, 2004).

13 Elite residential estates on Rublevskoe Shosse in Moscow. 
14 In 2015, Putin awarded Mikhalkov with the Order 'For Merit to the Fatherland', 'for his contribution to the development of Russian culture, cinematic and theatrical art, and his many years of creative activity'. He received the highest class of the award, a First Class Order, which is also the highest civilian decoration of the state, having previously received the Fourth, Third and Second Class orders (President of the Russian Federation 2015). 


\section{Aleksandr Nevskii: The saviour of Orthodox civilisation}

\section{Nevskii in the Russian historical and political imagination}

On the occasion of the Day of National Unity, Patriarch Kirill opened an exhibition called 'My History: Riurikids'. He personally guided President Putin through the show's extensive multimedia displays ('Patriarkh Kirill otkryl mul'timediinuiu vystavku' 2014). The exhibition, which ran from 5 to 20 November 2014 at the Moscow Manege, recounted the history of Rus' from its founder Riurik to Fedor, the last ruler of the Riurik dynasty. According to Archimandrite Tikhon (Shevkunov), ${ }^{1}$ one of the exhibition's principal organisers, "[t]he era of the Riurik dynasty had a decisive influence on the formation of statehood and all aspects of life of Rus", yet few people today know its history ("Vystavka "Riurikovichi"" 2014). The exhibition aimed to address this lack of historical understanding, as well as provide 'the attentive viewer with the unexpected key to understanding contemporaneity' (ibid.). Its language and style were indeed firmly embedded in a contemporary worldview (I base my observations on my exhibition visit on 10 November 2014). For example, one of the displays argued that Ivan the Terrible fell victim to 'the first information wars in the European press', a clear reference to the portrayal of the events in Ukraine by Western and Ukrainian media. The display about Aleksandr Nevskii exemplifies the two political questions that his memory has been most closely associated with in recent years: the place of religion, and specifically the Russian Orthodox Church (ROC), in the Russian state and the political challenges that result from striking a balance between West and East and accommodating multiculturality within both the domestic and the international frameworks. The main part of the display highlights Nevskii's battle against Western assaults on the state (military and religious alike) and his decision to orient the state towards the East. At the top, Nevskii's rule is summarised as follows: 'Strengthen the defence to the West, and search for friends to the East'. Two banners flank this display, bearing quotes by Patriarch Kirill and Minister of Foreign Affairs Sergei Lavrov that reflect the religious and political aspects of the Nevskii memory. In the words of the patriarch: 
Aleksandr Nevskii embodies genuine patriotism, steadfast standing in the fatherly faith, the strategic vision of a statesman, [and] a sense of responsibility before God for the fates of the people, entrusted to him as earthly ruler.

Lavrov's quote points out the prince's political legacy by stating that 'Aleksandr Nevskii laid the foundations of Russia's multipronged diplomacy'.

Aleksandr Nevskii (1220-1263) became the Prince of Novgorod at the tender age of 16 and later also served as Grand Prince of Kiev and Grand Prince of Vladimir. He came to power at a decisive moment in the history of Kievan Rus', in the wake of its subjection to the rule of the Golden Horde commonly referred to in Russian as the 'Tatar Yoke'. Along with the political pressure emanating from the East, the integrity of Novgorod was under threat from the West - most notably from the Swedes and the Teutonic Knights who sought to extend their influence in both political and religious matters. The allegedly concerted efforts by the Pope of Rome to convert the Orthodox city-state to Catholicism ${ }^{2}$ are frequently quoted in today's Russia to justify the adoption of a defensive stance vis-à-vis Europe. Nevskii's best-known military achievements are the Battle on the Neva (1240) against the Swedes, after which he was named, and the legendary Battle on the Ice (1242) on Lake Peipus against the knights of the Livonian Order.

The remembrance tradition associated with Nevskii reaches back to the late thirteenth century. Frithjof Benjamin Schenk (2004) has extensively explored its development up to 2000 and has identified several stages: sacralisation (thirteenth-fifteenth centuries), russification (fifteenth-seventeenth centuries), stateification (eighteenth century), nationalisation (nineteenth century), dethronement (1917-1937), recruitment (1939-1945), consolidation and criticism (1945-1985) and pluralisation (1985-2000). The following paragraphs will briefly summarise Schenk's argument to trace back the origins of the concepts that Nevskii is associated with in contemporary Russia. In particular, Schenk's interpretation of the evolution of the Nevskii memory during the 1990s is essential for determining the characteristics that are unique to the period after 2000 .

While the memorialisation of Nevskii had already started to develop at an earlier stage, in particular at local level in Vladimir where the saint lay buried, the political importance attributed to him peaked for the first time during the reign of Ivan the Terrible. Subsequent peaks occurred under Peter the Great and Stalin - and I would add, to a minor extent during the 2000s. For Ivan the Terrible, Nevskii, posited as the founding father of the Riurik dynasty, served the construction of a genealogy of the Moscow state. Moreover, he was portrayed as the exemplary defender of the Orthodox state against its Catholic and heathen enemies. Around the same time, the religious image of Nevskii as a saintly figure was affirmed and definitively established with his canonisation by the Russian Orthodox Church in 1547. Thus a two-pronged cultural memory was formed, encompassing a religious and a state-oriented 
component. The development of a multifaceted memory in the fifteenthseventeenth centuries reflected the complementary notions of society then prevailing:

Während Aleksandr Nevskij im Kirchlichen Diskurs die Idee der Sakralgemeinschaft verkörperte, deutete er im dynastischen Diskurs auf ein Gemeinschaftskonzept, dessen konstitutives Element der Herrscher und sein Machtbereich war. Herrschaftsverband und Sakralgemeinschaft waren die beiden Bestandteile der 'Rus'-Konzeption' (russkaja zemlja), die sich das Großfürstentum Moskau als eigenes Konzept kollektiver Identität vom Kiever Reich angeeignet hatte.

(Schenk 2004: 88. Italics in original)

Peter the Great was the first to instrumentalise the memory for a specific political goal. He posited Nevskii as an imperial ruler and deflected the prince's glory onto himself and the capital city he founded.

Nicht mehr die Würde der herrschende Dynastie oder die Heiligkeit der russischen Kirche prägten - wie noch im 16. und 17. Jahrhundert - die Ausrichtung des Aleksandr-Nevskij-Bildes. Im imperialen Petersburger Diskurs hatte er auf die Person und das Amt des aktuellen Zaren und Kaisers, auf die neugegründete 'herrschende Stadt' St. Petersburg und auf das Rußländische Reich als Imperium zuverweisen.

(Schenk 2004: 125)

Nevskii became the northern capital's patron saint and, to affirm the bond, Peter the Great ordered the construction of the Aleksandr Nevskii monastery, where Nevskii's relics were transferred in 1724 from the Rozhdestvenskii monastery in Vladimir.

In the nineteenth century the memory of Nevskii acquired a third connotation, reflecting the development of nationalist discourse. Propelled by the intelligentsia and drawing upon a newfound interest in folklore, the nationalist image of Nevskii imagined him 'nicht nur als Verteidiger des Landes und des Glaubens, sondern auch der russischen Kultur, insbesondere der Sprache' (Schenk 2004: 179). This third associated image, of military commander and national hero would later resurface under Stalin to great effect. In the period following the October Revolution, the memory of Nevskii was viewed negatively because the political ideas associated with it were incompatible with the ideology of the nascent communist state - in particular, the sacral and imperial discourses. Under Stalin, however, Nevskii and other historical figures $^{3}$ were rehabilitated. The memory of Nevskii acquired exceptional political significance in the late 1930s since it could easily frame how the Soviet Union would successfully respond to the threat posed by Germany. The formerly multifaceted memory became fully desanctified, and the only part of it to be preserved involved Nevskii's role as military commander. The Order of 
Aleksandr Nevskii was reinstated in 1942 as a military honour, differing little in name from its tsarist precursor, the Imperial Order of Saint Aleksandr Nevskii. In 2010, the military honour named after Nevskii underwent yet another transformation. Its badge was redesigned to more closely resemble the tsarist order and its purpose was reformulated as a civilian, rather than a military, award.

In the Perestroika period, as constraints over historiography and - to a lesser extent - religion were relaxed, a process of re-sanctification began. Nevskii's relics, which had been moved to the Museum of Religion and Atheism in St Petersburg, ${ }^{4}$ were returned to the Aleksandr Nevskii monastery in 1989. Reflecting the manifold political ideologies and concepts of national identity that were circulating in the late 1980s and especially the 1990s, the memory of Nevskii became subject to pluralisation. The respective 750th anniversaries of the Battle on the Neva and the Battle on the Ice in 1990 and 1992 heightened the already growing interest in the historical leader. The federal government, the ROC, academic and amateur scholars, historicalpatriotic groups, the army and local governments all contributed to the postSoviet re-evaluation of Nevskii. Schenk emphasises that contemporary memory images of Nevskii - the patriotic general, the local prince, the patron saint - coexist and complement rather than rival one another.

Als Kollektivsymbol übernimmt Aleksandr Nevskij dabei eine wertvolle Brückenfunktion. Der Held von der Neva ist eine ideale Integrationsfigur im Sinne des 'patriotischen Konsenses'. Er gilt sowohl als Zeichen der vorrevolutionären, als auch der sowjetischen Zeit. Er repräsentiert einen wehrhaften Staat und eine autoritäre politische Führung. Seine Biographie eignet sich als Projektionsfläche für Antiokzidentalismus und Antiislamismus. In der Erzählung von seinen Heldentaten kann die WirGruppe sowohl als nationale, russische Gemeinschaft als auch als Gruppe orthodoxer Christen beschrieben werden

(Schenk 2004: 468)

As will become clear later on, the religious element of identification has considerably strengthened since the turn of the twentieth century.

The memory of Nevskii is intricately connected to the city of St Petersburg, where the majority of the material traces dedicated to him are located. In 2002 the infrastructure of remembrance was complemented by a statue placed in front of the Aleksandr Nevskii monastery ('Pamiatnik Sviatomy Blagovernomu Velikomu kniaziu Aleksandru Nevskomu' n.d.). The equestrian statue depicts the saint in full armour carrying a shield and spear. Its unveiling took place on Victory Day in the presence of the Metropolitan of St Petersburg and Ladoga, Vladimir, the governor of St Petersburg Vladimir Iakovlev, and political and cultural representatives. In 2005, two bas-relief plaques were added to the pedestal depicting the transfer of Saint Nevskii's relics to the monastery by Peter the Great and the 1240 Battle on the Neva. 
The combination of the design of the statue, the bas-relief plaques, its location and its unveiling taking place on Victory Day (rather than, for example, on the saint's feast day on 6 December) all testify to the continued inseparability of the religious, military and political aspects of the memory.

Such a long and rich tradition of remembrance, in combination with the lack of historical sources documenting Nevskii's life, has resulted in a cultural memory that is largely mythic in nature, much more so than, for example, the memory of 1812 or Petr Stolypin. Within the cultural domain, Sergei Eisenstein's Aleksandr Nevskii (1938) has been key in shaping the image contemporary Russians have of the medieval prince, both visually and narratively (the scene of the Battle on the Ice in particular). ${ }^{5}$ It is telling that the Stalinist classic was favoured over a contemporary representation such as Aleksandr: The Neva Battle (2008) to represent Nevskii's rule in the film festival accompanying the Riurikids exhibition ("Na vystavke "Moia istoriia. Riurikovichi" prodolzhaetsia programma pokazov rossiiskogo kino' 2014). ${ }^{6}$

More recently, Aleksandr Nevskii has appeared in media other than film, sculpture and iconography. Over the course of three years, Unicorn Games Studio released the video games XIII Century: Glory or Death (XIII vek: Slava ili smert', 2007), ${ }^{7}$ XIII Century: Rusich (XIII vek: Rusich, 2008) ${ }^{8}$ and History of War: Aleksandr Nevskii (Istoriia voin: Aleksandr Nevskii, 2009). ${ }^{9}$ All three games allow players to engage in a classic battlefield video game in thirteenth-century style and differ little in terms of gameplay (Arbatskii 2008; Khromov 2010). Nevskii, and in particular the Battle on the Ice, were featured in the 2013 superhero comic The Monk (Inok). ${ }^{10}$ Its protagonist, Andrei Radov, travels back in time to take part in various historical battles to protect Orthodox civilisation from the numerous enemies (Mongols, Christians, the devil) that seek to destroy it. In the comic, it is Andrei who purposefully causes the ice to crack underneath the feet of the Livonian army and thereby secures victory.

\section{A beacon of Orthodox morality in the face of globalisation}

The Russian Orthodox Church has been one of the principle driving forces behind the renewed actualisation of the memory of Aleksandr Nevskii in the post-Soviet era. This trend has continued and intensified in the 2000s. It has to be noted that the ROC is an internally diverse institution. It consists of a multitude of factions, each with their particular views on ecclesiastical matters as well as on political questions. ${ }^{11}$ In this chapter, I mainly address the views and actions of the ROC leadership, the Holy Synod and the Patriarch, whose position tends largely to coincide with the so-called traditionalists within the Church. The political orientation of the traditionalists can be described as 'orthodox statism', characterised by 'the desire for a powerful Russian state, with the renewal of Orthodox values as the source of the country's strength' (Papkova 2011: 47). In the chapter on Ivan the Terrible, I will turn my attention to 'fundamentalist' tendencies within the ROC, through the example of 
Orthodox Brotherhoods and their views on (memory) politics. The lack of uniformity is an important factor when we seek to understand the ROC's use of historical references to support its policies: while the official church has increasingly been associated with the Kremlin and is perceived to be one of the pillars supporting the concept of traditional Russian statehood, the political views put forward by other, more fundamentalist movements are, in fact, oriented towards undermining the state as it has been shaped during the Putin era (see chapter 6).

Since the dissolution of the Soviet Union, the ROC has successfully re-established itself as the principal religious organisation in Russia (Richters 2013). Both Yeltsin and Putin supported the restoration of the Church and granted it significant privileges in return for the legitimation the association with the ROC bestowed on their positions of power. For Putin,

the Church as a social institution turned into another 'cultural institution' that was useful for the state in order to demonstrate to foreigners its thousand years of tradition, to shore up its support for his xenophobic policies, and to channel pro-Russian sympathies among Russian émigrés in ways benefiting the government.

(Mitrokhin 2009: 319)

The ROC has become a highly visible component of political symbolism, with high-ranking representatives taking active part in political ceremonies such as the presidential inauguration ceremony.

The ROC views itself as the moral compass of the Russian nation in a rapidly globalising world that threatens the foundations of Orthodoxy. Consequently, it envisages its political role as

[helping the] post-Soviet regime build an effective means of weathering, if not outright resisting, the shocks of globalization, which is generally regarded as a western-inspired weapon against Russia. The task is defined as a joint church-government project of ensuring the survival of a specific Russian national and religious identity in a rapidly changing and hostile world, through the spiritualization of Russian society.

(Papkova 2011: 48-49)

From the perspective of the ROC, church-state relations should ideally be fashioned in line with the 'symphonic model' which implies close cooperation with the state, yet without state interference in the ROC's internal affairs (Papkova 2011: 32), a relationship based on the theological notion of symphonia, or harmony, that strikes a precise balance between the opposing models of a state church and a secular society. The ideal of symphonia between church and state is an ideal indeed, since it has never been fully realised. 
The ROC's outlook on how the Russian state should be organised largely coincides with the priorities of the Putin regime. Yet with regard to certain matters, their opinions diverge significantly.

Many of these priorities - the strict moral censorship of television, a ban on abortion, legislative restrictions on the activities of religious competitors, the introduction of catechism in state education, and state support of the institution of priests in social organizations - are not met with understanding on the part of the Russian government and actually clash with the current trends in domestic policy.

(Mitrokhin 2009: 319)

Since Patriarch Kirill became head of the Church in 2009, and increasingly since Putin was re-elected president in 2012, these differences have become less pronounced. The government has shown itself more willing to accommodate concerns expressed by the ROC, for instance by responding to calls to intervene in cultural matters on the grounds that feelings of religious people have purportedly been violated. The authorities have increasingly adopted spiritual and religious terminology and symbolism and have placed an emphasis on defending traditional values and the centrality of the nuclear family. During Putin's first two terms in office, it appeared that Orthodox beliefs could still be overruled by political objectives. Pragmatic considerations prevailed over an unwavering embrace of Orthodoxy as part of the state's ideology. Since then, however, there has been a considerable shift, as the neo-conservative turn in Russian politics that intensified after the annexation of Crimea has augmented the relevance of and support for the agenda set by the ROC.

The concept of tradition is of fundamental importance to the overlapping interests of the state and the Church. Yet, in addition to the occasional incongruence between their perceptions of what tradition actually entails, and how it can be combined with features of modern society (e.g. the internet and social media), ${ }^{12}$ there exist diverging definitions of 'traditional society' even within the ROC itself. The seemingly condensed constellation of Orthodox traditional values, upon closer scrutiny, turns out to be heterogeneous and at times at odds with itself. The Church's recent attempts to adapt to contemporary society and its mediatised nature have only enhanced some of its internal divergences (Tolstaya 2014).

As it has sought to reconnect with the Russian diaspora and, more generally, with Orthodox believers outside of the country, the ROC's political objectives have reached beyond national borders. The concept 'Russian world' (russkii mir) is generally used to denote this extended sphere of influence (see Suslov 2018). For the state, cooperation in this sphere 'for the purposes of expanding and consolidating the Russian world' (Payne 2010: 726) has been advantageous since it has added yet another means to define its transnational sphere of influence, especially in relation to the so-called Near Abroad: in addition to 
appealing to shared linguistic and ethnic categories (Russian speakers and ethnic Russians living outside of Russia), the (Russian) Orthodox religion could now function as a marker of association, suggesting the existence of an intrinsic connection between Russia and Orthodox believers worldwide. For the ROC, economic interests have been involved as well, since part of its concerted efforts with the foreign ministry have been aimed at the reacquisition of church property seized during or following the 1917 revolutions (idem: 726).

Several scholars have pointed out that while the Church appears to hold a position of political prominence, its ability to influence state politics remained limited during the timeframe under discussion here (Anderson 2007; Mitrokhin 2009; Papkova 2011). The state was the dominant partner in a relationship that Anderson characterises as one of 'asymmetric symphonia' (Anderson 2007). The Church's limited political leverage reflects the state's perception of the ROC's measure of societal authority: ${ }^{13}$ "without overwhelming support from the people it claims to serve and represent, [the ROC] cannot have great authority with the state' (Mitrokhin 2009: 318). Its close association with the state is nonetheless advantageous. For example, the Church has received government funding for certain of its research and media projects (idem: 308). ${ }^{14}$ In 2010, a law was passed requiring the restitution to the Church of property seized by the Soviet state. Furthermore, the ROC achieved a long-awaited success with regard to the inclusion of religious education in school curricula. The course 'Fundamentals of Religious Cultures and Secular Ethics' was first given as a trial offering from 2009 to 2011 and was subsequently included in the standard curriculum in 2012 (Richters 2013: 46-47; Clay 2015). Parents have the option to choose among modules on one of the 'traditional religions' - Orthodox Christianity, Buddhism, Judaism and Islam - or on secular ethics or world religions. The trial of Pussy Riot for the performance of their 'punk prayer' in the Cathedral of Christ the Saviour (Ponomariov 2013) and the subsequent passage of a law making it a crime to insult religious feelings marked an increasing sensitivity concerning religion in the public sphere and the increasing say of the ROC in matters touching on social values, which has intensified since 2012 .

\section{The Russian Orthodox Church and cultural memory}

Similar to its effect on Russian politics, the disintegration of the Soviet Union compelled the ROC to explicitly conceptualise its identity and place in society. Cultural memory has been an instrumental tool for substantiating the assertion that the contemporary ROC should be viewed as heir of a long Orthodox tradition and, consequently, could now, as a religious organisation, reclaim its righteous position as the principal religion of the Russian state. Both the distant and the more recent past were effectively, yet not always uniformly, utilised to place Russian Orthodoxy at the heart of the Russian nation and to proclaim its importance as the principal driving force behind 'the spiritual revival of the Fatherland' (Garrard \& Garrard 2008: 243). ${ }^{15}$ 
The ROC's restorative efforts have taken many forms: the reclamation of lost Church properties, as already mentioned; the restoration or reconstruction of churches that were damaged or destroyed under Soviet rule - most notably, the Cathedral of Christ the Saviour in Moscow ${ }^{16}$ - and the construction of new churches in the traditional Russo-Byzantine medieval style. With 'Programme 200', announced in 2010, the ROC set out to significantly increase the number of churches in Moscow - by at least two hundred, as the programme's name suggests - to improve accessibility for believers; this project, once completed, will leave a noticeable mark on the city's architecture. One should also mention the (re-)establishment of religious practices such as processions and pilgrimages (see, e.g., Rock 2014). A speech delivered by Patriarch Aleksii II upon the completion of the construction on the Cathedral of Christ the Saviour highlights the symbolic importance of the 'resurrection' of Orthodox landmarks that had been lost during the Soviet era:

The miracle of the resurrection of the Cathedral required several years of concentrated, selfless and loving labour. The Cathedral now glorifies Christ and helps our long-suffering people return to their spiritual roots the Holy Faith of their ancestors.

(Garrard \& Garrard 2008: 82)

The symbolic and tangible restoration of 'Orthodox Russia' complements and supports the Church's aim of political restoration, discussed above.

Referring to statements made by Patriarch Kirill, Mikhail Suslov argues that there is an inherent paradox in the ROC's 'historical imagination', resulting from its being informed by two contradictory metanarratives: one that emphasises the autonomy of Russia as a civilisation (which is defensive and displays the influence of Slavophile thought) and one that views the position of Russia in the world in messianic terms (which is offensive and shows traces of Eurasianist thinking) (Suslov 2013). In the skilful hands of Patriarch Kirill, however, Suslov asserts, the opposing paradigms merge so that the ROC's array of objectives are deftly combined. As a result, Patriarch Kirill, on the one hand, 'emphasises, that Russia's struggle with the external enemy has always borne the character of a fight for its civilisational authenticity against the West: in 1612 the Russians defended their faith, in 1812 their culture, [and] in 1942 their very right to existence' (idem: 144). On the other hand, however, 'tying in the battles of the past with the war for the spiritual frontiers of Russia that is going on today, Kirill outlines the parameters of cooperation with the West in the context of Christian transnationalism' (Suslov 2013: 144).

Two memorialisation practices deserve particular mention: the canonisation of Tsar Nicholas II and his family and the growing cult of the New Martyrs and Confessors of Russia. Responding to societal sentiments, the ROC went ahead with the canonisation of the imperial family in 2000. They were sainted as 'passion bearers': a category that acknowledges their religious 
devotion and their resigned acceptance of their deaths, yet clearly distinguishes them from those 'martyrs' who lost their lives because of their faith. The ROC found it important to thus differentiate them from those who could have saved their lives by denouncing their faith. On the site where the Ipatiev house once stood in Yekaterinburg - where the Romanovs were held captive and later killed - the Church on the Blood was erected and consecrated in 2003 .

The ROC explicitly placed the canonisation of the imperial family in the context of a second, much larger group of new saints, the New Martyrs and Confessors of Russia (Garrard \& Garrard 2008: 125). Since the turn of the millennium, some two thousand individuals who were persecuted and killed by the Soviet state because of their religious beliefs - both ROC clergy and laity - have been canonised. This newly created memory culture within the ROC has been actively affirmed via the commissioning of icons of the new martyrs and the dedication of numerous churches across the country to their memory (Fedor 2014). New martyrdom is of particular significance because it is the only example of a memory practice commemorating the victims of Soviet repression that has been condoned by the state. ${ }^{17}$ As Julie Fedor explains, the inseparable link between the Putin government and the FSB on the one hand, and those responsible for the acts of repression on the other, hampers the authorities from taking an effective stance on these crimes without questioning their own legitimacy. Therefore,

[i]n fulfilling the role of custodian of the memory of Soviet state terror, the ROC MP [Moscow Patriarchate, M.W.] is effectively acting as a proxy for the current state authorities, including the successor agencies to the Soviet state security organs.

(Fedor 2014: 129)

The symbolic assumption of responsibility for the memory of the victims of Soviet repression is reinforced on the material level by, for example, the transfer of mass burial sites from the FSB to the Church. This appears to be an attempt to provide closure to the question of remembrance:

by transferring these sites to the church, the state has [...] effectively handed over to the church the problem of dealing with the Soviet past. The ROC in turn has duly repeatedly declared the historical reconciliation of victim and perpetrator, thereby bestowing historical legitimacy upon the current regime.

(Fedor 2014: 129)

On another occasion, however, the Church has shown itself surprisingly accommodating towards the contemporary heirs to the communist past. In 2014, Patriarch Kirill awarded Gennadii Ziuganov, the leader of the Communist Party of the Russian Federation, with the Order of Glory and 
Honour to the third degree (the highest) on the occasion of his seventieth birthday ('Patriarkh Kirill nagradil Ziuganova Tserkovnym ordenom' 2014).

On a number of occasions, the ROC has involved itself in cultural events and productions about episodes in history that it associates itself with. For example, the exhibition about the Riurikids, discussed in the introduction, was organised by the Humanitarian Projects Fund. This fund was established in 2013 on the initiative of Archimandrite Tikhon to organise a five-year exhibition cycle around the theme 'My History', the first of which was dedicated to the Romanov dynasty ('Proekt "Moia istoriia" n.d.). It works in close cooperation with the Moscow Patriarchate, as well as the Ministry of Culture and other federal, regional and local authorities. Archimandrite Tikhon curated both exhibitions and serves as chairperson of the Fund's council of experts.

In the cinematic sphere, Vladimir Khotinenko's The Priest (Pop, 2009) is a prime example of Church involvement in cultural production. The film narrates the story of a group of Orthodox priests that was sent to the Pskov region by the Metropolitan of Latvia from 1941 to 1945 to reopen churches that had been closed by the Soviet authorities. As Pskov was German-occupied territory at the time, the successful completion of their mission depended on their cooperation with the occupying forces. The ROC has tried to replace the Soviet narrative of collaboration with 'one in which the priests of the Mission are depicted as saintly men of God and true Russian patriots' (Anemone 2010). The Priest made an important contribution towards sharing this patriotic reinterpretation with the general public. The Church was closely involved in the production of the film. It was made with the blessing of the late Patriarch of Moscow and All Russia, Aleksii II, and the first screening took place in the Cathedral of Christ the Saviour. ${ }^{18}$ The Priest received direct and indirect state funding.

In his review of the film, Antony Anemone interestingly refers to the contemporary memory of Nevskii as a means to understand the reinterpretation of the Pskov mission.

The key to the film's (and novel's) ideological meaning is Aleksandr Nevskii, the favorite saint of the hero of The Priest and the hero of Eisenstein's great anti-German movie of 1938. As the patron saint of patriotism and Orthodoxy, Nevskii summarizes and suggests one way of solving the historical paradox that stands at the heart of the Pskov Spiritual Mission. The problem, brutally stated, concerns the admissibility for Russian patriots of collaborating with the Nazis in order to reintroduce Christianity to those parts of the land of the Soviets occupied by the Wehrmacht. As the priest says at one point, neither the Germans, nor the Bolsheviks are eternal: only Christ is eternal. Hence, the ultimate goal of serving Christ can never be a mistake.

(Anemone 2010) 
The leniency allowed by this historical model for the sake of pragmatism and compromise in the name of the Orthodox faith's continued existence and future prosperity can indeed benefit Church officials as they seek to adapt their institution to modern society and make the most of what it has to offer.

Another much-debated example is the 2008 documentary The Fall of an Empire: The Lesson of Byzantium (Gibel' imperii: Vizantiiskii urok), broadcast on Rossiia 1. The documentary was written and narrated by, again, Archimandrite Tikhon. It draws explicit parallels between Byzantium and contemporary Russia to warn against the corrupting influence of the West. Presented as the 'spiritual heir' of Byzantium, Russia should emulate the conditions of the Orthodox empire in its prime: it was a centralised state headed by a strong government, and an empire, moreover, in which Orthodoxy served as a unifying factor and dictated a path of development that was different from those of both the East and the West (Baïdine 2011: 105).

The memory of Nevskii has become an integral part of the ROC's 'memory vocabulary', both within the observed ecclesiastical canon and in the Church's media appearances. The feast day of Saint Aleksandr Nevskii, traditionally celebrated on 6 December according to the Orthodox calendar (23 November before the adoption of the Gregorian calendar), is but one element of the saint's contemporary veneration. The memory has been made to suit the ideas on Russian society and state-church relations supported by the traditionalist wing within the ROC, as well as its outlook on the world and on interethnic and interconfessional relations. Then Metropolitan and now Patriarch Kirill has personally supported the saint's memory in a way that recognises the complementary resonances of the multiple strands of memory identification associated with Nevskii - its state-oriented, military and patriotic interpretations, in addition to its religious and moral ones. Patriarch Kirill's appearance on the TV show The Name Is Russia, which will be discussed in detail in the second part of this chapter, demonstrates the ROC's dedication to the memory of Nevskii, as well as its awareness of the potential impact of the medium of television on the historical consciousness of the mass audience. Building upon the popularity of the TV project, the ROC initiated the travelling exhibition 'Aleksandr Nevskii - The Name of Russia'. Despite its title, the objects displayed - a series of icons produced with a special technique involving powdered (precious) stones and artificial crystals, and paintings depicting various aspects of the Russian landscape - bore little connection to the show's televised namesake ('Vystavochnyi proekt "Aleksandr Nevskii Imia Rossii" startoval v Sankt-Peterburge' 2009).

A recent addition to the material infrastructure of the cultural memory, or its 'memory hardware' (Etkind 2009), deserves mention. Since 2013, construction had been underway on a new church dedicated to St. Nevskii near the Moscow State Institute of International Relations (MGIMO). Plans for constructing a church at the site were originally developed in 1999 and received the blessing of Patriarch Aleksii II in 2005, at which point its devotion to Nevskii was decided. Yet sufficient funds for its 
construction were only secured within the framework of 'Programme 200' ('O khrame' n.d.). The church has been erected on the site where there had previously been a small brick church, which was closed in the 1930s and demolished in 1941. The design of the single-domed, white-plastered brick church is very traditional, as is the case with many new churches built over the past decades. The church was consecrated by Patriarch Kirill in March 2016.

The Church's active involvement in the negotiation of Nevskii's memory, combined with its self-appointed role as the moral guardian of the Russian nation, occasioned a minor television scandal in 2006. The long-running satirical programme Gorodok, broadcast by RTR, dedicated an item to Nevskii on the anniversary of the Battle on the Ice. It shows the moment when Nevskii comes up with his ingenious tactic that will win the battle: not only will his troops confront the enemy on the ice, they will remove their heavy armaments to gain an advantage. With a cheeky play on the words 'We will show them ...', the soldiers, standing in formation clothed only in felt hoods and valenki, ${ }^{19}$ bare their genitalia as they salute their commander. The chairman of the Orthodox-patriotic social movement 'Aleksandr Nevskii', Viacheslav Ulybin, lodged a complaint with the procurator of St Petersburg demanding the termination of the show on the basis of a violation of religious sensitivities. According to Ulybin, in the sketch, 'the feat of Russian soldiers, defending the Fatherland, is filed as some sort of action by animal-like imbeciles, and the saintly knight, celebrated by the Orthodox Church, as the leader of such [people]' ('Otets Vsevolod Chaplin: Rossii nuzhna Antidiffamatsionnaia liga' 2006). The vice-chair of the Duma's Committee on Social Unity and Religious Organisations, Aleksandr Chuev, concurred that if the complaint accurately described the show as it was broadcast, this would amount to an insult to national saints, as well as a violation of the feelings of Orthodox believers ("Chuev: Siuzhety "Gorodka" o "Ledovom poboishche" nado dat' pravovuiu otsenky' 2006). Chuev took the matter very seriously: 'You can mock everything and subvert any ideals you want, but states in which this is permitted and nations who allow themselves to do so, quickly perish' (ibid.). ${ }^{20}$

When asked to respond to the sketch, the (then) deputy head of the Moscow Patriarchate department for external church relations, Vsevolod Chaplin, without having seen the show, deemed it to be an example of the harmful tendencies prevailing on Russian television:

Unfortunately, humoristic programmes that are broadcast during television prime time, in particular on Saturday and Sunday evenings, quite often express derogatory and offensive appraisals with regard to Russia, its history and its people. We need something like an anti-defamation league that would monitor such occurrences and call offenders to account.

('Otets Vsevolod Chaplin: Rossii nuzhna Antidiffamatsionnaia liga' 2006) 
After the court refused to open a criminal case against the show's producers because of a lack of corpus delicti, Ulybin turned to President Putin for support of his cause. In an open letter, Ulybin challenges the court's decision and asks, 'If [showing] completely naked soldiers under the command of a saint, shown on state television, is not considered a sneer at sanctity (which, in addition, incites religious enmity) - then what is?' (Ulybin 2006). However, Ulybin's efforts were in vain.

\section{Nevskii as the founding father of Russian foreign policy}

In 2007, Minister of Foreign Affairs Sergei Lavrov commented on the significance of Nevskii for Russian diplomacy during a meeting of the Board of Trustees of the 'Aleksandr Nevskii' programme - a private initiative that will be discussed in detail below. The meeting took place at the Moscow State Institute of International Relations (MGIMO). According to Lavrov, Nevskii focused his attention on two questions, each of which has equally preoccupied the Russian government since the turn of the millennium: the 'gathering of the Russian lands' - in other words, the reining in of any signs of separatism and the reorganisation of federal structures while influence is simultaneously maintained and extended over the 'Near Abroad' - and the strengthening of the Russian state ('Sostoialsia Popechitel'skii sovet programmy "Aleksandr Nevskii" 2007). Apart from the similarities in policy objectives between Nevskii and the contemporary Russian state, Lavrov singles out Nevskii's unique contribution to the development of Russian diplomacy as it is still practised today: 'The activities of Aleksandr Nevskii in the West and in the East laid the foundations of what we call multi-vector diplomacy. In terms of foreign policy, Russia should orient itself in all directions' ('Rossiiskie diplomaty budut udostaivat'sia znaka sv. kniazia Aleksandra Nevskogo' 2007).

In his appreciation of Nevskii's qualities, Lavrov puts across a multifaceted image yet refrains from using religious categories. The image of Nevskii is mobilised to highlight the challenges Russia faces in effectively organising its ties and addressing existing tensions among national, ethnic and religious communities, both within and beyond its state borders. Nevskii, he states, was 'a legendary figure, a politician, military commander, diplomat and statesman' ('Sostoialsia Popechitel'skii sovet programmy "Aleksandr Nevskii”" 2007).

During the meeting it was emphasised how the contemporary practice of linking the figure of Nevskii to the sphere of diplomacy builds upon on previously established custom - an example of reclaiming lost tradition. Anatolii Torkunov, who is a Russian diplomat, rector of the MGIMO and member of the board of trustees, explicitly embeds the plans that they are discussing for the establishment of an Aleksandr Nevskii distinction for diplomats (znak) in historical practice:

Aleksandr Nevskii is the patron of Russian diplomacy; in the nineteenth century, you could find an Icon of Aleksandr Nevskii in every embassy. 
Peter I already established this tradition. And in the minds of many, victories in the diplomatic and military arenas were associated with the name of Aleksandr Nevskii. There are churches in Sofia and Belgrade that bear his name in honour of military victories of the Slavs.

('Sostoialsia Popechitel'skii sovet programmy "Aleksandr Nevskii'",

The plans for the distinction were realised, and at the first awards ceremony in 2009 it was again emphasised how this builds upon the tradition that Empress Catherine I founded through the establishment of the Order of Aleksandr Nevskii in 1725 ('Evgeniiu Primakovu vruchena premiia Aleksandra Nevskogo' 2009).

While Lavrov adheres to the language of foreign policy in his statements about Nevskii, politics and religion are continuously interwoven in the societal projects initiated in his memory. The 'Aleksandr Nevskii' programme mentioned above is a good example. The Saint Andrew Foundation and the Centre of National Glory initiated the programme in December 2006 with support from the Moscow Patriarchate and the Ural Mining and Metallurgical Company (UGMK). Its aim is to increase societal awareness about this 'key figure' in the lead-up to the celebration of the 800th anniversary of Nevskii's birth in 2021 ('Programma "Aleksandr Nevskii", 2014). More broadly formulated, the programme's main objective is to stimulate the development of spiritual and moral values in Russian society and to foster a worldview that emphasises selfless dedication to one's country and people. Nevskii is perceived as great military commander and protector of the Fatherland, but to an even greater extent he is regarded as a man who lived a holy life, as well as a statesman and diplomat.

The programme comprises multifaceted activities. First, it organises a tour of Nevskii's relics to cities in Russia and within the dioceses and archdioceses of the ROC (e.g. those in Latvia, Belarus and the Czech Republic). Second, facilitated by financial support from UGMK, it is involved in the construction of churches dedicated to Nevskii in the borderlands of the Russian Federation - for example, on the island of Sakhalin and in the city of Baltiisk in the Kaliningrad region. Third, annual 'Aleksandr days' have been organised in several Russian cities, including various activities aimed at children. Finally, the programme is active in the academic sphere through conferences, fora and the publication of research volumes.

Since 2009, Patriarch Kirill serves as the honorary chairman of the programme's board of trustees. Its members are governmental representatives, clergy, businessmen and representatives of societal organisations. In addition to the patriarch, the board is co-chaired by Vladimir Iakunin - former director of Russian Railways and the chairman of the St. Andrew Foundation and the Centre of National Glory - and Andrei Kozitsyn, the general director of UGMK.

The programme's initiative for an Aleksandr Nevskii distinction for diplomats appears somewhat remarkable at first glance, given the ecclesiastical 
background of its founding organisations. Yet it asserts the mutual advantageousness of state-church cooperation in the foreign policy domain: the Ministry of Foreign Affairs strengthens its image by the association with a morally superior type of foreign policy exemplified by Nevskii, while the Church is able to assert its influence abroad more effectively through its close relations with the ministry. Evgenii Primakov, minister of foreign affairs in the years 1996-1998, was the first recipient of the award in 2009. The distinction for diplomats is not reserved for members of the diplomatic corps and the Ministry of Foreign Affairs. In fact, Patriarch Aleksii II had been chosen as the first laureate but passed away shortly before the ceremony was to take place in 2008 ('Evgeniiu Primakovu vruchena premiia Aleksandra Nevskogo' 2009). In 2010, the golden distinction was awarded to his successor Patriarch Kirill in a ceremony at the MGIMO. Later meetings of the board of trustees and the coinciding awards ceremonies have taken place at the Cathedral of Christ the Saviour, for instance in 2014 when Patriarch Kirill awarded the Aleksandr Nevskii distinction to Minister of Foreign Affairs Lavrov. Hence, all aspects of the Aleksandr Nevskii distinction affirm the bonds between Russian Orthodoxy and official foreign policy - from its concept and its laureates to its awards ceremony locales.

The 2010 meeting at the MGIMO was also the occasion of the unveiling of a bas-relief plaque depicting Nevskii. Patriarch Kirill asserted: 'This bas-relief reminds those who study here of the fact that active state, diplomatic and military action can be combined with earnest Christian ministry' ('Patriarkh Kirill: "Aleksandr Nevskii - primer dlia budushchikh diplomatov" 2010). The plaque, in combination with the newly constructed church on its grounds (mentioned earlier) and the photography exhibition 'Aleksandr Nevskii - The Name of Russia', on display next to the bas-relief in December 2011 ('V MGIMO proshlo otkrytie fotovystavki "Aleksandr Nevskii - imia Rossii", 2011), ${ }^{21}$ testify to a deliberate close linkage of the figure of Nevskii and the institution that educates Russia's future diplomats.

While the government-endorsed image of Nevskii as a statesman and skilful diplomat has been most closely associated with the Ministry of Foreign Affairs, his name has more recently been quoted within a more militaristic context. In December 2013, Minister of Defence Sergei Shoigu officially transferred a nuclear submarine named after Aleksandr Nevskii to the armed forces ('Vladimir Putin: Do 2020 goda v sostav flota voidut vosem' podvodnykh kreiserov i vosem' mnogotselevykh atomnykh podlodok' 2013). The state has demonstrated its future commitment to the memory of the Prince of Novgorod in yet another way: by presidential ukaz, the 800th anniversary of Nevskii's birth will be celebrated in 2021 (President of the Russian Federation 2014).

The political appropriation of Nevskii as an exemplary figure has been limited, yet the narrative about him has demonstrated its potential to bridge the religious and political spheres and establish common ground. This fits with the government's tendency to 'integrat[e] orthodox symbolism and 
cultural capital into both the construction of its own legitimacy and the construction of a viable post-soviet national identity' (Papkova 2011: 189). In conclusion, it is worth noting that both the ROC and its associated Orthodox organisations and government representatives emphasise that contemporary veneration of Nevskii reaches back to an imperial tradition and generally steers clear of anything that would suggest Stalinist or other Soviet associations.

\section{Film and television analyses}

In the years after 2000 very few cultural productions were dedicated to the memory of Aleksandr Nevskii. A notable exception is the television documentary series Who Are We? Russian Reforms (Kto my? Reformy po-russki, Lev Brodskii, 2000), broadcast by the Kul'tura channel, which dedicated an episode to Nevskii. The show sought to counter the prevailing image of Nevskii as a military commander and, instead, portrayed him as a political reformer. It highlights how Nevskii adapted to the changing geopolitical conditions of his time in order to save the 'Russian soul' from the dire conditions that Kievan Rus' found itself in. His definition of the state's policy towards the East and the West is earmarked as the essence of 'Russian-style reform'. But the relative latency of the memory of Nevskii on the big and small screens changed dramatically in 2008 when two major productions brought the medieval prince back into the public eye: the historical blockbuster Aleksandr: The Neva Battle and the TV project The Name Is Russia ${ }^{22}$ that resulted in Nevskii being elected the greatest Russian of all time.

\section{Aleksandr: The Neva Battle (2008)}

Sergei Eisenstein's image of Nevskii is arguably the most widely known (non-religious) representation of the medieval prince. The makers of the historical blockbuster Aleksandr: The Neva Battle (Aleksandr. Nevskaia bitva, 2008) avoided any direct comparison with Eisenstein's iconic film by situating their narrative a few years earlier in Nevskii's life. The film positions itself as a prequel to its Stalinist precursor, ending the narrative where Eisenstein's film began. Yet whereas the Stalinist interpretation stressed his might on the battlefield, the post-Soviet Nevskii is first and foremost a morally superior figure and guardian of the Orthodox Russian state. The film was directed and co-produced by Igor' Kalenov, who was making his feature-length film debut. He is also the founder and director of the film's production company Nikola Film. ${ }^{23}$ The project was very personal to Kalenov:

I became interested in the personality and deeds of Aleksandr Nevskii when I was still a child after I got the wonderful colouring book 'The 
Battle of the Neva.' Thirty-five years later I got the opportunity to realise my childhood dream of making a film about the Novgorodian prince.

('Nachalis' s'emki fil'ma o molodykh godakh Aleksandra Nevskogo'

Furthermore, he felt Nevskii's story was timely: 'I am convinced that our society now needs historical examples that show that it is necessary to reach compromises in order to resolve global problems' (Ramm 2008).

Initially, Aleksei Karelin had been assigned to be director of the project, but during production Kalenov decided to part ways with him and take on the director's role himself (Kvasha 2008). The film was subsidised by the Federal Agency for Culture and Cinema (Roskul'tura) and premiered in Russian cinemas on 1 May, in the lead-up to the Victory Day celebrations. Despite the favourable release date, its performance at the box office was mediocre, drawing just over 577,000 viewers ('Aleksandr. Nevskaia bitva' n.d.). ${ }^{24}$ Its DVD release was more successful. Aleksandr topped DVD sales in the last week of May 2008, and was in second and fifth position for the preceding and subsequent weeks, respectively (InterMedia 2008a; 2008b; 2008c). In interviews, Kalenov avoided making direct associations and comparisons with Eisenstein's Aleksandr Nevskii, stating that each director had 'shot a different kind of film':

It's not a poster or an epic, but a story about a boy who is entering adulthood and learns to live by the rules dictated by politics. Our film is about what it's like to be alone at the top. And with all that, as a future politician, a future soldier, he contrives to preserve his mercy and compassion.

(Ramm 2008)

During an interview for the website film.ru, Kalenov was asked why he had decided to shoot a historical film and whether it had become fashionable to do so - citing other examples, such as 1612 (Khotinenko. See chapter 5) and Mongol (Bodrov), that had premiered the year before. Kalenov's response to this seemingly innocuous question is quite telling about the political sensitivities involved in making historical cinema. First, he denies being part of a 'trend' since in the preceding decade just one film, 1612, had been produced on Russian history. He attributes the overall increase in historical films produced in Russia to circumstantial factors such as the advancements in computer technology and the fact that 'the political pathos has subsided somewhat now' (Kvasha 2008). Kalenov concludes by emphasising his artistic independence:

And then they try to accuse me of [fulfilling] some kind of political order. But we are just making a film; moreover, we are shooting it not as a 
historical drama, a historical epic; we produce an ordinary contemporary film, a spy detective.

(Kvasha 2008)

Evidently, this particular interview was not the first time the director was confronted with the insinuation that Aleksandr was a case of goszakaz.

The question of goszakaz indeed remains complicated. Even if the government does not directly solicit a production, a director or producer is often influenced in his selection of projects to pursue by a sense of which topics or genres are likely to be funded (Interviewee I). Indeed, Kalenov has stated that it is easier to secure ten million dollars for a blockbuster production than raise one million to shoot an intimate story about ordinary people (Ramm 2008). Therefore, unless a director is dedicated to the realisation of a particular idea and is willing and/or able to do so through alternative funding, a measure of (anticipatory) conformity is likely to arise.

The film's narrative relates how Nevskii establishes himself as sovereign of his court and becomes married to the daughter of the Prince of Polotsk. Whereas in Eisenstein's film the Battle on the Ice takes centre stage, Kalenov's film focuses on political intrigues and betrayals at the court. The military confrontation with the Swedes serves as a meagre postscript. For the battle scene, help was enlisted from historical re-enactment groups, which is common in Russian historical film production (Interviewee F). Not only is there the difference in narrated events between the films: Aleksandr demonstrates few borrowings from the Eisenstein classic. The iconic imagery has not been adopted or recontextualised in evident ways.

The young Nevskii (played by Anton Pampushnyi) is handsome and has a calm but energetic demeanour. The producers deliberately cast a relatively unknown actor in the leading role to prevent any external associations with him (Ramm 2008). His most salient features are his sense of compassion and overall good morals - which at times verge on the incredible. A crucial scene of the detective plotline is the attempt to poison Nevskii at his wedding banquet. A ceremonial goblet of wine is passed between the prince and his men to celebrate the holy matrimony. The court jester, who has fled under the table after being bullied, notices how someone puts a few drops of poison into the goblet and then passes it back. The goblet is refilled and offered to Nevskii. As he delivers a speech and moves it toward his lips, the jester snatches the goblet away, drinks its contents, then slowly succumbs to the poison as Nevskii, now aware that a spy has infiltrated his court, holds his hand. The death of the jester, who sacrificed his own life to save his monarch, torments Nevskii and keeps him awake at night. As the search for the person responsible for the poisoning intensifies, Nevskii is firm that not a single innocent death will be permitted. Despite the precariousness of the situation and the risks involved in having a spy among his inner circle, Aleksandr overrules his advisers as they move to punish those in charge of pouring the wine - just in case. The young prince's ability to act wisely and emphatically in times of 
crisis demonstrates his innate moral superiority - a quality that supports his canonisation by the Orthodox Church.

The main geopolitical claim the film puts forward is that Novgorod, and the 'Russian land' in general, was the target of a concerted Western attack. It is intimated that the Pope of Rome, the Teutonic Knights of the Livonian Order (here often referred to as 'Germans') and Sweden are conspiring to convert Novgorod to Roman Catholicism and bring it under their influence. The opening scene spells out the intentions of Novgorod's western neighbours. In a voice-over, Andreas von Velven, one of the main spies in the narrative, introduces himself as a knight of the Livonian Order who has been sent on a special mission: to increase the Order's influence over the 'uncivilised' Slavic lands. Immediately, the scene is set for a confrontation that is as much about preserving religious and cultural independence as it is about fending off territorial expansion. Von Velven coordinates the efforts to subvert Novgorod by obtaining the military intelligence needed to launch an attack through corrupt boyars - notably a map of the Neva indicating suitable locations for landing and setting up camp - and enlists the military support of the Swedes to carry it out. Christian monks visit the court to offer the Pope's support against the Tatars, though in reality the aim of their visit is to collect the map they have commissioned of the Neva.

The missionaries' audience with Nevskii exemplifies a recurring motif showing the alleged moral superiority of Orthodoxy over Roman Christianity. In addition to delivering the Pope's offer of protection, the monks present Nevskii with a Bible. As he intently thumbs through it, the camera repeatedly pauses on miniatures depicting crusaders. The images show the violent suppression and murder of heathens and adherents of different faiths. The soundtrack mixes Christian hymns and screams of suffering to create the impression that Aleksandr is visualising the events described in the Bible. Suddenly overcome with resolve, he slams shut the book of scripture and reproves the monks for the Pope's worldly politics. Orthodoxy, he tells them, is respectful of other religions and would never attempt to impose itself on peoples of different faiths, let alone force them to convert by military means. $\mathrm{He}$ angrily sends the representatives away and warns that he will no longer receive them in the future. Just as Nevskii is onto the 'true' character of Roman Christianity, he also sees through the Pope's promises. Even if we convert, he proclaims, they will not come to our aid when their military assistance is needed.

Novgorod's enemies in the West take advantage of tensions among Novgorod's boyars. The court is divided about Nevskii's foreign policy, especially regarding his cooperation with the Tatars. His benevolence vis-à-vis the expanding Mongol empire is met with mistrust and is perceived as a serious threat to Novgorod's independence. His reserve in expanding relations with the West is thought to be unfounded and damaging to trade relations. The expansion of their trade interests is indeed the principal motive why the corrupt boyars are cooperating with Von Velven. When they meet with him in an 
underground tunnel, one of them proclaims, 'We seek the Western way of living' - a phrase with an unmistakable contemporary ring to it. When the news comes about Swedish warships approaching the estuary of the Neva, the subversive boyars are proved wrong. Not only have they failed to recognise the true intentions of their Western trading partners and underestimated the military threat emanating from the West, they have wrongfully questioned Nevskii's diplomatic competence in navigating good relations with the East.

The motif of betrayal surfaces in multiple contexts. Aleksandr's closest friend Ratmir violates his trust by falling in love with his bride and is briefly suspected of attempting to poison him. Prince Dmitrii, the son of exiled Prince Iaroslav, infiltrates the Novgorod court and is the true culprit. After his cover has been blown, he returns to his father at the Swedish court and is sworn into knighthood. In return for his allegiance, the Swedes promise to install him on the throne once Novgorod has been taken. The deceptions and betrayals can be read as offering direct parallels with contemporary political intrigues, as becomes clear from Kalenov's choice of words to describe the 'spy detective' component of the narrative: 'We have spies who 'muddy the waters' in Novgorod with the help of local 'oligarchs" (Ramm 2008). One critic took it upon himself to put forward some guesses: 'You can look for heroes of our time in the film characters: the rogue prince - Berezovskii? The corrupt rebel-boyars - the accused in the Iukos case? In fact, even without [such] comparisons one is left with extremely obvious geopolitics' (Liashchenko 2008).

The possibility of drawing such direct analogies notwithstanding, the juxtaposition of Nevskii on the one hand and the corrupt boyars and Prince Dmitrii on the other serves to highlight the difference between those who seek a position of power and those who are actually worthy of occupying one. And only a person worthy of having and exercising power, such as Nevskii, can lead a nation in a wise and morally sound way during times of crisis (this argument resonates with the myth created around the leadership qualities of Vladimir Putin, see chapter 5).

The film premiered in the wake of increasing tensions between Russia and the Baltic states. In Estonia, these tensions escalated in April 2007 following the removal of the 'bronze soldier', a monument dedicated to the Soviet soldiers who died in the liberation of Estonia from Nazi occupation. The relocation of the statue led to several days of rioting in Tallinn and a diplomatic row between Estonia and Russia (Bruggemann \& Kasekamp 2008). Estonia was targeted by an unprecedented cyberattack that caused a shutdown of major governmental information portals and necessitated a complete cut-off from international data flows to restore national access to the Internet (Lesk 2007). The claim of Western countries conspiring against Novgorod further resonates with Russia's contemporary apprehensiveness about the bloc formation of, for example, Poland and the Baltic states within the European Union on policy matters pertaining to EU-Russian relations. Nevskii's accommodating stance on strengthening bonds with the Tatar Horde, then, 
should be read in light of the contemporary rapprochement between Russia and China.

Aleksandr was poorly received by critics. One reviewer remarked that the storyline was as (un)surprising 'as a paragraph in a schoolbook' (Gavrilova 2008). 'One would have liked to see bold historical parallels, and some kind of analysis of events', the critic continues, concluding that acclaimed directors no longer dare to take on such material in the way that Eisenstein had (Gavrilova 2008). The film critic writing for Kommersant was equally unimpressed. In a review humorously named 'Aleksandr Iaroslavich doesn't change confession', a play of words on the Soviet classic on Ivan the Terrible (see chapter 6), she states:

Any ancient battle miniatures, the ones that illustrated chronicles, [...] also captivate not with their refinement of lines, their play with light and shadow and psychological depth, but with their blank expression and naïve unsophistication, allowing the small yellow circle of a nimbus to be painted around the head of a still living Aleksandr Nevskii, galloping on his horse holding a sword, and in that way with a minimum of effort in one stroke convey all of the grand meaning of this figure for Russian history.

(Maslova 2008)

A critic for the website Ruskino.ru welcomed the production of historical Russian films and praised their potential to contribute to the understanding of history among the younger generation (Stepnova 2008). While this alone is enough to demonstrate the value of Aleksandr, the critic reflects, its execution could have been more convincing. She argues that the authors failed to commit themselves to a single characterisation of Nevskii. Their attempt to include all aspects of his multifaceted personality results in an unpersuasive sequence of events lacking motivational coherence and depth. Unlike the first critic quoted above, she feels that one particular historical parallel was actually too explicit:

And the phrase 'There are so many enemies around us' would be more appropriate for a film created in 1938 - at the height of spy mania - than today. (Although, in the grim Stalinist times, Sergei Eisenstein shot a film about a patriot and military commander, and not [a film] about a spy hunt).

(Ibid.)

Those viewers who shared their views online expressed highly diverse opinions, ranging from high praise to crushing critique and everything in between. Some questioned the film's historical accuracy by comparing it to the events as they are described in medieval chronicles.

There are, of course, plenty of absurdities and speculations in the film. It's strange that from the very beginning, Gavrila Aleksich fights on foot during the battle on the Neva instead of hopping on a horse in pursuit of 
the enemies on the Swedish ship, as is reported in the chronicles. Overall it's a historically truthful, patriotic film. Nowadays, films about the struggle of the Russians with foreigners [inozemtsami] are few and far between. I've had enough of all their ethno political correctness.

(tsenitel' istorii 2011)

Others conceded that the patriotic ideals embodied by the narrative make up for these factual shortcomings.

It's a terrific film! We watched it with the whole family, very instructive. It's lively, conveys the historical events pretty well. But most importantly the character of Aleksandr is simply delightful - those are the kind of leaders we need right now! It is exactly because of such godsend people that Rus' managed to survive! I even cannot believe it's a Russian film made with quality!

(Taiso4ka 2010)

And another example: 'We need this kind of film to raise our national consciousness. Brilliant work on the part of the director, screenwriters and actors. BRAVO RUSSIA!' (zlo 2008). Comments about the narrative's truthfulness to historic events at times elicited harsh responses. For example, the comment 'It's a good film: historically reliable, patriotic. Filmed soundly. Watchable' (Mario Puso 2008) received the following reply: 'You are a fool my friend, period! Use your brain!' (meus 2008).

A certain one-sidedness in the depiction of the main hero did not escape viewers' attention.

I didn't like how they portray Aleksandr in an exclusively positive way and as right about everything (this error is made in a lot of films lately). It reminds me of commissioned cinema [zakaznoe kino]. I do not dispute that he was great and all. It's just that anyone who is in power has to occasionally take tough decisions, but they have omitted this and don't show it.

(mig-24 2008)

Other commenters also criticised the somewhat simplistic patriotism; in the words of one commenter: 'Depressing flag-waving [ura-patrioticheskaia] agitation, incompetently done and without ardour. A waste of time' (tourmate 2008). Another commenter complained: 'Again they take us for cattle. As if no one presses a key [on their keyboards, M.W.] and reads the real story about who Aleksandr was on the internet. A catchpenny print style [lubochnaia] story of kvass-patriotism' (Andrei 2013).

Aleksandr: The Neva Battle portrays Nevskii as a morally superior leader amidst corrupt boyars conspiring with the West. Supported by a small circle of faithful men, Nevskii succeeds in exposing the collaborators and staves off 
the Swedish attack. Unlike the boyars who conspire with the West to further their personal gains through trade, Nevskii correctly assesses the threat the European powers pose to Novgorod's political and religious independence. The confrontation between Novgorod and the West is repeatedly and explicitly framed as a struggle to defend the Russian lands against religious expansionism from outside. While the advance of the Mongol horde is no less impending, Nevskii demonstrates a remarkable ability to negotiate beneficial conditions for Novgorod with Eastern peoples. Since Tatar advancement poses no direct threat to the princedom's religious beliefs, unlike with Novgorod's Western enemies, a cooperative approach is deemed to be more fruitful.

The latter argument to a certain extent echoes Eisenstein's Aleksandr Nevskii, where Nevskii proclaims that the danger from the Germans is more pressing than the threat posed the Tatars since it cannot be warded off by paying tribute. Another minor correspondence between the two films is a moment when it is rhetorically asked whether one would sacrifice the 'Russian land' (russkaia zemlia) for the sake of trade opportunities. The major difference lies in the importance attributed to religion in the representation of Novgorod and 'Russian civilisation'; in short, what Nevskii is called to defend. In both films the Western enemy acts explicitly in the name of Christianity and seeks to attain its goals through acts of violence. Unlike in the Soviet representation, where Russian Orthodoxy is featured primarily as a circumstantial aspect of the historical setting, Kalenov's Nevskii is devoted to his faith and acts explicitly in its defence. His diplomatic and military feats are framed in such a way as to bestow upon Nevskii the reputation of not just the defender of the Russian people(s), but the defender of Orthodox civilisation as such.

\section{The Name is Russia (2008)}

From May through December 2008, the Rossiia channel organised and broadcast the cross-media project The Name Is Russia. Through several rounds of online and telephone voting, viewers had the opportunity to elect the greatest Russian of all time. After an initial narrowing of potential candidates from 500 to 12 on the basis of votes cast online, the finalists were judged on their merits in 12 prime-time broadcasts and a final episode. On 28 December, Aleksandr Nevskii was announced the winner. The project, which bore the slogan 'The historical choice of 2008', followed in the footsteps of international precedents, such as the 2002 BBC project 100 Greatest Britons, where Winston Churchill was voted the winner, and the Ukrainian adaptation of the format that saw Iaroslav the Wise being elected the greatest all-time Ukrainian in spring 2008. Several types of interactive media (e.g. online and telephone voting, a website forum, a LiveJournal page) were incorporated into the project design to stimulate social participation in the election. In addition, the online dimension increased its appeal to the younger generation. As a result, the project should be viewed as 'a carefully constructed and 
rigorously manipulated social project that aims to reify and reinforce Russian national sentiment by offering civic platforms of discussion and presentation' (Strukov 2009: 33).

A jury of notable Russians consisting of politicians, scientists and artists represented the 12 finalists. It appears that the final composition of the jury differed somewhat from what was originally intended. In an interview published in July 2008, VGTRK director general Anton Zlatopol'skii indicated that Nikita Mikhalkov had given his preliminary consent to host the show (Bandenko 2008). Aleksandr Liubimov, however, fulfilled the role of presenter in the finals and Mikhalkov took a seat among the members of the jury. Liubimov was first deputy director general of VGTRK at the time and had initiated the project (Strukov 2009: 32). Some last-minute changes occurred with regard to the members of the jury as well. According to Zlatopol'skii, 'Viktor Chernomyrdin will represent Peter the First, Valentina Matvienko will speak on behalf of Catherine the Second. And Anatolii Chubais will make his appearance with us, and many others ...' (Bandenko 2008). Neither Matvienko, then governor of St Petersburg, nor Chubais, who led the process of privatisation in the early 1990s, took part in the finals. The finalists and their representatives are summarised below in order of broadcast.

\begin{tabular}{l|l}
\hline Aleksandr Nevskii & Metropolitan of Smolensk and Kaliningrad Kirill \\
\hline Peter the Great & Viktor Chernomyrdin, Russian ambassador to Ukraine \\
\hline Iosif Stalin & Valentin Varennikov, Army general \\
\hline Dmitrii Mendeleev & $\begin{array}{l}\text { Sergei Kapitsa, professor; vice-president of the Russian } \\
\text { Academy of Natural Sciences }\end{array}$ \\
\hline Aleksandr Suvorov & Sergei Mironov, Chair of the Federation Council \\
\hline Fedor Dostoevskii & $\begin{array}{l}\text { Dmitrii Rogozin, Representative of the Russian Federation } \\
\text { to NATO }\end{array}$ \\
\hline Catherine the Great & Aleksandr Tkachev, governor of Krasnodar Krai \\
\hline Vladimir Lenin & $\begin{array}{l}\text { Gennadii Ziuganov, leader of the Communist Party of the } \\
\text { Russian Federation }\end{array}$ \\
\hline Aleksandr II & $\begin{array}{l}\text { Andrei N. Sakharov, director of the Institute of Russian } \\
\text { History }\end{array}$ \\
\hline Ivan the Terrible & Il'ia Glazunov, artist \\
\hline Aleksandr Pushkin & Iurii Kublanovskii, poet \\
\hline Petr Stolypin & Nikita Mikhalkov, film director \\
\hline
\end{tabular}

With regard to the representatives, the participation of (then) Metropolitan of Smolensk and Kaliningrad Kirill - who thereby represented the ROC on a prime-time TV show - is striking (we will return to his motives for doing so later on). It demonstrates that the producers felt that politicians, artists and 
scientists would be most authoritative in questions concerning national history. The choice of an army general to represent Stalin is informative as it affirms the connection between veterans of the Second World War and the memory of Stalin. Moreover, it is generally known that Varennikov was implicated in the 1991 coup d'état against Mikhail Gorbachev. It is unclear whether the selection of a man with such associations was a conscious decision on the part of the producers, or whether the choice was solely necessitated by the need to find a person of good social standing who was willing to represent the Soviet leader on national television.

The competition sparked international controversy at an early stage when Stalin topped the list in the online voting leading up to the television finals. The programme's production team attributed the apparent popularity of Stalin to the involvement of hackers. They published two messages on the website that explained how the voting system fell victim to a so-called denialof-service attack. ${ }^{25}$ In addition to flooding the computer system with requests that caused it to malfunction, 'massive voting for I.V. Stalin was organised from several internet sources' ('Imia Rossiia. FLOOD ATTACK' 2008). About a week after the event, on $17 \mathrm{July}$, a list of (user) names appeared on the project website. The 22 listed 'villains', the post stated, had 'turned Stalin into a computer virus' ('IMIA ROSSIIA. "TOP 22 NEGODIAIA"' 2008). The user names are nondescript (e.g. 'Grom', 'cyber', 'DND') leading one to ask what effect was intended by publicising this 'list of shame'. Zlatopol'skii has commented on the uproar and has denied the allegation that the producers intervened because Stalin's lead in the polling was making them nervous. He stated:

It would be foolish to argue with the fact that we are talking about one of the most iconic figures in the history of contemporary Russia. The appearance of Stalin among the top positions in the rankings did not surprise us; we were ready for that, what's more, we were expecting something to that effect. [But] it's a different story when at some point the technical means of the voting system cannot cope with the increased attention from the audience, and we even had to suspend the operation of the computers for several hours because failures had begun to occur. In part, the interference was provoked by spammers who undertook a coordinated attack on our website in order to sow chaos and disable the system. We made it clear that we know the real names of the attackers and will not let them behave like hooligans with impunity. Perhaps, you mistook the harshness of our tone for nerves?

(Bandenko 2008)

The first television broadcast, explaining the selection procedure, foregrounded the hacker incident as if to reassure the viewers that the results of the selection process were fair. The incident and the publicity it generated nevertheless undermined the project's credibility and fed into rumours of falsification after the project drew to a close. 
During the televised stage of the election, a conscious effort was made to demonstrate societal resonance. In short video clips, (groups of) individuals described who they were voting for and why. Thus, the programme created the impression that the project was on the minds of the general public and Russian citizens felt personally connected to one or more of the finalists. One of these segments contains a rare explicit acknowledgement that Lenin and Stalin continue to enjoy popular support in some circles. At the beginning of the episode on Catherine the Great, a group of communists in St Petersburg is briefly introduced. They are planning to cast their votes for Lenin, according to the voice-over. However, the icon depicting Stalin that hangs on a wall visible behind them and the fact that they have requested his canonisation by the Russian Orthodox Church suggest that they have yet to make their final choice.

The general dynamics of the panel discussions underscore that the question of how the Soviet past, including its propaganda and historiography, should be valued has proved enduring. While the project may have aimed to determine a new national symbol, it largely turned out to be an occasion for the public to scrutinise the legacy of Soviet narratives of glorification. Because of the diversity of historical figures who reached the competition's final stage, the jury could not avoid evaluating the contemporary relevance of the Soviet past and its heroes (Lenin, Stalin), as well as the Soviet glorification of statesmen from earlier periods of Russian history (e.g. Aleksandr Nevskii, Ivan the Terrible, Peter the Great). Over the course of the discussions, Soviet mythology is deconstructed, the 'true' course of historical events is supposedly revealed on the basis of extensive quotations, and commonly held beliefs about the virtues and vices of these great Russians are challenged so as to establish more 'historically accurate' narratives.

Throughout the series, enduring Soviet characterisations and attitudes towards history are called into question. In the episode on Catherine the Great, for instance, it is repeatedly asked whether Krasnodar should be renamed Yekaterinodar, its name before the Russian Revolution. Certain judges, however, most notably Gennadii Ziuganov, defend the continued honouring of the Soviet canon's heroes - a position that is not without resonance among (part of) the Russian population.

While the discussions mostly revolve around facts and their interpretation, members of the jury at times demonstrate the need to explicitly position themselves in certain ways with respect to the candidate being discussed. In the cases of Ivan the Terrible and Stalin, some jurors appeared uncomfortable with being 'forced' to consider these candidates as potential winners. The apparent uneasiness was most likely prompted by the fact that the group of finalists could be 'split equally' into 'builders' and 'demons', as jury member Sergei Kapitsa remarks in the first episode.

The question is rightly raised how the candidates, especially those from earlier periods, should best be approached. On the one hand, their actions have to be historically contextualised, viewed against the standards and 
circumstances of their day. Consider, for example, how the late Il'ia Glazunov chooses to defend Ivan the Terrible by pointing out that several European rulers of his era were responsible for the deaths of an even greater number of their citizens. On the other hand it is argued that attempts of this sort to reach historical understanding should not downplay crimes and overt acts of cruelty. The question that forms the guiding thread through the project as a whole, therefore, and one that remains unanswered, is: can a tyrant be allowed to be named the greatest Russian of all time? The majority of the jury's members appear to answer this question in the negative, which endows the project with a tension that is hard to resolve. Because if, through a fair and transparent voting process, the audience selects, for instance, Stalin as its winner, then who are these 12 jurors to decide that this is not allowed? It is true perhaps, then, that the only difference between a Russian dictatorship and a Russian democracy is that, with the latter, the people can choose by whom they are exploited, as Mikhalkov jokes in the closing remarks on Ivan the Terrible.

The jury's members struggle to reconcile their understanding of historical greatness with the selection of finalists put before them by the voting audience. With regard to Ivan the Terrible, Viktor Chernomyrdin, for example, expresses his doubts as to whether a majority of the jurors would cast their votes in his favour. Still, he continues, the Russian people did vote for Ivan and this should be respected. The jury's task, he generalises, is to discuss the individuals whom the voters have put before it, not to question the right of any of them to be there. The writer Viktor Erofeev has also touched upon the fundamental difference between the Russian people's understanding of history and that of the so-called educated elite with reference to The Name Is Russia, addressing in particular the popularity of Stalin:

Russian [russkoe] popular consciousness managed to prevail in various spheres and for various reasons because it was not disenchanted by the Enlightenment, and for the elite it was even disadvantageous to free it from its illusions. Therefore our Russian [rossiiskoe] popular consciousness reacts entirely differently to historical figures than European [consciousness]. And we, as elites, [react] half this way, half that way because we arose from the people - some up to the knee, some up to the waist. [...] The popular self-consciousness greatly appeals to me: it is built on imagination, on the negotiation of history. But it becomes monstrous once we land in our reality.

(Buntman 2009)

One of the most insightful explanations for Ivan the Terrible's place (and that of several other candidates) among the final 12 is put forward by jury member Sergei Kapitsa. He argues that it signals the existence of a 'spiritual vacuum' and deep-rooted difficulties with the adequate understanding of one's national history. Kapitsa draws attention to the tendency to impose 


\section{Case studies}

contemporary value judgements onto the past and to let historiography be guided by 'historical feeling' rather than by the search for truth. In an apparent attempt to redirect the course of the discussion, Kapitsa concludes that the jury is guilty of this very tendency in its attempts to somehow justify the fact that Ivan the Terrible had been chosen. Mikhalkov's closing remark that, in judging such a complex historical figure, one should trust one's gut feeling (literally, 'inner tuning fork') demonstrates the accuracy of Kapitsa's observation. As the judges repeatedly proclaim that the jury's task is to try and understand why the public voted for these candidates - in other words, as they attempt to bridge the gap between their understanding of exemplary historical figures and the understanding of those who have cast their votes - it becomes increasingly clear how great the distance is between the public and this particular jury.

\section{Aleksandr Nevskii}

The television broadcast phase of the project opened with a discussion of the candidacy of Aleksandr Nevskii. Eloquently and charismatically, Metropolitan Kirill delivered a plea in favour of the Prince of Novgorod in which the challenges of Nevskii's rule were interwoven with considerations of contemporary political and societal issues. In various interviews he has elucidated the motivation behind his participation on the jury. In addition to supporting the basic tenets of the project, Metropolitan Kirill felt it imperative to have the Russian Orthodox Church represented on the show:

And, of course, in such a discussion about iconic names in Russian history the voice of the Orthodox Church, whose role in the creation of Russian civilisation and Russian culture is eminent and undisputed, should necessarily be heard.

("Postizhenie Rossii, ili Otkrytyi urok grazhdanstvennosti", 2008)

Television was familiar terrain for Metropolitan Kirill. Since 1994 he has hosted the programme The Pastor's Word (Slovo pastyria), which continues to be broadcast weekly on Channel One. Nonetheless, Kirill felt it necessary to receive the blessing of Patriarch Aleksii II before he agreed to participate in The Name Is Russia and represent the views of the ROC within a non-religious television format.

[The Name Is Russia] is a discussion, and upholding my position could well be accompanied by a certain tension in the dialogue with others. But the Church is called not to divide, but to unite. And therefore I thought, do I have the right, as metropolitan, a hierarch of the Russian Church, to enter a discussion that could divide people? And, unable to find an answer, I turned to His Holiness Patriarch Aleksii. After he heard me out, he answered immediately. His Holiness the Patriarch did not always 
answer immediately. [...] But here, to my surprise, he immediately said, with a kind smile: 'Lord [Vladyka], you should definitively agree - you have to defend Aleksandr Nevskii.'

('V preddverii Novoletiia i Rozhdestva Khristova Mestobliustitel'

Patriarshego Prestola vstretilsia s radiozhurnalistami i predstaviteliami informatsionnykh agentstv' 2008)

In addition to his conviction that Aleksandr Nevskii should be named the greatest Russian of all time, the saint's memory appealed to Metropolitan Kirill on a personal level. He had spent a great part of his life in St Petersburg and would often 'have recourse to his heavenly intercession' in prayer at the Aleksandr Nevskii monastery, where the saint's relics are interred ("'Postizhenie Rossii, ili Otkrytyi urok grazhdanstvennosti"' 2008). Furthermore, it was at the St Petersburg monastery that Metropolitan Kirill received his ordination to the priesthood.

Host Aleksandr Liubimov introduces Nevskii as 'warrior, ruler, a symbol of courage [and] fortitude'. The introductory video clip that follows establishes the parameters for the discussion that ensues: a clash of (ideologically informed) interpretations of distant history. Against a soundtrack of resounding church bells, the voice-over begins: 'Everyone knows St. Aleksandr Nevskii from Soviet cinema. A noble commander, illustrious warrior ... but by no means a saint.' Accompanied visually by fragments from Eisenstein's Aleksandr Nevskii, the narrator recounts the political realities of the thirteenth century and the real Aleksandr Nevskii: this was an era characterised by a battle of all against all, including the Russian rulers themselves. In their rivalry the princes where guided by interests other than attaining the ideal of the Orthodox nation. The Battle on the Ice, as the best-known event associated with the memory of Nevskii, receives particular attention. Eisenstein's representation of the battle scene is superimposed on the image of a frozen lake smeared with blood. The soundtrack and intonation of the narrator build up to create heightened suspense.

The clip argues that Nevskii's politics aimed to establish control over the Russian lands in order to unite them in a single state. His cooperative stance towards the Horde was based on his pragmatic consideration of what was beneficial for Russia, regardless of what he himself could stand to gain from the alliance. His willingness to forego opportunities for personal benefit influenced the moment when Nevskii assumed the role of monarch: Nevskii's accession to the monarchy only towards the end of his life was not due to any disinclination on his part, the narrator asserts, but reflected his reluctance to allow himself to assume such a position of luxury. The video segment concludes by asking what remains of the historical figure of Nevskii in the various representations and interpretations of his rule that have since developed. Of greater importance, however, than uncovering the historical truth within these narratives of memory, the narrator continues, is an acknowledgement that Nevskii - in all the facets of his character - is remembered today. In a 


\section{Case studies}

somewhat surprising turn considering the clip's opening sentence, the final lines proclaim that the true essence of Aleksandr Nevskii lies in his relation to God. A portrait of Nevskii as saint and a sudden transition from minor to major key in the musical score affirm the divine connotation.

In his opening plea, Metropolitan Kirill presents Nevskii as 'the saviour and builder of Russia'. A leader, moreover, who does not require rehabilitation or defending - like some of the other finalists - since all the stories about his feats known to the Russian people are laudatory. Yet, Metropolitan Kirill continues, the challenge lies in conveying his contemporaneity to a modern audience. What sets Nevskii apart is the multifacetedness of his persona. The plea summarises his merits as a 'supreme strategist' - a politician, ruler, philosopher and military commander. In the opinion of Metropolitan Kirill, Nevskii's contribution to Russian history could not have been more decisive; in fact, without him Russia and its 'civilisational code' would not exist today. He recognised the imminence of the threats posed by expansionary foes from East and West alike but, instead of fighting against these adversaries, Metropolitan Kirill argues poetically, he fought for the preservation of national identity and consciousness. Nevskii succeeded in doing this by adopting a 'delicate, courageous diplomacy' that sought to accommodate the Tatar Horde rather than take on an opponent that was too mighty to conquer. He correctly understood that Tatar expansion was economically motivated and would therefore have a limited impact on Russian society, whereas Western expansion was not just economically, but politically and religiously motivated. Metropolitan Kirill asserts that with respect to these enemies, whose expansionist aims included the subjection of Russian civilisation to their cultural norms, Nevskii allowed no compromise. Creating a clear contrast with modern society's capitalist values, Metropolitan Kirill emphasises how the prince chose to sacrifice wealth in order to preserve his people's fundamental values. $^{26}$

Besides saving Russian civilisation from impending ruin, Aleksandr was exceptional in strength, wisdom and physical appearance. He was a young and handsome man, Metropolitan Kirill proclaims, with no equal in the Bible. Yet Nevskii's most important virtue is his sanctity. Indeed, Metropolitan Kirill asserts, if Russian history had seen a larger share of saintly rulers, its course would have been markedly different. The plea takes an interesting turn when Metropolitan Kirill proceeds to argue that, through his skilful engagement with the East, Nevskii laid the groundwork for a multiethnic society - a claim he reasserts later on. The prince's policies with regard to international relations and the interaction among ethnic groups formed the basis for Russia's later development as a large state. In other words, it is with Nevskii that the Russian imperial state, with its primacy of Orthodox Russians among other peoples inhabiting the same land, has its origin. ${ }^{27}$

When Nikita Mikhalkov, as chair of the jury, asks Metropolitan Kirill to further elucidate the contemporary relevance of Nevskii, the latter draws an unexpected parallel between the symbolic importance of the Battle on the 
Neva and current Russian involvement in the military conflict between Georgia and Abkhazia. Nevskii should be understood as a 'post-Perestroika ruler', he states, though the Perestroika Nevskii had lived through was far more invasive and bloody than its contemporary analogue, involving the complete loss of the Russian state. Then, large states had disintegrated and their peoples become weakened and demoralised, he continues, and this still occurs. The sudden appearance of Nevskii, who took on the Swedes and managed to defeat them, had a tremendously positive effect on Russia's confidence in its own strength and ability to defend itself. Metropolitan Kirill then proceeds to introduce the contemporary parallel, but fails to make the exact point of comparison explicit. He states that Russia now finds itself in a period when it is accumulating potential strength. This amassing of power is aimed not at waging war and pursuing territorial expansion but at evolving into a great power. Whereas great power status is usually understood in military and economic terms, here it is equated with being a powerful spiritual organisation. A great Russia, Metropolitan Kirill continues, will serve as a centre of civilisation within the globalising world.

A second historical parallel is then invoked: the incessant endeavours of representatives of Western Christian civilisation to influence, dominate and ultimately destroy Russian civilisation. Sergei Mironov links the memory of Nevskii to the enduring debates about whether Russia should orient itself eastwards or westwards and concludes that European Catholic civilisation has been putting Russia under pressure for centuries and continues to do so today. Here, a comparison with the conflict in Georgia is made once more. Ziuganov argues that Roman popes deliberately tried to change Russian civilisation. Today, he claims, the West continues to act along the same lines. Ziuganov recounts a visit to Strasbourg (attending, most likely, a meeting of the Council of Europe) where, he claims, some sixty delegates directed accusations at Russia because the president of Georgia, Mikheil Saakashvili, backed by the United States, had initiated a war against Russia.

Despite Metropolitan Kirill's persistent attempts to steer the discussion in the direction of a multifaceted but first and foremost saintly memory image, the image of Nevskii as military commander is repeatedly emphasised. The established Soviet narrative and its emphatic visual portrayal appear to be inescapable, even among a jury of educated men. The discussion explicitly touches upon the difficulty of separating the man from the myth: who exactly have the viewers voted for and whose merits should the jury judge? Being furthest removed in time, Nevskii appears more a mythic figure than a fleshand-blood individual - like the Russian bogatyrs, as Aleksandr Tkachev points out.

Several commentators have claimed that the results of the popular voting were falsified, not by hackers, but by the project's producers themselves. Liubov Borusiak has demonstrated how the leaders of the project not only tried to influence online voting in the first stages of the competition, but actually manipulated results (by declaring invalid a large number of votes for 


\section{Case studies}

Stalin because of the alleged hacker involvement), as well as selecting and shaping the image of Nevskii, the eventual winner, to fit their desired vision of Russian identity (Borusiak 2008). Even if the voting results were not falsified, the deliberate way the project was set up (the selection of representatives, the programming of the episodes) appears to have affected its outcome. This line of argumentation has been put forward, for instance, by Anatolii Golubovskii:

The viewers, who, from the first programme of the series (Aleksandr Nevskii), were impressed by the rhetoric of Metropolitan Kirill, were [merely] waiting for the concluding benefit performance by Mikhalkov (Stolypin). They poorly remembered everything that happened in between the first and final programmes. [...] They remembered the first hero because he was first, the last one because he was last. Their representatives were Metropolitan Kirill and Nikita Mikhalkov, the most vivid and distinct participants of the project, who were the evident leaders among the jury. As a result: Nevskii in first place, Stolypin in second. And in third place came Stalin - some kind of compromise to the real leader in public opinion. The sequencing in the format worked neatly in this case.

(Golubovskii 2009)

In a similar vein, Nikolay Golev and Olga Yakovleva have argued that 'the project results are not identification of the Russians' real attitude to a historic character but their attitude towards the project and its participants' (Golev \& Yakovleva 2012: 1840). The death of Patriarch Aleksii II on 5 December 2008 , as the project was drawing to a close, may have been a further impetus to vote for (Saint) Nevskii.

The Name Is Russia project, and the societal questions it represented, sparked discussion in both traditional and new media. Several counterprojects soon emerged online, demonstrating both the general appeal of its underlying idea - determining a contemporary cultural memory vocabulary for Russia and the disappointment with or distrust of such an election run by a state TV channel. The website Russia without a Name (Bezymiannaia Rossiia) set out to prove that the online voting results were manipulated (Strukov 2009: 38). ${ }^{28}$ Anti-Name of Russia (Anti imia Rossii) used the same preliminary list of 500 names but asked people to vote for the biggest antihero of Russian history. This resulted in a top three consisting of Boris Yeltsin, Vladimir Lenin and Iosif Stalin ('Anti imia Rossii' n.d.). The Shame of Russia (Pozor Rossii), created as a negative counterpart to the original project, gave users the option of adding candidates without any restriction. Its top three names were Vladimir Putin, Minister of Emergency Situations Sergei Shoigu and Berl Lazar, the Chief Rabbi of Russia ('Vse kandidaty' n.d.). The Name of Russia - The Historical Choice of Russia (Imia Rossii - Istoricheskii vybor Rossii) allowed its users to vote for not one but two categories and yielded quite different 
results, in part because it also listed living persons. The 'Glory of Russia' category was headed by scientist Viktor Skumin, the former special forces commander Cheslav Mlynnik, and Stalin. The category 'Shame of Russia' was won by a large margin by the president of Belarus, Aleksandr Lukashenko, followed by Vladimir Putin and St Seraphim of Sarov. ${ }^{29}$ What is particularly interesting is that many names appear on both lists, which reflects a lack of societal consensus. Viktor Skumin, for example, also occupies fourteenth place in the 'Shame' rankings, while St Seraphim takes seventh place among the most glorious persons of Russian history. The administrators described the project as follows:

'The Name of Russia' is an open project for those who are not indifferent to history, tradition, faith and the future of their Fatherland. Today, too many people want to turn Russia into a faceless unity of citizens, concerned with just one objective - the objective of personal enrichment. Acting in this manner, these betrayers of their own people attempt to depersonalise Russia. And it would seem there is no possibility to interfere with their plans. But we say: Enough! The Name of Russia is Personality and National self-consciousness.

('Imia Rossii' n.d.)

They also expressed the concern that the television project, as well as the politically oriented online counterprojects (expressing, e.g., 'leftish' views on history) may well serve to divide rather than unite society. Finally, the website The Names of Russia - The Historical Choice of ... (Imena Rossii - Istoricheskii vybor ...) has produced yearly rankings since 2009. In many ways, it is an unofficial continuation of the television project except that there is no predetermined shortlist of names and users are free to vote for any person they deem worthy of representing Russia. The resulting top ten is first and foremost a collection of popular cultural figures and professional athletes. The 2009 rankings list singer Vitalii Grachev, cultural icon Filipp Kirkorov and hockey player Aleksei Cherepanov as its top three ('TOP-100 reiting saita "Imena Rossii" za 2009 god' n.d.). The only politician who made it into the top ten is Dmitrii Medvedev, in fifth place.

In retrospect it can be said that the project did not succeed in the difficult task of electing a new symbol for Russia while navigating the difficulties involved in any genuine discussion of the many facets of Russian history. Mikhail Morozov argues that, precisely because its format eschewed acknowledging the actuality of uncomfortable or painful questions, the project should be regarded as 'amoral'.

The laws of the talk show genre do not suit such a delicate, morally sensitive matter like history, moreover a recent history where the victims of Stalinism or their children are still alive. In the broadcast about Stalin one of the judges begins: 'Stalin was a genius ...' - the audience bursts 


\section{Case studies}

into applause - 'a genius of villainy' - [and] the applause continues as if nothing happened.

(Morozov 2009)

With the audience and the jury locked in fundamental disagreement, The Name Is Russia was unable to reach a convincing verdict.

Yet the project did receive an enormous amount of media attention and thereby greatly familiarised the general public with the historical figure of Nevskii. Metropolitan Kirill has given his view on how the outcome of the programme - its election of Nevskii - should be interpreted:

I viewed this project as the moral orientation of our whole society. We say that we are an Orthodox people, an Orthodox country. But how do we define this, how do we identify [ourselves]? I believe that the votes of almost 50 million people attested that, miraculously after so many years of godlessness and the destruction of sanctities, precisely sanctity remains the dominant value of our people. Indeed, when we call Rus' holy we speak in the first place about a system of values in which sanctity was the characterising moral dominant, prevailing over all other values.

('V preddverii Novoletiia i Rozhdestva Khristova Mestobliustitel' Patriarshego Prestola vstretilsia s radiozhurnalistami i predstaviteliami informatsionnykh agentstv’2008)

In a somewhat contrived turn in his argument, he further claimed that people of all faiths voted for Nevskii, and that this should be interpreted as a promising sign for Russia's future:

Therefore I am thankful for those who supported the name of Aleksandr Nevskii - both Orthodox persons, Muslims, adherents of other faiths and atheists - who in their hearts felt that if we elect Aleksandr Nevskii as the name of Russia, we will have a future.

(Ibid.)

In the opinion of Metropolitan Kirill the project's importance, therefore, was its contribution to collective memory formation, since memory is what will bind together the various peoples of Russia.

\section{Conclusion}

The cultural memory of Aleksandr Nevskii has a long and rich history of remediation and political appropriation that has culminated in a varied spectrum of memory images. Interpretations of Nevskii as statesman, saint, military commander and so on have ebbed and flowed subject to contemporary needs of symbolic state formation. Since Perestroika, the ROC has actively stimulated a revival of Nevskii - to be precise, a revival of an Orthodox 
interpretation of the historical figure that draws upon pre-revolutionary cultural memory. The saintly image of Nevskii aimed to counter his place in Soviet memory culture, which emphasised his military achievements. The memory of Nevskii provided a suitable vehicle to historically found the idea of Russia as a traditionally Orthodox state and legitimise the increasingly close relations between the ROC and the Russian state. The ROC has been a driving force behind and consistent partner in state-supported efforts to acknowledge the contemporary relevance of Nevskii and popularise his memory. In the memory of Nevskii the ROC and the Ministry of Foreign Affairs have found common ground to help spread their vision of Russia's active role in a globalised world, in particular with regard to the extension of influence within the so-called Near Abroad. In official memory culture, Nevskii has come to represent a new strand of state patriotism that carries an Orthodox overtone. His memory is connected to an understanding of Russia as a civilisational stronghold within a globalising and secularising world, and Orthodox Russians as benevolent primi inter pares within the Russian state. The Nevskii memory was shaped to engage with the established discourse of distrust of the West and to relate to contemporary political issues, such as the challenges posed by the political, cultural and confessional accommodation of national minorities.

Within the cultural domain, 2008 was a watershed year in the (re)popularisation of Nevskii with the general public. Analysis of the historical blockbuster Aleksandr: The Neva Battle and the much discussed Channel One cross-media project The Name Is Russia has demonstrated the opportunities provided by remediation. Yet it also proved how a history of remediation can restrict attempts to change existing historical understandings. Whereas active remediation of established visual and narrative elements enhances recognisability, it also creates expectations. Both productions testify to a deliberate effort to consolidate an understanding of the Russian state as traditionally Orthodox. This effort links up with and revives the pre-revolutionary tradition of remembrance. Yet this line of interpretation clashes with the persistent Soviet memory tradition, as was particularly evident in the panel discussion on The Name Is Russia. The visual and narrative components of the Soviet myth as it was shaped on the eve of and during the Second World War including distinctive scenes like the Battle on the Ice - continue to inform contemporary understandings of Nevskii's contribution to Russian history. As a result, multiple interpretations coexist, to a certain extent merging into a composite memory that can be viewed as an Orthodox reframing of the predominantly military Soviet myth.

Aleksandr Nevskii has been used to propagate notions of preservation and restoration rather than reform and modernisation, as was the case with the memories of Petr Stolypin, discussed in the previous chapter, and the Time of Troubles, the topic we will turn to in the chapter that follows: the restoration, specifically, of the great Orthodox Russian state, tasked with protecting Russian (Orthodox) civilisation against Western cultural encroachment. 
Therefore, Nevskii's recent prominence is an early manifestation of the shift to an increasingly conservative political orientation that followed Putin's election for a third presidential term in 2012. The political endorsement of the eight hundredth anniversary celebration of Nevskii's birth in 2021 should be viewed in light of these neo-conservative views on the Russian state and the dramatically increased stress placed on 'traditional' - that is, Orthodox - societal values and on Orthodoxy as a marker of national and state identity.

\section{Notes}

1 Archimandrite Tikhon is generally presumed to be Putin's confessor.

2 This claim has, however, been questioned by historical research. See Schenk (2004: $50)$.

3 Notably, Peter the Great, Dmitrii Donskoi, Kuzma Minin and Dmitrii Pozharskii.

4 Located in the Kazan Cathedral.

5 The film and its production history have been extensively studied, see, e.g., Bartig (2013): 74-104; Morrison (2009): 217-246; Dobrenko (2008); O’Mahony (2008): 160-174; Taylor (1998): 85-98; Goodwin (1993): 156-178.

6 The programme furthermore included the films Minin and Pozharskii [Minin $i$ Pozharskii] (Pudovkin \& Doller, 1939); Andrei Rublev [Andrei Rublev] (Tarkovskii, 1966); Iaroslavna. Queen of France [Iaroslavna, koroleva Frantsii] (Maslennikov, 1978); Tsar [Tsar'] (2009, Lungin) and a selection of contemporary animation and documentary films.

7 Released internationally under the name XIII Century: Blood of Europe.

8 The name 'Rusich' is an archaic, poetic term to refer to the inhabitants of Rus'.

9 Released internationally under the name Real Warfare: 1242.

10 Accessed 13 December 2015, http://ruscomix.ru/index.php?do=cat\&category= inok.

11 These factions can be roughly divided into three groups: 'the traditionalist group that advocates a political ideology of orthodox statism and that overlaps in important ways with the formal positions of the patriarchate; the fundamentalist wing, which is clearly xenophobically nationalist in its orientations; and the liberal wing, which is markedly pro-western and supportive of liberal democracy' (Papkova 2011: 19).

12 On debates about the internet and 'digital anxiety' within the ROC, see Suslov (2015).

13 This is the result of, e.g., internal fragmentation, low attendance of Church services and repeated scandals that have damaged its reputation.

14 Mitrokhin puts forward the example of the 'Orthodox Encyclopedia' project: 'Having received financing from the budget of the Russian Federation in the 1990s for the publication of a research encyclopedia on Orthodoxy, the project in the 2000 s developed into a huge internet project, and then into becoming the main supplier of Orthodox content for television, all at government expense. Currently all of the Church's research and part of the Moscow Patriarchate's media resources are being financed through this project' (Mitrokhin 2009: 308).

15 On the ROC, patriotism in a broader sense and local patriotic church practices, see Rousselet (2015).

16 For a detailed account on the history of the Cathedral of Christ the Saviour - its founding, destruction and reconstruction - see, e.g., Garrard and Garrard (2008): $70-100$. 
17 Other attempts to investigate and pay tribute to those who fell victim to Soviet repression, such as the activities of the Memorial Society, have repeatedly come under pressure from state authorities. More recently, the state has signalled a minor shift in its stand on the matter: a monument to commemorate the victims of political repression in Russian history, entitled 'The Wall of Grief', was unveiled in Moscow on 30 October 2017, the annual Day of Remembrance of the Victims of Political Repressions.

18 Patriarch Aleksii II endowed his blessing on several other films as well, including the documentary The Life of Saint Sergius of Radonezh [Zhitie prepodobnogo Sergeia Radonezhkogo] (Novikova, 2005); Pavel Lungin's The Island [Ostrov] (2006); and, the animation film Prince Vladimir [Kniaz' Vladimir] (Kulakov, 2006) (Norris 2013:178-179, 219).

19 Traditional Russian felt boots.

20 In a response to the filed complaint, Il'ia Oleinikov, one of the show's hosts, ridiculed that if indeed their item about Nevskii was impermissible because of a violation of the feelings of Orthodox believers, they should also be sued by the Ministery of Defence for dishonouring the military, 'since in the item they are so poorly dressed' ('Veruiushchie vorvalis' v "Gorodok"' 2006).

21 The touring exhibition was organised by the 'Aleksandr Nevskii' programme and, among others, was exhibited in the Cathedral of Christ the Saviour, the Pskov kremlin and the Church of All Saints in Yekaterinburg.

22 The name of the show is often translated as The Name of Russia even though this is gramatically incorrect. The choice is understandable since The Name Is Russia (Imia - Rossiia) is awkward in both English and Russian and was, in fact, heavily criticised.

23 Nikola Film previously produced art house films such as Kira Muratova's Chekhovian Motifs [Chekhovskie motivy] (2002) and Passions [Uvlechen'ia] (1994), Aleksandr Sokurov's The Sun [Solntse] (2005) and Father and Son [Otets $i$ syn] (2003), and 1990s cult classic Peculiarities of the National Fishing [Osobennosti natsional'noi rybalki] (Rogozhkin, 1998).

24 With a budget of 8 million dollars, Aleksandr earned 2.9 million dollars in box office returns in Russia ('Aleksandr. Nevskaia bitva' n.d.).

25 A denial-of-service attack is an attack aimed at the interruption or suspension of services of a website or network by sending a massive number of requests to a server that causes it to overload.

26 At this point, Metropolitan Kirill invokes the Russian philosopher Lev Gumilev to support his argument. He states that the protection of the will of the people was a necessary condition for Gumilev's 'ethnogenesis' to take place. On the traces of the philosophical concepts developed by Gumilev that can be found in the views expressed by Patriarch Kirill, and in particular how they relate to the concept of 'Holy Rus", see Suslov (2014).

27 The plea bears resemblance to the concept of "Holy Rus", which Metropolitan Kirill has since placed at the centre of his vision as patriarch of the ROC; see Suslov (2014).

28 At the time of writing the website was no longer hosted at the original url www. unnamedrussia.com, nor available in cache.

29 Rankings consulted on 9 October 2014. On the memory of St Seraphim of Sarov in post-Soviet Russia, see Garrard \& Garrard (2008). 


\section{The Time of Troubles: The cyclical return of chaos}

In the run-up to the presidential elections of 2012, a music video by the Tajik singer Tolibzhon Kurbankhanov went viral and collected more than 1.5 million views on YouTube in less than a month. The song, entitled 'V.V.P.' in reference to Putin's initials, praises the accomplishments of Russia's 'saviour'. The lyrics of the song perfectly sum up the central message of Putin's (memory) politics: 'VVP - saved the country / VVP - protects / VVP - picked Russia up [from its knees] and continues to develop it / VVP - saved the nation / VVP - guards / VVP - while in power, he maintains stability'. Indeed, the song was such a smitten homage that members of the opposition first thought it was a well-executed parody. The clip gave rise to heated online discussion, focused on identifying who was behind the propaganda stunt: the Putin camp or its opponents. In an interview with Izvestiia, Kurbankhanov maintained that the song was sincere and that he had recorded it on his own initiative. ${ }^{1}$ He was, in fact, taken aback by the song's reception:

I did not expect a negative reaction; I wrote from the soul, what I had on my heart. [...] And then they say some headquarters [shtaby] paid me money for the clip. I read in your newspaper that someone even filed a complaint against me because I defamed Putin. For me this is very insulting to hear!

(Maetnaia 2012)

The inspiration for the song, he continues, came from witnessing the street protests in Moscow in late 2011: 'I stayed with friends in Moscow in December, watched these meetings of yours on Bolotnaia [Square] and [Prospekt] Sakharova and wondered: how can you protest against a person like Putin? He is very wise, modest, behaves with great dignity' (ibid.).

In an almost overly laudatory, over-the-top way, Kurbankhanov's lyrics rephrase the essence of what can be called the Putin myth: 'Let us remember those years / When he was not there - there were only worries / The country in crisis, the people suffered / And at that moment, God sent him.' Memory politics has played an important role in consolidating this image of Putin as the national saviour and guarantor of stability. The cultural memory of choice 
for its framing has been the seventeenth-century Time of Troubles, or smuta. As we have seen in chapter 3, the memory of Petr Stolypin was used to support a comparable notion during the final stage of Medvedev's presidency, as the political regime moved from consolidating its position of power towards maintaining it.

The political appropriation of the memory of the Time of Troubles aimed to turn a period in recent history, the 1990s, into a powerful rhetorical tool by framing it in historical terms. The political myth that was created represents the Yeltsin era and its political, economic and social upheavals as the latest chapter in a historical sequence of recurring systemic crises (smuty). The Putin regime could thus characterise the contemporary political situation as the end of the Troubles of the 1990s. As Sander Brouwer rightly points out,

by recycling the narrative of the 'Smuta-and-ensuing-liberation-in-1612' the government is not only positioning itself as the new liberators of Russia (with which you can agree or disagree), but, moreover, is presenting a model of history in which its own emergence is presented as predetermined.

(Brouwer 2016b: 133)

The effect of this framing, however, goes beyond attesting to the effectiveness of Putin's political strategy during his first term as president and thus strengthening the regime's legitimacy. The conceptualisation of post-Soviet collapse as a Time of Troubles symbolically reintegrates the Soviet period into an all-encompassing meta-narrative of Russian history that is characterised by alternating periods of glorious might and turbulent upheaval. In this metanarrative, the Soviet period is just one variation on the historical theme, another link in the chain of Russia's cyclical history. As will become clear from the subsequent analysis, the ad hoc transformation of this recent period in history into cultural memory was facilitated by the rich remediation history of narratives about the Time of Troubles. At the same time, the same accumulation of memory texts created access points for the formulation of historically framed political critique.

The memory of the Time of Troubles is typically singled out as the central tenet of contemporary Russian memory politics in the period under discussion here, in addition to the political establishment's constantly shifting attitude towards Stalin and the Soviet past more generally (e.g. Prozorov 2008; Laruelle 2009; Vázques Liñan 2010; Hill \& Gaddy 2012; Petersson 2013). While this claim is correct, these studies have thus far largely ignored two important aspects. First, they fail to address how the political usage of the memory has evolved over time and how it relates to other circulating memories. Second, they omit the reception of the institutionalisation of the memory and its associated cultural products, and insufficiently acknowledge attempts by other actors to subvert official memory culture. This chapter aims to address these gaps. It first outlines the remediation history of narratives 


\section{Case studies}

associated with the Time of Troubles from the seventeenth century to the present. Then, it examines the institutionalisation of the memory and the documentaries and film produced to support it. The chapter concludes with a study of the film Boris Godunov (Mirzoev, 2011) as an example of a subversive remediation that aims to question official memory culture.

\section{The Time of Troubles in the Russian political and cultural imagination}

With the death of Ivan the Terrible's son Fedor in 1598, the ruling Riurikid line came to an end. The succession crisis set the stage for a power vacuum to emerge some years later as the rule of the elected Tsar Boris Godunov, who had previously served as Fedor's regent, came increasingly under pressure as a result of famines (1601-1603) and rivalries among the boyar families. While opinions differ about the exact duration of the Time of Troubles, its beginning is generally dated to the invasion of the First False Dmitrii in 1604, which presented a serious challenge to the legitimacy of Godunov's rule, and Godunov's sudden death the following year. The period was characterised by anarchy and constant power struggles that had detrimental effects on the life, security and well-being of the population. There were numerous pretenders to the throne, most notably the three 'False Dmitriis', each of whom claimed to be the miraculously saved son of Ivan the Terrible. The young tsarevich had died in 1591 - according to the official version, from self-inflicted knife wounds during an epileptic fit, though the responsibility for Dmitrii's death is often ascribed to Godunov. As the political situation was constantly changing, the boyar families vied to maintain and expand their political influence, continually shifting alliances. Finally, the course of events was influenced dramatically by political interference by the Swedes and the Poles. The latter eventually succeeded in placing Prince Wladislaw, the son of King Sigismund of Poland, on the throne. The (symbolic) end of the Troubles is typically dated to 1612, when a people's militia led by Prince Dmitrii Pozharskii and Kuzma Minin, a butcher from Nizhny Novgorod, succeeded in liberating Moscow. The following year, 16year-old Mikhail Romanov was elected tsar by the Zemskii sobor. Since his father was the nephew of Anastasiia Romanova, Ivan the Terrible's first wife, his lineage made Mikhail a highly suitable candidate for the throne. Political and social unrest nevertheless continued for several years after the tsar was crowned. Only in 1617 was a peace treaty signed with Sweden and the city of Novgorod returned to Russia. Troubled relations with the Poles persisted even longer, including yet another (this time, unsuccessful) attempt to seize the throne in 1617.

The memory of the Time of Troubles supports a cyclical conception of historical development because, despite having a revolutionary component, it did not result in actual changes in governmental administration. As Maureen Perrie points out, it was a conflict

fought out under the banners of competing claimants for the throne, rather than of competing types of monarchy. Of course the various 
candidates represented different styles and systems of rule; but they all based their claims to the throne on their legitimacy as the 'true' tsar rather than on any programme of social or political reform.

(Perrie 2006: 430)

The symbolic potential of the Time of Troubles has been recognised by many rulers, all seeking to employ it to their advantage. Equally, the events have inspired many Russian artists. The complexity of the events and the multitude of actors has made the memory of the Time of Troubles and the 'archive' of its representations highly diverse. It is best described as a memory cluster, consisting of multiple, mutually interdependent narratives (see also chapter 2). Over time, new narratives have been added, while others have fallen into disuse or been explicitly challenged or rewritten as political and ideological preferences shift. Within the existing accumulation of stories, paintings, statues, literary works and other memory texts on the Troubles, three core thematic topoi can be discerned. The first is the struggle between Boris Godunov and the False Dmitrii. The second concerns the peasant Ivan Susanin, who sacrificed his life by leading the Polish troops in their search for Mikhail Romanov into the forest under false pretences and thereby saved the newly elected tsar from certain death. In these narratives, Susanin was made a symbol of patriotism and devotion to the tsar. The third line of narration describes the popular uprising led by Minin and Pozharskii and the expulsion of the Polish-Lithuanian occupiers from Moscow in 1612. This narrative is closely connected to the symbolic canonisation of the year 1613 as the founding moment of the Romanov dynasty, the anniversary of which was celebrated, for example in 1913 and, somewhat awkwardly, in 2013.

Not long after state order was restored, a commemorative practice to mark the ending of the Troubles was established. Pozharskii financed the construction of a wooden church on Red Square dedicated to the Virgin of Kazan, to whose icon he had prayed during battle. A religious procession was held annually on 4 November, the feast day of the Icon of Our Lady of Kazan. Kazan Cathedral, as it is now known, was later replaced by a brick church and after several expansions and alterations was finally demolished in 1936 as Red Square was adapted for the presentation of military parades. The church was rebuilt between 1990 and 1993. The image of the Time of Troubles as a symbolic representation of the survival of the Russian state in the face of foreign aggression took definite hold in the first three decades of the nineteenth century. While earlier artistic works had been dedicated to, for instance, the figure of Pozharskii, Russian involvement in the 1806/7 war with Napoleonic France gave the memory effort particular impetus. Artists such as Gavriil Derzhavin, Sergei Glinka, Matvei Kriukovskii and Sergei Shirinovskii-Shikhmatov contributed to a body of poems and tragedies describing the liberation of Moscow. The period started to be viewed as a 'key event in national history', gradually eclipsing the perceived importance of the rule of Peter the Great (Zorin 2001: 161). Indeed, '[i]n the first half of the 1830s 
Minin and Pozharskii's march on Moscow and the Zemskii sobor of 1613 were canonised definitively as the mythological genesis of Russian statehood' (idem: 161).

The most visible monument to the events, the statue of Minin and Pozharskii on Red Square, also dates from this period. It was initiated by the Free Society of Lovers of Literature, Science, and the Arts in 1803. The organisation proposed erecting a monument in Nizhny Novgorod, where the people's militia was formed, to commemorate the 200th anniversary of the liberation of Moscow. In 1808, Tsar Aleksandr I gave his approval for the monument, but, because of the great historical importance of its subject, it was decided to erect the statue in Moscow instead. The victory over the Napoleonic army in 1812 imbued the statue with even greater patriotic significance. The bronze statue of the two heroes, which would become a symbol of the victory in the Patriotic War, was finally unveiled in 1818. On the pedestal there are two relief plaques: one that depicts Pozharskii ousting the Poles on horseback, the other the famous scene of citizens donating their possessions to finance the military campaign. The statue, as a highly recognisable visual symbol, later appeared on banknotes and post stamps (and, more recently, on everything from kitsch paraphernalia and posters announcing the Day of National Unity to internet memes). In 1931 the statue was relocated from its central position on the square opposite the entrance of what is now the GUM building, to the side of the Saint Basil's Cathedral, to make room for the military parades. Troops of the Soviet army passed by the monument before marching off to the war front in 1941, the symbolism of which is often alluded to.

Along our first line of narration, which concentrates on the Time of Troubles and Boris Godunov, Pushkin's play Boris Godunov (1831) continues to be one of the most influential cultural texts to date. The play had a troublesome beginning. The original version - named Comedy about Tsar Boris and Grishka Otrepiev, written in 1825/6 and inspired by the Decembrist rebellion - was censored and could not be published until after the death of Tsar Nicholas I. The 1831 edition, less politically controversial, 'hewed more or less to [Nikolai] Karamzin's politically safe view of the Time of Troubles' (Dunning 2010: 243). Modest Musorgskii based his opera Boris Godunov (1868-73) on Pushkin's play as well as Karamzin's (then) authoritative work History of the Russian State. In the opera, the role and destiny of the Russian people is emphasised, to such an extent that, according to Burton Fisher, it 'provides the essence of Russian nationalism in music'. Fisher argues that

[a]lthough Tsar Boris, the guilty usurper of the throne, dominates this pageant of Russian history, the principal protagonist of the opera is the Russian people, for whom Musorgskii provided a remarkable dramatic presence through forceful and compelling choral writing. 
The opera was later revised by Nikolai Rimskii-Korsakov, whose version has since become the standard for staged productions.

With regard to our second narrative theme, the opera A Life for the Tsar (1836), composed by Mikhail Glinka, transferred the folkloric tale about peasant Ivan saving the new tsar to the sphere of high culture. Use of the story was suggested to him by Vasilii Zhukovskii. The poet also contributed the words for the final chorus. The opera, with its dedication to the tsar in both title and story development, meshed particularly well with the political and cultural climate under Nicholas I. The tsar granted his approval of the work and gave the composer a ring set with precious stones following its premiere (Brown 1974: 87). The opera was a great success, with contemporaries crediting Glinka with having created the first national opera. Moreover, 'the myth of Glinka as the founding father of Russia's national music was already established among growing numbers by the end of 1836' (Frolova-Walker 2007: 52).

The memory of the Time of Troubles again appeared in official culture in the late 1930s as part of the effort to "[rework] the history of the Russian Empire to create a heroic myth of Russian statism' (Gill 2011: 122), together with other evocations of pre-revolutionary Russia and its heroes, including Aleksandr Nevskii and Ivan the Terrible (see chapters 5 and 7). The elements of the memory that were irreconcilable with Soviet ideology - notably the glorification of tsarism and Russian Orthodoxy - were played down and the role of the people in overcoming the crisis brought to the fore. In the context of increasing political tensions and the imminence of war, two major cultural productions gave shape to the Stalinist reworking of the memory. The first was the opera Ivan Susanin (1939), an adaptation of Glinka's A Life for the Tsar. By then several attempts had already been made to revise the successful opera in such a way that its glorified monarchy would be replaced with a more suitable object of admiration. Marina Frolova-Walker cites a 1926 production Hammer and Sickle, staged in Odessa, with the action set during the Civil War rather than the Time of Troubles; and Minin (1937), staged in Baku, in which 'all references to the Tsar [were replaced] with references to the eponymous Minin' (Frolova-Walker 2006: 200). However, these early Soviet-era attempts at refurbishing Glinka's opera did not make it onto the stages of Moscow and Leningrad.

By 1937, however, the political situation had changed dramatically and, as 'Stalin was carefully cultivating a new Russian nationalism, a revival of $A$ Life was perfectly suited to the new post-revolutionary state that was taking shape' (Frolova-Walker 2006: 201). The opera was revised considerably and, most notably, it has Susanin lead the Poles into the forest in order to save, not the young Romanov tsar, but Moscow and the Motherland. Interestingly, in a feature article on the opera's premiere in Pravda, B. A. Mordvinov invoked a wider historical context to justify this particular adaptation. 'This treatment of the subject matter is completely justified both historically and dramatically', he writes. 'Our historical consultants have identified a series of 


\section{Case studies}

analogous circumstance in the Russian national past - both during the period of the Polish intervention and during the Patriotic War of 1812' (Mordvinov 2006 [1939]: 278). The connection linking the events of 1612, 1812 and the Second World War that appears frequently in twenty-first-century public discourse, and to which I will return shortly, thus has a Stalinist precursor.

Remarkably, the opera was presented as a restoration of the composer's original conception rather than as a Soviet revision - a move aligned with the Stalinist imagination of Glinka as 'a man of the people who had to compromise his vision because of Tsarist censorship' (Frolova-Walker 2006: 201). By blaming the original librettist, Baron Rosen, of having altered the opera beyond the composer's intentions, 'the Soviet rewriting of the libretto and the appropriation of Glinka's music, which before the revolution had been regarded as a Russian national treasure', was justified (Beam Eggers 2006: 262). The alterations made to the representation of the Poles, Susan Beam Eggers suggests, indicate that Ivan Susanin was intended to be an anti-fascist narrative, a response to increasing tensions with Nazi Germany.

In the libretto of Ivan Susanin, the lines between figurative and actual enemy are intentionally blurred. Direct and indirect references to Germany, as well as allusions to the thirteenth-century Teutonic invaders, instruct the Soviet audience that the Poles should be seen as representing an aggressive and reactionary Germanic culture.

(Beam Eggers 2006: 268)

Furthermore, the addition of a reference to Aleksandr Nevskii's famous Battle on the Ice created a connection with Eisenstein's cinematic epic that premiered the year before and its anti-German thrust (see chapter 4).

The other two heroes selected to personify the memory were captured on the big screen in Sergei Pudovkin's Minin and Pozharskii (Minin i Pozharskii, 1939). This film shows the efforts of these men to unify the people against the enemy and includes a scene in which the citizens place their possessions on a large pile set before Minin's feet. This sacrifice on the side of the people is mirrored by the depiction of Prince Pozharskii as a self-sacrificing hero. In one of the opening scenes, Pozharskii declines a large mug of beer offered by Minin, who is noticeably intoxicated, and instead lies down to sleep, seemingly overcome with the suffering of his people. In the final scene, Pozharskii bows before the gathered crowd, signalling their importance in the victory that has been gained. The closing image summarises the moral of the film. As the lines are shown on screen, the following text is sung, building up to a climax:

Do not forget, o beautiful Moscow

How we managed to deal with the enemy

In harsh times of battle

Rise, o immortal strength of the people

Strength of the people! 
To further substantiate the reinterpretation of the memory, Soviet historiography studied the Troubles predominantly as a 'peasant war' spurred by class uprisings, a Marxist reading that has since been convincingly challenged (Dunning 2001: 3).

Adaptations of Boris Godunov tend to appear in times of change. Consider, for example, the Soviet-era cinematic adaptations dating from 1954 (an opera film directed by Vera Stroeva and based on Musorgskii's work) and 1986, directed by and starring Sergei Bondarchuk, one of the most celebrated directors of (historical) film in the Soviet Union. The engrained subversive potential of the story is evinced by the fact that, in times of strict political control, productions were obstructed or were followed by repercussions for those involved. In 1984, for instance, the stage director of the Taganka Theatre, Iurii Liubimov, was banned from the stage after producing 'a defiant, aggressively modernized production of Pushkin's Boris Godunov, during which the actors came down off the stage to accuse the audience of political passivity and submission to a series of shabby pretenders' (Emerson 1992: 547. Italics in original). The close connection between the play and the reigning political winds is evinced by the fact that by 1988, as Perestroika took hold, Liubimov was allowed to resume the staging of the play at the Taganka. The revival of Pushkin's Boris Godunov subsequently continued throughout the 1990s. New theatre and opera productions, partly developed in connection with the twohundred-year anniversary of Pushkin's birth in 1999, resonated with the fundamental cultural shift taking place following the Soviet collapse. According to Nicholas Rzhevsky, 'Boris Yeltsin, 'selected by the people', offered a historical juxtaposition to his tragic namesake as a central figure in the break with old belief systems' (Rzhevsky 2009: 237). Moreover, 'The fall of the monarch away from God in Pushkin's narrative served to interpret contemporary history and the post-Soviet devaluation of transcendent orientations, whether they concerned religion or the abstractions of the Marxist-Leninist creed' (Rzhevsky 2009: 237).

As for the other great opera, the original A Life for the Tsar replaced its Soviet adaptation in the first post-Soviet decade. Yet, in concert with the increasingly positive reappraisal of Soviet history and culture under Putin, its most acclaimed opera also returned to the Bolshoi stage and the 'audience can now see the same spectacle that Stalin enjoyed, give or take the occasional sprinkling of post-Soviet religious fervour' (Frolova-Walker 2006: 215).

\section{Institutionalisation of the memory: the Day of National Unity}

In 2005, the Putin government took advantage of the memorialisation of the 1990 s as a Time of Troubles as it had already developed in the arts and mass media, as well as in political circles. The trope fitted the need to symbolically confirm the success of Putin's first term; with little effort, the historical parallel could be used to signify how under the president's skilful guidance, 
Russia had finally found its footing on the right path. The narrative's element of far-reaching foreign interference now came to express how the 'roaring '90s' had been overcome by cutting loose from Western advisers (e.g. the IMF) and, instead, pursuing Russia's 'unique path' of development. Moreover, it resonated with two additional issues that figured extensively in Russia's relations with the West at the time: the wave of colour revolutions that had swept across the post-Soviet space (and the alleged Western involvement in them) and the 2004 enlargement of the European Union, which included the accession of the Baltic states. As was also the case with the incorporation of Petr Stolypin into official memory culture (see chapter 3), this example of memory politics is best described as reactive rather than proactive in nature. It instrumentalised a mnemonic framework that was already actively circulating in public discourse and, in this case, had become embedded in common parlance. The principle marker of the institutionalised memory became the Day of National Unity, to be celebrated on 4 November. The holiday was explicitly framed as a reestablishment of the tsarist commemoration, celebrated annually on 4 November until 1917, of the expulsion of the PolishLithuanian occupation force in 1612. In addition to reclaiming this 'lost tradition', the chosen date was significant for yet another reason. It enabled a simultaneous government attempt to address the pressing question of repurposing the traditional Soviet-era 7 November holiday commemorating the October Revolution. As such, the new holiday was intended to provide 'a foundation myth for the multinational and multiconfessional post-Soviet Russia' (Brouwer 2016b: 126).

The first celebration of the holiday was marked by a ceremonial reception at the Kremlin. In the presence of several hundred officials and representatives of cultural and charitable organisations, Putin gave a speech in which he outlined the meaning of the new holiday. First, in line with the holiday's name, he emphasised the vital importance of national unity. Referring to the people's uprising that had liberated the city of Moscow from the foreign occupants, Putin stated: 'It was a victory of patriotic forces; a victory of the course towards the strengthening of the state through centralisation and joining of forces; the formation of a world-power [derzhava] - great and sovereign - began with this heroic event' (Romanenkova 2005).

Yet the speech's most important theme is the merit and longstanding tradition of civic engagement and charitable work, placed in the context of a more broadly defined idea of civil responsibility and social cohesion:

Back then, the people themselves defended Russian [rossiiskuiu] statehood, showed genuine civic spirit [grazhdanstvennost'] and the highest sense of responsibility; not under coercion from above but at the call of the heart, people of various ethnicities [natsional'nostei] and confessions united in order to, collectively and independently, determine their fate and the fate of their Fatherland. 
In connection with this often-neglected aspect of the initial conceptualisation of the official memory, the youth movement Nashi organised a 'Day of Good Deeds', with actions ranging from cleaning up and painting stairwells, fences and benches to feeding stray animals (Vinogradov et al. 2005). In 2007, together with another youth movement called Rossiia Molodaia, Nashi organised a blood donation campaign in the same vein under the slogan 'We are all of one blood'. As Stephen Hutchings and Vera Tolz argue, the donation of blood has particular symbolic significance when combined with the holiday's underlying idea of binding together a multinational state.

In the 'one blood' motif the spiritualization of the opolchentsy [the People's militia, M.W.] unifies the original act of 'sacrifice' in driving the Poles from Moscow, the 'unity in diversity' represented by the opolchentsy and Orthodox exhortations to give charity, thus embodying Russian's inherent self-sacrificial generosity.

(Hutchings \& Tolz 2015: 79. Italics in original)

The president laid flowers at the statue of Minin and Pozharskii and attended the unveiling of a close copy of it, sculpted by Tsereteli, in Nizhny Novgorod. On that occasion, Putin referred to the 'deep historical roots of the holiday' and emphasised how the uprising that had come together there had united 'representatives of various classes and nationalities' ('Putin: Istoriia Rossii svidetel'stvuet' 2005). Furthermore, he asserted that the Time of Troubles is but one example of civil unity decisively influencing the course of Russian history.

All of Russia's many-centuries-long history testifies to the fact, that only together, by uniting forces, can we adequately respond to the challenges of the time, successfully resolve important, truly fateful problems. And the unveiling of this monument pays tribute to our national traditions [and] to the courage of our ancestors.

(Ibid.)

In response to the official celebrations, a nationalist 'Right March' (Pravyi marsh) was organised by the Eurasian Youth Union (Evraziiskii soiuz molodezhi, see also chapter 6) and the Movement against Illegal Migration (Dvizhenie protiv nelegal'noi migratsii) (Vinogradov et al. 2005). Several thousand people participated in the march that has since become known as the 'Russian March'.

The first celebration was marked with 'hesitant media fanfare' (Hutchings \& Tolz 2015: 73) that, according to television critic Sergei Varshavchik, was remarkably coherent across the major TV channels. News reports and documentaries dedicated to the 4th of November, he notes, all presented a similar narrative about the holiday's contemporary meaning, namely that in our troubled times' a lesson should be drawn from the past about the 'mature civil 


\section{Case studies}

initiative originating from below' that emerged in response to the foreign occupants who had violated Russia's national sovereignty (Varshavchik 2005). While Varshavchik's assessment is essentially correct, it obscures the fact that the productions were, in fact, markedly different - in both style and content and in how they employed the language of cyclical return. Moreover, only one of the documentaries explicitly mentions the Day of National Unity. I will return to the documentaries that aired on the occasion of the holiday's inauguration in the second part of this chapter, where I also contrast them with a more propagandistic documentary broadcast the following year.

While the Day of National Unity is often described as simply and solely celebrating the ousting of the Poles, the religious component of the tsarist holiday - the feast day of the icon of Our Lady of Kazan - was revived as well. To do so was particularly advantageous for the state. Hutchings and Tolz are right to argue that ' $[t]$ he re-appropriation of Orthodoxy within official patriotic discourse provide[d] an opportunity for the sanctification of DNU [Day of National Unity, M.W.]' (Hutchings \& Tolz 2015: 77). It corroborated the illusion that the new holiday was actually a long-cherished tradition. The Orthodox celebration was given a particular impetus by the return of an eighteenth-century copy of the (presumably lost) icon, of which the exact origins are unclear, to Moscow in August 2004. It was gifted by Pope John Paul II, who had possessed the icon since 1993 when it was transferred to him from Fátima, Portugal. The icon was subsequently moved to Kazan where, since 2005, it has been carried in the semi-annual processions that take place on the icon's feast days of 21 July and 4 November. The procession itself is a pre-revolutionary practice, revived only in the early 2000s. ${ }^{3}$

From the first celebration of the new holiday, the exhibition 'Orthodox Rus" has been organised annually to coincide with it. ${ }^{4}$ In a letter addressed to the participants of the simultaneously organised forum, Putin praised the event and made a link between patriotism and 'spiritual values':

It is pleasing that you raise the topical and important questions of preserving the historical, cultural and spiritual values of our multinational people, original folk art, [and] the education of the youth in the spirit of patriotism. Undoubtedly, these are the areas in which it is necessary to strengthen the cooperation of governmental, societal and religious organisations.

(Putin 2006)

Despite the exhibition's explicitly Orthodox name, Putin thus initially framed the event in multi-ethnic and, implicitly, multiconfessional terms. Already in 2007, however, Russian Orthodoxy received greater emphasis in his address. While he still referred to the importance of developing a 'constructive interconfessional dialogue', Putin stressed how 'in the history of our Fatherland, Orthodoxy has always played a unifying role, has served the high goals of 
fostering patriotism, [and] the strengthening of spirituality and morality' (Putin 2007). It is within the framework of the 'Orthodox Rus" exhibition series that the yearly multimedia exhibits 'Russia - My History', discussed in chapter 4, have been organised since 2013. In this new format, the exhibitions have become very popular, drawing some 300,000 and 250,000 visitors in 2013 and 2014, respectively. Its content and orientation increasingly indicate the influence of the Orthodox Church.

The presidential speeches marking the commemorative date have varied in emphasis and phrasing. For example, in 2011, Dmitrii Medvedev combined previously established components of the memory with the vocabulary of economic and technological innovation that was central to his presidency. He stated:

Patriotism, civicism, love for the Fatherland - these are the fundamental values that have always bound together the multinational Russian [Rossiiskoe] state. Even now, they form our moral foundation; a millennial heritage, yet at the same time one of the symbols of young democratic Russia, a country that is now dealing with fundamentally new challenges, such as the formation of a modern and innovative economy, the technological re-equipment of industry, the modernisation of administration, and even the modernisation of public life as a whole.

('V Rossii otmechaiut Den' narodnogo edinstva' 2011)

It is noteworthy that, in contrast to Putin's speeches, Medvedev shows some restraint in presenting Russia's history as strictly continuous by suggesting that the state's current development constitutes both a continuation of history and a distinct new stage.

The memory narrative and the cyclical model of historical development it presupposes were picked up by Russian historiography. A joint publication of the academic journal Vlast' and the Sociological Institute of the Russian Academy of Sciences, on the topic of 'The Nation and Power during the Russian Smuta' (Marchenia \& Razina 2010), argued that the history of contemporary Russia should be studied in parallel with the other smuty, explicitly referring to the early seventeenth century and the Bolshevik revolution.

In a completely different genre, the gaming industry also hopped on the smuta bandwagon. The strategy videogame Empire: The Time of Troubles (Imperiia: Smutnoe vremia, Lesta Studio, 2009) ${ }^{5}$ covers the history of Rus', Poland and Grand Duchy of Lithuania between 1350 and 1650. Its scope, therefore, goes far beyond the Troubles itself. It is a 'global strategy game', as one reviewer describes it, recounting

the endless internecine bickering of Russian principalities, gradually gathering into a unified kingdom of Moscow. In addition to the Russian princes, the Tatars, Germans, Ukrainians, Swedes and all other 


\section{Case studies}

inhabitants of the eastern edge of the civilized world try to chew off their piece of the Eastern European pie.

(Prosvirnin 2010)

It is not the first videogame set in the early seventeenth century, though. The first-person-shooter game Time of Troubles: The Living Dead (Smuta. Ozhivshie mertvetsy, NewCom) was released in 1997. Using various weapons, including an axe and a rifle, the player has to fight off axe-wielding zombie boyars to escape a subterranean labyrinth (Logos 2011). ${ }^{6}$ Players of more traditional games can try their hands at two themed board games. Time of Troubles: 1605-1612 (Smuta: 1605-1612, Casus Belli, 2011) is a highly detailed strategy board game. Due to its historical 'realism', the game store Mosigra warns, the rules are so complicated that the first attempt to play it will take around five hours (Mosigra n.d.). The release of the second game, Times and Epochs: Time of Troubles (Vremena i Epokhi: Smuta, Gemenot, 2012), was timed to coincide with the bicentennial celebration of the liberation of Moscow. In addition to the Russian Kingdom and Poland, players can lead Sweden or the Crimean Khanate into battle and 'write [their] name into history' (Vremena i Epokhi n.d.).

The memory narrative and, in particular, the holiday created to mark it have resonated with the general public only to a limited extent, it seems. According to opinion polls conducted by the Levada Centre, the percentage of people who can correctly name the holiday celebrated on 4 November increased from 8 per cent in 2005 to 43 per cent in 2012, but it still did not exceed half of those polled (' $16 \%$ rossiian otprazdnuiut Den' narodnogo edinstva' 2012). ${ }^{7}$ Interestingly, the poll shows the persistence of the new name given to the 7 November holiday during the 1990s: 25 per cent of respondents answered that 4 November was the Day of Accord and Reconciliation in 2012, down from 33 per cent in 2005. Despite the fact that the Day of National Unity became more well known, the percentage of respondents who planned to actually celebrate the holiday has increased little since its introduction, from 12 per cent in 2005 to 16 per cent in 2012. The poll outcomes furthermore demonstrate that the governmental effort to provide an alternative to the commemoration of the October Revolution, to replace 7 with 4 November, had only limited effect. In 2012, 18 per cent of respondents still planned to mark the 7 November holiday (exceeding those who celebrate 4 November by 2 per cent), a mere 5 per cent drop compared to 2005. It has to be emphasised, however, that the majority of respondents (61 per cent in 2012) did not plan to celebrate either date. Eight years after its introduction, Lev Gudkov, the director of the Levada Centre, summarised the public understanding of the Day of National Unity as follows:

They view it as an initiative by the authorities to extinguish the memory of 7 November. The initial ambiguity is disappearing; people agreed with 
the official name but it does not evoke any emotions. A very small proportion [of respondents] identifies with this holiday.

(Goncharenko 2013)

The holiday's failure to become the national celebration of Russia's 'rebirth from the ashes', as was intended, is also in part connected to the (ultra) nationalist Russian March that soon overshadowed it (see also Zuev 2013).

Much earlier, as the government-backed cultural attempts to popularise the memory were in full swing (including the release of the blockbuster film 1612 that will be discussed below), opposing voices had already manifested themselves in public. The most notable of these can be heard in the theatrical play 1612 (2007) written by Elena Gremina, Kshishtof Kopka, Maksim Kurochkin and Evgenii Kazachkov for Teatr.doc, the leading company in (experimental) contemporary Russian theatre. ${ }^{8}$ The play reconstructs historical events, but in an unconventional way. The production was staged in cooperation with the Polish theatre company Ad Spectatores from Wroclaw; the roles of Polish historical figures were played by Polish actors and spoken in Polish while Russian characters were performed by Russian actors speaking Russian. According to Gremina, who is also the co-founder and director of Teatr.doc, 'in that way we can view it [the historical events, M.W.] from both sides' (Vinokurov 2007). After its premiere in Poland, its Russian premiere took place on 4 November 2007. In an interview with Radio Svoboda, Gremina explained how the play fitted the political-cultural situation at the time:

Clearly, we are now at a certain point where we have to remember what happened to us, to imagine our history, to compose, perhaps, some new myths or reevaluate old ones. And that, of course, is what this holiday is about.

(Vinokurov 2007)

She points out that, contrary to its intended effect of unification, the holiday has had primarily a divisive effect.

[T] his Day of National Unity somehow rather divides people; because people, compatriots who live in the same country, have completely different ideas about what is happening and what our path is; entirely different manifestations of 4 November are taking place.

(Vinokurov 2007)

The play she wrote, in fact, is part of this plurality of interpretations.

Contrary to the oppositional sentiment towards Poland or 'the West' engrained in the official commemoration of the Time of Troubles, the play is of a conciliatory nature. As a reviewer for Rossiiskaia Gazeta put it, the merging of the two languages and the two theatrical companies on stage draws out commonalities between the opposing sides in the conflict, rather 


\section{Case studies}

than their mutual enmity: 'And suddenly it becomes apparent how easily we are able to understand a foreign language, as age-old neighbours in time and space; how much you can hear in it that is native [rodnoi] and familiar' (Karas' 2007). When asked whether there will be a new Time of Troubles in Russia, Gremina suggests that Russia has moved beyond this point - without clearly indicating whether she feels that it does not apply to contemporary Russian history or that the latest Time of Troubles has now ended (which would be in line with the regime's interpretation).

It appears to me that we have already passed the moment when it [a new Time of Troubles, M.W.] could have happened. But now there is instability... perhaps it is not one of the processes that can happen in our society. I nevertheless believe that we are now going by some other scenario. By which - that will become clear as time goes by.

(Vinokurov 2007)

\section{Memory chains}

Notwithstanding the government's effort to associate itself with the memory of the Time of Troubles and its overcoming, the memory soon began to appear in combination with other historic dates in official statements. In particular, the pairing of 1612 and 1812 - the year marking the victory over Napoleon in the Patriotic War - largely replaced the usage of the memory of 1612 on its own. Both historical events were included in the programme of the Year of Russian History that was celebrated in 2012. The commemorative year thereby affirmed the central position the two dates occupy in official memory culture, as well the tendency to combine them. The decision to incorporate 1612 into a memory chain (see chapter 2) can be explained by the memory image's failure to resonate with the general public in the way it was intended, as the opinion polls indicate. Through association with 1812 the weak memory image was strengthened. Moreover, this could all be done without altering or negatively affecting the core idea of the institutionalised memory of 1612 and the holiday associated with it. In fact, the memory chain further confirmed the underlying notion that Russian history is cyclical in nature. Consider, for instance, the following example. In a carefully orchestrated ceremony on 29 August 2012 in the Catherine Hall of the Kremlin, President Putin presented state awards to more than fifty 'outstanding Russian citizens'. In his congratulatory speech, Putin referred to episodes from Russian history to frame the kind of patriotism exemplified by the awardees.

I am certain that you love Russia and that, for you, this feeling is not merely loud, official words but, first and foremost, it is the meaning of life. This is exactly how true patriotism has always been understood: as a profound awareness of one's personal involvement in the fate of the 
country, as civil responsibility and the aspiration to dedicate one's talent to Russia [and] one's fellow citizens, as the willingness to stand with one's Motherland at all times: in moments of triumph as well as in periods of trial and adversary. The examples of this are the heroic events of 1612 that put an end to the Time of Troubles, and the Patriotic War of 1812.

('V Kremle vrucheny gosudarstvennye nagrady' 2012)

The patriotism of today's 'Heroes of Russia' is placed in a historical tradition that connects contemporary Russia to the Time of Troubles and the war against Napoleon - even if the dangers Russia faces today are of a rather different kind.

The shift from 1612 to 1812 offered yet another major advantage. The victory over Napoleon provides an opportunity for pairing with the 1945 victory in the Second World War as well. ${ }^{9}$ This association is facilitated, in particular, by the overlapping geographical locations of important battlefields and remembrance sites. The battlefield at Borodino is a case in point. The rolling hills west of Moscow were the site of the famous nineteenthcentury Battle of Borodino, presented in the official account as a turning point in the war with Napoleon. And it was also the site of particularly intense fighting against approaching German forces in 1941. One now encounters, spread out across a territory measuring more than one hundred square kilometres, more than three hundred memorial objects. Those commemorating the Battle of Borodino were erected in 1839 and on the occasion of its centennial anniversary in 1912. Most of the monuments dedicated to the 1941 battle date to the 1960s and 1970s. Both battles are commemorated annually with historical re-enactments of key battle scenes: the battle of 1812 on the Day of Borodino (the first Sunday of September) and the military clashes of 1941 during a historical-military festival held on the second Sunday in October. ${ }^{10}$

In 2012, Putin attended the re-enactment of the Battle of Borodino. In his speech, Putin praised the soldiers who had sacrificed their lives there. At the same time, he foregrounded how the memories of the Patriotic War and Great Patriotic War are connected and, at that particular location, overlap geographically. In fact, the commemoration of the Battle of Borodino was used as an occasion to award the nearby villages of Maloiaroslavets and Mozhaisk with the title of 'City of Military Honour', an honorific title generally associated with the Second World War. 'It is symbolic,' Putin stated, 'that precisely here, where 'Russians gained the right to be unconquerable' [a quote from Napoleon, M.W.], the certificates conferring the honourable title of 'City of Military Honour' will now be awarded to the cities of Maloiaroslavets and Mozhaisk' ('Torzhestva po sluchaiu 200-letiia Borodinskogo strazheniia' 2012). The reason for bestowing the honour, he added, lay in the 'deeds of [the cities'] population and their defenders during the Patriotic Wars' (ibid. Emphasis added). Borodino provides yet another example of a reclaimed tradition: at the 2014 re-enactment, the speaker repeatedly emphasised how 


\section{Case studies}

the event not only brought the battle of 1812 back to life, but simultaneously constituted a revival of the first re-enactment that had taken place there in 1912. As the speaker repeatedly proclaimed, it was 'a reconstruction of a reconstruction' (author's visit, 7 September 2014). The same year, the political instrumentalisation of the Patriotic War was affirmed by the erection of a bronze statue of Tsar Aleksandr I next to the Kremlin wall in celebration of the 200th anniversary of the war's conclusion. Confirming how 1612 and 1812 are inextricably interwoven in the regime's memory politics, President Putin's speech conveyed the essence of the political smuta narrative by pointing out that in the battle against Napoleon 'people of all classes, of different ethnicities' rose up to fight ('Otkrytie pamiatnika Aleksandru I' 2014).

If we look at how the memory of the Time of Troubles has figured in memory chains in the broader public discourse, it becomes clear that it is actually part of two opposed memory chains. The first is a positive chain connected by the notion of the restoration of order, which corresponds to its governmental usage. In this chain, the end of the Time of Troubles is linked to the victory over Napoleon and the rule of Putin in the new millennium. The victory in the Second World War, though sometimes added to the memory chain, does not form an essential part of it. At first sight, the frequent omission of the Second World War from this constructed chain of victories appears to be somewhat incongruous, given the prominent place of 1945 in contemporary memory politics. A possible explanation for the absence of one of the primary vectors of national pride lies in the emphasis placed on the importance of Russian Orthodoxy in uniting the people and gaining victory: in the commemoration of the victory in the Second World War, religion is at best a subsidiary aspect. The second memory chain possesses a negative connotation and focuses on the Time of Troubles itself that is, on the condition of disorder, anarchy and suffering during the period. In this chain, the Time of Troubles is connected to the Russian Revolution and the disintegration of the Soviet Union (1605-1917-1991). One also comes across references to the Time of Troubles in connection to the Stalinist terror and, specifically, the year 1937. The Soviet period, thus, provides very important and indelible components of the negative, even traumatic version of the memory chain.

To demonstrate how these two narrative strategies function in Russian public discourse, let us consider the following statement by Patriarch Kirill, which actually combines the two linking strategies:

I would like to say that what the country went through in the 1990s is comparable to other significant cataclysms in the history of our country, with the Time of Troubles of the seventeenth century, the Napoleonic invasion, with Hitler's act of aggression and the Civil War, because in each of these cases the very existence of the country, the existence of the people, was in question. 
In Patriarch Kirill's statement as it is recorded in the official transcript, he thus interweaves Soviet and non-Soviet periods and frames all of them in a negative light. The news coverage by Channel One, however, edits its coverage of the meeting in which he made this statement in an important way. On the channel's website, the broadcast news coverage is accompanied by a written transcript of the video. In the video, the patriarch's statement is edited in such a way that the historical comparison he puts forward consists only of the Time of Troubles, the Napoleonic invasion and the Civil War. Filtered out is his mention of the Second World War in a negative rather than victorious context. In the transcript, then, the chain of history is edited even further to fit the 'victory format' of 1612-1812-2012:

'We would like to have a conversation with you [Vladimir Putin, M.W.] as prime minister, but first of all as a candidate for the position of President of our country; what is more, the candidate that has, of course, the greatest chance of actualising this candidacy into an actual appointment', remarked Patriarch Kirill. He compared the events of the '90s with the Time of Troubles of the seventeenth century, with the Napoleonic invasion. 'Because in each of these cases the very existence of the country, the existence of the people, was in question. I believe, that it is very important to understand that the emergence out of these difficult '90s represents a special page in the many-centuries-long history of our Fatherland', Patriarch Kirill stressed.

(Liakin 2012)

The relevance for contemporary politics is further emphasised by the placement of the historical comparison directly after the Patriarch's expression of support for Putin's presidential candidacy, which he had actually made much earlier in the meeting.

In those cases where the memory of the Second World War is inserted into the victorious narrative of emergence from crisis, the frame of the recurring Time of Troubles appears to have a neutralising function; it serves to historicise the memory of the war by integrating it with previous heroic deeds. Consider, for example, Channel One's coverage of the state ceremony where President Dmitrii Medvedev awarded the cities of Vladivostok, Tver and Tikhvin with the title of 'City of Military Glory'. The reporter makes the following comment about the city of Tver:

In the course of its history, going back almost nine centuries, the citizens of Tver have more than once come to the defence of Russia; that was the case during the Time of Troubles, during the invasion of the Poles, and in 1812 , when the city formed the first people's militia.

(Krasnov 2011)

As a result, the historical periods that were portrayed under Yeltsin as disparate eras - casting the post-Soviet as a departure from the Soviet period, or 
the Soviet period itself as a breach in the continuity of the (imperial) Russian state - are reintegrated into a single historical narrative. The perceived 'right' to celebrate all of their victories, from the time of Kievan Rus' up to now, and to consider them one's own is symbolically reclaimed. All the paradoxes and incongruities of Russia's '1000-year history' are brushed away for the sake of reviving the veneration of the Russian state itself.

\section{Film and television analyses}

\section{TV documentaries on the occasion of the Day of National Unity (2005-2006)}

On the occasion of (the introduction of) the Day of National Unity, several state TV channels broadcast documentaries on the Time of Troubles and its contemporary relevance. It is fair to assume that these programmes were all produced on the initiative of the state to popularise the new holiday. Nevertheless, they diverge considerably in both style and content, and this merits notice. In what follows, I will analyse three documentaries from 2005 and contrast them with a fourth documentary from 2006. As will become clear, the latter is markedly more propagandistic in nature. The measure of deviation among such 'state-ordered' documentaries tends to receive little notice. Yet such divergence serves as a valuable reminder that, first, the production of (contemporary) television 'propaganda' is a highly complex process that involves an extensive network of people representing various backgrounds and agendas, thereby resulting in varying end products (showing indirect or diffuse top-down control); and, second, that conversely this diversity is exactly what is needed to get the message across to the various groups that make up the target audience. Generational differences and other factors influencing viewing preferences are thus taken into account, ensuring the diffusion of the core message to the widest possible audience.

Russian Alarm (Russkii nabat, Ivanov, 2005), broadcast by Channel One, is a rather unsurprising, fact-oriented documentary that simply narrates the main historical events of the Time of Troubles. Images of tumbling church bells and whirlwinds introduce the turbulent historical episode. At no point in the discussion, however, is direct reference made to a contemporary parallel. A ceremonial military parade in the Kremlin, shown at the beginning and end of the documentary without commentary or indication of the occasion, is the only element that connects past and present. As is the case in many Russian documentaries, the narrator takes centre stage. Sitting in a library, leaning over ancient-looking books, Sergei Shakurov recounts the Time of Troubles' main incidents. Shakurov is a well-known Soviet and Russian actor, who, in the spring of that year, had played Leonid Brezhnev in an eponymous TV series (Brezhnev, Snezhkin, 2005). The scenes of direct narration are interspersed with fragments from early and late Soviet films and opera recordings. For the most part, the original soundtrack of these productions is preserved. 
The opera sequences, therefore, leave a distinct mark on the overall feel of the documentary. As it draws to a close, Orthodox hymns resound.

Time of Troubles (Smuta, Skoblin, 2005), broadcast by NTV, is markedly different in its argument and style. The opening titles introduce the topic in unabashed terms. A thick red substance - that appears to be blood - slowly spreads across the map of Russia as the voice-over summarises the problems at hand: hunger and murder have become the lot of ordinary people; for boyars and other servants of the court, betrayal is now the norm; the Muscovite state has lost vast stretches of territory, as well as half its population. This disarray, the voice-over states, is what will later be known as the Great Time of Troubles (velikaia smuta). The documentary is narrated by Vladimir Menshov, well known for directing the Oscar-winning Soviet-era classic Moscow Does Not Believe in Tears (Moskva slezam ne verit, 1979). Menshov immediately makes clear that the term smuta should be used in plural form and frames the Time of Troubles as a recurring phenomenon. He claims that Russian history has known at least four such 'Times' - and invokes the Tatar Yoke, the Time of Troubles itself and the October Revolution. The negative memory chain that was discussed above is thus extended back in time, thereby lengthening the perceived timespan of Russian history (approaching the cliché tysiacheletie). The viewer is left to guess the fourth instance - which turns out to be the most recent period - until it is revealed at the end of the documentary. In its description of the historical events, the documentary pays particular attention to the topic of imposture (samozvanstvo) and the various interests that may have played a role for those involved (e.g. the False Dmitrii; Marina Mnishek and her family; and Marfa, the mother of Dmitrii who affirmed that the False Dmitrii was her son). A noteworthy aspect of the documentary is its looking beyond the opposition of Russia and its enemies in Europe. It places the confrontation between Russia and the Polish-Lithuanian occupiers within a larger geopolitical framework that includes the Ottoman Empire. Also, it informs the viewer that Marina Mnishek sought refuge from Shah Abbas I of Persia. The Iranian ruler, however, refused her request since he did not want to get tangled up in Russian affairs.

The documentary further asserts that the period following the October Revolution was in many ways similar to the Time of Troubles. In fact, as in the early seventeenth century, it argues, impostors came to power. At this point, historical footage of Vladimir Lenin is shown. More generally, the Soviet authorities are portrayed as weak and insecure, all the way through the 1930s. One of the reasons the statue of Minin and Pozharskii had to be moved, it is claimed, was that those in power feared it would incite a people's rebellion. Minin's hand raised in the direction of the Kremlin and, more specifically, Lenin's tomb and the platform used by Soviet dignitaries on official occasions would provoke hostile sentiments against the establishment. The negative depiction of the first decades of Soviet rule deviates markedly from how smuta and the Russian Revolution are typically combined. The term smuta is widely used to denote the societal impact and disruption caused by 


\section{Case studies}

the Revolution and subsequent civil war, but not to negatively portray Lenin or the inception of the Soviet state per se.

In Time of Troubles, Menshov provides his commentary from historically relevant locations. His narration is complemented by a separate voice-over. To boost the documentary's credibility, there are interviews with several historians, most with heavily laden bookshelves or computers in the background. The documentary includes extensive images of artworks and cinematic fragments, as well as historical film footage drawn from various periods. Many of these are overlaid with a yellowish filter, which blurs the images and takes away the evident differences in origin and period between them. The original sound is omitted. Unlike the previous documentary, the relation between the images shown and what is recounted by the voice-over is not always clear. In fact, because of the filter, it is sometimes difficult to make out what exactly the fragments depict. Because of the visual blurring, there is greater emphasis on the voice-over narration.

Hieromonk Feofan, the only non-historian interviewed, reiterates that the meaning of the Time of Troubles transcends its seventeenth-century historical origin and that its 'message' continues to be relevant today. He states that in different times the country has faced different enemies; but more important than the identity of the adversary is the overcoming of these trials (ispytanie) through the unification of the people. The trial Russia endures at the moment, he concedes, may be different in nature from that of the earlier episode, yet it requires the same national unification. In the conclusion, Menshov returns to the question of the fourth Time of Troubles. He asserts that, according to historians, Russia is currently experiencing another smuta, which began with the disintegration of the Soviet Union. Perhaps, he cautions, it is still going on. After naming the symptoms evident in both periods - among them the loss of a large part of the state's former territory - Menshov finally arrives at the state-sponsored line of interpretation. It appears, he assures the viewer, that this most recent Time of Troubles is coming to an end. This is evinced by the restoration of destroyed monuments and an increasing interest among Russians in national history (here he refers to the great number of documentaries shown on TV). Menshov briefly touches upon the criticism that the date chosen for the national holiday bears little actual historical significance, yet emphasises how the need for the holiday itself is indisputable: 'We need it in order to remember our history and take pride in it'. Only then, he asserts, can our history evolve from one characterised by recurring Times of Troubles into one of development and the unbroken flourishing of the state. Interestingly, Menshov thus suggests that the historical pattern characterised by returning cycles of greatness and Times of Troubles can somehow be transcended.

The third documentary from 2005, The End of the Time of Troubles (Konets smutnogo vremeni, Kraus) broadcast by Rossiia, concentrates on the final years of the Time of Troubles and places considerably more emphasis on the role of Russian Orthodoxy. The events leading up to the year 1610, which 
begin the narration, are recounted in broad brushstrokes. As in the previous documentaries, the Time of Troubles is visualised through shots of paintings, etchings, schematic visualisations of military manoeuvres and film scenes from Minin and Pozharskii and Eisenstein's Ivan the Terrible Part I, often overlaid with dancing flames. In addition, it includes extensive re-enacted scenes and shots of landscapes, turbulent skies, churches and monasteries. Compelling symphonic music on the soundtrack, rapid cuts and an authoritative voice-over provide intensity and suspense at regular intervals. Compared to the other two documentaries, it includes more interviews with well-known figures, including the late painter Il'ia Glazunov, who went on to represent Ivan the Terrible in The Name Is Russia a few years later (see chapter 4), and popular historical writer Boris Akunin. Whereas the majority of those interviewed see times of troubles as a natural consequence of momentary absences of authority in Russia's 'traditionally' power-centric structure, Glazunov asserts that these periods of turmoil do not arise of themselves but are organised. 'Smuta' and revolution are one and the same thing, he claims. The documentary reiterates the standpoint that the Time of Troubles was overcome because the Russian people united against a common enemy. (Then) Metropolitan Kirill further stresses the indispensable role of the Orthodox faith in the survival of the Russian state. His position is supported by the manifold shots of Orthodox churches, resounding hymns and ringing bells, and by the extensive discussion of the fate of Patriarch Germogen and Orthodox monasteries. Historian Igor' Andreev confirms the importance of religion in this period. He summarises the role of Orthodoxy as the 'protection of national dignity and self-esteem'. In fact, according to Andreev, the Church played a crucial role in inspiring the idea of 'national liberation'. As the voice-over later points out, the leading role of Orthodoxy, however, did not preclude support from other national groups. All nationalities - Kalmyk, Tatars, Mari and so on - joined the militia led by Minin and Pozharskii. And those peoples who did not take part in the military effort, it is claimed, contributed financially.

Metropolitan Kirill draws attention to the symbolic importance of the end of the Time of Troubles and establishes parallels with other periods in history, in particular with the Second World War.

We have always fallen victim to outside aggression at times when we lost internal cohesion and strength. And, as a matter of fact, Hitler also attacked us, believing that Communist rule had led to the weakening of the internal spiritual strength of the people. And that the German forces simply had to come in and, as the internal wave of resistance to Soviet authority was rising, that everything would fall apart. That was their primary estimation.

Glazunov similarly invokes the memory of the Second World War, and cites how only national heroes such as Aleksandr Nevskii and Minin and 


\title{
144 Case studies
}

Pozharskii succeeded in mobilising the people. The viewer is then presented with historic footage of the Soviet armed forces marching across Red Square, its troops passing the statue of Minin and Pozharskii as they leave for the front. Metropolitan Kirill is given the final word and sums up how Russia is fated to live through Times of Troubles, but will always return to greatness.

\begin{abstract}
Russia is a great power [velikoe gosudarstvo]. Russia is a very wealthy state in terms of resources and opportunities. And she is very attractive [pritiagatel'na] to many. This wealth is very attractive to many. And you have to be able to keep and protect this wealth. And it [the wealth, M.W.] is so great that only a great power can keep and protect it. Therefore, Russia can only be great, and we must add multinational, or she will not be at all.
\end{abstract}

While the documentary presents the historical events so that they translate easily to the political situation in the present, the parallel with contemporary Russia is left implicit. The three documentaries broadcast by the main TV channels on the occasion of the first celebration of the Day of National Unity thus differ considerably in terms of style, as well as in the particular events they recount and emphasise. Still, all three reiterate the motto of the holiday: only through the unification of the people can Russia overcome (recurring) Times of Troubles and reclaim its natural position as a great power. Since the TV productions were likely initiated because of the new holiday, it is noteworthy that only one of them - The End of the Time of Troubles - is framed this way. Russian Alarm even lacks explicit references to present-day developments.

The 2006 documentary The Time of Troubles (Smutnoe vremia, Buturlin), on the contrary, is far more explicit in its historical and political claims. As one would expect on the basis of its title, the programme discusses the lead-up to Time of Troubles, followed by the unfolding of its crucial events and ultimately its ending. But the narrative takes several detours at important points, suggesting that the topic is but a means to discuss larger issues of Russian politics and, in particular, the relation between state and society. Even more so than the previously discussed productions, the documentary exemplifies the rhetorical importance of (remediated) visual elements, montage and intertextuality for the construction of a persuasive memory text. Narrator Mikhail Leont'ev, a television host and political commentator notorious for his bold statements, asserts that, for Russia, imposture has become a 'chronic disease' afflicting the country's historical development and the way it has coped with transitions in power. There have been three Times of Troubles in Russian history, it is stated: in 1605, 1917 and 1991. Leont'ev thus reiterates the standard negative memory chain. The documentary provides explicit comparisons between the seventeenth century and the 1990s in both image and narration. The importance of the Orthodox faith for the Russian state is emphasised and reinforced by many shots of Orthodox churches. The 
documentary employs a mix of archival and cinematographic moving images taken from different time periods. Some are highly recognisable, such as scenes from Minin and Pozharskii; others are difficult to place in time, such as historical footage of fatally starved children that accompanies the narrative about famine during Godunov's reign.

The naming of the three periods in Russian history that are deemed to be comparable and, to a certain extent, dictated by the rules governing Russia's historical development leads the way to a wide array of alleged historical parallels: the death of Ivan the Terrible and subsequent shared political rule by several boyar families is compared to the death of Stalin and the system of collective leadership during the Khrushchev period; Boris Godunov is mirrored by Khrushchev; the Rule of the Seven Boyars (semiboiarshchina) is equated with the level of political influence of the oligarchs in the second half of the 1990s (semibankirshchina), ${ }^{11}$ and so on. A number of these parallels are constructed solely through a montage of moving images - for example, when a voice-over commenting on the death of Ivan the Terrible is accompanied by footage of Stalin lying in state. The documentary argues that the crises of the 1990 s and the early seventeenth century share yet another characteristic. The existing power vacuum was not only exploited by a small group of political elite to their personal advantage, it was exacerbated by foreign (i.e. Western) interference. Images of packets of dollar bills, smiling politicians and signs with anti-American slogans ('Yankees, get out!') indicate Western influence over the process of democratisation and the transition to a market-oriented economy in the (early) 1990s. It is argued that foreign 'occupation' temporarily compensated for the ruling political elite's lack of legitimacy. To end a Time of Troubles, and for a strong Russian state to re-emerge, the foreign 'occupier' has to be expelled and state power restored.

The Russian state, according to the same logic that has it repeatedly slipping into political chaos, also succeeds in eventually overcoming these periods of near-collapse. But, so the documentary warns, emergence from a Time of Troubles is a prolonged process. Two factors are outlined as decisive for the restoration of political order: the will of the Russian people and the Orthodox Church. Also here a parallel is drawn between 1612 and the transition from the 1990 s to the Putin era:

Without the spiritual sanction of the Church, which at the time was the only remaining all-Russian legitimate institution, just like it was four hundred years later, there would have been nothing on which to found a people's militia to restore the country.

In these concluding passages, the Soviet parallel that was featured throughout the documentary remains absent and is also less self-evident. If, indeed, the Russian Revolution was a Time of Troubles, when did it end? Which period in the early history of the Soviet Union should be considered as the period of restoration and, consequently, to be in some ways analogous to the present? 
This is but one example of instances where the divergent parallels drawn between periods and historical leader-figures appear to be incongruous, even mutually exclusive.

All four documentaries discussed above remediate visual memory texts to support and enliven their narratives. Yet, whereas in the 2005 documentaries the (audio-)visual materials served to visualise the particular event being discussed and, therefore, had an affirmative effect, in the latter documentary we find a recurrent discrepancy between narration and image. Here, rather, remediation is a destabilising factor; it complicates the argument by implicitly introducing additional historical parallels. The frequency of these incongruences suggests that, first, the documentary is as much about the relation between contemporary Russia and its Soviet past and the overarching claim of Russia's historical continuity as it is about portraying the 1990s as a Time of Troubles. Second, it is clear that the suggestive montage is a deliberate strategy that is implemented throughout the entire documentary. Consider, for example, the following sequence in which Leont'ev introduces the topic of 'legitimate power':

There exists such a concept of 'legitimate power'; that is, power that is lawful. Moreover, not only, and not so much as in the formal and legal sense, but [as it is understood] in the collective consciousness of the people. Only a legitimate power can be stable, only such a legitimate power can endure the trial of crisis, only that kind of power has the right to undertake tough actions against its enemies.

For the narrator, the mentioning of 'tough actions' suffices to leave behind the topic of the previous passages, Boris Godunov, and to introduce Ivan the Terrible, who is commonly held to epitomise this kind of cruelty exercised by the state against its enemies. The narration about Ivan is, however, accompanied by scenes taken from the late Soviet film Boris Godunov. So, while the narrator recounts how Ivan the Terrible committed filicide, the viewer is presented with footage recounting the political repressions of a political leader who reigned almost two decades after him.

The mixing of the two rulers in fact serves as a prelude to the subsequent temporal leap to the twentieth century and the introduction of Stalin. Suddenly, and in image only, the narrative presents the viewer with a brief sequence on Stalin and the Gulag. We see historical footage of Stalin standing on a ship navigating the Belomor Canal, constructed by forced labour of Gulag inmates, followed by a close-up of the Soviet leader facing the camera and looking on with determination. A folkish, old-sounding tune accompanies the black-and-white images. As the music continues, the documentary shows footage of a group of prisoners marching under armed guard. Then, images of a train moving through the snow-covered landscape and the felling of large pine trees suggests we are heading east into Siberia. Even though the marching prisoners and winding train tracks would have sufficed to indicate 
the topic to the viewer, the shot of prisoners behind bars being transported on the train leaves little room for other interpretations. Instead of putting forward a negative appraisal of the events shown, the optimistic music continues; the train continues on its way. In the images that conclude the Stalin sequence, the viewer again sees him, this time from the back, looking forward across the water. The Stalinist intermezzo concludes as suddenly as it began. The music ends and the narrator again highlights his central argument:

Nonetheless, according to the popular consciousness, Ivan Vasil'evich was a cruel tsar but [acted] within his rights. In popular folklore, there are no examples of a negative attitude towards [Ivan] the Terrible, because Ivan was a legitimate [ruler] by the standards of the medieval tsar, anointed of God.

As Leont'ev proclaims in the voice-over that Ivan the Terrible was a legitimate ruler, notwithstanding his exceptional cruelty, one of the most famous scenes from Ivan the Terrible Part I is shown. In this scene, Ivan, who has abdicated the throne because of his mistrust of the aristocracy and has left Moscow, is asked by the Russian people to return to the capital and reclaim his position as tsar. Ivan eventually agrees, but only under the condition that he be invested with absolute power. The absolute rule of the state leader is presented as a 'social contract' between the monarch and the people, who have asked for his protection and guidance. As a result, the montage described above places Stalin in the context of returning cycles of state violence and repression.

The argumentative power of (moving) images, as evinced by these documentaries, leads me to briefly reflect on how such remediated audiovisual materials interact with both individual and collective memory, and in what ways it may influence viewer interpretation. As demonstrated above, remediated materials are edited and processed in various ways, all of which influence their respective meanings and affective effects. They can be used to perform many functions, such as:

1 Fillers ('random' archival footage, period contextualisation, geographical contextualisation)

2 Character builders (images/audiovisuals of specific persons to visually complement and fill out a characterisation provided by the voice-over or narrator)

3 Enliveners (added sound effects, acted scenes, scenes from feature films)

4 Iconic images (images or audiovisuals that have become synonymous with a period or character, e.g. Eisenstein's films, certain paintings). The recognisability of such imagery helps to ease in the message and reduces friction in the viewing experience.

5 Emotive triggers (specific images that have the potential to elicit a strong, emotive effect)

6 Justifiers (shots of documents or books, specific uses of archival footage) 


\section{Case studies}

7 Cheats (material that has been manipulated for it to perform one of the functions outlined above, e.g. manipulation of feature film to appear blackand-white and serve as periodisation (1) or authentic footage (1 or 6)).

All these functions were reviewed in passing as we discussed the four documentaries. Still, through montage, a fragment can also become a vital element in a line of argument that transcends its direct content and referents, as was the case with the suggestive sequencing in the latter documentary. In the analysis of Vladimir Mirzoev's Boris Godunov we will come across another example of such argumentative juxtaposition of archival footage.

Which strategies to use, and to what extent they are employed (either consciously or subconsciously), are decisions made by the director and, to a lesser extent, the editor(s) involved. One of the professionals interviewed for this study, a former archival editor for the Kul'tura channel, was responsible for locating and selecting suitable video fragments to be included in documentaries and other productions (Interviewee A). The initiative in this selection process, the interviewee asserted, lies with the director. This does not necessarily mean that the final selection is entirely intentional on the director's part. For example, the director's understanding of the different types of available materials may not correspond with reality: the interviewee recalled once receiving a request to supply a director with archival footage (khroniki) of Karl Marx. With regard to the editing process itself, and with determining how montage affects the meaning and emotive impact of constitutive elements, the director is again decisive. According to Interviewee B, a television video editor, the editor's role is typically restricted to the technical execution of edit cues from the director, with little or no personal input allowed.

While, for a director, archival footage and (dated) feature film may simply be a cheap and effective means to visually fill out a documentary, the potential affective effect of including such material on the viewer is significant. Indeed, when 'contemporary screen-representations of these historical periods make use of visual material from well-known films of the Soviet period', as Sander Brouwer argues with respect to two of the documentaries discussed above, such use 'filter [s] the 'cultural memory' of these distant events through the prism of the Soviet "collective memory"' (Brouwer 2016b: 123). How exactly the affective structure is influenced by the inclusion of these materials differs (greatly) from one particular example to the next and defies theoretical generalisation. Indeed, as we have seen, the practice of remediation can work to either neutralise the opposition between the different periods in Russian history (for instance, the filter overlays in Skoblin's Time of Troubles; the Ivan-Stalin sequence in Buturlin's The Time of Troubles) or, on the contrary, it can reinforce the differences.

\section{2: Chronicles of the Time of Troubles (2007)}

In addition to the television documentaries discussed above, Vladimir Khotinenko's blockbuster historical film 1612: Chronicles of the Time of Troubles 
(1612. Khroniki smutnogo vremeni, 2007) made a considerable contribution to refreshing Russians' memory about this turbulent episode in national history. It makes extensive use of Hollywood stylistics, incorporates fantasy elements (among other things, a unicorn) and is overflowing with special effects. 1612, therefore, had far greater appeal and, consequently, potential impact than the documentaries discussed earlier, especially on the younger generation. As with the documentaries, the film is generally presumed to be a goszakaz, a production commissioned by the Kremlin to explain the events commemorated on the Day of National Unity. As the reviewer for Kommersant put it, it was a 'kinopodarok' to the authorities, a cinematic gift (Maslova 2007). A glance at the parties involved in the production appears to confirm close links to the powers that be. 1612 was co-produced by Nikita Mikhalkov (see also chapter 3), Leonid Vereshchagin (director of Mikhalkov's production company TriTe) and Viktor Veksel'berg, a patriotic oligarch involved in 'the business of blockbuster history' (Norris 2012: 255). The production was backed by the commercial bank VTB and the power holding company Unified Energy System of Russia, ${ }^{12}$ and was subsidised by the Federal Agency of Culture and Cinematography. In addition, Veksel'berg reportedly contributed four million dollars to the production budget (ibid.). The date of the release, 1 November 2007, coincided with the holiday celebrations and conveniently preceded the parliamentary elections that took place on 2 December that year. In an interview with Izvestiia, Khotinenko argued that the Time of Troubles is one of the most important periods in Russian history. Moreover, he stated, it provides an essential historical parallel for understanding the post-Soviet development of the country: 'I am talking about the period after Perestroika. We lived in another Time of Troubles for a long time. It even coincided with the one in the 17th century in duration' (Ramm 2007). According to Khotinenko, the post-Soviet Troubles thus ended soon after Putin took office.

As was the case with the film Aleksandr: The Neva Battle, discussed in chapter 4, the production explicitly diverges from its iconic Soviet predecessor to avoid coming across as a remake. In fact, unlike in Minin and Pozharskii, the two heroes who liberated Moscow play only minor roles in 1612. The main protagonist is an ordinary man, an enslaved serf named Andrei (Petr Kislov). When first introduced, Andrei is sold to a Spanish mercenary on his way to join the Polish troops. When the Spaniard is killed, Andrei assumes his identity and, together with his Tatar friend Kostka (Artur Smolianinov), plays a decisive role in the military defence against the Poles. In the end, Andrei is crowned tsar as Mikhail Romanov, based on a fictional genealogy drawn up by the boyars who elected him. Andrei's motivation to take up arms in the first place is highly personal. He wants to save Godunov's daughter, Kseniia, with whom he has been in love ever since his childhood at the Godunov court. She is held captive by the Polish lord Osina, who plans to use her to make a claim on the Russian throne. This fictional dramatisation of Kseniia's life is a pivotal element in the storyline. In effect, Kseniia becomes the female personification of a Russia held hostage by the Poles. Osina forces her to give 
up her native language and convert to Catholicism, mimicking the (supposed) attempts to assimilate Russia under Polish rule. Despite the ordeals she has to endure, Kseniia fights to stay true to her Russianness and her Orthodox faith. As her male counterpart, Andrei then comes to personify the Russian people who rise up to the challenge of liberating her. The appearance of Minin and Pozharskii is slightly awkward, as they do not take part in the actual action. In the words of a reviewer for Russkii Zhurnal, 'Why do we need Minin and Pozharskii when we [already] have Andreiko [diminutive of Andrei, M.W.] and his unicorn?' (Maler 2007). Yet the fact that they are included at all affirms their iconic importance. The two heroes who stand immortalised on Red Square continue to be the most recognisable personifications of the Time of Troubles. As such they are an effective memory trigger. The brief appearance of the two heroes suffices to integrate the film into the intertextual web of associations connected to the memory. The representation of the Time of Troubles reiterates the core elements of memory established by previous mediations. In contrast with the products of Soviet memory culture, 1612 presents the Orthodox faith as the unifying force behind the Russian nation and as the keeper of Russia's spirituality (dukhovnost') in times of political turmoil.

Khotinenko plays fast and loose with the historical facts; any illusions one might have concerning the film's historical accuracy are soon shattered. Indeed, the take-home history lesson boils down to a rather simplistic message along the lines of 'there once was a Time of Troubles and it ended in 1612 when 'we' kicked out the Polish interventionists'. In comparison with Minin and Pozharskii, 1612 places more emphasis on the distinction between the opposing sides in the conflict. For example, in the Soviet film all characters speak Russian, including the Poles. In 1612, members of each nationality speak their own language. Moreover, Kseniia's speaking Polish with Osina is explicitly portrayed as a betrayal of her Russian roots. Second, the conflict's religious aspect is foregrounded; the Russian side has to wage battle to preserve its religious independence. Here it is suggested that the Poles, in turn, are influenced by the Pope. In the end, however, so the film tells us, the concerted efforts of Russia's Western enemies to subjugate Orthodoxy fail and, thanks to the victory over the Polish-Lithuanian occupiers, Orthodoxy continued to form a central element of Russian identity. We came across a similar conspiracy of European states aiming to convert and culturally subjugate Russia in Aleksandr: The Neva Battle (see chapter 4). There is one exception to the strict opposition of religions and cultures: Tatar Kostka is portrayed as a true Russian who is willing to fight for his Motherland yet, at the same time, adheres to his own cultural practices and beliefs. For example, when Kostka decides to marry a Russian girl, the marriage is performed according to the rules of his community through the public proclamation 'Wife, wife, wife!' Kostka, thereby, becomes the poster boy of Russian tolerance and singlehandedly establishes the Russian Empire as a multinational polity. 
Khotinenko has denied the allegation that the Russian authorities commissioned the film. 'If there was [a state directive]', he stated, 'then it was completely imperceptible to me.'

I discussed the goals of the film with the general producer Nikita Mikhalkov. Together we looked at the material, discussed it, he made some comments. But he was extremely delicate in this. We reasoned like this: ' 1612 ' is shot for a contemporary young audience, so the story has to be entertaining and humorous. There were no other goals.

(Ramm 2007)

While talking about his intentions for the film, however, Khotinenko repeatedly gets tangled up in his own formulations. As he tries to articulate his vision in a way that would circumvent any admission of government involvement, he nonetheless ends up explaining how the film's style is aimed at bringing across the new holiday's message.

I could have shot a quasi-historical austere film, but then a very limited number of viewers would have watched it. And I would not have fulfilled my task. No, not a directive from the Kremlin, but my own creative task, that is more important to me. I really wanted as many people as possible to learn about this period. So they know it is not just an arbitrarily named holiday in commemoration of an age-old victory over the Poles. It is not about the Poles at all. It is our concern [nashe delo], our history.

(Ramm 2007)

As a result, his denial lacks credibility. Arif Aliev, the writer of the script, concedes more in his answer and grants that '[p]robably there was an order to produce it'. He then hurries to downplay the negative connotations associated with accepting state directives by pointing to historical precedents.

But if you visit Luxor [Egypt] and get to the bottom of how ancient Egyptian architecture was built, you'll be astonished to discover the strict frameworks within which the architects created their buildings. All temples were created by government decrees. And yet they are rational, harmonious, and emotional. So the strict framework helped the artist. If there is no framework at best you get the Black Square. This would be the death of audience-friendly cinema.

(Quoted in Norris 2012: 262. Italics in original)

It is interesting, in this respect, that not much in the film actually informs the audience about the historical events or, for that matter, the intended meaning of the holiday. Moreover, the remainder differs little from other recent (Hollywood) fantasy action films in everything from its narrative structure to its character development, to its visuals and humorous interludes. 


\section{Case studies}

Indeed, one reviewer criticised the film because he felt the fantasy aspect overshadowed its educational aim.

As a result, while watching you get the impression that you are watching [...] a bad version of 'Lord of the Rings' [...]. You get the suspicion that they wanted to film another fantasy story on alternative history, like 'Volkodav' [Wolfhound of the Grey Hound Clan, Lebedev, 2006, M.W.] but then even more unreliable [nedostovernee], but then the opportunity arose to turn it into a historical film under goszakaz; therefore we now have a Spanish cavalier alternating with unicorns in the fairy-tale forest of indeterminate ancient Rus' [neopredelenno-drevnei Rusi]. But what has the year 1612 got to do with it? How is this about the national holiday?

(Maler 2007)

Notwithstanding its initially lukewarm reception by both viewers and reviewers, 1612 has since become a new staple representation of the Time of Troubles. In the years after its release, the major TV channels included broadcasts of the film in their programming to mark the Day of National Unity and, on one occasion, Defender of the Fatherland Day (23 February). ${ }^{13}$

What, then, can the film tell us about the aims, intended message and style of films produced in close rapport with the state in this period? Andrei Archangel'skii convincingly argues that 1612 is in many ways an exemplary product of contemporary Russian goszakaz. Lacking underlying ideological convictions or values, he asserts, these films aim to propagate the particular type of patriotism that has been actively fostered since Putin first took office: patriotism that invests primary importance in the state for securing the well-being of its citizens.

The cult of stability, and essentially the cult of power, is not a value, not an idea. Today, goszakaz does not seek to change the individual [since] it understands the futility of this task in an open society. All efforts are aimed at the instillation of a single thesis: that the concepts of 'current life' and 'power', 'power' and 'patriotism', 'power' and 'Motherland', 'power' and 'Russia' are inseparable, equal, identical. And therefore the state is sacrad and constitutes an a priori value. With the help of goszakaz, the state now, first of all, protects itself, tries to imbue [the viewer with the notion] that it is more important than the individual, even though it claims the opposite in words.

(Arkhangel'skii 2013)

State patriotism as a body of thought, then, allows itself to be woven quite subtly into all kinds of stories and genres, ranging from historical entertainments such as 1612 to documentaries, TV series and even talk-show formats (as we have seen in the previous chapters). It provides a core motivational structure for the narrative, beyond which there can be a great measure of 
differentiation in execution and style. The secondary emphases may differ for example, the stress on the importance of national unity with regard to the Time of Troubles, or exceptional leadership and the managing of oppositional forces in the case of Petr Stolypin - but in the end they all invariably claim primacy for the state. In the 2011 TV series on Peter the Great (Bortko, broadcast on Rossiia 1) Peter Rollberg discerns a similar pattern. 'Peter the First: The Testament makes it abundantly clear what the tsar is fighting against, but not what is he fighting for' (Rollberg 2014: 353. Italics in original). As a result, Rollberg argues, '[s]tate stability and continuity are consistently invoked as values per se, needing no further legitimisation' (ibid.). In 1612, the glorification of the state security apparatus is further reinforced by the casting in several of the supporting roles. For example, Mikhail Porechenkov, who plays Pozharskii, was generally known at the time as a national security agent in popular Channel One TV series such as The Storm Gates (Grozovye vorota, Maliukov, 2006) and the sixth season of Lethal Force (Uboinaia sila, Snezhkin, 2005). For the role of Minin Andrei Fedortsov was cast, an actor who had played leading roles in the film Russian Special Forces (Russkii spetsnaz, Mareev, 2002), its successor TV series Russian Special Forces 2 (Spetsnaz po-russki 2, Mareev, 2004) and all six seasons of Lethal Force. The casting creates (yet another) direct connection between, on the one hand, the Time of Troubles and those who succeeded in safeguarding the state back then and, on the other hand, contemporary national security organs.

Furthermore, the film demonstrates how the state has attempted to 'efficiently [constrain] debate of such sensitive topics as imperial collapse' (Condee 2008: 182) through its memory politics. The internalisation of this narrative of collapse is highly paradoxical. As Nancy Condee rightly argues, productions such as 1612 and the TV series Death of the Empire (Gibel' imperii, Khotinenko, 2005) offer evidence of how 'patriots of today are licensed to address, among other topics, Russia's vulnerability to periodic collapse' (ibid.). Yet permission to show Russia's weaknesses is granted only in order to effectively argue the contrary: 'A simulacrum of risk, this institutionalization of crisis strategically undergirds and strengthens precisely the myth of imperial continuity over the centuries, at the behest of a highly centralized, statist production structure' (ibid.). The implicit and explicit references to the primacy of the state and its security forces, which abound in the TV series mentioned by Condee even more explicitly than in the film, further affirm the myth. ${ }^{14}$

Let us now move on from the state-aligned productions that, by and large, supported governmental memory politics, and turn to a film production that sought to subvert its central premises in the concluding section of this chapter.

\section{Boris Godunov (2011)}

In contemporary Russian memory culture, memory clusters provide important entrance points for the formulation of alternative and/or critical memory narratives, as I argued in chapter 2. Shifting attention from one figure or 


\section{Case studies}

narrative in the cluster - here, the end of the Time of Troubles - to another associated memory - in this case, Boris Godunov - mobilises the subversive potential engrained in the dynamic nature of cultural memory. This chapter's final case study aims to elucidate how this subversiveness is enacted. It examines how the memory of Boris Godunov was employed to provide a counter-narrative to the state-sponsored interpretation of the contemporary significance of the Time of Troubles as it has been outlined above. A discussion of the film Boris Godunov (2011) directed by Vladimir Mirzoev forms the core of the analysis. The film builds upon and adds another chapter to the long tradition of artistic representations of the reign of Boris Godunov. As will become clear from the analysis that follows, Mirzoev's contemporary cinematic interpretation constitutes a decisive turning point in the political significance of Godunov's memory in contemporary Russia. Yet he was not the first (art-house) director to address the topic in post-2000 Russia. Acclaimed film director Aleksandr Sokurov ventured beyond his familiar terrain to direct a modern adaptation of Musorgskii's opera for the Bolshoi Theatre in 2007. Contrary to established tradition, Sokurov took the rarely performed 1871 version of the opera as the point of departure. According to a reviewer for Nezavisimaia gazeta:

For Sokurov, 'Boris Godunov' is yet another occasion for reflection on the themes 'power and personality', [and] 'father and son' that are central to his work. To him, 'folk drama' (in the style of Musorgskii) takes second place; it rather becomes a context that helps to uncover the characteristics of a person, of his personality, his actions and their consequences.

(Gaikovich 2007)

In an interview with Izvestiia, Sokurov confirmed that the play fits in particularly well with his tetralogy on power, which includes the films Moloch (1999), about Adolf Hitler, and Taurus (2001), portraying Vladimir Lenin (Babalova 2007). In Sokurov's interpretation, Boris is not a madman - as he is often portrayed - but a man who realised his dream of becoming tsar. This, in turn, affects the general tendency of the play:

We are not creating a depressing performance; we are not doing a performance, where you should be in tears after the death of Boris. Our Boris is a strong person. All of our characters are strong. It is a story about worthy opponents, [about] different yet very strong people. Godunov accepts death without fear. Perhaps, with some sadness, but without fear.

(Babalova 2007)

Mirzoev's Boris, instead, draws upon the theatrical tradition and directly contests the political use of the Troubles memory. More specifically, it 
contests the claim that the post-Soviet Troubles have come to an end under Putin. Mirzoev takes Pushkin's theatrical classic and transposes it to presentday Russia. As the actors pronounce lines from the original text, the skyscrapers of Moscow-City provide the contemporary backdrop for its tale of political intrigue. The temporal transposition makes it evidently clear that the questions the narrative puts forward are no less valid today than they were at the time of Pushkin's writing. This is also why many interpreted it as a film critical of the state, despite Mirzoev's denial that it was. The film premiered on the Day of National Unity and was screened in just one movie theatre in a Moscow suburb. Already at the time of its release it was suggested that the film's distribution had been deliberately hindered because of its potential political resonance. For instance, in an interview with the director on TV channel Dozhd', an interviewer asks why the film was only screened in one out-of-the-way cinema ("Vladimir Mirzoev: "Borisa Godunova" nikto ne zapreshchal' 2011). She interprets the film's not being shown in other (arthouse) cinemas as a clear sign of top-down obstruction. Mirzoev's reply is telling. He emphasises the pragmatic, economic concerns that informed their decision to opt for a limited screening and aim for a television broadcast or DVD release instead. As it is highly unusual to earn back production costs through box-office ticket sales, he states, it would be senseless to spend another million roubles on the advertising campaign necessary to get people to go and see the film in theatres. When a second interviewer again insists that there must be a link between the film's 'sharp political statement' and its limited distribution, Mirzoev replies that he and the others involved with the film did not intend to produce a political satire. Instead, they sought to explore the effect of clashing time periods, of the seventeenth century, Pushkin's time, and the present; to explore 'denotations, associated with autocracy, absolute rule, imposture, [that] turn out to be very relevant to us up to this day' (ibid.). It must be noted here that uploads of the film were quickly posted to YouTube and Vkontakte, which allowed anyone interested in the film to see it very easily regardless of whether its cinematic distribution had been actively obstructed.

The delivery of Pushkin's (well-known) nineteenth-century lines in a completely modernised setting has two contradictory effects. The easy merger of both worlds - visual and verbal - reveals the continuing relevance of the story and its underlying questions, and how the Putin regime is perhaps less 'post-' than it would like to appear. There are a few instances, however, where the narrative feels (intentionally) awkward. The scene where Godunov accepts the throne in the presence of the Patriarch and boyars is the most explicit example of such an effect. Godunov speaks laconically and without conviction. His declaration sounds 'fake', in stark contrast to actor Maxim Sukhanov's persuasively passionate performance throughout the rest of the film. How to interpret this moment, where what you see and what you hear are 'unlinked', is determined, I would suggest, by the scene's recognisability. A comparable image of a long table, presided over by the head of state who is flanked by 
state officials in business suits and the patriarch, appears frequently on the Russian news. The intertextual referentiality - from film to news image and back - enables a similar transposition of the feeling of awkwardness from 'historical' fiction onto contemporary political reality. By making the viewer experience the artificiality of political speech, such statements are exposed as being merely part of a modern façade disguising the age-old driving forces that, in reality, continue to motivate Russian governance.

In addition to its modern setting and strict adherence to Pushkin's original lines, the film stands apart from previous adaptations in two important ways. First, Godunov is not simply tormented by feelings of guilt but is actually haunted by the ghostly appearance of Tsarevich Dmitrii, for whose death he is allegedly responsible. As a memory text, the film therefore is yet another example of the pervasiveness of 'ghostware' (Etkind 2009) - vampires, ghosts and other uncanny apparitions - in post-Soviet Russian culture. As Alexander Etkind argues, these 'uncanny' appearances are symptomatic of the lack of acknowledgement for the crimes committed by the Soviet authorities against their own population. 'In a land where millions remain unburied', he writes, 'the dead return as the undead' (idem: 182). While Etkind's conceptualisation of ghostware is primarily based on the (ghostly) return of victims of the Gulag, the tsarevich's outfit and haircut reveal that Mirzoev is speaking to yet another traumatic event. Dressed in a marine costume, the ghost of Tsarevich Dmitrii evokes memories of that other murdered tsarevich, Aleksei, who was often pictured that way. The death of this heir to the throne in 1918, Mirzoev appears to suggest, came at the beginning of another Time of Troubles: the Russian Revolution and subsequent Civil War. If we follow Etkind's line of argument, Aleksei's return as an 'uncanny' presence can be interpreted as a reflection of the fact that members of the murdered imperial family did not receive proper burials until the late 1990s. The remains of the tsarevich and one of his sisters were located and exhumed from a forest near Yekaterinburg only in 2007. In addition, the apparition points towards the ongoing problematic nature of public condemnation of the crime. For example, in November 2015 the inhabitants of Moscow voted against a proposal to rename metro station Voikovskaia, named after one of the organisers of the execution Petr Voikov, in an electronic referendum ('Moskvichi progolosovali protiv pereimenovaniia "Voikovskoi"” 2015).

The allusion to Tsarevich Aleksei forms an important element in the second distinctive feature of the film as well: the merging of temporal layers goes beyond establishing a connection between the Time of Troubles and today's Russia. The citation of Pushkin, of course, subtly introduces a nineteenth-century subtext. More importantly, however, is a sequence that reinforces the evocation of the early twentieth-century history by the ghostly appearance of Tsarevich Aleksei. As the False Dmitrii marches on Moscow, shots of the actors fighting from trenches are interspersed with archival film footage of an unidentified battlefield, likely dating from the First World War. The footage shows charging groups of foot soldiers, the firing of cannons and 
machine guns, and tanks and explosions. The explanation for including these images can, of course, be simply budgetary. Unlike Bondarchuk's 1986 production of Boris Godunov, which features extensive battle scenes with cavalry and plenty of foot soldiers, Mirzoev had to work with a minimal cast and an equally limited budget. The archival footage, then, is an effective substitute for these indispensable, but budget-wise unattainable shots of battlefield action. The highly dated visual materials, however, suggests there was more informing the selection than simply practical concerns. Moreover, it has a highly significant effect: since the images are obviously from neither then (the seventeenth century) nor now (the twenty-first), the battlefield becomes an abstract, de-temporalised space. Without recognisable features, it can be whenever and wherever. As a result, memories of other, more recent wars and their (documentary or fictional) visual representation are drawn into the narrative (e.g. the Chechen wars and the Russian military intervention in Georgia). On the contrary, the grand battle scene in Bondarchuk's Boris, showing outdated fighting techniques, was obviously placed in the past and thereby created temporal distance for the viewer.

That the film was not actually banned top-down from reaching a wide audience becomes clear from its being aired in 2013 by one of the major state TV channels, Channel One, albeit just after midnight. It was part of the programme Private Screening (Zakrytyi pokaz). ${ }^{15}$ The format of the show begins with a brief introduction of the film and its director, followed by a full-length broadcast of the film, which is then discussed by a panel of specialists in the presence of the director and members of the cast. The panel is divided into two groups, those in favour of the film and those against it. As can be expected of any panel of Russian experts discussing a cinematic interpretation of a Pushkin play, they are mostly concerned with whether it is a correct rendering of Pushkin's original. But, interestingly, this programme on state television also shows the film being perceived as a reflection, rather than critique alone. The show's host, Aleksandr Gordon, expresses the opinion that Mirzoev is an 'anti-romantic': he does not adhere to the romantic worldview, which interprets reality in terms of absolute laws, patterns and divine harmony. Instead, he highlights the absence of such laws, and therefore the impossibility of judgement - the impossibility of differentiating between right and wrong. According to Gordon, Mirzoev does not paint a distorted picture of the present. Rather, he holds up a mirror to the viewer, who is then confronted with the fact that there are no absolute principles by which to interpret the meaning of his direct reflection. Mirzoev appears to agree with this analysis and connects it to the film's central topic of autocracy. He states:

If we acknowledge that the world is now fundamentally heterogeneous, polyphonic, polysemantic and so on, then how can one person, [...], even a great person [...], be the absolute focal point of the history and fate of a vast country? This is unrealistic. 


\section{Case studies}

It is clear that Mirzoev's observation implicitly refers to Putin. Still, the subtlety of the clash of time periods indeed points towards a reflexive intention, an intention to transcend the immediate political context and contemplate persistent patterns in Russian governance. The eagerness of critics, of conservative and oppositional orientations alike, to read political critique into the film partly obscured this aspect. Also, it testifies to the polarised nature of the public debate as tensions increased in late 2011.

The continuing power of the film was more recently acknowledged at a conference on theatrical adaptations of literary classics held on 31 March 2015 by the Likhachev Research Institute of Cultural and Natural Heritage. ${ }^{16}$ Examining the merits of so-called experimentalist interpretations, Mirzoev's film was put forward as an example of an adaptation straying too far from the original. According to Aleksandr Uzhankov, a professor of the Literary Institute, Pushkin is nowhere to be found in Mirzoev's rendering. He states:

[Mirzoev] seems to take a historical layer, the same characters, but [suddenly] there appears some boy in a sailor suit, implying that this is already not the 17 th century, but the 20 th, an allusion to the revolution. And Boris Godunov is not the one who came to the throne, and not an allusion to Yeltsin, but already an allusion to some 'New Russian' who, by principle, cannot rule the whole world.

(TASS 2015)

Other recent theatrical productions based on Pushkin plays receive equally condemnatory judgements. The experts conclude that, while directors cannot be coerced to relate to their subject matter 'like Pushkin, with love for Russia' because that would be a form of censorship, they strongly advise the Ministry of Culture to finance only those productions that 'do not destroy tradition, but, instead, contribute to the upbringing of a generation' (TASS 2015).

One of the plays that gave particular offence to the experts was a contemporary interpretation of Pushkin's Boris Godunov directed by Konstantin Bogomolov, which premiered at the Lenkom Theatre in Moscow in 2014. In many ways, this built upon the aesthetics developed by Mirzoev and employed similar tactics: collapsing historical time, modernising the stage setting and incorporating the visual aesthetics (and here, also the language) of the mass media (author's visit, 29 September 2014). Contrary to what Mirzoev does, Bogomolov's play deviates freely at times from Pushkin's lines in both language and narrative content. Large screens on either side of the stage were used to make implicit historical parallels unmistakably clear. For instance, as Boris Godunov placed the Monomakh Cap on his head, images of the presidential convoy on its way to Putin's inauguration ceremony were shown on screen; when Ivan the Terrible was mentioned, the screens lit up with an image of Stalin; at the mention of Andrei Kurbskii, the boyar who betrayed Ivan the Terrible by defecting to Lithuania, the audience was presented with a picture of Boris Berezovskii. The play actively engages the 
audience in such a way that it creates tension. When Boris Godunov, played by acclaimed theatre actor Aleksandr Zbruev, appears on stage, a person from the audience yells 'Aleksandr Viktorovich, aren't you ashamed of yourself for taking part in such postmodernist nonsense?' In response, Zbruev draws a pistol and shoots the man, who, it is then revealed, is part of the show; the shooting is a simulation, not an actual assassination. Another moment of noticeable discomfort among audience members occurred as the 'people' await the arrival of their tsar. The scene's spatial organisation invites the audience to associate itself with the people. In a painfully protracted scene, the screens repeatedly showed the lines 'The people are stupid cattle' and 'The people patiently wait to be told what will happen next'. While the play is more direct and radical in its execution than Mirzoev's film, its political argument largely coincides with the latter's. Placing equal emphasis on the cyclical nature of historical development in Russia, it paints a grim picture of the prospects for actual political change in the near future.

Mirzoev's perceptiveness about political mythmaking is confirmed by a play he directed for the controversial theatre company Teatr.doc in 2013. The play Tolstoi - Stolypin: Private correspondence is based on a script written by Ol'ga Mikhailova. It embeds historical documents - the correspondence between Stolypin and Tolstoi - within a fictional narrative framework that has the two men come together in the city of Penza to aid a peasant woman put on trial. There, they engage in a polemic 'about private property, the court, the role of the state in man's life, matrimony and violence' (Matvienko 2013: 96). The play approaches its topic in a way comparable to Mirzoev's film: it draws out points of historical convergence and enduring socio-political tensions, yet its authors are reluctant to provide their audience with conclusive take-home answers to the fundamental political questions posed.

Mirzoev, with his love for transformations, leaves the message implicit [and] multi-faceted. The story, which gravitates, it would seem, to an unequivocal conclusion, becomes blurred by the changeable nature of his directing. And this, as a result, reconciles some with the bitter fate of the peasant woman, who is protected by neither justice, nor even Tolstoi and Stolypin, and others with the untimely death of the reforms that were not fated to gain a foothold in the fertile Russian soil.

(Idem: 97)

The topic and timing of the production, staged shortly after the state efforts to promote Stolypin peaked in 2012, testifies to Mirzoev's continued willingness to provide a counter-narrative to such state-supported memories.

\section{Conclusion}

In 2014, Putin was presented with a secondary school history textbook entitled The History of Russia 2014-2045 at the infamous Seliger patriotic youth 
camp. ${ }^{17}$ The book, published in ' 2045 ', was prepared by scholars of the People's Friendship University of Russia and describes (or forecasts, if you will) Russia's near future. In its rosy depiction of what lies ahead, the textbook reiterates the central elements of the official political and national identity discourse. Yet it deviates on one meaningful point. The Constituent Assembly, it writes, confirms the end of 'the third Time of Troubles' in 2019 (Voronin et al. 2014: 14-15). Why does this evidently Kremlin-loyal publication place the end of this third smuta in the future, moreover at a five-year distance? What ever happened to the claim that Putin has already succeeded in overcoming the Troubles of the 1990s in his first presidential term?

With the establishment of the Day of National Unity, the Russian government had tried to capitalise on the (by then established) practice of interpreting the turbulent 1990s as a Time of Troubles. The cultural memory and its underlying cyclical conception of historical development were used to symbolically ground the contemporary Russian state in history and undergird Putin's legitimacy on the basis of his success in delivering Russia from its latest return to chaos. To underscore the claim of historical continuity linking the pre-revolutionary, Soviet and Russian periods, the 'invented tradition' of 4 November was explicitly introduced as a 'reclaimed tradition', as re-establishing a tsarist commemorative practice. As Sander Brouwer correctly points out, '[b]ehind the Smuta-talk there really is the Empire-talk, a form of statehood presented as peculiarly Russian - so as to include the Romanov as well as the Soviet period, plus the modern Russian Putin regime' (Brouwer 2016b: 138). It is an attempt to foster an understanding of patriotism that grants primacy to the state. Moreover, it is an effort, at times awkward and contrived, to reconcile a multi-ethnic (imperial) ideal of state governance with the attribution of a privileged status to and leading role for Russian (Orthodox) culture within that state. As time progressed, the balance between these seemingly opposing ideals increasingly favoured the primacy of Russian culture, language and heritage, which has, more recently, come to dominate the political and mainstream media discourses.

As a tool for political rhetoric, the mnemonic framework of the Time of Troubles works two ways: it can either assert that stability has been restored and Russia has once again emerged as the great power it is destined to be, or it can be used in a cautionary sense to warn that, in Russia, there is inevitably a constant risk of revolution and a return to chaos, such that anyone who rocks the boat and threatens the status quo should be repressed. While the usage of the memory typically combines both aspects, the emphasis gradually shifted from affirmative to cautionary over time. That the fictional history textbook places the definitive end of the 'third Time of Troubles' in 2019 fits this pattern: against the backdrop of the (then) upcoming presidential elections in 2018, the second aspect of the memory is invoked to caution that the Russian state can only fully re-emerge if the regime is given sufficient time to deal with the foreign and domestic enemies who seek to undo its accomplishments. 
As one of the main tenets of the regime's memory politics, this instrumentalisation was at once successful and unsuccessful in the period analysed. It was unsuccessful in the sense that the initiative failed to gather popular support. Opinion polls demonstrate that, by 2012, still only a small proportion of the population could correctly name the holiday and even fewer actually celebrated it. Moreover, the celebration was soon overshadowed by the nationalist marches that negatively affected its reputation. The regime's acknowledgement of this fact is evident from the shift towards integrating '1612' into a memory chain with '1812' (and, in some cases, '1945'). The linking of the victories was affirmed by their parallel celebration in the Year of Russian History in 2012. The simultaneous marking of the 1,150th anniversary of Russian statehood further emphasised how the new pantheon is dedicated to glorifying state patriotism, not national patriotism. Even as Russian Orthodoxy and the Russian nation have increasingly become central to the state's conception of post-Soviet identity, it continues to be formulated in terms of a multi-ethnic and multi-confessional 'imperial' state structure. The holiday and its narrative of 'unity in diversity' may largely have failed to take hold and, in fact, often did more to expose inter-ethnic tensions than to remedy them (Hutchings \& Tolz 2015: 73-96), but the intended political effect was nonetheless achieved: the consolidation of Putin's image as the bringer and guardian of stability, the able protector of the Russian state (and its people[s]) against foreign enemies and their Russian accomplices who aim to plunge Russia back into the vortex of troubled times. Therefore, on a more abstract level, it succeeded in realising its main goal, which was to consolidate the regime's position of power.

With regard to the mediation of memory politics and its societal dynamics, this case study shows a significant degree of variation within the initial media campaign. The documentaries and film that were part of the 'smuta-propaganda' range from factual to insinuating and employ a wide range of stylistic approaches. Notwithstanding the variation in execution, style and content, all adhered to the central components of the smuta memory (and by extension, the Putin myth). In addition, the case study has shown that there were, in fact, counter-narratives - for example, in theatre and cinema - that were enabled by the cultural memory's remediation history and the rich cluster of associated memory narratives. The memory of Boris Godunov in particular was used to frame political critique and question the state's memory politics. The question remains, of course, how great the reach of these critical productions is, since they typically appeal to the liberally oriented, educated elite. With a limited audience, can such niche productions affect public opinion in a way that translates into real-world political consequences? In this respect, it is useful to recall that it was the educated middle class that took to the streets in the winter of 2011 and shook the political system. Also, it is no coincidence that since Putin's re-election in spring 2012, alternative cultural productions have increasingly been obstructed or targeted by harassment. With regard to theatre, the repeated evictions of Teatr.doc is the best-known example (a 
similar tactic was employed against oppositional TV channel Dozhd'). With regard to cinema, indirect measures affecting, among other things, financing and distribution now make sure that producing critical films has become considerably more difficult or even impossible. These measures include the 2014 profanity law that forbids swearing in cinema, theatre and other media and the law against Nazi 'revisionism' and the spread of 'false' information about the role of the Soviet Union in the Second World War (I will return to these measures in the Conclusion). They reveal that the authorities recognise and fear the subversive potential of alternative cultural productions, as their outspoken or sometimes, on the contrary, highly subtle critique threatens to burst the imaginary bubble of stability created by the Putin regime.

\section{Notes}

1 That same year, Kurbankhanov recorded two more songs praising Putin in no less laudatory terms, 'Thank you, God, for Vladimir' and 'Congratulations with your anniversary, Mister President!'

2 Estimates of the number of people who participated in the original russkii marsh range from two thousand to ten thousand participants (Vinogradov et al. 2005).

3 The icon of Our Lady of Kazan has since ventured far beyond Russian territory. On 7 April 2011 it reached the International Space Station where it was temporarily kept in the Russian section of the vessel.

4 Exhibitions under the same name were organised by the Russian Orthodox Church in smaller and different formats in St Petersburg, and later Moscow, since 1995. The scope of the event, however, was significantly widened and reformulated in 2006.

5 Released internationally under the name Reign: Conflict of Nations in 2010.

6 A gameplay video of the game by user 'Quarantineism' can be viewed on YouTube: 'Smuta. Level 1-2: The russian ghostbuster strikes back', 15 August 2010, accessed 1 March 2016, www.youtube.com/watch?v=M3wqfvqUOsI\&feature= youtu.be.

7 To his number one could add the 3 per cent of the respondents who answered, 'Day of the Liberation from the Polish-Lithuanian interventionists'.

8 The play was directed by Mikhail Ugarov and Ruslan Malikov.

9 With regard to the Time of Troubles, the opportunities for establishing such a direct link with the 'Great Patriotic War' are limited to and necessarily remediated by means of Stalinist wartime propaganda, including the Soviet army parade that marched past the statue of Minin and Pozharskii before heading to the Western front in 1941, mentioned earlier.

10 The first re-enactment of the battle of 1812 took place in 1987 as part of the 175th anniversary celebrations. Since then, the re-enactment has expanded and professionalised. The military festival commemorating the 1941 battle was first organised in 1999.

11 The term 'semibankirshchina' was first coined in 1996 in reference to the group of oligarchs that helped Yeltsin secure victory in the presidential elections (Brouwer 2016b: 126).

12 The company, headed by Anatolii Chubais, effectively had a monopoly on the Russian electricity market at the time but has since been reorganised.

13 Reruns of the film were broadcast by Channel One on 4 November 2008 and 4 November 2009; by NTV on 23 February 2009 and 4 November 2010; and by Channel Five on 4 and 10 November 2013. 
14 For an analysis of Death of the Empire, see Condee (2009).

15 The programme aired on 31 May 2013 at 00:15 hours.

16 This organisation was founded in 1992 to further the protection of UNESCO World Heritage sites in Russia. Affiliated with the Ministry of Culture, its tasks have more recently (in 2013) been expanded to include, among other objectives, the study of contemporary art and its perception by professional and mass audiences.

17 The Annual International Youth Educational Forum at Lake Seliger has been organised by youth movement Nashi since 2005. For a detailed description and analysis of the Seliger camps, see Mijnsen (2014) and Hemment (2015). 


\section{Ivan the Terrible and the Oprichnina: Subversive histories}

On 21 June 2012 a memorial plaque dedicated to Ivan the Terrible was unveiled on one of the central streets in Arkhangelsk, a city founded during his reign (IA REGNUM 2012). The plaque features an engraved image of the famous statue by Mark Antokol'skii of the tsar seated on the throne that is on display in the Tret'iakov Gallery. The inscription reads:

To the founder of Arkhangelsk, Great Prince of Moscow Ivan IV the Terrible, the first Russian tsar, initiator of the democratic reforms of the 16th century, patron of book printing in Rus', from the grateful people of Arkhangelsk.

At the time of its unveiling, the plaque was the first and sole public monument to Ivan the Terrible in Russia. ${ }^{1}$ The lack of public remembrance of the ruler who succeeded in massively expanding the territory of the Russian state indicates the controversial nature of his memory. Few tsars are as heatedly debated as Ivan, whose legacy never fails to divide an audience (a quality shared by, most notably, Peter the Great and Stalin). Such discussions revolve around the question of whether his geopolitical triumphs should outweigh his reputation as a tyrant. The memory carries a particularly intense emotional charge because of its close connection with the memory of Stalin. The latter included Ivan in his pantheon of national heroes in the 1940s. Yet Stalin himself was and continues to be condemned for the repressions he orchestrated through a comparison with Ivan's historical image. It is hardly surprising, therefore, that the Russian government has shied away from associating itself with the Terrible Tsar.

The praise of Ivan's 'democratic reforms' on the memorial plaque unavoidably seems a strained interpretation of events. Indeed, to apply the concept of democracy to developments in sixteenth-century Russia is problematic in and of itself. Yet the claim illustrates how Ivan the Terrible is one of the prime subjects for writers of 'alternative history', a line of revisionist thinking that contests the veracity of established historiography. As a 'misrecognised' ruler with a record of historical documentation that leaves ample room for creative interpretation of the facts, Ivan has attracted the attention of various 
marginal groups who use his memory to propose alternative types of governance for contemporary Russia. As this chapter will demonstrate, the memory of Ivan has proved to be the historical framework of choice for those at the extremes of the political spectrum who seek to challenge existing state structures.

\section{Ivan the Terrible in the Russian historical and political imagination}

Ivan IV (1530-1584) succeeded to the throne at the tender age of three, after which the boyar families at court struggled for power and his mother Elena Glinskaia acted as his regent until her death in 1538. Crowned Tsar of All Russias in 1547, Ivan was the first ruler to carry the imperial title. As a statesman, he is most noted for the territorial expansion he achieved, including the conquests of the khanates Kazan and Astrakhan in the 1550s and the expansion into Siberia. In addition, he is credited with administrative and judicial reforms. Despite his early successes, the protracted Livonian war, which aimed to push the Russian state westward and gain access to the Baltic Sea, was eventually lost. In 1565, following the defection to Lithuania of Prince Kurbskii, one of the tsar's closest boyars, and motivated by his increasing suspicion that the boyars who remained were treasonous, Ivan divided the country in two by establishing the oprichnina: a part of the state's territory placed under the tsar's direct control and administered by the oprichniki, Ivan's elite guard. The remainder of the state, referred to as the zemshchina (the 'land'), Ivan left to be ruled by a council of boyars. Until the disbanding of the system in 1572, the oprichniki terrorised the state's residents by using exceptionally cruel methods to suppress any form of (suspected) resistance. The massacre of the inhabitants of Novgorod, thought to be conspiring with the king of Poland, stands as a particularly brutal episode in the reign of terror conducted by Ivan during this period. As an exceptional type of state organisation (as well as because of its conspicuous cruelty), the concept of the oprichnina has gained symbolic significance that exceeds far beyond its original historical context. Interpretations of its nature still vary widely. While for some, the oprichnina signifies the (necessity of the) use of strong means by the state to create unity, for others it represents state terror directed against one's own population and the aristocracy or political elites.

As Maureen Perrie shows in her study on the image of Ivan the Terrible in Russian folklore, the popular appreciation of the tsar was for the most part favourable. While the folkloric narratives acknowledge the state's acts of cruelty committed during his reign, his involvement in such acts is justified by shifting the blame from the tsar onto his entourage:

Alongside the 'good tsar' motifs are descriptions of Ivan's cruelty not only towards treacherous boyars and corrupt officials, but also towards innocent victims. Yet Ivan is not criticized for this: the blame lies not so much with the tsar himself as with the evil informers who have led him 
unwittingly to commit injustice. [...] Ivan's image in folklore, therefore, is a generally sympathetic one. [...] Yet the paradox remains, that his image in folklore is much more favourable than his historical reputation would seem to warrant.

(Perrie 1987: 114)

What is, perhaps, even more surprising is how pervasive these very motifs continue to be in twenty-first-century memory discourse. We will come across similar lines of reasoning in the television and film productions that are discussed in the second part of this chapter.

The foundational text for later representations of Ivan the Terrible is Nikolai Karamzin's History of the Russian State (1816-1826). This early nineteenth-century depiction of Ivan proved both novel and enduring. As Kevin Platt points out in his study on the interconnected myths of Ivan and Peter the Great as symbols of terror and greatness in Russian culture,

to the eighteenth-century Russian historical imagination, Ivan had been known as a severe but pious ruler, who had earned much glory by his conquests. Karamzin, relying on previously little-known sources, created the modern tradition in which Ivan's name was synonymous with unbridled despotism.

(Platt 2011: 22)

The figure of Ivan thus became emblematic of tyranny in the nineteenth century. In addition to painting a gruesome picture of the tsar's personal involvement in torture of various kinds, Karamzin's work gave rise to the 'good tsar - bad tsar' motif: the division of Ivan's rule into benevolent and malevolent periods, with the transition from the former to the latter marked and motivated by the death of Ivan's first wife, Anastasiia. As the intellectual debates between the Westernisers and the Slavophiles unfolded in the middle of the nineteenth century, new aspects of Ivan were highlighted. While, on the one hand, the 'Asiatic' characteristics of Ivan's personality were explored, some Westernisers, such as the historian Konstantin Kavelin, 'interpret[ed] Ivan's reign as a concerted but ultimately unsuccessful effort to reform [Russia's] archaic social principles', namely the fundamental conflict of interests between the state (in the figure of the grand prince) and the boyars (idem: 70). In this view, the violence of Ivan's rule is interpreted as a necessary evil dictated by the forces of historical progress; or, to rephrase this in terms of contemporary political discourse, Ivan employed repressive measures for the sake of modernisation.

Two well-known artistic representations of Ivan date to the last decades of the nineteenth century: the statue of the seated Tsar sculpted by Mark Antokol'skii (1871) mentioned earlier, and Il'ia Repin's painting Ivan the Terrible and His Son Ivan, 16 November 1581 (1885), which dramatically depicts the moment when the tsar realises he has (accidentally) killed his son by striking him on the head 
with his sceptre. Repin painted the work as an allegorical response to the assassination of Tsar Aleksandr II in 1881 and the public executions of those held responsible. Through historical association, the painting places the reactionary policies implemented by Aleksandr III in response to the assassination in the context of the tragic murder that had taken place exactly three hundred years earlier. Thereby, Repin 'condemns violence and calls for a reconciliation' to avert further bloodshed, as this could endanger the future existence of the state (Platt 2011: 114). According to Platt, by choosing the act of filicide to frame his political commentary, the painter furthermore hinted that the 'root cause of the bloodshed of the present is to be found not in the rebellious conspiracies of terrorists but in the age-old, reflexive violence of the autocracy' (ibid.). During the fin de siècle, the perception of the medieval tsar shifted once more. Now, the ambivalence towards the figure of Ivan, and the 'ironic amalgamation of terror and greatness' engrained in his historical myth, became the primary prism through which to view his legacy (Platt 2011: 132). The duality found in Ivan came to be seen as indicative of the opposing forces shaping the development of Russian collective identity.

Much of the complexity in the contemporary usage of the memory of Ivan lies in its continuously being intertwined with the remembrance of Stalin. Indeed, 'reference to Stalin and his era is pre-loaded into any contemporary representation of Ivan' (Platt 2010). The link between these rulers was gradually established from the 1930s onwards. The state-sponsored rehabilitation of Ivan, part of the wider revival of patriotic narratives in Stalinist Russia, developed "with input "from below" as well as "from above" (Perrie 2001: 196). Historiographical and artistic representations and re-evaluations of Ivan began to appear as early as the 1930s. The rehabilitation was then affirmed by the state in 1940/41, when Sergei Eisenstein and Aleksei Tolstoi, who had both already proved their skill at adapting historical figures to current ideological needs, ${ }^{2}$ were commissioned to produce a film and a play on the topic. The image of Ivan sought by Stalin in these productions was 'an analogue of his own self-image as a heroic and far-sighted ruler', and in both cases he was personally involved (idem: 194). It was not, at this point, the intention to justify Stalinist repression. In fact, the rehabilitation campaign took pains to place the cruelty of Ivan's rule into historical perspective by pointing out how the norms governing state conduct were different in his time. Therefore, 'a more apologetic stance (i.e. using Ivan's bloody rule as a legitimating precedent for the Stalin era's excesses) was not part of the officially sanctioned line' (Brandenberger \& Platt 2006: 166).

It was within the context of this Stalinist effort at patriotic mobilisation that Sergei Eisenstein created the epic depiction of the Terrible Tsar in the film classic Ivan the Terrible (Ivan Groznyi, 1945). As German troops approached Moscow, a large part of the film industry were evacuated to Alma-Ata. The preparations for and the shooting of the film (intended to be part of a planned trilogy) therefore took place in Kazakhstan. Part I finally premiered in January 1945 to positive reviews and was awarded the Stalin 
Prize. Part II, however, met the opposite fate. Following the official screening, the film was heavily criticised and its release was put off. Eisenstein was allowed to continue working on it so as to address the criticisms Stalin had raised about its depiction of Ivan and his oprichniki. But as a result of Eisenstein's severe health problems the project was never finished. Part I contains direct references to the ongoing war against Nazi Germany. For example, Ivan's suggestion that the English trade ships sail to the White Sea instead of approaching Moscow through the ports in the Baltics mirrors 'the importance of Great Britain's Arctic convoys during the Second World War' (O’Mahony 2008: 179). Ivan is shown to have a darker side, yet even when committing sins he acts for the sake of uniting Russia and warding off domestic and foreign enemies. The depiction of the tsar's personality and motives is markedly grimmer in Part II, where it is suggested that 'Ivan's cruelty has been driven less by political necessity than by his childhood traumas and a continuing desire to maintain personal authority' (idem: 183). It is this aspect that most likely impeded the film's release. As Mike O'Mahony concisely states, '[i]n the wake of the Purges of the late 1930s and the new post-war campaign to re-impose Stalin's authority, such a presentation of tyranny was, at best, a high-risk strategy, and it is hardly surprising that the film was banned' (ibid.). The figures of Ivan and Stalin remain inextricably connected to this day, in the form of a mnemonic parallel that had already taken shape during Stalin's lifetime. Indeed, as Maureen Perrie remarks, '[s]o intertwined have the reputations of the two rulers become that it is difficult to see how any future rehabilitation of Ivan can avoid being received as an attempted apologia for Stalin or as a justification for a latter-day strongman' (Perrie 2001: 196).

The image Eisenstein created of Ivan is equalled in familiarity only by the Soviet comedy Ivan Vasil'evich Changes Profession (Ivan Vasil'evich meniaet professiiu, Leonid Gaidai, 1973), based on Mikhail Bulgakov's play written in the mid-1930s but only published in 1965. In the film, engineer Aleksandr Timofeev is building a time machine in his Moscow apartment when he creates a time vortex. Accidentally, he sends the building's warden Ivan Vasil'evich Bunsha and the petty burglar George Miloslavskii into the sixteenth century. Tsar Ivan the Terrible, for his part, gets transported to the twentieth century. Since Bunsha is the spitting image of the tsar, he disguises himself as the medieval Ivan Vasil'evich while Timofeev works to repair the time machine.

The most radical interpretation of Ivan's rule has been proposed by the mathematicians Anatolii Fomenko and Gleb Nosovskii as part of the 'New Chronology'. According to this theory, the reigning chronology of history is fundamentally incorrect and results from centuries of falsification. The different stages in Ivan the Terrible's reign can be explained, they claim, by the 'fact' that Ivan IV is actually a composite of four subsequent rulers. It was the third 'Ivan' (according to the theory, Ivan IV's son Ivan Ivanovich) who established the oprichnina under the influence of his pro-Western relatives, the Zakhar'in-Romanovs. The proponents of the New Chronology assert that 
several members of the oprichnina, including Maliuta Skuratov, were actually 'anti-oprichnina activists' (Halperin 2011: 8). The Romanovs are responsible not only for the establishment of the oprichnina but for the later falsification of historical events to cover up their tracks. As Charles Halperin explains, this act of falsification is central to the 'logic' of the four Ivans theory:

To hide the Romanov role in the oprichnina the Romanovs rewrote the reign of Ivan IV as a single ruler who was responsible for the terror. In the process they vilified anyone who had opposed the Zakhar'in faction during the reign of 'Ivan IV.' Thus Skuratov and [Vasilii] Griaznoi became oprichnina thugs, reversing their actual opposition to the oprichnina propagated by the Zakhar'ins.

(Idem: 9)

While the New Chronology has been fiercely criticised by academics from various disciplines and is commonly branded pseudo-history, publications propagating its line of thinking can be found in most Russian bookstores and have proved remarkably popular.

Following the collapse of the Soviet Union, political elites steered clear of any association with Ivan, a tendency that largely continued into the $2000 \mathrm{~s}$ (except for certain more marginal groups that will be discussed below). In the cultural and, in particular, historiographical domains, competing images of the Tsar flourished, albeit with 'enormous interpretational looseness' (Platt 2011: 261). The most notable development was the call for Ivan's canonisation as an Orthodox saint in the context of the religious revival in the late 1990 s, to which I will return shortly.

One of the best-known mobilisations of the memory of Ivan in contemporary Russian culture is Vladimir Sorokin's dystopian novel Day of the Oprichnik (Den' oprichnika, 2006). In direct response to political developments, and in tune with far-right political discourses that will be addressed below, Sorokin remediated the oprichnina myth to 'challenge the neo-traditionalist political and cultural discourses that [...] moved into the mainstream during the Putin era' (Lipovetsky \& Wakamiya 2014: 273-274). Set in a near future when the Russian Empire has been restored and is protected by a great wall along its borders, the narrative describes a day in the life of an oprichnik. Much like Aleksandr Solzhenitsyn's One Day in the Life of Ivan Denisovich (1962) had described the painful reality of life in the Soviet labour camps, Day of the Oprichnik delivers its most potent political critique through the apparent normalisation of the cruelty it exposes. When combined with the historical framework of the oprichnina, this business-as-usual attitude reveals the inherent dangers of historicising political action. As Mark Lipovetsky and Alexander Etkind assert:

Without fail, historical explanations of political processes remove responsibility from those who take and implement decisions in the 
present. [Andrei] Komiaga, the oprichnik of the 21st century, practises state banditism, not because someone in the very same place practiced the same activities five hundred years earlier. He pillages, rapes and kills because his superiors order him to, and because they taught him to do so at the history department, and also because he simply is a bastard. In this elementary sense, the depth of historical explanations only distracts from direct political, ethical and legal judgements.

(Lipovetsky \& Etkind 2008)

Therefore, the novel should be considered a critique of the Putin regime's memory politics and its increasingly authoritarian political course.

Sorokin openly acknowledged that the novel was intended to comment on current political developments, though even he could not have imagined how prophetic his vision would prove to be. In an interview with Der Spiegel, Sorokin remarks that in terms of the relation between the state and its people and, in particular, the 'sacred willingness to make sacrifices' demanded by the state of its citizens, Russia continues to function according to the state structure developed by Ivan the Terrible (Doerry \& Schepp 2014 [2007]: 278):

In my book, I am searching for an answer to the question of what distinguishes Russia from true democracies. [...] Germans, Frenchmen, and Englishmen can say of themselves: 'I am the state.' I cannot say that. In Russia only the people in the Kremlin can say that. All other citizens are nothing more than human material with which they can do all kinds of things. [...] In our country there are special people who are permitted to do anything. They are the sacrificial priests of power. Anyone who is not a member of this group has no clout with the state. One can be as pure as can be - just as magnate Mikhail Khodorkovskii was - and still lose everything in a flash and end up in prison. The Khodorkovskii case is typical of the 'oprichnina' - the system of oppression I describe.

(Idem: 278-279)

Sorokin's novel illustrates how Ivan's oprichnina can function as a persuasive mnemonic framework to criticise the state's encroachment on societal freedoms. The mere mention of the word oprichnina within any discussion of current affairs will commonly be understood to imply condemnation, particularly among the educated elite. Yet, as we see below, the opposite attitude that is, praise of a strong hand in political affairs, prompted by the same memory image - also has its adherents. The divide between the opposing sides typically mirrors (and is understood to be implicitly connected to) the positions taken with regard to the appreciation of Stalin.

According to opinion polls conducted by the Levada Centre, Ivan continues to appeal to a particular segment of Russian society. When asked to name five to ten of the most successful persons of all time drawn from all countries in 2008, 5 per cent of the respondents mentioned Ivan IV (a slight 
increase from 4 per cent in 1991, 1994 and 1999) (Gudkov 2010: 39). In the election of the greatest Russian of all time on The Name Is Russia the same year, the medieval ruler took tenth place (see chapter 4 ). The positive reappraisal of Ivan the Terrible and the application of his memory to frame a conceptualisation of Russian statehood are most prominent among two groups. First, there are the Orthodox fundamentalist patriotic groups who seek, among their other political objectives, to canonise Ivan. Second, the legacy of Ivan is utilised in ultranationalist circles to formulate a radical political agenda that, if implemented, would undermine existing state structures. It is to the latter group of philosophers, historians and politicians that I turn first.

\section{The concept of 'Novaia Oprichnina'}

In contemporary Russia, the memory of the oprichnina has been used both to criticise the increased authoritarianism and the silencing of the opposition under Putin and to advocate an even stronger vertical political structure. The idea of establishing a new oprichnina in Russia, referred to as novaia oprichnina or neooprichnina, ${ }^{3}$ has been proposed in earnest by a group of contemporary political thinkers and publicists. They argue that the oprichnina represents a truly Russian way of modernisation and is the only available means to overcome the vices of the current political system - most notably, corruption. As we will see, this concept's main proponents are not minor figures. Although these individuals long operated on the margins of political discourse, their thinking has more recently been adopted by parts of the mainstream. Before exploring two conceptualisations of how the oprichnina should be implemented in contemporary Russia as a political system, it is useful to sketch three distinct dichotomies that characterise the term's usage in public debate. First, novaia oprichnina is used either as a figure of speech or as an actual model for emulation. For example, back in 1998, the chair of the Russian Agrarian Youth Union used it to frame the organisation's objective: 'Let our union in some way be a new oprichnina for Russia, a peasant oprichnina, ruthlessly sweeping all that impedes the peasant to live out of our house!' (Zhelenin 1998). An article published by RBK Daily under the headline 'Putin's new oprichnina' was a response to a statement by President Putin that, after the 2008 elections, a group of new people will come to power ('Novaia oprichnina Putina' 2007). Here, in a more politicised application of the term, oprichnina denotes a 'rotation of the political elite' - that is, a moment when the current elite is replaced by a new ruling elite. Such a rotation can occur gradually through individuals' upward political mobility, or it can come about through a revolutionary change. The article claims that the rotation forecast to come after the 2008 presidential elections has precursors: the original oprichnina under Ivan IV, the forced 'rotation of elites' that took place both under Peter the Great and Stalin and, finally, the replacement of leading officials by individuals from Putin's St Petersburg network of trustees at the beginning of his first presidential term. 


\section{Case studies}

Second, the term is used either as part of a cautionary expression or with the aim to mobilise. The journal Russian Entrepreneur, for instance, employed the term in 2002 in its assessment of the goals and strategies of the newly founded United Russia party. The establishment of a 'mass parliamentary party', it asserts, is a logical and - based on global experience - necessary step to ensure the survival of a federal type of government and to centralise control. Yet, referring to the case of United Russia, 'here it in fact concerns a kind of 'silent oprichnina', within the framework of which an immense part of the political sphere is placed under the control of 'appanage [udelnykh] princes" (Lutomin \& Sergeev 2002). On the mobilising end of the spectrum we find, among others, Aleksandr Dugin, who advocates the creation of an extra-systemic 'Russian order' modelled as a new oprichnina to fundamentally change the political structure of the Russian state (I will return to this point shortly).

Third, in articles that use the term in the cautionary sense and that tend to be located on the liberal side of the political spectrum, oprichnina is often equalled with other (Russian and Soviet) state security organisations, such as the Federal Security Service (FSB) and the People's Commissariat for Internal Affairs (NKVD). For example, in a radio interview, the opposition journalist Oleg Kashin uses the term in response to the tightening of political control following Putin's re-election in 2012. Listing the groups of 'extremists' who have managed to secure their place within the top echelons of power, he states:

[T] he new security officers [siloviki], [and] also the, as they say, 'new middle class', [...] people, who constitute a substantial power base nowadays, a gigantic number of people and then, you know, the MVD [Ministry of Internal Affairs, M.W.], FSB, other special forces, FSO [Federal Guard Service, M.W.], the federal taxation service, and so on, and so on, they are a kind of new oprichnina altogether.

(Dymarskii \& Larina 2012)

Much earlier, and in a markedly different context, an article from September 1991 had used the term to denote and conceptualise the Communist Party as a social institution in the wake of the August coup d'état by communist hardliners (Korzhavin 1991). As we will see, articles that use the term in an effort to mobilise, on the contrary, tend to adhere to nationalist and/or conservative political orientations. Here, the oprichnina is conceptualised as an organisation that still has to be founded and that will operate outside the existing state structure. Eventually, it will undermine and transform the state's very foundations. Thus we have two competing understandings of the oprichnina concept as it pertains to contemporary Russian politics: first, as a means of state repression (from a liberal, oppositional perspective) and, second, as an extra-governmental means to fundamentally alter the existing political structure (as invoked by right-wing nationalist and conservative groups). 
The permeation of these ideas into the mainstream media was and remains limited, however. A survey of the major print-media outlets using the Integrum World Wide media database returns a mere 34 hits for 'novaia oprichnina' and just one mention of the term 'neooprichnina' within the 12-year period from 2000 to $2012 .{ }^{4}$ Moreover, in the majority of these articles the term is used in a cautionary sense. A notable exception is its use in the weekly newspaper Zavtra, an oppositional and increasingly nationalistic publication. In addition to Zavtra, the circulation of these concepts takes place in conferences, lectures and round tables, through book publications and, increasingly actively, online. Anyone with an interest in the topic can listen to hours of lectures and interviews on the oprichnina and related themes on YouTube, Vkontakte and other video-sharing platforms.

Aleksandr Dugin appears to have first used the term novaia oprichnina in $2000 .^{5}$ In an article in Zavtra, Dugin speaks of creating a new 'KGB': a 'new cast [or] social stratum' that should be formed outside of party structures, the bureaucracy and business circles and have the aim of ' $[\mathrm{t}]$ ransferring the country onto the track [relsy] of patriotism, the preservation (and strengthening) of territorial integrity and sovereign development along its own national path' (Dugin 2000). The members of this still-to-be-formed 'continental KGB' will make up the 'backbone of a Eurasian Renaissance' in the struggle against American domination in global affairs. Here, the term 'new oprichnina' appears in a more or less metaphorical sense towards the end of the argument:

[T]he Eurasian secret services will inevitably be something completely new - conservative, on the one hand, and revolutionary, on the other ... . It has to be a kind of 'new oprichnina.' Especially in the first and most difficult phase when the citadel of strong agents of influence, entrenched in the essential sectors of our society, has to be crushed. This new class has to be delegated powers in the same proportion as during the conduct of military operations.

(Ibid. Italics in original)

In addition to its political purpose, Dugin's oprichnina is thus a military force operating outside of existing state structures. By 2005, the term had become a central element of his doctrine and political agenda. Dugin now calls for the creation of a 'Russian order' (russkii orden), which he equates with a new oprichnina. In an article published in Ogonek, Dugin's phrasing of the issue directly appeals to the political tensions that arose in the wake of the colour revolutions and, in particular, the 2004 Orange Revolution in Ukraine. The opening paragraph thus formulates the necessity of a new oprichnina:

The Russian oprichnina is both a historical and a meta-historical phenomenon. [...] In contemporary Russia the oprichnina has become manifestly unavoidable. The situation is similar to the 16th century: external 


\section{Case studies}

threats (onset from the West, expansion of NATO, 'orange processes' in the CIS) and domestic decay of the vertical of power (a hitherto unimaginable level of corruption, moral decline, alienation, incapacity of the elite).

(Dugin 2005a)

Since 'Putin is no [Ivan] the Terrible', the oprichnina will gather behind 'Holy Rus', which lies hidden underneath the rubble and sediments of history' (ibid.).

The commitment to the term oprichnina was confirmed at the founding congress of Dugin's youth movement, the Eurasian Youth Union we already come across in chapter 5, that same year. The congress took place at Ivan's former residence in Aleksandrovskaia Sloboda, the 'birthplace' of the oprichnina, and framed its members as 'new oprichniki' whose mission is to counter the spread of the 'orange plague' in Russia ('Evraziiskaia oprichnina vosstanovit v Rossii sakral'nuiu vlast" 2005). The Eurasian Youth Union continued to use the term, for example during their 'Easter imperial march' on 8 April 2007, when they carried large banners with the slogan 'Hail the oprichnina!' (Kozenko 2007). During the congress, Dugin presented a paper on the 'metaphysics of the oprichnina', his most detailed exposition of the concept. This lengthy document dwells extensively on the multi-layered (and in Dugin's rendering, mystic) symbolism associated with Ivan's oprichnina as well as later emulations of the model, in particular with regard to Stalinism. Ivan, as the 'tsar of the Eurasians', is presented as a direct model to emulate: '[Ivan] the Terrible began to bring Russian Byzantism to its full realisation in conjunction with the Horde covenant of empire-building of Genghis Chan. He modernised Rus', but it was modernisation without Westernisation' (Dugin 2005b. Emphasis added). Here, with Dugin, we thus find a conceptualisation of a 'Russian' approach to state modernisation that is simultaneously complementary to the state's memory politics in its anti-Western stance and in direct conflict with the regime's primary interests as it seeks to undermine the power that be.

According to Dugin, the members of the oprichnina dedicated themselves not to the state or to their own interests but to a higher purpose, which he refers to as the 'sacrality' particular to Ivan the Terrible's rule (groznaia sakral'nost'). To serve this sacrality (which, in short, amounts to a Eurasian interpretation of the Orthodox messianism we saw in chapter 4), the oprichnina has to bring about a rotation of the elites, a term we came across earlier in the overview of the public debate. If necessary, this process has to be enforced through violent repression:

If there are ways of raising new fresh people from the bottom to the heights of power, that is a good thing, but if not, then [these ways] have to be artificially created. In rigid [zhestkikh] societies, repressions serve this purpose. The oprichnina, in this sense, was a chord in the rotation of the elite in Russian society. Moreover, this sociological function was 
subordinate to its geopolitical function - the strengthening of tsarist power - and its metaphysical [function] - the service to 'terrible sacrality'. Here the parallel with Stalin again suggests itself.

(Dugin 2005b)

In this quote, Dugin puts the common association between Ivan and Stalin as repressive rulers to good rhetorical use. The brief sentence invoking Stalin suggests the existence of a universal rule concerning 'elite rotation'. And by thus justifying the violent acts committed by these two heads of state on the grounds of 'geopolitical' necessity, Dugin suggests that, when conditions so dictate, the same principle should apply to present-day politics. Indeed, Dugin asserts that the oprichnina's task - 'passionate service to the sacred Motherland, the Absolute Motherland, its unity, its greatness, its might' - is as relevant today as at any point in the past (Dugin 2005b). The 'neooprichnina, 6 therefore, is the 'model for a Eurasian conservative revolution' that should and will necessarily take place, even if the majority of Russian citizens are against it ('Motherland Rus' goes above all else'), or if it would require a direct confrontation with the powers that be (ibid.). In case the ruling elite understands the necessity of structural change and chooses to work towards its implementation, the new oprichnina will serve as a 'conservative-protective force' to safeguard the process (ibid.).

A competing operationalisation of the concept was proposed by Andrei Fursov, Maksim Kalashnikov and Vitalii Aver'ianov in The New Oprichnina, or Russian-style Modernisation (Fursov, Kalashnikov \& Aver'ianov 2011). ${ }^{7}$ The publication was prepared for the Institute of Dynamic Conservatism, an organisation established in 2009 as a neo-conservative think tank that merged into the Izborsk Club in 2012. The latter now unites the most 'prominent conservative right-wing intellectuals of modern Russia' and propagates the belief that 'post-Soviet identity has to encompass both the technocratic Soviet element and the mystical Orthodox one' (Engström 2014: 361). All three authors have established reputations. Fursov is a prominent historian and sociologist. Kalashnikov, whose real name is Vladimir Kucherenko, is a publicist and nationalist political writer. In his books, with titles such as Towards USSR 2.0 (2003), he praises the Soviet Union and criticises the current Russian regime. Finally, Aver'ianov, the director of the Institute, is an Orthodox writer and philosopher. The book in many ways is a collection of various writings, building upon the previous works of the contributing authors that are also referenced throughout, and it contains some previously published material. For example, the chapter 'The Innovative Oprichnina of Lavrentii Beriia' had been published the year before by Kalashnikov as a paper entitled 'We Need a New Beriia' in Zavtra (Kalashnikov 2010).

The book offers an extensive discussion of the oprichnina as a historical phenomenon (with overt contemporary political connotations) as well as the various groups and individuals who have been responsible for the 'misrepresentation' of Ivan and the oprichnina. The image of Ivan in historiography, 
the authors assert, is not simply incorrect; it even conflicts with common sense. The primary explanation for this distortion of historical facts lies in Western attempts at falsification.

In the case of Russia, the West and especially Latin Rome start to employ a new method of struggle from the 16th century onwards: psychological propagandistic warfare. The public opinion in Europe during the Livonian war was formed by means of manifold 'flying leaflets' that pictured Tsar Ioann as a monster and the Russians as aggressors and fiends. But the propaganda was not limited to this, of course. Because of the historical and political circumstances, Ioann the Terrible came under heavy fire in a new type of war. Discrediting him became a matter of honour to the enemies of Russia, both during his lifetime and after his death. He messed up the plans [sputal karty] of the Western strategists, the Roman missionaries, Livonian knights, Polish and Swedish aggressors (yet another characteristic that connects him with Stalin). But the particularity of this propagandistic war is the fact that it does not diminish [deaktualiziruetsia] over time.

(Fursov, Kalashnikov \& Aver'ianov 2011. Bold in original).

The claim that the alleged disinformation campaign against Ivan has not diminished fits within the accusations of information warfare that have since come to dominate mainstream media (and that, vice versa, European countries accuse Russia of waging, with good reason). Among the Russian names that are mentioned as accomplices in the mistreatment of Ivan's memory are Nikolai Karamzin, who is described as a 'fabulist' with a liking for gothic narratives, and Vladimir Sorokin and Pavel Lungin (the director of the 2009 film Tsar, discussed later on in this chapter), who are both accused of entertaining 'particular sentimental-intimate relations with Western countries' to account for their negative appraisals of Ivan (Fursov, Kalashnikov \& Aver'ianov 2011). In other words, anyone who voices criticism of Ivan is not a true patriot.

The diagnosis here of the problem of contemporary Russian politics is largely identical to what Dugin proposes - namely, corruption. The oprichnina, able to cleanse the political system in a way that the system itself cannot, can move the state from its current state of degradation and stagnation towards innovation, the authors argue. Here we again find a direct reference to the Orange Revolution in Ukraine to demonstrate the need for exceptional measures:

The most dreadful thing is that the governmental apparatus of the RF [Russian Federation, M.W.] can no longer independently cleanse itself of total corruption. Avaricious beings have firmly lodged themselves in it, and do not allow honest and competent ones to enter. 'Anti-selection' was and is going on. The sad experience of the 'orange revolution' in Ukraine (which, in effect, is the same kind of society [sotsium]) has shown that no 
liberal-democratic procedures can eradicate corruption or the omnipotence of the criminalised 'elite'.

(Fursov, Kalashnikov \& Aver'ianov 2011)

In comparison to what Dugin imagines, the vision put forward by Fursov, Kalashnikov and Aver'ianov is less militant and more technocratic, and lacks Dugin's mysticism. Since the publication is a collection of varied writings rather than an argumentative whole, there is no unified vision of how exactly Russia should be structured in the future. The most detailed description of Russian society during and after the proposed establishment of a new oprichnina can be found in the chapters written by Kalashnikov. He envisions the oprichnina as a fully developed parallel system of governance that in a true and distinctively Russian way, he claims, will be democratic in serving the interests of the state and the people, rather than those in power. While the oprichnina will have at its disposal a secret security service and a small army, these resources form only a part of a much wider system of 'structures of innovation':

The central concept is simple: it is necessary to establish a dictatorship of honest, patriotic people, who stand above the government. People, who are devoid of self-seeking motives, who are preoccupied with the greatness of the country and safeguarding the people. They have to construct a closely knit society capable of controlling the state apparatus, of moving their people to key leadership positions, [and] shaping the judiciary, the prosecutor's office, secret services and top administration of the MVD [Ministry of Internal Affairs, M.W.]. [...] It is a kind of corporation of 'stern judges'. Stern, but fair. What is more, it should be based on the structures of civil society and local self-government, cooperating with them. Such a corporation should recruit individuals from all layers of society, selecting those who combine intelligence, patriotism and selflessness in their service to the common cause. And the selection of worthy candidates is performed by the wise, strong and incorruptible members of the corporation.

(Fursov, Kalashnikov \& Aver'ianov 2011)

Contrary to the territorial division into oprichnina and zemshchina established under Ivan, the new oprichnina will give rise to a parallel system operating throughout the entire territory of Russia. This network of advanced cities (futuropolisy), the author clarifies, will be similar to the system of closed cities of the Soviet military-industrial complex. Kalashnikov attaches great importance to advances in psychology and information technology to establish this neo-Soviet 'democratic dictatorship'. Modern psychotechnologies, he claims, make it possible to select 'thousands of absolutely [kristal'no] honest and noble-minded individuals' to fill the ranks of the oprichnina. As a result, those who are deceitful, who strive for power for the sake of power or have sadistic 
inclinations will be filtered out. Modern technology, he concludes, will thereby help avoid the pitfalls of the oprichnina as established by both Ivan and Stalin.

While this plan is no less rich in anti-Western sentiment than Dugin's writings, the opposition with the West is not solely confrontational in this case. The West, in particular the United States, is depicted as a separate civilisation that harbours a negative attitude towards Russia. At the same time, however, it is recognised and at times emphasised that both are subject to the same detrimental global trends that have to be overcome (among them corruption and other vices of capitalism). The combination of these two lines of thinking (eternal opposition and common problems) results in the view that the current race between Russia and the US will be decided by which nation succeeds in decisively addressing these issues first. To do so in Russia, the authors assert, the new oprichnina is the only available means.

Both conceptualisations of the new oprichnina thus attack the state-supported notion that stability is a necessary requirement for development, a premise central to official memory politics. Instead, it is argued that the corruption of the ruling political system is pronounced enough to jeopardise the future existence of the Russian state. (Conservative) modernisation is essential, yet it can be achieved only through a fundamental reform of the system undertaken from outside the established power structures. Thus, reform must still be a top-down initiative, but one not instituted by the Kremlin. In rather vague (and in the case of Kalashnikov, somewhat naïvely optimistic) terms, a truly Russian type of democracy is envisioned as the end goal. The authors behind these two conceptualisations of a new oprichnina are among the 'founding fathers' of the so-called conservative turn in Russian politics since 2013 (Engström 2014), along with television journalist Mikhail Leont'ev (see chapter 5), archimandrite Tikhon (see chapter 4) and Sergei Kurginian, whose activities will be discussed towards the end of the current chapter.

The memory of the oprichnina has been used to critique political developments in a non-mobilising manner as well, as we have already seen with regard to public discourse and to Sorokin's dystopian fiction. To conclude this section, I would like to offer another example. The oppositional art collective Voina, from whose ranks Pussy Riot later emerged, has drawn upon the oprichnina concept in their performance art. They targeted Mikhail Leont'ev's restaurant Oprichnik in Moscow (now closed) in an art action named 'The dogs' heads of Russia, or The goldfish' ${ }^{8}$ On the night of 28 December 2008, the doors to the restaurant were welded shut with metal plates, locking the customers inside. ${ }^{9}$ As the action was unfolding, members of the collective shouted various slogans, such as 'Give us the Iron Curtain!', 'No to the oprichnina!', 'We will strike Russia on its dogs' heads with an electric welder' and 'Canonise Ivan the Terrible! Misha Leont'ev - to the stables!' (plucer 2008). In line with Voina's usual postmodern eclecticism, the action was defined as a protest against 'oprichnina, glamour, wild boar in raspberry wine and personally against the union of Misha Leont'ev with Ivan the Terrible'. 
Art activist Oleg Vasil'ev interpreted the action in a more directly political sense. Addressing President Dmitrii Medvedev in a blog post published on 31 December 2008, Vasil'ev drew a parallel between Ivan's temporary abdication of the throne to Simeon Bekbulatovich in 1575 and Putin's handover of power to Medvedev in 2008. He asks whether Medvedev will return the throne to its 'rightful owner', as Bekbulatovich had before him:

Art group 'Voina' gives Dmitrii Anatol'evich the chance to become the real president of all of Russia; art group 'Voina' closes the symbol of a connection between ages and situations, the symbol of the return of the oprichnina. Just like the army of the Crimean khan Devlet Girai [15511577, M.W.] that brought an end to the history of the first oprichnina, art group 'Voina' closes the restaurant 'Oprichnik', owned by 'journalist' Mikhail Leont'ev, one of the principle dogs of the Putin oprichnina. [...] Dmitrii Anatol'evich, on the eve of the New Year the group 'Voina' gives you the chance to put an end to the new oprichnina, another shameful episode in Russian history. Will you seize it?

(Epshtein 2011)

The comparison to Bekbulatovich was widely made during Medvedev's presidency. For example, in the online petition 'Putin has to go', first posted in March 2010 and signed by more than 150,000 people, Medvedev is referred to as an 'obedient locum tenens' and 'the contemporary Simeon Bekbulatovich' ('Putin dolzhen uiti' 2010). As became clear in 2011, Medvedev's occupation of the presidential 'throne' was indeed temporary: Putin returned to power in 2012 .

\section{Ivan the Terrible and Orthodox fundamentalism}

In addition to the renewed interest in the concept of the oprichnina within nationalist and neo-Soviet circles, Ivan espouses particular appeal to certain marginal groups adhering to fundamentalist conceptions of Russian Orthodoxy. These adherents of so-called Tsarebozhnichetsvo 'sacralise the Russian sovereigns as divine recruits, chosen by God to ensure for Russia the realisation of her messianic destiny as the protectress of Orthodoxy on earth' (Knoppe 2006). One of their objectives has been to push for the canonisation of Tsar Ivan IV. The 'extremist, populist, and imperialistic elements' within the Russian Orthodox Church, where this initiative originated, assert that all accusations against Ivan are simply false; they are the result of incorrect interpretations of available historical sources combined with slander voiced by Ivan's contemporaries and enemies (Bodin 2009: 101). As Per-Arne Bodin points out, the argument in favour of Ivan's canonisation 'demonstrates [...] a highly conspirational way of thinking [that is] characteristic of Russian popular political discourse' (idem: 100). So much so that Bodin labels the accumulation of materials in favour of Ivan's sanctity and the exposure of 
purportedly false accusations against him as the creation of a 'counter-history' (idem: 101). The canonisation bid was rejected by the ROC in 2004, along with a similar proposal regarding Grigorii Rasputin. Canonising Ivan, it was argued, was out of the question due to Ivan's persecution of the Church. Indeed, the main obstacle to canonisation is that it would sanctify a person held responsible for the death of a saint (Metropolitan Filipp). Hypothetically speaking, so the ROC reasoned, canonising Ivan would require the canonisation of Filipp to be undone. Another complicating factor is that the debate on Ivan tends to interweave itself with the perhaps even more controversial debate surrounding the canonisation of Stalin (Bodin 2009: 106).

Within these fundamentalist Orthodox circles, Ivan is lauded as the first tsar of the Russian Empire and praised for his contribution to the development of the Russian state, his military victories and territorial expansion. In addition, and this is what sets them apart from nationalist movements, they glorify autocracy and (God-ordained) violence. Their political views tend to be anti-establishment, with regard to both the ROC and the state. As they do not recognise the position of the patriarch, these Orthodox communities exist on the fringes or outside of Church structures and many are considered splinter sects by the ROC. Anti-Putinist rhetoric is a common though less essential element. As such, their political position corresponds to how Kathy Rousselet characterises the attitude of local, patriotic religious groups towards the state more generally:

They are often very critical towards the social and economic situation of Putin's Russia, but they do not necessarily question the established status quo. Many reject any form of political action in the partisan sense of the term. However, they call for a moralisation of the country. Although morality is part of the Soviet heritage, it seeks to overturn its original foundations. The patriotism of believers is multifaceted: while this same patriotism echoes official calls, in some respects it also diverges from these calls.

(Rousselet 2015: 66)

Here it has to be emphasised that, in their glorification of empire and 'strong and cruel' leadership, the patriotism of such groups typically is openly antiSemitic and xenophobic (Bodin 2009: 106).

Various Orthodox brotherhoods worship Ivan the Terrible across Russia. The social organisation of these communities (characterised by, e.g., seclusion from society, glorification of the head of the brotherhood) appears to support their designation as religious sects. A notable example is the 'Oprichnoe brotherhood in the name of the blessed Tsar Ioann the Terrible', an Orthodox community located in the city Liubim and the nearby village of Kashcheevo, some 100 kilometres northeast of Yaroslavl. The community, which consists of several families and is supposedly structured after Ivan's oprichnina, is led by a man named Andrei Shchedrin. Writing under several pseudonyms, 
Shchedrin actively agitates against both the patriarch and the state in a leaflet ('Oprichnyi listok') that the 'oprichniki' hand out and circulate across the country. Their starkly anti-Semitic ideology sees the president and the patriarch as servants of the antichrist. ${ }^{10}$ In 2005 , the local administration in Liubim decided to erect a statue of Ivan as the city's founder. As was reported in the press, its representatives approached the famous sculptor Zurab Tsereteli with a commission to design the sculpture (Radulova 2005). Whether Shchedrin was involved in the initiative is unclear. The plan elicited criticism from the Yaroslavl eparchy of the Russian Orthodox Church. The archbishop of Yaroslavl and Rostov Kirill addressed a letter to the governor, procurator and the head federal inspector of the region to warn against the possible negative consequences of the planned monument, citing the presence of the Oprichnoe Brotherhood in the locality as an aggravating factor.

[T]he initiative by the head of the Liubim local branch, Koshkin A.V., to erect a monument to Tsar Ivan the Terrible in Liubim can have very unpredictable consequences. Please note that the controversy surrounding the figure of Ivan the Terrible and the possibility of his ecclesiastical veneration is one of the destabilising factors of the 'near-Orthodox' [okolopravoslavnoi] community. The erection of a monument in the city of Liubim will lead to the settlement of a great number of mentally unstable persons in the city, which will undoubtedly worsen the crime situation in the district. In the city of Liubim, its vicinity and the Pervomaiskii district the totalitarian sect 'Oprichnoe Brotherhood', whose unlawful acts were subject of investigation by the prosecutor's office and the FSB, already operates.

(IA REGNUM 2005)

It is unclear whether the Archbishop's appeal resulted in any action on the federal level to overrule the decision by the local administration of Liubim. The statue, in any case, was not erected.

Soviet-era Estrada singer Zhanna Bichevskaia is one of the public figures who strive for a positive reappraisal and canonisation of Ivan in various media. She has dedicated several songs to 'Saintly Ioann', in which she sings to his glory and comments on the contemporary lack of positive appraisals of him. ${ }^{11}$ According to Aleksandr Dvorkin, an expert on sectarianism in contemporary Russia, Zhanna Bichevskaia acts as the 'vocal cords' of the alternative Orthodox groups who see the monarch as the head of the church (Skoibeda 2013). The song 'The Terrible Tsar', for example, reiterates the notion that the monarch is created by God and answers to Him only ('The tsar does not belong to the earthly court / he is answerable to God alone'). The lyrics recall Ivan's rule as a period of glory, whose memory has been made murky by 'boyar thieves' ('In admiration of the Tsar, the people pray / the Tsar is frightening to the thief-boyars / and in the byliny songs [Ivan] the 
Terrible appears / as a righteous sovereign'). The final verses emphasise the link between respect for Ivan and patriotism:

I am proud of the achievements of our ancestors

The decisive moment has come for the Russians

Tsar Ioann the Fourth the Terrible

Among the saints, is praying for Rus' to God.

Another song called 'Tsar Ioann' pictures Ivan's submission to serve God and 'the native land'. The final verses again address the listener and spur them to remember, 'in this wicked, most dangerous hour', how the 'Godanointed Tsar Ioann [...] defended and saved our faith.' While her views support the centralisation of power, Bichevskaia is by no means a Putin supporter. Rather, she advocates the restoration of the monarchy under a direct descendant of the Romanovs (Sobakin 2012).

Another public figure who has come out in defence of Ivan is the businessman and societal actor Vasilii Boiko, who renamed himself Boiko-Velikii (which translates as Boiko the Great) in 2009 by adopting his mother's maiden name (Velikaia). ${ }^{12}$ A strict adherent of (fundamentalist) Orthodox principles, Boiko is an eccentric figure who typically dresses in a 'Russian' costume consisting of a decorated caftan (predominantly in white, blue or red, the colours of the Russian flag) and elegant boots. In 2010 his (at that time) extreme views on Russian society sparked public outrage when he enforced a series of religiously derived rules of conduct on the employees of his dairy concern, Russian Milk. Among other measures, these rules stipulated that employees who have had an abortion or who facilitate the termination of a pregnancy would be dismissed (Novoselova 2010). ${ }^{13}$ Boiko-Velikii openly criticised Pavel Lungin's film Tsar in an open letter published in Izvestiia, in which he accuses the director of blasphemy and of insulting the Russian people (I will return to Boiko's criticisms later on). He was also one of the main signatories of an open letter addressed to the Minister of Culture and the director of the Tret'iakov Gallery demanding that Il'ia Repin's painting Ivan the Terrible and His Son Ivan be taken down and locked away in the gallery's storage room. In a clear reference to the legislation protecting the sensitivities of religious believers that was adopted in June $2013,{ }^{14}$ the signatories claimed that the painting falsifies history (since, they assert, Ivan did not kill his son) and 'constitutes blatant slander of not just Tsar Ivan but also the Russian Orthodox Autocracy [russkoe Pravoslavnoe Samoderzhavie], of the entire Russian people' (Mil'shtein 2013). The director of the Tret'iakov Gallery, Irina Lebedeva, refused to comply, stating that art is not intended to be an 'illustration of history' but rather is an expressive act.

Boiko-Velikii was, in addition, the force who initiated the consecration of a small chapel in honour of (the non-canonised) Tsar Ivan the Terrible in December 2011. The chapel is located on the premises of an auto repair factory in Moscow owned by an investment company headed by Boiko. In his speech at the opening ceremony, Boiko-Velikii claimed that Ivan had 
performed a miracle on the factory's grounds. On 15 December 2009 the factory was attacked by raiders who sought to seize the property, BoikoVelikii recounts - but then he prayed to Ivan and the seizure was miraculously averted ('V Moskve osviashchena chasovnia v chest' sv. blgv. Tsaria Ioanna Groznogo' 2011). The Russian Orthodox Church has distanced itself from the veneration of Ivan by pointing out that the cleric who performed the consecration, Aleksei Aver'ianov, does not officially belong to the Church. In a letter to Boiko-Velikii, obtained by the information agency Interfax, Metropolitan Ilarion stresses that Aver'ianov was stripped of his status as priest in 1996. According to the agency, Aver'ianov stands at the head of the Orthodox community to which Boiko-Velikii belongs ('V Tserkvi napominaiut o nekanonichnosti klirika' 2012). The Orthodox eccentric has since founded the political party 'People's movement 'Holy Rus" (Narodnoe dvizhenie 'Sviataia Rus'). Contrary to the fundamentalist Orthodox groups discussed earlier, Boiko-Velikii does not necessarily aim to undermine the political regime. In fact, he is the recipient of multiple state awards and, as conservatism has more recently become part of the political mainstream, finds himself increasingly close to the powers that be.

The contemporary debates employing the memory of Ivan the Terrible discussed above draw out a number of unpleasant and controversial aspects of Russian society: from the anti-Semitism of Ivan's Orthodox proponents, to the inextricable connection, to (the glorification of) Stalin and the racist contexts in which his name is at times used. For example, during a hockey match in Magnitogorsk in 2007 against the Kazan club 'Ak Bars', supporters of the local club Metallurg held up banners with the slogans 'We will not disgrace Ivan the Terrible', 'Ivan captured Kazan, and we will capture it' and '1380', the date of the Battle of Kulikovo Field. The supporters also chanted 'Beat the Tatars!' ('Rasistskii intsident na khokkeinom matche v Magnitogorske' 2007). Both circles discussed above, who propagate the memory of Ivan and the oprichnina from different sets of convictions, can be considered socially marginal. Yet, as some additional examples below will confirm, some of the proponents of these views have had significant access to the public domain through various media. Moreover, several of them (e.g. Dugin, Kurginian) and the ideologies they represent have since moved considerably closer to the mainstream of political debate in Russia, in particular since the re-election of Putin in 2012 and the annexation of Crimea in 2014.

\section{Film and television analyses}

In the period 2000-2012, the domains of cinema and television made a considerable contribution to the remediation of the memory of Ivan the Terrible, including its inherent controversies and politically subversive potential. The remainder of this chapter discusses three examples that show the variation among these productions. The first, the historical TV series Ivan the Terrible, was produced for state television. The feature film $T$ sar, by contrast, targeted 
both national and international audiences with a more artistic depiction of Ivan's rule. Finally, The Trial of Time is a particularly insightful example of the prolific talk-show genre. The analyses affirm how reinterpretations of Ivan's rule are taken to imply direct commentary on current political affairs and rarely fail to cause a stir.

\section{Ivan the Terrible (2009)}

The television series Ivan the Terrible (Ivan Groznyi, 2009), consisting of 16 episodes, was broadcast by Rossiia in May 2009. The film recounts the story of Ivan from before he was born up to his death. The series was directed by Andrei Eshpai, who also oversaw the TV adaptation of Anatolii Rybakov's famous Children of the Arbat (Deti Arbata, 2004). The producer, Vladimir Dostal', has been involved in numerous historical television productions, including the TV series Stolypin ... The Undrawn Lessons discussed in chapter 3. The director of the latter TV series, Iurii Kuzin, states on his LiveJournal blog that Dostal' initially approached him for the Ivan project in 2006. Kuzin provided him with his director's interpretation of the script and published fragments from this document on LiveJournal in November of that year (Kuzin 2006). The collaboration, however, did not work out. In a blog entry posted on 20 May 2009, after the TV series was first broadcast, Kuzin severely criticises the final result and appears to place the blame for it on Dostal':

How could it happen that TV Channel 'Rossiia', [...] thought it possible to broadcast a series of such questionable quality? In 2006, by the way, Vladimir Nikolaevich Dostal' invited me to work on this project and even asked me to write an explication of the scenario by Aleksandr Lapshin, which I did, offering my conception of the tyrant's personality: 'Ivan the Terrible - A Bastard on the Throne.' The conditions under which I agreed to work on the series did not suit V.N. Dostal' since they required the producer to provide what he is unaccustomed to give: a qualitative scenario! Qualitative editing! Qualitative production! All of this, alas, I was deprived of [when working on] 'Stolypin' [Stolypin ... The Undrawn Lessons, M.W.] and I can only sympathise with Andrei Eshpai.

(Kuzin 2009)

The project was, indeed, a difficult one for Eshpai because of the nature of its subject matter as well as the scope of the production. Yet, as the director remarks in an interview, for him the effort was worth it:

I think that we did not go through all of this in vain: [I have] the impression that the appearance of the film was conditioned by time itself. Ten years ago it could not have been made - even from a material point of view. Neither now, in times of crisis. That means we chose the most 
opportune moment for looking into the past and understanding our present.

(Khlobystova 2009)

As is often the case in such interviews, the director is (intentionally) vague concerning the particular contemporary developments illuminated by such a turn to the past. The specific aspect of Ivan's character that sparked the director's fascination provides us with an important clue here. According to Eshpai, what sets Ivan apart from other oppressive rulers in Russian history (and history in general) was his propensity to repent later in life:

Not one of the tyrants started to have doubts before passing away; neither Peter I, nor Stalin, nor Caligula. But with Ivan this was the case. He perceived the death of his son [Tsarevich Dmitrii Ivanovich, M.W.] as punishment. It convinced him that he was doing something wrong. The letters, death bills in which he commemorates all who had been murdered, and of course also his own pains and illness started to tell him that he was not God. He started to question himself. Exactly in that moment, when I understood this, I became interested in analysing his deeds.

(Khlobystova 2009)

Eshpai, in fact, frames the project as an exploration of human nature itself, which also has direct implications for understanding contemporary political reality. In our souls, he asserts, we all harbour both the magnificent (prekrasnoe) and the uncanny (zhutkoe). The only difference between then and now is that we are now conditioned not to give in to our passions. To glimpse into the past, therefore, can help us reach a greater understanding of ourselves - the heights to which a person can climb and how far one can fall: 'After all, humanity is so often mistaken acting upon their beliefs, and that is a very sad thing' (Khlobystova 2009). According to Eshpai, the aim of revisiting history should ultimately be to learn from historical mistakes and overcome our inner propensity for evil:

If we understand where we erred, understand to what we are entitled and to what we are not, if we repent - that would already be a big step forward. Otherwise we will commit even more terrible mistakes than before. And this is particularly frightful when it concerns those in power. You understand perfectly well what would happen in that case ....

(Khlobystova 2009)

The allusion to the crimes committed by Stalin's regime in this remark is unmistakable. Yet, in equal measure, this call for self-reflection and the overcoming of historical patterns clearly alludes to twenty-first-century politics.

The TV series contains many violent scenes, some of which are uncomfortable to watch. Throughout the series, and particularly in the episode on the 
oprichnina, the characters engage in various types of torture, (mass) murder and rape, all of which are depicted fairly explicitly. Even as a teen, Ivan is involved in the abduction and rape of young women and on a few occasions, as tsar, personally takes part in torturing suspects and convicts. While the series in no way excuses these violent acts, it offers a framework to understand the tsar's acts of cruelty against his allies, enemies and citizens. Shortly before he assumes the throne, Metropolitan Makarii, a close advisor to Ivan, endows the young tsar with a higher mission. Reminding him of his glorious descent - from the Roman emperor Augustus, Riurik, and the emperors of Byzantium - Makarii asserts that in Ivan, as in all Russian princes, the two historical Romes are united: the Rome of the Caesars and that of Byzantium. 'Byzantium has fallen under the Turkish yoke but,' the Metropolitan states with a meaningful pause, 'the city [ $\mathrm{grad}]$ of Moscow remains. The Third Rome! And as the last remaining [ruler] you must preserve it!' Ivan protests that he is not ready to take on such a responsibility, but Makarii insists:

Byzantium passed the beacon [ogon'] of faith on to us. We are the last to preserve her flame [svet]. And the tsar is like the highest igumen [abbot, M.W.]. Understand, grand prince, that this is not about you, but about Christianity, [it is about] how the apostles, martyrs and saints preserved it. The most simple person, the very last, can live freely because they bear responsibility only for themselves before God. But you ... you are responsible for all of the people. [...] Understand, lord, that the Russian state cannot exist without a monarch. [...] because we are the heirs of Greek Orthodoxy, which Byzantium has now betrayed under pressure from the Ottoman yoke.

Ivan's actions, he urges, will decide the fate and survival of both the Russian state and the Orthodox faith. It is only upon Makarii's insistence that Ivan agrees to ascend the throne. Throughout his life, he perceives the crown to be a burden and on repeated occasions asks rhetorically to be released from his predestined duty. His self-sacrifice for the sake of the state's survival and his purported lack of power-seeking behaviour at first resonate strongly with the myth that has formed around Putin's ascension to power and his selfless acceptance of the 'burden' of state leadership.

The series reiterates the standard narrative's division of Ivan's rule into distinct phases: the good tsar, the cruel tsar and the repentant tsar. The endorsement of Karamzin's characterisation of Ivan is affirmed by the concluding shot of the series, where the historian is quoted. Ivan's somewhat troubled youth is presented as a formative phase, contributing to the behaviours he adopts later in life. His exposure to violence and the behavioural patterns he picks up from observing court life shine through during the German language lessons the young boy receives from his mother. When she asks him to translate the verb 'to hang', Ivan replies, 'Hang whom?' In a similar vein, the boy wonders whether the object of the verb 'to cut' (rubit') 
would be a cabbage or a head. Another telling moment is when Ivan fails to remember the German word for 'goodness', but is able to instantly offer translations for 'evil', 'state' and 'power'. The word 'European' (evropeets) prompts the boy to think about Russia's identity and somewhat confused, he asks, 'Mama, and who are we then? Asians?' She replies, reassuringly, that they are Russians (Rusi): 'Also Europe, but [a] different [Europe]' (Tozhe Evropa, no drugaia). Growing up, the relationship with his regent, Ivan Shuiskii, who he considers oppressive, is particularly problematic. Ivan's first wife, Anastasiia, on the other hand, has a pronouncedly positive, calming effect on his mental state and actions. Despite the serious difficulties they encounter in raising an heir to the throne (two of their children die at a young age), their marriage is portrayed as a union of love. When Anastasiia dies as a result of poisoning, Ivan is heartbroken and his character takes a turn for the worse. Apart from Anastasiia, the portrayal of all female characters is markedly negative. Driven by their lust for power, they manipulate their environments and, time and again, turn out to be the driving force behind conspiracies and crimes committed by men.

The transition between the phases - from troubled youth to benevolent ruler during his first marriage, and ultimately to the outright cruel despotism that follows his wife's death - is mirrored by changes in his entourage. In visually comparable scenes, the viewer sees his closest circle of advisors change in composition: the boyars and clergy at the beginning of his reign yield to the new oprichniki who come to make up half of his advisors; then the council consists solely of oprichniki only to revert, finally, back to a small group of boyars. The appearance of Maliuta Skuratov in particular signals a turning point. As Ivan's main executioner, Maliuta is depicted as having a twofold negative influence. First, Maliuta advocates an alternative moral standard to that of forgiveness, which he had adhered to under the influence of metropolitans Makarii and Sylvester and his first wife. Under the sway of Maliuta, Ivan soon adopts the executioner's motto, 'an eye for an eye and a tooth for a tooth'. Second, Maliuta implements a system of intelligence collection that exacerbates Ivan's paranoia. As reports on alleged conspiracies against the tsar continue to mount, Ivan becomes overwhelmed and starts to distrust even his most loyal advisors. However, the intelligence Maliuta gathers does actually constitute systematic disinformation: on several occasions it is suggested that accusation letters are false (for example, because they are not signed) and that the oprichniki have planted incriminating materials on innocent suspects to warrant taking repressive action against them.

In addition to the influence of his entourage, a second factor affecting Ivan's behaviour is the 'heavenly response' to his actions. Medieval Russia is portrayed as a society guided by superstition, signs, premonitions and heavenly signs in the clouds. When the city of Moscow burns down, Ivan interprets the calamity as a punishment for sinful behaviour. Conversely, acts of benevolence are rewarded with the conquest of Kazan and the birth of an heir to the throne. While Ivan and various other characters are routinely shown 
praying, the notion of 'the repenting tsar' features only in the episode on Metropolitan Filipp. The issue of (excessive) confession and repentance is made explicit once, when Filipp remarks that Ivan has turned confession into a habit. His repentance, therefore, lacks substance. As long as Ivan fails to change his actions - the sign of actual repentance - Filipp refuses to pronounce his blessing.

Proponents of Ivan typically cite his education, eloquence and desire to develop his country intellectually; therefore, he could not have been a complete madman or outright tyrant (see the analysis of The Trial of Time towards the end of this chapter for examples of this argument). The topic of his intellectual sophistication appears in the TV series in a slightly forced manner. As a young man, Ivan demonstrates interest in books, and his knowledge of many languages is mentioned. Moreover, he is complimented on his writing. But the motif of Ivan's educated nature largely disappears as soon as he ascends the throne. A second narrative line, connected to this argument, concerns the deacon Ivan Fedorov who is sent to Cracow to study and on his return to Moscow establishes a print works. The printing of religious books encounters stark resistance from the Church, which seeks to prosecute Fedorov and his partner, Petr Mstislavets. After the print yard has burned down as a result of arson, Fedorov asks the tsar for assistance and protection. Notwithstanding Ivan's support for the printing practice (recall how Ivan is called the 'patron of book printing' on the memorial plaque in Archangelsk), Fedorov and Mstislavets flee to the Grand Duchy of Lithuania to escape persecution.

The episode in which Ivan abdicates and retreats to Aleksandrovskaia Sloboda, iconically depicted in Eisenstein's Ivan the Terrible, is rewritten to follow the historical account more closely. Instead of agreeing to return to Moscow upon the request of the Russian people (as the Stalinist interpretation had it), the entire episode is presented as a clever political play to force the boyars into submission. Unable to exert control over the citizenry in the tsar's absence, the boyar envoy agrees to grant the ruler absolute power. In its representation of the oprichnina that is established upon the tsar's return, there are no traces of the 'new oprichnina' discourse described earlier. The oprichnina is but a means for absolutism and, above all, for carrying out state terror. After its establishment, stories of betrayal dominate the narrative. While some conspiracies are real, many more are false - based on contrived allegations. As mentioned, the stream of intelligence reports (often of doubtful accuracy) intensifies Ivan's paranoia. Therefore, while on the one hand it is evident that Ivan acts violently against loyal state servants (and their innocent families), the portrayal of his involvement in the system of intelligence gathering to a certain extent places the blame elsewhere. He acts upon the information he is given, information that - the viewer knows - is incorrect. It is interesting to note that 'arch-traitor' Prince Andrei Kurbskii is portrayed as loyal. The series suggests that the motivation for defecting to the enemy lies in the atmosphere of (false) allegations and conspiracies at court. As even the 
loyal boyars, one after the other, suffer the wrath of Ivan and his oprichniki, Kurbskii is convinced he will be next. To the viewer, the case of Kurbskii can be read as a reference to more recent examples of those who have fallen out of favour with the regime or have chosen refuge in the West, such as Boris Berezovskii and Mikhail Khodorkovskii.

The depiction of Russia's foreign policy, in particular, suggests contemporary parallels. Russia's relations with the West and the East as they are depicted in the series are based on opposed logics. The countries beyond its western border - in particular Lithuania, Sweden and Germany - are seen as enemies who are seeking to expand their influence eastward (cf. the eastward expansion of NATO). The countries to the east, on the contrary, are perceived not as enemies but as targets for Russia's own expansionary policy. In addition, there is a measure of differentiation with regard to the group of Western states, as becomes clear when Ivan's court is visited by foreign envoys dispatched by Queen Elizabeth of England and, on another occasion, the Pope of Rome. The contrast in their visits' purposes, as well as in Ivan's response to their requests, echoes the polarised depiction of court envoys in Aleksandr: The Neva Battle (see chapter 4). The English envoy seeks to establish trade relations, primarily to obtain the natural resources needed for the construction of a naval fleet, a proposal the tsar gladly endorses. Yet, as the troubled journey of the delegation to Moscow confirms, there are political obstacles to overcome: since the Swedes and 'Germans' obstructed naval passage across the Baltic Sea, the delegation was forced to take the hazardous northern route, and two of its vessels were lost (an echo of Eisenstein's Ivan). As the envoy points out, they share interests and enemies, as England aspires to expand to the east and Russia to the west. Under the pretext of trade relations, Ivan thus forms a strategic alliance in support of his effort to gain access to the Baltic Sea. The strategic pragmatism of the arrangement resembles Aleksandr Nevksii's negotiations with Tatar delegates.

The envoy from Rome, to the contrary, is portrayed as deceitful. While ostensibly offering assistance in Ivan's military pursuits, his true aim is to convert the Russian people. Ivan is not deceived, however, and refuses to abandon the religion of his ancestors. In a telling confrontation, the envoy argues that while Russia strives to be part of Europe, it will never be treated as an equal because its people live 'in barbarity'. Enraged, Ivan counters the accusation by pointing out that it is the Catholics who engage in barbaric acts and seek to (violently) subject the whole of Europe to their control. In a similar vein, Aleksandr Nevskii cited violence and expansionism to express the (moral) superiority of Orthodoxy over Roman Catholicism. The two Western envoys represent opposing foundations for Russo-European relations in the twenty-first century. The first is a type of pragmatic relationship, in which Russia is treated as an equal partner. This is the scheme that the Kremlin would like to see realised. The second envoy, in contrast, epitomises the attitude that the regime accuses the West of adopting in its stead and that 
the Kremlin perceives as threatening: a Europe that imposes its belief system on Russia and refuses to accept the country as its equal.

Television critic Sergei Tsyrkun correctly points out that the series is a radical departure from previous cinematic interpretations in how it represents Ivan's character: neither confident nor mad, Eshpai's Ivan is first and foremost tormented by doubt and self-questioning. In Tsyrkun's reading, this doubt originates from the tsar's frustrated desire to change Russian society:

You get the impression that it is not the belief in his own strength, but the feeling of powerlessness in relation to the cycle of life surrounding him that evokes some kind of panicked aggression in the tsar. [...] We are not used to seeing Ivan this way. The Terrible Tsar is usually depicted as sublime (velichestvennym) and self-confident, as Nikolai Cherkasov played him [in Eisenstein's Ivan the Terrible, M.W.]. However, in reality, there were other sides to him as well. [...] The authors of the film succeeded in laying bare the human qualities of Ivan the Terrible by turning him into a conversation partner for the viewer. In one of the scenes he suddenly asks his fiancée Anastasiia: 'Do you pity me?' This question appears to be directed to the viewer.

(Tsyrkun 2009)

The dependence on guidance from his entourage noted earlier is clearly linked to the fear and uncertainty Tsyrkun highlights in his review. As a result, the TV series chips away at the Stalinist image of Ivan, while simultaneously adopting a somewhat apologetic stance with regard to the excessive violence he inflicted. In this respect, it is important to remind the reader that this position echoes the government's positive reappraisal of the legacy of Stalin during the period when the series was produced (see Introduction). At the same time, however, by showing the excesses to which autocratic rule can lead, the series also makes an (admittedly modest) argument against the concentration of power and its far-reaching consequences. As we will see, the film Tsar, released the same year, introduces yet another reinterpretation of Ivan's personality and motives by focusing on Ivan's eschatological beliefs that, in a way, express the same innate fear highlighted by the TV series. Unlike the series, however, the latter production clearly formulates a political critique.

According to TNS Gallup Media, Ivan the Terrible was the third most popular TV series in Russia during its first week. Some 19.5 per cent of the total viewing audience tuned in to the episode broadcast on 13 May ('Telereitingi' 2009a). The final episodes attracted a markedly lower number of viewers: an absolute drop from 6.9 to 5.6 per cent of the sample group, representing 16.7 per cent of the total number of viewers during primetime on 21 May ('Telereitingi' 2009b). ${ }^{15}$ Online viewer comments on the websites Kinopoisk, Ruskino, Kino-teatr and Imkhonet show a mixed audience response. Some commenters greatly appreciated the series. For example, 
'Diadia Patrik' remarks, 'Great series. The few historical mistakes do not harm it at all' (Diadia Patrik 2010). Another commenter concludes, 'Here you have everything in one... Classic Russian historical cinema! It has it all: and drama, and beauty and love... Wonderful!' (akini 2009).

The review of comments reveals that many viewers approached the series as a film about history and therefore set out to assess whether or not it depicts Ivan 'correctly', rather than as an exploration of character - the more likely intention of the series. For example:

The filmmakers [kinoshniki] made a heinous lampoon about Russian history. Their Ivan is a hysterical alcoholic, whose intellectual level corresponds to the average goat butcher [drunk] on beer and vodka. But the real Ivan was a poet and composer, he had a wonderful library, and generally he was a wise ruler who expanded the borders of Russia further than any other. [...] All accusations from the side of the westerniser Karamzin and his less articulate followers are founded on the letters of traitor Kurbskii and other resentful persons. And that is like writing the history of the Patriotic War on the basis of the books by [Viktor] RezunSuvorov [Russian historical revisionist writer, M.W.], ignoring other available sources.

(Gost'_Vladimir Panteleev 2009)

The author of the comment continues by placing the TV series in the context of a continuing anti-Russian smear campaign orchestrated by the West.

All nations constantly emphasise their historical achievements, albeit out of a feeling of self-conservation, but only our socialist traitors, led by the West that is deadly afraid of us, not only pull out the most problematic episodes in our history, but even cover them generously with their unsophisticated speculations and outright lies. It is understandable, when various pugs in the Baltics, Georgia and so on do such things, but when an openly anti-Russian film is shown on channel 'Rossiia' it is bitter and offensive.

(Gost'_Vladimir Panteleev 2009)

The revisiting of darker periods in Russian history and the humanisation of Ivan are thus seen to be aspects of an 'anti-Russian' act driven by the West.

What is particularly relevant with regard to my analysis is that commenters indicate various parallels between the TV series and other historical events, as well as with older cultural productions. For instance, one commenter was simultaneously reminded of multiple phases in the development of Soviet cinema.

The actor who plays Vasilii, the father of Ivan, looks very much like a secretary of the partkom [Party Committee, M.W.] or the director of a 
kolkhoz in Soviet films of the likes of 'The Eternal Call' [1973-1983 TV series, M.W.]. And the actor who languidly plays Ivan as an adult looks like [Igor] Tal'kov [Soviet singer, M.W.] ... . His hair and beard are cut in a contemporary style and he does not look like Tsar Ivan but like some boy-majeure [son of well-to-do parents, M.W.] in an ' 80 s film, spoiled by his wealthy parents.

(Frigirifico 2009)

Particularly noteworthy is the following remark: 'The duet between Maliuta and the tsar smacks of the duet between Beriia and Stalin', referring to the balance of power between the Soviet leader and the head of the NKVD (vitalyklichko 2009). The comment is unsurprising given the longstanding tradition of conflating Ivan and Stalin, which I noted earlier. Yet it would be problematic, of course, if the authors really intended Ivan and Maliuta to be read as an allusion to Stalin and Beriia. It would mean that, in parallel with the series' depiction of Ivan and Maliuta, a similar shift of responsibility for the systemic violence from 'tsar' to 'executioner' would apply to Stalin. If the suggested parallel holds, Stalin would have to be seen as being duped by the web of misinformation created by Beriia. While some viewers may have also read parallels with Putin's Russia in the depiction of Ivan, the picture that emerges is complex and not necessarily positive: while certain acts of repression are excused by placing the blame on Ivan's entourage and, in particular, Maliuta, the personality of the tsar as it is depicted in the series is quite the opposite of the image that has been cultivated of Putin as head of state. Therefore, as a (pro-Kremlin) political statement, the series is ambiguous at best.

To conclude, two matters deserve mention. First, the suggestion that Dostal' was already working on the project in 2006 gives us an important clue about the initial incentive for the TV series. It would mean that the production was conceived in the wake of the first peak of oprichnina discourse (associated with, in particular, Dugin) and within the context of policy changes instituted in response to the colour revolutions. This is also around the time that Sorokin published his anti-utopian novel Day of the Oprichnik. Second, when viewed in light of the year in which it was eventually broadcast, the TV series largely echoes the core elements of official memory politics at that time, as well as the regime's foreign policy objectives. Still, as the online discussions about the TV series demonstrate, the memory of Ivan does not easily lend itself to political mobilisation, even if the state had intended it to. The sheer divergence of opinions and interpretations, and the varying viewing strategies they reveal, testify to both the complexity of the memory and the lasting impact of previously mediated images on the appreciation of later representations.

\section{Tsar (2009)}

That same year, on 4 November, Pavel Lungin's feature film Tsar (2009) had its Russian premiere. The film competed in the Un Certain Regard section of 
the Cannes Film Festival in 2009 and was generally well received internationally. In 2010, it was awarded two Nika awards ${ }^{16}$ for 'Best male role' (Oleg Iankovskii) and 'Best art direction' (Sergei Ivanov), and was nominated in two more categories, including 'Best film'. Unlike the TV series, the film concentrates on a particular episode during Ivan's rule: the period when Filipp served as metropolitan of Moscow and defiantly criticised the tsar's violent repressions via the oprichnina. The moral and, by extension, political confrontation between Ivan and Filipp stands at the heart of the narrative. By isolating the conflict with Filipp, the director takes the notion of 'multiple Ivans' out of the equation; because the evil he exposes is not counterbalanced by earlier successes or stints of nobler behaviour, it has to be taken at face value. To Lungin, Ivan symbolises the recurrence of state-sponsored violence, as well as the 'somewhat masochistic love' that dictators such as Ivan and Stalin continue to receive in Russia (Shigareva 2008).

In general, [Ivan the] Terrible is one of the key themes to our country because precisely he changed the entire history of Russia. His ghost looms over us to this day; sometimes drawing closer, at other times receding. Currently it is receding, thank God. But there were times, when it flew up very close. Ivan the Terrible is Russia's eternal temptation.

(Shigareva 2008)

Lungin's perception that the ghost of Ivan is receding is highly significant for the evaluation of the film's political intention.

Lungin's depiction of Ivan, who is played by the actor and singer Petr Mamonov, sparked harsh criticism from various groups in society. As the reviewer for Novaia gazeta noted:

Not just the Orthodox and deputies are arguing about the film, which touches upon the metaphysical layers of national history, but also serious scientists, philosophers, clergymen. The main stumbling block is the representation of Ivan Vasil'evich. In the film, the tsar is compared with the Antichrist, with a Caesar breaking faith, [or] even a vampire: he is frightening, with a single tooth glistening, falling from the ecstasy of prayer into the ecstasy of murder.

(Maliukova 2010)

Lungin indeed presents a terrifying image of a tsar driven by apocalyptic religious beliefs and paranoia (though the description 'vampire' does perhaps not do justice to the complexity and depth of Mamonov's performance). Metropolitan Filipp, played by Oleg Iankovskii, one of Russia's most famous actors, who passed away shortly before the premiere, functions as his negative image; he grasps reality, is composed, acquiescent and morally superior. In a way, the film is as much about (Saint) Filipp as it is about Ivan, which is confirmed by the fact that Iankovskii sought the blessing of Patriarch Aleksii 
II for playing the role. By depicting Filipp's martyrdom, the film acts almost as a twenty-first-century hagiography. Filipp's composure and actions are saintly in every way: he is unyielding in his moral beliefs, unfazed by direct confrontations with evil that threaten his life. He even performs a miracle shortly before he gets killed. Filipp's ability to act without political intent is thus markedly different from the at times pragmatic ways in which the ROC has defined its relation to the state in post-Soviet Russia (see chapter 4). Despite the pervasive Orthodox overtones and the ROC's official support, the production was fiercely contested in certain Orthodox circles, as will be discussed later in greater detail.

The confrontation between tsar and metropolitan plays out against the backdrop of relations triangulated among ruler, entourage (boyars, oprichniki, clergy) and the people. The film thereby engages with three current political matters of great significance: first, the increasingly close relations between the state and the ROC; second, the struggle between the president and the oligarchs; and finally, the concentration of power in the figure of Vladimir Putin and the question of popular support. The film can be seen as a critique on all three counts. With regard to the latter issue, the subjugation of citizens and their dependence on the ruler's guidance is epitomised in a scene that makes a direct reference to Eistenstein's Ivan the Terrible. The scene is set shortly before the tsar summons Filipp to his court to replace the previous candidate for the metropolitan throne, whom he rejected for his criticism of the oprichnina. Ivan publicly laments that there is no metropolitan in Moscow and is joined by his subjects in a long procession. As the tsar is pulled across the snow on a carpet, the people form a winding line behind him. The image Lungin creates is reminiscent of the procession gathering at Aleksandrovskaia Sloboda to beg for the tsar's return in Eisenstein's classic depiction of subjection to the monarch. The visual quotation reinforces the contradictory message. As Kevin Platt vividly asserts: '[W]hile the original shows the common people longing to submit to the order of their tsar [...] Lungin's remake shows the Russian people being swept along with Ivan in his foam-atthe-mouth madness' (Platt 2010). When read as a critique of current political issues, the recasting of the relation between ruler and subjects, as one based not on a 'social contract' but rather on the exploitation of dependency and emotion, would directly challenge the Putin myth (see chapter 5).

As was the case in the TV series, Ivan is significantly influenced by his entourage. The dynamic between the tsar and his closest group of oprichniki at times resembles that of a gang of young men, here dressed in black and dark blue with their hoods pulled down, provoking one another to make the next move in their tyrannical game of violence. Filipp tries his best to counteract this spiral of violence but Ivan is past redemption. As the struggle between ruler and metropolitan unfolds, it becomes increasingly clear that Ivan has lost all moral sense. Reinforced in his paranoia by Maliuta, he is unable to objectively reflect on his actions. Lungin allows for a hint of tragedy, as Ivan appears to be yearning for guidance but, when given counsel, is 
unable to accept it. The tsar masks his overruling of Filipp's advice by quoting the scriptures and in other ways undermining the position of the metropolitan as a moral authority. Here we can see a clear reflection of the one-sided pragmatism with which the Russian government has long approached its relations with the ROC, seeking closer ties as far as it has suited its domestic and foreign policy ends (see chapter 4). As tsar, Ivan maintains, he is accountable to God alone, not to His worldly servant. He furthermore differentiates between how he should be judged as a man and as ruler. The condition of exceptionality Ivan creates for himself refutes the moral restrictions on his behaviour suggested by Filipp. More generally, his perception of the world around him is selective and made to fit his preconceptions. Ivan thus creates his own truth, particularly with regard to the tortures and murders committed by the oprichniki. For example, whenever the tsar benevolently grants mercy to a suspect, Maliuta and his squad execute the order not by returning him to freedom but by killing him. And as Ivan acts upon confessions obtained 'without torture', these have, in reality, been extracted through violent intimidation. Ivan's pretence of ignorance concerning (the excesses of) the rampage led by Maliuta is shown to be a self-induced delusion.

Whereas in the TV series Ivan was firmly in control of the political game, albeit growing increasingly volatile and paranoid, in $T$ sar he often appears to have completely disconnected from reality. Withdrawn into his mind and absorbed in his obsessive mental ramblings, Ivan is seemingly unaware of what goes on around him. In one of the scenes, he sits outside in the courtyard. As he reads out loud from the scriptures, people are being chased and assaulted around him. Immersed in his reading, Ivan is seemingly unaware of the ongoing brutalities. Filipp enters the courtyard and is appalled by what he sees; here, he acts as witness to the systematic cruelty that Ivan is no longer able or willing to take note of. At times, Ivan even appears to be hallucinating. After granting mercy to one of his boyars (who was granted freedom via death), the tsar wakes up in the middle of the night and starts talking to himself, acting out both sides of a conversation with his victim. The nightmare of guilt is a clear indication that, in reality, Ivan is well aware of how Maliuta executes an order of purported benevolence.

I agree with Kevin Platt that the film's political message is both self-evident and contradictory. On the one hand it 'debate[s] the relationship between subjects and state and the legacy of despotic authoritarian politics in Russia today' and should be regarded as 'a manifesto on contemporary society and politics' (Platt 2010). At first glance, the unforgiving depiction of Ivan 'would appear to unite it with other anti-tyrannical representations of Ivan and Stalin, such as Sorokin's Day in the Life of an Oprichnik, which warn against a possible resurgence of tyranny' (ibid.). While the film unmistakably warns against the concentration of power in the hands of a single individual, Lungin's remark about the receding ghost of Ivan's tyranny, quoted earlier, suggests that his criticism of the regime was less pronounced than, for instance, Sorokin's (or that Lungin was optimistic about the changes brought about by 
the presidency of Medvedev). At the same time, however, as Platt points out, Lungin's 'critique is also aimed at the anarchy, amorality and spiritual emptiness of the present':

In this latter aspect, it participates in the current backlash against the excesses and anarchy of the 1990s and resonates with the longing for traditional patriotic values and order that dominates much political rhetoric in Russia these days - tendencies that have supported the consolidation of power in Putin's 'sovereign democracy'.

(Platt 2010)

Lungin has indeed noted that the resemblance between contemporary Russia and the latter stages of Ivan's rule lies in how the lack of a sense of purpose (smysl) has brought society to a breaking point:

On the basis of some complicated calculations, the year 1566 somehow rhymed with the number of the Devil, 666, to them [Russian society at that time, M.W.]. And the whole country was firmly convinced their final days were approaching. And, in a strange way, this feeling of the end of the world, of Doomsday, the feeling that, in expectation of the Last Judgement all is permitted, is very familiar to us. Evidently, today, just like almost five centuries ago, we are once again reaching a low point. And after this we will start to ascend; towards a life, full of some kind of meaning.

(Shigareva 2008)

The film thus simultaneously challenges and reiterates the central tenets of the regime's political discourse; it acknowledges that Russian society is in need of a cure, but disapproves of the treatment it has been given.

As mentioned earlier, the film elicited harsh responses. The journalist and historian Viacheslav Maniagin, who has published extensively on Ivan the Terrible's reign, even addressed an open letter to President Medvedev demanding that the film be taken out of cinemas. He argued that it maligned the founder of the Russian state and falsified history. ${ }^{17}$ The choice of words here is hardly coincidental since a copy of the letter was also sent to the Commission against the Falsification of History. According to Maniagin, allowing the 'false' depiction of Ivan the Terrible to circulate freely would be not just undesirable but harmful to Russia and especially to her image abroad:

But if you believe that the founder of our state was such a tyrant, then it is also possible to believe that contemporary Russia, as they say in the West, is a stronghold of totalitarianism, tyranny, an antidemocratic, antipublic [antinarodnym] state, ruled by inadequate individuals [ne sovsem adekvatnye lichnosti].

(Maliukova 2010) 
Maniagin is not the only public figure to take offence at the film. In an open letter published in Izvestiia on 13 January 2010, Boiko-Velikii, who was already introduced above, accused Lungin of falsifying history and committing blasphemy. In the letter, he enumerates each point where, he claims, the storyline of the film is not supported by historical evidence. For instance, he argues that the depiction both of Ivan's character and of the oprichnina itself is faulty and deceptive:

The oprichniki did not drench the country in blood. The oprichnina was aimed at eradicating boyar treason and the Heresy of the Judaizers and concerned only individual boyar families, part of the clergy that had lapsed into heresy and those representatives of the capital, Tver and Novgorod 'elites' who were willing to cooperate with catholic Rome. The Russian people preserved the memory of Tsar Ivan as a just Tsar in their chronicles, songs and byliny.

(Boiko-Velikii 2010)

In the opinion of Boiko-Velikii, the offence committed by Lungin through his interpretation of the events at Ivan's court is exceptionally grave - even graver, he claims, than the betrayal by Prince Andrei Kurbskii:

Tsar Ivan Vasil'evich Groznii was already slandered during his lifetime: by the traitor and deserter Andrei Kurbskii and many others, and after his life a flood of defamations descended upon him. But Pavel Lungin, Aleksei Ivanov, Petr Mamonov and others who were involved in the scenario and creation of this film have exceeded, in our opinion, all slanderers and villains that have accumulated over the course of five centuries.

(Ibid.)

Boiko's strong response exemplifies how Ivan's contemporary proponents counter any form of critical assessment of his legacy by labelling it an antipatriotic act (a type of rhetoric that has become problematically pervasive during Putin's third presidential term).

Some weeks later there was an incident at the award ceremony for 'Person of the Year 2009', organised by information agency RBK, where Lungin received an award for his contribution to the development of Russian cinema. Boiko-Velikii, who was also among the awardees for his contribution to developing a tradition of Orthodox maecenatism, seized the opportunity to criticise Lungin's film in his acceptance speech. According to a reporter for Nezavisimaia gazeta, Boiko urged contemporary sponsors of culture to reconsider the types of projects they were investing in, stating that 'Lungin is a good director, but Tsar is an awful and unreliable film' (Volchkova 2010). For one of the actors, the criticism had personal consequences. Ivan Okhlobystin, a popular actor and (since 2001) Orthodox priest who played the role 


\section{Case studies}

of court jester Vassian, asked Patriarch Kirill to release him from his priestly vows in response to the critique the film and he himself had received. He felt he could no longer credibly combine both aspects of his life ('Otets Ioann Okhlobystin khochet ostavit' sluzhenie sviashchennika' 2009).

Nikolai Uskov, a medieval historian and (then) the editor-in-chief of the Russian journal $G Q$, commented on the flood of criticism in an opinion piece for Nezavisimaia gazeta. In a highly critical piece, he challenges the 'self-proclaimed patriots' who were attacking Lungin by arguing that '[Ivan], of course, was white and fluffy, murdered very few people and did so solely for the sake of the greatness of Russia' (Uskov 2009). Uskov argues that no 'thinking person' would voluntarily support the state-centred, destructive type of patriotism espoused by these individuals. In fact, the admiration for figures such as Ivan the Terrible, he claims, is indicative of fundamental issues that continue to hamper the development of Russia into a modern society. To do credit to Uskov's argument, I quote him here at length. The position that Uskov sketches in the first few lines corresponds to the core message of the state's memory politics and its supporters.

Ancient people said: 'Our motherland is there, where life is good.' Our patriot has begotten something paradoxical: 'Our motherland is there, where life is bad.' From his point of view, the worse, like in the times of Ivan the Terrible or Stalin, the better. The thinking individuals [...] induce panic, they say Russia can disappear, that domestic and foreign enemies will rip her apart, will tear her into pieces. To prevent this, all of us have to stand with our pants pulled down as well. I always wanted to object to these thinking individuals. Perhaps, just let that kind of country [takaia strana] disappear. Perhaps, after centuries of forcing the people to stand with their pants pulled down and contriving all sorts of theories about the sublime mission of extraordinary ghouls [vydaiushchikhsia upyrei] it has been enough. Because I believe that no one is threatening Russia; who needs our problems, except for us? In these times, we have to remember one thing: that, in your motherland, life has to be good. In the globalised world, countries compete with each other for human capital, for the most highly educated, energetic, creative people. The individual does not exist for the government but the government exist for the individual - that is the foundational principle of modern society. Otherwise, the little men [liudishki], as Ivan Vasil'evich would put it, will run away. Of course, in such a system it will be considerably harder for thinking individuals to pass their own interests off as mystical ones and, generally, will have to work and not just nag. But, gentleman, that is exactly why you are thinking individuals.

(Uskov 2009)

Uskov's appeal to 'thinking people' to break the repetitive cycles characterised by the repressive submission of the Russian people to the needs of 
the state appeared at a time when memory politics activity was peaking in Russia. Indeed, his plea should be read as a direct response to and critique of its core elements. The heated debates surrounding the film expose mounting tensions regarding the state's patriotic rhetoric, in particular among the cultural elite. While the increasing reliance on patriotism and the historical justification of politics was criticised by some as being merely a façade to legitimise an authoritarian system of governance - the opinion expressed by Uskov - for others such as Boiko-Velikii, the regime, on the contrary, remained insufficiently conservative and traditionalist.

\section{The Trial of Time (2010)}

The sharp polarisation of opinions about Ivan's legacy and how these standpoints are assumed to reflect one's political orientation are most evident in the final example I want to discuss. The talk show The Trial of Time (Sud vremeni) aired in the second half of 2010 on Channel Five, which at the time was a TV channel with a distinctly liberal orientation. Mimicking the format of a court of law, the show put historical personalities and events on trial. The political relevance of the historical questions under discussion was heightened by the evident political leanings of the show's hosts - the well-known television journalist and historian Nikolai Svanidze in the role of judge, and journalist Leonid Mlechin and political figure and theatre director Sergei Kurginian as prosecutor and defence attorney. What is particularly insightful about this case is that a telling discrepancy soon became apparent between the results of the studio-audience vote - siding with the liberally inclined Mlechin - and the opinion of viewers at home as expressed through online and telephone voting - supporting the 'pro-Soviet' conservative views of Kurginian. Whereas typically the discussions about history are the object of societal commentary, here it was the voting dynamics that triggered debate. So much so, in fact, that the producers felt compelled to dedicate a special broadcast to the issue. As will be discussed in the next chapter, dedicated in its entirety to the show's revealing production history, this broadcast, which was appropriately named 'The Trial of The Trial' (Sud nad Sudom), set out to discuss the 'incorrect' (i.e. anti-liberal) voting of the home audience and how it should be interpreted. Why was the audience of a liberal TV channel not siding with the liberal standpoint represented by Mlechin?

The talk show was cancelled after only a few months, despite its popularity and evident societal resonance. In part this was the direct result of a managerial takeover and rebranding of the channel (I demonstrate how Channel Five was thus 'brought in line' with state interests in chapter 7). But in a surprise turn of events, the show made a comeback on state-owned Channel One. I will return to 'The Trial of The Trial' special broadcast and the show's cancellation and reappearance in the next chapter since it shows the politics of television programming at work. Also, The Trial of Time is a rare case where it is actually possible to directly trace the interaction between the levels 
in memory politics, namely those of the state, political and cultural elites, media and audiences. Within the context of the current chapter, however, my discussion of the programme limits itself to the three-part episode about Ivan the Terrible.

To fully appreciate the significance of the show and its discussions, it is important to point out that Kurginian has since used the popularity of The Trial of Time as a springboard to create his own political platform. After the show was cancelled, he launched a series of online video lectures on history (in particular, the collapse of the Soviet Union) and associated political matters under the name 'The Essence of Time' (Sut'vremeni). In Russian, the difference in name is but one letter and the two words (sud vs. sut') sound very similar. The online community that formed around the lectures soon developed into an offline social movement under the same name, complete with weekly newspaper and regular participation in rallies. In 2012, Kurginian published the book The Essence of Time: The Philosophical Rationale of Russian Messianic Pretences in the 21th Century, which outlines the foundations for the movement's political agenda. He is one of the driving forces behind contemporary Russian messianism, which has increasingly influenced the state's political discourse. The Trial of Time, as well as its successor that will be discussed in the next chapter, proved to be a suitable platform for one of the 'godfathers of post-Soviet conservatism' to mediate his views on Russia - past and present - and rally support for his view of Russia's future, which Maria Engström has summarised as 'The Soviet Union 2.0'. (Engström 2014: 359).

\section{Ivan the Terrible}

As already noted, the debate about Ivan the Terrible on The Trial of Time illustrates the polarisation of views on his legacy in contemporary Russia. Pitching liberal against conservative understandings of his rule, the show revolves around the question of the permissibility of repression and state violence under exceptional circumstances. The confrontation between Kurginian and Mlechin reflects a fundamental difference between state-aligned and oppositional memory politics. As I indicated briefly in the introductory chapter, state-aligned forces tend towards the opinion that certain restrictive measures are necessary to safeguard stability and stave off revolution. Those holding oppositional views, to the contrary, turn this black-and-white opposition between order and chaos inside out and recast such enforced, top-down stability as repression. The debate thereby points towards a fundamental point of contention between liberal and conservative views on the role of the Russian state. Here it has to be stressed, however, that Kurginian's position is significantly more extreme than that of the central government at the time.

In the programme, in response to the central question 'Ivan IV: bloody tyrant or successful political actor?', three main issues emerge as the debate develops. The first two reflect key aspects of the memory politics debate: 
whether modernisation must go hand in hand with authoritarianism and to what extent violence can be justified by exceptional circumstances. Regarding the issue of modernisation, the question is posed whether is it possible to carry out substantial reforms without increasing state control and enacting (excessive) violence. Kurginian argues that this is, indeed, an unavoidable fact of historical political development. Mlechin, on the contrary, asserts that this is only partly the case. To carry out fundamental reforms, a certain measure of authoritarianism may indeed be required; yet, he argues, one has to take into consideration the cost exacted by such progress. In particular, Mlechin feels that certain excrescences of authoritarian rule, such as waging war against one's one people, are unnecessary and can harm state interests. Such unwarranted acts of violence should therefore be condemned rather than condoned or rationalised. His argument clearly refers to contemporary attitudes towards Stalin as well as Ivan.

The second dominant issue concerns the historical contextualisation of Ivan's rule and, in particular, how his actions compare to those of other, equally bloody medieval rulers. Was Ivan an exceptionally violent ruler, or was he simply a product of his time? For example, after enumerating the number of victims of sixteenth-century state repression in England and France, Kurginian concludes that Ivan acted in accord with the norms of the era; therefore, any claims about extreme cruelty are fictitious 'fantasy' (fentezi). His line of argument mirrors how Il'ia Glazunov chose to defend Ivan on The Name Is Russia (see chapter 4). Moreover, he argues that the oprichnina (and, by extension, all acts of cruelty associated with Ivan's reign) should be viewed as an historical anomaly. Displaying a clear disregard for the crimes committed by the Soviet state, Kurginian maintains that the oprichnina was a unique deviation from the 'special Russian path, which is particularly peaceful, particularly humanistic, [and] in which atrocities never occurred'. Mlechin does not go along with the reductionism of the proposed logic. In the discussion of tyranny, the inevitable comparison between Ivan and Stalin is eventually raised. For instance, the film director Pavel Lungin, who is called as a witness by Mlechin because of his work on Tsar, comments: 'We can talk about tyrants. We can talk about Iosif Vissarionovich Stalin. But no one asserts that Iosif Vissarionovich went into some cellar and personally took part in tortures. [But] he [Ivan the Terrible, M.W.] personally performed tortures.' The comparison between Ivan and Stalin is not explored in detail, however, and appears to be purposefully circumvented by both Mlechin and Kurginian.

The final issue that is repeatedly raised is the enduring question of whether Ivan suffered from mental illness. The debate revolves around the argument, introduced by Kurginian, that Ivan's intellectual and artistic talents would refute allegations of insanity (though he leaves open the possibility that Ivan was schizophrenic). Kurginian's lyrical praise of Ivan's 'mastery of the word' and 'almost encyclopaedic' knowledge evokes a stark response from Svanidze: 
The talents of Ivan the Terrible are beyond doubt. [...] But, you know, it so happens that Hitler was a pretty good artist. Stalin wrote poetry. Mao Zedong wrote poetry. Pol Pot studied at a French university. They were all very bright, creative individuals.

That Ivan possessed exceptional intellectual and artistic capacities, therefore, says little about his mental stability, nor does it prove 'ethical adequacy'. In Kurginian's propagandistic style of reasoning, however, rhetorical effect takes precedence over logic. What is particularly alarming, then, is the home audience's unfaltering support for Kurginian's position.

At several instances, the discussion goes beyond an analysis of the past and the exploration of subtle historical parallels and evolves into a direct commentary on present-day socio-political issues. For example, as he addresses the question of waging war against one's own people, Kurginian links the topic directly to the danger posed by separatism and terrorism to the territorial integrity of the Russian Federation today. Such 'separatist hotbed[s]', he claims, typically end in the break-up of a state. To underscore his argument, Kurginian evokes with evident exaggeration the traumatic experience of the dissolution of the Soviet Union:

You have already seen this happen once, when the break-up of the Soviet Union caused millions of deaths, about which simply no one speaks. You already saw how these separatist tendencies ended in - of course not the [actual] burning of people at the stake - but with chopping of heads with blunt grub axes.

Here he refers to his personal experience when visiting the Central Asian cities of Fergana in Uzbekistan and Osh in Kyrgyzstan. Yet, he warns, this potential contagion could all too easily spread to Russia as well.

And you see that the Russian Federation crumbles as well. A place you should fight for as if it were the last stronghold. A place where you understand that further disintegration will be final. And [you understand] that you simply give away your state and your civilians to the delight of whichever terrorist gangs. You start to fight a war. That is horrible. It is tragic. It should not be glorified. But isn't it a historical necessity?

His argument echoes the rhetorical opposition between stability and collapse that forms the foundation of governmental memory politics, but amplifies it to the extreme.

Kurginian's emotional appeal is one of several instances where past and present are interlaced. Lungin even directly refers to the contemporary debate that frames the oprichnina as a typically Russian way of modernisation that I discussed earlier. He summarises the argument as follows: 'Fortunately, we do not have [Ivan] the Terrible [Groznogo], but we do have the oprichnina. It is a 
norm of life in Russia! This is our modernisation.' Lungin disagrees, however. 'Wrong!' he says, 'Russia is not that kind of country!' Lungin's final verdict about the tsar is emphatically negative: Ivan is 'the author of the Time of Troubles'.

Kurginian's rhetorical methods deserve particular attention. In the debate with Mlechin, as well as in his interaction with the experts invited as 'witnesses', he habitually adopts a cynical stance. When the historian Igor' Pavlovskii, a professor at the Moscow State University, points out that Russia was in a state of 'moral decline' under Ivan the Terrible, Kurginian undermines Pavlovskii's credibility by ridiculing the sources this claim is based on. 'How can we quantitatively demonstrate the moral decline of the people in this period? With focus groups? Sociological questionnaires? Neurolinguistics?' Kurginian asks. The enumeration of objective-sounding sociological research methods, all of which are of course unavailable to the medieval historian, has the desired effect: the fact that Pavlovskii has based his estimation on period memoirs now comes across as speculative and unreliable. On other occasions, Kurginian takes the logic underlying the opposing party's position and pushes it to the extreme. For example, Mlechin criticises Ivan's waging of war against his own population, which was not, moreover, in the service of direct state interests. He argues that Ivan's implication in the resulting deaths should, therefore, be viewed as a particular kind of serial killing, rather than as the unfortunate but inescapable by-product of medieval state conduct. Kurginian then connects the question of a war waged against one's people to the American Civil War. Should, then, the generals involved and the actions taken to counter the secession of the Southern states also be denounced as 'not humane'? It was, after all, 'a civil war in the super democratic United States' (emphasis added). He ends such 'logical' arguments with a series of rhetorical questions: 'But exactly from this, contemporary America was born. And now let's ask ourselves the question. But what if it had not happened? Then there would be no state. And what would have come in its place?'

The aim of such logical interventions is to suggest that the liberal position is overly optimistic or even naïve about the recurrence and necessity of violence in historical development. Such accusations exacerbate the negative image of liberalism in Russia resulting from the experiences with neoliberal 'shock therapy' reform during the 1990s. Here, Kurginian also accuses Mlechin of applying double standards and, consequently, of violating scientific norms. Russia is judged harshly while similar violent episodes in other countries are glossed over, so he claims. While Kurginian's appeal for adhering to scientific standards finds little actual cause in Mlechin's argumentation, the accusation is no less rhetorically persuasive.

Both sides agree that, to reach a final conclusion on Ivan's rule and legacy, the outcomes of his rule should be a principal factor. Their perceptions of the outcomes are, however, radically opposed. To Mlechin, the two phases of Ivan's period of power represent two paths of development. The first, the 'establishment of a normal system of life', merits emulation while the second, 
'war against one's own people', has to be rejected. The end result of Ivan's rule, Mlechin concludes, was 'monstrous for Russia'. For Kurginian, the hackneyed cliché of territorial expansion is sufficient ground to judge the outcomes positively. The tsar who 'unified Siberia', captured Kazan and Astrakhan and 'in fact, thereby established the state' should necessarily be considered successful. Kurginian refers to other historical leaders with complex legacies to argue that their 'plusses and minuses' are a fact of history that has to be accepted; acts of violence, he asserts, do not preclude political greatness. In fact, it would be 'absurd' to characterise 'he, who won the Battle of Poltava and defeated Sweden' (i.e. Peter the Great) and 'he, who did some other things [kotoryi sdelal chto-to eshche] and won the Great Patriotic War' (i.e. Stalin) as tyrants.

I despise tyranny no less than those, who exclaim their hatred of it here! And precisely to prevent tyranny we need our history in its entirety. We need to return to our own history! To understand it and recognise that we have a lot of great historical figures, great politicians. Outstanding [figures] with their plusses and minuses. And as we understand and relive this [history] we will find our path! We will rise to our feet. We will no longer be a country with a broken historical backbone.

The voting results are unsurprising. While the majority of the studio audience ( 73 per cent) believe Ivan the Terrible was a 'bloody tyrant', the overwhelming majority of viewers (87 per cent) deem him a 'successful political actor'. In his concluding remarks, Svanidze comments on the positive appreciation of Ivan in folk songs and tales, including those originating in Novgorod where the repression was particularly merciless. 'Nowadays,' he remarks, 'this would be called Stockholm syndrome', referring to the psychological condition where a hostage develops sympathy for his captor. Moreover, he adds in evident reference to contemporary debates regarding the need for a strong hand in politics, it is a condition which periodically repeats itself in Russia.

\section{Conclusion}

Around the time when the TV series and feature film about Ivan were released, various memes began to circulate online in which a photoshopped version of Repin's painting Ivan the Terrible and His Son Ivan shows the Terrible Tsar 'killing' all kinds of persons and, in particular, other artworks. In these memes, the distressed tsar pressing his son's lifeless body against him becomes a vampire-like figure, sucking the life out of whatever he gets his hands on: from Ivan Kramskoi's Portrait of an Unknown Woman to Kuzma Petrov-Vodkin's Bathing of the Red Horse and Vladimir Malevich's Black Square. ${ }^{18}$ More recently, the motif reappeared in the context of the conflict in Ukraine. This time, it is the nation of Ukraine - depicted via the country's 
outline in yellow and blue - that suffers the tsar's wrath (JoyReactor 2014). The meme illustrates the versatility and recognisability of the figure of Ivan, as well as the complexity and extremely politicised nature of his memory. While for some Ivan stands for the might and supremacy of the Russian state (or, indeed, of Russia as a Eurasian empire), for others he symbolises the atrocities committed by this very state and the extreme toll that Russian imperial greatness has taken on its population throughout history. As this chapter has shown, the meanings attributed to the oprichnina are contradictory. What the groups and individuals who mobilise this particular cultural memory have in common, however, is their highly critical stance towards the political establishment. Taking various political, ideological and religious beliefs as points of departure, they employ the memory of Ivan and his oprichnina to challenge or undermine the current regime and the political system in which it operates. As a cultural memory with a particularly subversive potential, the figure of Ivan allows itself to be exploited for divergent political agendas, from re-establishing the Orthodox monarchy or creating a Soviet Union 2.0. to demanding democratisation and respect for fundamental civil rights.

The complexity of the memory, which is the direct result of its remediation history and the memory chain it invokes, makes it highly unstable. The conflation of Ivan and Stalin further exacerbates this volatility. Whereas, in the cases of the Time of Troubles and Aleksandr Nevskii the fact that the memory of each had been mobilised as part of Stalinist propaganda had a somewhat positive effect on its employability in the interests of the regime, the opposite is the case for Ivan. Why this is the case parallels in many ways the state's paradoxical attitude towards the memory of Stalin. To be able to benefit from the powerful patriotic symbolism of the victory in the Second World War, governmental memory politics has attempted to separate Stalin, the commander of the Red Army who secured victory in the war, from the Stalin who orchestrated terror against his own population. While the memories of the end of the Time of Troubles and Aleksandr Nevskii are related to the positive former aspect of the memory of Stalin, it is to the second image of tyranny that the memory of Ivan is inescapably bound. Therefore, as long as the conflicting representations of Stalin remain unresolved, the memory of Ivan will similarly continue to polarise audiences.

\section{Notes}

1 The absence of commemorative infrastructure altered dramatically in 2016 and 2017 when statues of Ivan the Terrible were erected in Moscow and Orel, see chapter 8 .

2 Namely, Eisenstein with the film Aleksandr Nevskii and Aleksei Tolstoi with the novel Peter I.

3 Novaia oprichnina, neooprichnina and new oprichnina are used interchangeably from hereon.

4 I used the Integrum World Wide media database to quantitatively analyse the number of times the relevant terms were mentioned in the central printed press 
(dataset 'SMI: Tsentral'naia pressa'). The query was performed on 18 March 2016 for the intervals corresponding to the presidential terms (1: 31.12.1999-06.05.2004; 2: 07.05.2004-07.05.2008; 3: 08.05.2008-06.05.2012; 4: 07.05.2012-31.12.2012). The query returned the following results in absolute numbers: 'novaia oprichnina': respectively 4/11/15/4 mentions; 'neooprichnina': respectively 0/0/1/0 mentions. By comparison, during Putin's third presidential term (up to the date of query) the terms were mentioned twelve times and twice, respectively. An initial survey of the results using the query terms 'oprichnina' and 'oprichnik' revealed predominantly historical, factual usage of the terms, which undermines their value as quantitative indicators.

5 Dugin used the word 'oprichnina' before this date, in particular to describe certain aspects of Bolshevik rule. Yet, these examples do not imply the creation of a 'new oprichnina', nor do they amount to a mobilising usage of the word. See, for example, Dugin (1998).

6 Dugin switches from 'novaia' to 'neo-' at this point.

7 In 2011, Mikhail Deliagin published a book titled The Path of Russia: The New Oprichnina, or Why You Do not Have to 'Get out of Russia' (Put' Rossii: Novaia oprichnina, ili Pochemu ne nuzhno 'valit' iz Rashki'). Despite the direct reference to the oprichnina in the title, the author appears to use the term mostly as a rhetorical ploy and its development as a political concept is superficial compared to the two (groups of) author(s) I discuss here.

8 Oprichnik was a restaurant serving 'old Russian' cuisine in a luxuriously decorated space, complete with dog's heads, brooms and other oprichina-themed decorations.

9 A recording of the action can be found on YouTube: www.youtube.com/watch?fea ture=player_embedded\&v=GfCTdH_AsyI (accessed 21 January 2018).

10 For a detailed analysis of the 'ideology' propagated by Shchedrin, see Dvorkina (2004).

11 The lyrics are written by Gennadii Ponomarev, Bichevskaia's husband.

12 I want to thank Birgitte Pristed for bringing Boiko-Velikii to my attention.

13 To avoid violating the law, the 'dismissal' would technically take the form of declaring the position held by the employee redundant.

14 The bill to 'counteract the insulting of religious convictions and feelings of believers' was signed into law by President Putin on 29 June 2013.

15 TNS Gallup Media provides two markers of popularity: rating and share. Rating refers to the percentage of participants of the survey who watched the programme. Since the sample size is static, it is an absolute figure that can be used to compare programmes broadcast at different times. Share is the percentage adjusted for the total number of viewers at time of broadcasting, which indicates the programme's relative popularity in relation to shows broadcast at the same time.

16 The Nika Award is Russia's most important film prize, awarded annually by the Russian Academy of Cinema Arts and Science. Since 2002, the Russian Academy of Cinematic Arts has hosted a competing awards ceremony - the Golden Eagle Award - for cinema and television productions.

17 For an analysis of the historical and historiographical sources Lungin's film draws upon, see Halperin (2013).

18 For a compilations of examples, see meme database JoyReactor (2010). 


\section{The Trial of Time}

The previous chapter introduced the talk show The Trial of Time and discussed the tensions between liberal and conservative views on Russian statehood revealed by the debate on Ivan the Terrible. In this final chapter I take the programme's production history as my point of departure to examine state interference in television programming about history. What conclusions can be drawn about the developments within state television during the second half of Medvedev's presidency on the basis of the talk show's cancellation and its subsequent 'upgrade' to Channel One? The case is of particular significance to the overall aim of this study since it illustrates how media outlets, in this case Channel Five, have been 'brought into line' with state interests. In addition, the show is a rare case where the different levels of memory politics - those of the state, elites, media and the general public come together. I will first provide some further information on the aims and format of the show, before turning to a detailed analysis of the societal debates the programme unleashed. I then continue with a discussion of the show's cancellation and subsequent reappearance and conclude by asking what insights this case provides us into the politics of television programming in Russia.

The Trial of Time premiered on Channel Five in the summer of 2010 as one of several shows to debut during the off-season. It replaced the talk show Freedom of Thought (Svoboda mysli), presented by Ksenia Sobchak, who would go on to become one of the faces of the protest movement in the winter of 2011/12 and later on, in 2017, announced to stand in the 2018 presidential elections. The Trial of Time was recorded in the same studio with few or no changes to the set. Mimicking the format of a court of law, the show put historical personalities and events on trial. As we have seen, history is almost by definition perceived to be political in contemporary Russia. In this particular case, the relevance of the historical questions under discussion was heightened even further by the evident political dispositions of the show's hosts - Nikolai Svanidze in the role of judge and Leonid Mlechin and Sergei Kurginian as prosecutor and defence attorney. While many off-season programmes fail to be renewed, The Trial of Time soon proved popular. In addition, the societal divisions it appeared to uncover stirred heated 
discussions: while Channel Five had a distinctly liberal profile at the time, the show's viewers at home were voting in support of the conservative 'pro-Soviet' views of Kurginian, instead of those expressed by the liberally inclined Mlechin. At the same time, the members of the studio audience were voting 'correctly' - that is, they sided with Mlechin. According to Vera Tsvetkova, writing for Nezavisimaia Gazeta, viewers and television critics alike found the show's 'intellectual discussion' to be emotionally captivating: 'Some even believe 'The Trial of Time' is more than just a show; in any case, this talk show has become the television [event], and perhaps even the societal event of the summer' (Tsvetkova 2010). Sergei Muratov, in his annual review of Russian television for Iskusstvo Kino, praised it as 'the most poignant, controversial and, in my opinion, one of the best shows of the decade' (Muratov 2011).

The objectives of The Trial of Time reflect the image of Channel Five at the time as a critical alternative to Channel One and other state-aligned channels. According to producer Natal'ia Nikonova, the show's principal aim was to 'find the truth' and rid it of 'mythological layers' (Dykhovichnyi 2010). To clarify the project's objectives, Nikonova juxtaposes it with the 2008 project The Name Is Russia that was discussed in chapter 4:

So if we differentiate it from the programme 'The Name is Russia,' [the latter] was truly a grand project that singled out something primary for Russians, something important. That is, it did not delve into details and detailed elaboration was not important; what was important was to clarify what is essential in the present, which person, which hero is important for Russians. Our program is sufficiently detailed and reconstructs in detail the event that is important to the program and tries to reveal the truth. I realise that it is a principally different project; it is a completely different framework of analysis.

(Ibid.)

Vladimir Khamynia, the general director of National Media Group Television (NMG), Channel Five's majority shareholder, agreed that countering existing 'myths' about Russian history should be one of the show's main objectives.

We turn to history in order to understand our contemporary self $[\ldots]$ The first challenge is [...] to peel away, if not to remove the outer shell of all kinds of myths, stereotypes, clichés, [and] labels that have been attached to this or that person in our history, to this or that event [or] this or that decision during various periods of our lives. After all, even in my lifetime [...] the appraisal of [various events in Russian history] changed multiple times. I am not even talking about people who are older; they already [encountered] several of such, so to say, opposite [poliarnykh] appraisals of one and the same historical event. 
The show's hosts were known to have outspoken political views, and the assignment of opposing sides on the topic under discussion was directly related to their political dispositions. As a result, the debates conflate past and present in two respects. First, historical parallels are drawn out and the subject is often placed explicitly within the context of current affairs. Then, these pseudo-historical debates are organised along evidently political lines (liberal vs. conservative) and, at times, revolve entirely around a discussion of the present. The potential for the show to function as a platform for political and not just historical discussion in this way was enhanced by its strategies for viewer engagement. The participation of viewers through internet and telephone voting, in addition to the (most likely carefully screened) studio audience, significantly influenced the show's dynamics and societal resonance. The voting results, without fail, demonstrated a clear-cut opposition between the home and studio audiences. Consider, for example, the response to the question of whether the Bolsheviks saved or destroyed Russia. The result of the online vote was 88 per cent in favour of 'saved'. In similar fashion, 72 per cent of the telephone votes supported the positive appraisal of the Bolsheviks. Of the studio audience, on the contrary, 71 per cent was of the opinion that the Bolsheviks destroyed Russia.

\section{The trial of The Trial of Time}

To discuss the 'incorrect' (i.e. anti-liberal) voting of the home audience and how it should be interpreted, a special broadcast was aired, appropriately entitled the 'Trial of The Trial' (Sud nad Sudom). On 7 October 2010, the special episode was broadcast in which the talk show judged itself rather than Russian history. As mentioned in the previous chapter, this remarkable act of self-reflection on television occurred in direct response to the uproar caused by the talk show's debates and, in particular, its voting practices. As occasional host Nika Strizhak summarises in her introduction:

[t]he forum went out of its mind, the telephones went crazy, viewers starting calling us, [and] critics started to scorch us. Some accused us of enforcing liberal ideas, [while] others said we trampled liberal ideas. They were even saying that we have somewhat incorrect viewers and that the channel has the right to, you know, to cheat somewhat and to alter the [results of the] voting somewhat.

('Stenogrammy suda vremeni' n.d.)

The special broadcast aimed to examine these voting patterns, to explain them and draw the necessary conclusions about how the programme should continue. During the special broadcast, emotions ran high. According to someone at the taping, some of the more heated clashes were even cut from the final edit (Larina 2011). What is particularly significant for the overall aim of this study is that the discussion touches on the social function of 


\section{Case studies}

television and, in particular, of Channel Five as a liberally oriented channel; on the importance of history in contemporary Russia and what the attitudes towards the Soviet past say about the 'success' of post-Soviet democratisation and liberalisation; and on the perceived divide between the 'intelligentsia' and the general public. The explanations put forward by the invited guests and experts underline why it is essential to take public opinion into account when examining memory politics. Otherwise, it is not possible to assess the reception or impact of the political mobilisation of history. At the same time, the discussion also demonstrates the inherent limitations in reliably assessing popular sentiments. Can the voting results of The Trial of Time indeed be interpreted as a valid representation of public opinion and, moreover, as a direct reflection of its viewers' political preferences?

According to one line of interpretation, the voting results prove that a gap exists between the more liberally inclined metropolitan 'elite' - represented by the studio audience - and 'ordinary people' - the viewers at home. Iurii Poliakov, the editor-in-chief of Literaturnaia Gazeta, for instance, argues that the studio audience consists for the most part of 'representatives [...] of the Moscow intelligentsia or future Moscow intelligentsia, mostly oriented on liberal values or closer to these values. And their views differ greatly from the views of Russia'. Here, a liberal political disposition is thus equated with antiSoviet views, while a positive appraisal of the Soviet era is thought to correspond to a conservative political outlook. Daniil Dondurei, the late editor-inchief of Russian cinema journal Iskusstvo kino, further argues that the voting results showcase how little actual change has occurred in people's thinking over the last two decades. He asserts that it shows that

[t]he reforms haven't started yet. That the majority of the population does not even live in the year 1991 but sometime considerably earlier. That in our country the overwhelming majority does not accept the regime described in the Constitution.

Assuming the same equation of an anti-Soviet stance on Russian history and liberal political views, a connected argument sees the voting results as proof that liberal-democratic thinking has failed to take hold in Russia. Yet, as Ekho Moskvy radio commentator Vitalii Dymarskii remarks, a 25 per cent share in support of the liberal ideal actually signals quite a significant change: 'And if this 25 per cent, these voters in favour of the liberal idea, would have the opportunity to vote for this liberal idea not only on television, then it would not even be that bad,' he adds.

Others question whether it is correct to make such far-reaching assumptions on the basis of the voting results, and with good reason: lacking proper systemic execution, the polls can hardly be regarded as a scientifically reliable sociological indicator. Among other things, the 'sample group' is insufficiently large to be representative of the population (in particular, the studio group) and was not collected randomly. Also, the questions were suggestively phrased 
and one could vote multiple times. The experts in sociological research who were present in the studio agree that there are some methodological reasons to take issue with conclusions drawn from the process; the voting was simply not intended to be a sociological survey. However, when the voting results are compared to formal opinion polls on similar questions, the latter show tendencies that clearly overlap with the home voting results. The main difference is that the formal polls are somewhat less polarised because they include a third option - 'difficult to say'.

After it has been established that the trend suggested by the voting results confirms certain sociological findings, a number of additional questions must be raised. For instance, it is suggested that the voting results also point to fundamental fault lines between age groups in Russian society. According to this argument, telephone voters tend to be older viewers, online voters are more likely to belong to the younger generation, and the studio audience would largely be of working age. The latter group, then, would be more liberally inclined, while the older and younger generations, it is argued, tend to have a more positive stance on the Soviet past. This claim, again, appears to be confirmed a poll conducted by Fond Obshchestvennoe Mnenie that is cited on the show. When asked a similar question about the outcomes of the Bolshevik takeover, the responses, when split into age brackets, show that the oldest age group views its impact positively. The age group of 40-to-50-yearolds interprets the Bolshevik legacy negatively, while the younger generation (including the 'Putin generation') is undecided.

The latter outcome has important implications pertaining to the state's efficacy in employing memory politics in support of its legitimacy. It means that the polarisation of society on matters of history along political lines, as the show's voting patterns appeared to indicate and which all the experts featured on the show agreed to be the case, had at that time not yet taken root among the younger generation. On the one hand, the undecidedness of this generation can be taken as a positive sign with regard to the possibility that a truly diverse public debate may develop in Russia (in other words, that a functioning civil society will emerge and evolve). That the largest anti-governmental protests in recent Russian history took place not long afterwards affirms this potential. On the other hand, however, it also points towards the existence of a very large group whose opinions could still be shaped. The regime's emphasis on patriotic education demonstrates its recognition that its potential to influence views on history and, by extension, politics, was greatest within this group. With the benefit of hindsight, we now know that the balance shifted in favour of increased polarisation rather than increased diversity of public discourse.

Finally, the special broadcast highlights the role played by media, and in particular television, in shaping the political views of their audiences. Some of the guests point out that the difference between the studio and home audiences may be connected to the audience members voting at the end of the programme - that is, after they have listened to the debate in its entirety; 


\section{Case studies}

viewers at home (could have) started voting as soon as the show begins. Therefore, they assert, the home vote is more likely to be based on predetermined preferences instead of a careful consideration of the arguments. In other words, the viewer's opinion depends on the host they identify most strongly with. Indeed, as is evident from the vote count shown on screen, viewers started voting even before the topic was introduced. The large majority of these votes were in support of Kurginian. Here it is worth recalling that in the case of The Name Is Russia (discussed in chapter 4), the popularity of the representatives also appeared to have been a significant factor influencing the voting results. Irina Petrovskaia, a television critic, argues that this effect was exacerbated by differences in presentation style. Kurginian's expressive debating method, she claims, appeals to viewers more strongly than Mlechin's more rational appearance of composure.

Sergei Kurginian operates in the style of a soapbox orator, of a rally type of person, who is more likely to appear at rallies or on squares with the corresponding use of all such methods. He often shouts; he gets wound up. I once saw a show where he promised to hit one of his opponents in the face. This is a highly advantageous position and is almost always happily accepted by the majority of our population. Because, perhaps, people often do not even hear what they are saying. This aesthetics is near to them; this manner of behaving is near to them.

The actual argumentation, then, is only of secondary importance. That Mlechin was no match for the propagandistic style of argumentation in which Kurginian excels, even on a show broadcast by a liberal TV channel, corroborates this conclusion.

\section{Cancellation and reappearance}

Notwithstanding the intensity of the debate just described, the format of The Trial of Time remained unchanged up until the talk show was cancelled at the end of the year. According to the official account, The Trial of Time fell victim to Channel Five's management takeover and subsequent rebranding. The channel's general director, Arkadii Solov'ev, was replaced by Aleksei Brodskii, who was brought in from Channel One. ${ }^{1}$ The apparent reason for the change in management was the channel's continued profitability issues ("Piatyi kanal" vozglavil top-menedzher "Pervogo"" 2010). Here it is worth mentioning that NMG, Channel Five's majority shareholder, also holds 25 per cent of the shares of Channel One. ${ }^{2}$ The Trial of Time was indeed not the only show to get the axe. The show Oil Painting (Kartina maslom), hosted by the outspoken public intellectual Dmitrii Bykov, for example, suffered the same fate, as did journalist Svetlana Sorokina's Program Guide (Programma peredach). Nikonova was dismissed and the shows she produced were 
terminated. This production and others were part of a brand-new slate of programming that had been launched only months before in March $2010 .{ }^{3}$ Sorokina dismissed allegations that the decision to terminate her programme was politically motivated (Bocharova \& Bacharev 2011). The change in management simply coincided with the decision not to prolong her contract, which, she stated, was a mutual agreement: 'My programme was not political but a retro programme. They (the new management) are now considering what they want to do with the channel. Why would they automatically prolong the contract?' (Bocharova \& Bacharev 2011).

While the termination of individual shows may, indeed, have been economically rather than politically motivated, the managerial 'takeover' appears in equal measure to have been directly related to Channel Five's content. In fact, there is sufficient reason to believe that the takeover aimed to bring the channel in line with state interests. According to Svanidze, for example, the 'actual director' of the channel is Konstantin Ernst, the general director of Channel One, who through the rebranding sought to leave his mark (pocherk) on it (Bocharova \& Bacharev 2011). A source cited by Gazeta.ru as a 'manager close to the channel' directly links the channel's liberal profile to the takeover:

The new management has its ideas about what would be great and is realising them. Now they decided to change the system. Above all, taking into account the production capacities and resources of Channel One. The last year was a continuation of what the team of Troepol'skii (the previous channel director) found there; the channel was intelligent, informative, with a Petersburg touch. It focused on history, reflection, [and] discussion; 'living history' became its main hero. But now 'Golden gramophones' and 'Old songs about the main thing' made their appearance there.

(Ibid.)

The latter title refers to a series of popular music shows, developed by Ernst, that capitalised on nostalgia for the Soviet era. That these programmes, which were originally commissioned by Channel One, were now broadcast as reruns on Channel Five raises questions since there was no official association between the two channels at the time. Another source associated with NMG is quoted as saying that the 'most important criteria' in the decision-making process were 'not business, not the media, but the relation to those in power [sviaz' $s$ vlast'iu] and the desire not to offend anyone' (Bocharova \& Bacharev 2011). In an article with the telling name 'Channel No. 5: The New Fragrance from Konstantin Ernst', Marina Naumova directly links the rebranding to Channel One's general director.

Such a replacement [of management, M.W.] is explained by interlocutors of Slon.ru in unanimous fashion: the government has given Ernst the task 


\section{Case studies}

to turn Channel Five into a political instrument; Ernst will now work on this part-time, without detracting from [Channel] One.

(Naumova 2011)

Sources cited by Delovoi Peterburg likewise claim that Channel One's top management was directly involved in the management change and rebranding at Channel Five ("'Piatyi kanal' vozglavil top-menedzher 'Pervogo"” 2010).

Set against the background of the alleged direct involvement of Channel One's management in Channel Five's overhaul, the reappearance of The Trial of Time on Channel One as The Historical Trial (Istoricheskii protsess) from August 2011 to June 2012 appears to support this claim. It also gives rise to two possible scenarios to explore. The first scenario would be the (political) approval of the show and its transfer to Channel One, despite the programme's 'liberal roots', in order to save it. The second possible scenario would involve the recognition of the format's potential to engage the general audience (that is, to serve as 'a political instrument') as the motivating factor behind its renewal. The nature and extent of changes to the format, which I will discuss shortly, appear to support the latter scenario.

The new project was again produced by Nikonova. Having worked for Channel Five for less than a year, she thus returned to Channel One, where she had previously been director of the studio for special projects ('Natal'ia Nikonova s "Pervogo kanala" stala general'nym prodiuserom "Piatogo", 2009). While instantly recognisable as the continuation of the original, The Historical Trial adopted a format that was different from that of its predecessor in two respects. First, one of the original hosts, Leonid Mlechin, did not return to the show. ${ }^{4}$ His role was taken up by Svanidze. In the new set-up, Svanidze and Kurginian went head-to-head without a judge or host serving as an intermediary. ${ }^{5}$ Second, the topics under discussion were formulated more broadly and explored diachronically. Instead of discussing a single event or historical figure, the show scrutinised a given phenomenon or issue as it had appeared throughout Russian history. For example, 'Legal security: from the Stalinist exceptional troika's to the Magnitskii case'; 'Political prisoners: from the Decembrists of Senate Square to the 'Decembrists' of Bolotnaia'; and 'The state and private life: from the Soviet law on homosexuality to today's anti-gay law'. As a result, the links to contemporary political and social problems were reinforced. The change of broadcast channel and alterations to the format had little effect on the viewers' voting; the home audience continued to side with Kurginian. ${ }^{6}$

What direct effect was exerted by the move to Channel One on the topics the show touched upon is a complicated matter. For example, The Historical Trial did not avoid politically sensitive issues. Its fourth episode, for instance, on the accumulation of capital, directly addressed the Iukos case and the trial of Mikhail Khodorkovskii. In fact, whereas The Trial of Time remained firmly embedded in historical examination, its successor moved significantly closer to current affairs. Television critic Irina Petrovskaia noted the following: 
History is absolutely a pretext to discuss current issues. And the show about Khodorkovskii, in particular, showed that they only use it as a springboard and subsequently the conversation is absolutely about what's contemporary and current. This is very important, because even on shows that regularly claim to be about themes that are either social or close to the political this is not the case. They do not manage to [address current affairs, M.W.] exactly because, clearly, there are a lot of these barriers, [dictating] what is not allowed, where you cannot go. But in this case I have the feeling that in the process of this discussion people are still relatively free and apparently even the editorial scissors do not mangle it much. Otherwise this would have been obvious and noticeable to all.

(Larina 2011)

How, then, should we interpret the fact that the Khodorkovskii case - talk of which had long been taboo on state television - could be openly discussed on the show? Petrovskaia suggests that it would be mistaken to take the discussion of Khodorkovskii, while remarkable, as proof of a loosening in policy; it is unlikely that it resulted from a desire to contribute to public opinion about the man or the case. Rather, she argues, it shows that Khodorkovskii was no longer seen as a threat. By allowing the case to be discussed, the channel accommodated a (liberally oriented) minority in society concerned with human rights. Kseniia Larina, journalist for Ekho Moskvy, places the Khodorkovskii discussion in the context of the other little-discussed topics addressed on The Historical Process. She makes an important and, I would argue, largely correct observation about the show's political orientation:

I believe there is also some kind of rather primitive hidden intent behind this. To once again demonstrate to the public and our leaders that the liberal share of our population is negligible. That it is unnecessary to fear them; that it is unnecessary to worry about this. The people are on the other side; the people are on the side of Kurginian and his companions. I believe that, among other things, the program was supposed to demonstrate this. You have the negligible numbers siding with Svanidze and those who can say something in defence of Khodorkovskii; and on the other side you have this people's tribune, the mouthpiece of public anger, that is designed to once again deliver a crushing blow to liberalism and these derelicts.

(Larina 2011)

The 'hidden intent' signalled by Larina is difficult to prove. Yet I think that the explanation for the continuation of the show can indeed be found in the particular way it functioned as a platform for political debate. Despite its origins at 'liberal' Channel Five - which, it appears, was rebranded partly as a result of political concerns - the format allowed proponents of liberal and conservative views to clash with each other in a controlled environment. In this 


\section{Case studies}

way it could contribute to developing the appearance of open discussion on Channel One and to enhancing the 'democratic image' of Russian state television in general. Since the voting results consistently demonstrated that the home audience sided with the conservative standpoints put forward by Kurginian, this was a safe bet. Moreover, the changes in format reinforced Kurginian's dominance on the show. With the departure of Mlechin, the programme's truly liberal face disappeared. Also, the lack of a judge to organise the flow of the discussion meant that greater preparatory coordination among the hosts was necessary, thus stifling the spontaneity of discussion. More importantly, it gave the expressive and emotional Kurginian even more opportunity to display his showmanship. With no judge to restrain him when emotions ran sky high and no one enforcing limits on speaking time, Kurginian was given pretty much free rein. Protracting his own pleas as long as possible, objecting visibly and vocally to the arguments of the opposing party and making interjections at every turn, Kurginian clearly ran the show. One could ask whether the programme's alterations in his favour were even necessary, since, as soon as the show's opening titles ran, the telephone voting count shown on the screen started to climb frantically in support of his position. The talk show, as a controllable simulation of genuine public debate, was perfectly suited to support the state's memory politics.

\section{Notes}

1 At Channel One, Brodskii served as the vice-director of informational programs.

2 The remaining shareholders around that time were the Russian state (combined $51 \%$ ) and OOO 'ORT-kb' (24\%). Data concerns 2012, accessed via INTEGRUM Business database. Both NGM (named OOO 'Rastr-Kom-2002' as shareholder) and OOO 'ORT-kb' are connected to Roman Abramovich (total share of 49\%).

3 General director Aleksandr Rodnianskii, brought in from STS-Media in 2009, was in charge of the change in programming. His efforts to improve the performance of the channel followed substantive rebranding attempts that had been carried through by his predecessors Vladimir Troepol'skii (brought in from VGTRK in 2008) and Marina Fokina in 2004. For a discussion of the programs mentioned here and, more broadly, the new image of Channel Five they were thought to introduce, see Kachkaeva (2010).

4 In media reports it is suggested that Mlechin's participation in the show was precluded by his position as one of the faces of the channel TV Tsentr.

5 Kurginian was later replaced by Dmitrii Kiselev.

6 The Levada Centre conducted an opinion poll about the show among 1600 respondents in 45 regions of the country. The poll showed that 6 per cent of the respondents watched The Historical Trial regularly, while 20 per cent tuned in occasionally and 73 per cent never watched the show. When asked which side they supported most, 22 per cent answered Kurginian and 33 per cent Svanidze, while 20 per cent supported both in equal measure, 14 per cent answered 'neither side' and 10 per cent found it difficult to answer (Levada Centre 2011). 


\section{Conclusion}

Let us return to where this story began: in the Alexander Gardens. In addition to the restored Romanov memorial obelisk, there have been two more additions to this well-tended garden of state symbolism. Combined, the three monuments constitute the final affirmation and closing act of the regime's memory politics as it developed between 2000 and 2012. The first is a statue to commemorate Patriarch Germogen, who died as a martyr in 1612 and is often thought to have inspired the people's uprising that brought an end to the Time of Troubles. The statue's history, like that of the obelisk, reveals much about the constant struggle over political symbolism in Russia. Twice, initiatives to erect a monument to Patriarch Germogen failed: first in the 1810 s, in the wake of the war against Napoleon, when the statue of Minin and Pozharskii was erected in reference to the events of the seventeenth century, and later in the period around the time of Germogen's canonisation by the Russian Orthodox Church in 1913. In the latter case a competition was held to design the statue but the realisation of the monument was prevented by the advent of war in 1914. The initiative for the current statue was taken in 2008 as memory politics peaked and the objectives of the ROC aligned with those of the state. In 2012, the Year of Russian History, Patriarch Kirill laid the foundation stone; the bronze sculpture was unveiled in 2013.

The second addition to the Gardens is a statue of Tsar Aleksandr I, already briefly mentioned in chapter 5, erected in 2014 in commemoration of the 200th anniversary of the victory over Napoleon - in itself, a peculiar afterthought to the state's elaborate celebrations that had marked that occasion a mere two years earlier. The bronze bas-reliefs that are mounted on a separate monument across from the statue of the tsar are a clear attempt to cover up the apparent inconsistency of celebrating a similar anniversary in nearly consecutive years: they show the 1812 battles of Borodino and Berezina, the 1813 Battle of Leipzig and the tsar's triumphal entry into Paris in 1814. The primacy of the two cultural memories the end of the Time of Troubles and the victory over Napoleon - was thus symbolically affirmed. The casting in bronze of these dominant narrative lines of memory politics also marks a turning point. In response to Putin's return to the presidency and, more importantly, the conflict in Ukraine 


\section{8}

\section{Conclusion}

and the Russian annexation of Crimea in 2014, both the tenor and the images of the state's engagement with history have started to shift. The case studies examined here have revealed some of the origins of this 'conservative turn' in Russian politics since 2012 (Makarychev \& Yatsyk 2014) as well as of the strands of contemporary Eurasian thought - aptly characterised by Dina Khapaeva as 'post-Soviet neo-medievalism' (Khapaeva 2016) - that inform it. In fact, the monument to Tsar Aleksandr I - who, after a brief infatuation with liberalism, was a markedly conservative ruler - also marks the definitive end of the pseudo-liberal discourse under Medvedev and the return of a strong hand to the Kremlin.

As in a historical film based on a true story, this study can only conclude by summarising how its protagonists have fared after 2012. Also, before turning to my main conclusions, I must offer some brief remarks on the impact of the recent dramatic (geo)political developments on the political use of cultural memory in Russia. With regard to the memory of '1612', the most significant event - the statue of Patriarch Germogen - has already been mentioned in the introductory paragraphs. The animated film The Fortress: With Shield and Sword (Krepost': shchitom i mechom, 2015, Dmitriev) deserves mention since it adapts the Time of Troubles myth to a young audience. Supported financially by Fond Kino, the film recounts the adventures of a young boy who helps defend the city of Smolensk to prevent the advancement of Polish troops to Moscow. While the argument of restored stability, which the memory of the Time of Troubles served to symbolise, continues to occupy a central position in the regime's claim to legitimate power, it now predominantly takes the form of its negative image. The regime has pressed on with the shift in the direction of cautionary warnings about 'revolution' looming on the horizon and the impending loss of the stability the government claims to have achieved, which I signalled in the chapter on Stolypin.

Meanwhile, the concept of (neo-)oprichnina continues to pop up from time to time in public discourse, in both its cautionary and mobilising capacities. For instance, upon the announcement that the government was establishing a National Guard in April 2016, commenters were quick to draw parallels with Ivan's oprichnina. The head of the new internal security corps, Viktor Zolotov, was referred to as the contemporary incarnation of Maliuta Skuratov. The absence of commemorative infrastructure connected to Ivan the Terrible, described in chapter 6 , has since been undone: giving rise to much controversy and protest, there are now three monuments to Ivan the Terrible on Russian soil. The first, a large bronze statue of Ivan on horseback raising an Orthodox cross, was unveiled in Orel in 2016. In 2017, two more were erected in Moscow: a bust of the tsar was included in sculptor Tsereteli's Alley of Rulers, where it stands alongside the busts of some forty Russian rulers from Riurik to Gorbachev, while a full-size statue was placed near the Alley's entrance. In an act of protest against the erection of the statue in Orel, an artist in Kansk erected an 'alternative' monument in the form of a 'wooden stake dripping with blood-red paint' (Shamanska 2016). 
In Volgograd, work has begun on the reconstruction of the Aleksandr Nevskii Cathedral, scheduled for completion in 2020. The six-domed chapel will closely resemble the original church that was torn down in 1932. The 'restoration' has met with significant societal resistance and, in a way, the construction echoes the restoration of the Romanov obelisk. The church was consecrated only in 1918; the period of its absence following its demolition now far exceeds the number of years it was actually a recognisable part of Volgograd's architecture. Apart from the planned celebration of the 800th anniversary of Aleksandr Nevskii's birth in 2021, his role as the principal 'Orthodox' national figure within governmental memory politics appears to have been taken over by Prince Vladimir. The shift is directly related to the annexation of Crimea. Indeed, as part of the justification of the 'reintegration' of the peninsula into the Russian Federation, Russian media have framed the ancient Crimean city of Khersones, where Vladimir the Great was baptised, as the cradle of the Orthodox Russian nation. A massive statue of Prince Vladimir bearing a sword and a cross was unveiled near the Kremlin on 4 November 2016

Finally, even if Stolypin should have failed to win the hearts of the general public, the political mobilisation of his memory continues. For instance, paraphrasing Stolypin, the quote 'We do not need great upheavals, we need a great Russia' was adopted as the slogan of the Anti-Maidan Movement. The movement, formed in January 2015, was initiated by, among others, the nationalist writer, politician and influential blogger Nikolai Starikov and Aleksandr 'the Surgeon' Zaldostanov, the president of the Kremlin-loyal Russian motorcycle club the Night Wolves. The movement formulates its aim as the prevention of "“colour revolutions", street riots, chaos and anarchy' ('Manifest' n.d.). The press conference related to its founding, hosted by RIA Novosti, was covered by all major television stations. A second example is the exhibition series 'My History' that we came across in the case studies and which has now found a permanent home at the VDNKh complex in Moscow. It advertises the section covering the period 1917-1945 with the headline 'From Great Upheavals to a Great Victory' and features a portrait of Stolypin in its advertisements. A new statue of Stolypin has also appeared, this time in the city of Cheliabinsk. After being installed on its pedestal in September 2017, the monument, gifted by the Fund for the Study of P.A. Stolypin's Legacy, stood covered with a cloth for months in anticipation of its ceremonial unveiling by President Putin during a visit of Kazach President Nursultan Nazarbaev on 9 November. The ceremony was dropped from the programme, however, and the statue finally unveiled in absence of its honorary guests two weeks later.

A particularly important development, and one which suggests that Stolypin's name will linger on in coming years, is the establishment of the Stolypin Club. The group presented its programme 'The Economics of Growth' in October 2015, expressing the aim to become an expert platform on economic reform for the formulation of the government's strategy for 2025 (Nikolaeva 
2015). The club includes individuals wielding direct political influence, such as Adviser to the President Sergei Glaz'ev. Their weight is such that a commentator for Nezavisimaia Gazeta characterised the discussions in the Presidential Economic Council regarding the 2025 strategy as a debate between 'Stolypinites' and 'Kudrinites' - those who side with the vision proposed by Aleksei Kudrin, former finance minister and now vice-chairman of the Council (Bashkatova 2016).

In general, there has been a pronounced intensification of memory politics on the part of the state and state-aligned actors. The opening ceremony of the Sochi Winter Olympic Games in 2014, as the apex of public diplomacy during this period, testifies to the regime's continued effort to place itself within an extended, unified historical narrative. As the quintessential event for the display of a state's vision of itself to the world, the ceremony focused squarely on Russian history and its achievements in the cultural sphere. Directed by Konstantin Ernst, the director of Channel One, the spectacle reiterated the symbolic continuity of Russian history in broad sweeps of retropop showmanship. It later became known that Ernst had originally planned to include a minute's silence in the ceremony to commemorate the Soviet soldiers who died during the Second World War (Kolesnikov 2014). The section of the ceremony would have had members of the audience - that is, sport fans from all over the world - hold up portraits of fallen Soviet soldiers. This element had to be cut after the International Olympic Committee objected to its evident political connotations. The idea indicates how the heightened attention to history in Russia since 2012 has centred on the memory of the Second World War. Since 2014, in particular, its public commemoration has become intertwined with the expression of 'pro-Putin "patriotic" attitudes' (Malinova 2017: 46). The Immortal Regiment parade, a relatively new commemorative ritual in which individuals carry photographs of relatives who fought or perished in the war (cf. the plan for the Olympics' opening ceremony mentioned above), is now a core element of Victory Day celebrations. The movement gained prominence in 2015 when Putin, carrying a placard with the photograph of his father, headed the parade as it marched across Red Square (Fedor 2017). The memory of the Second World War also functioned as the primary mnemonic source for framing the conflict in Ukraine by denouncing the Maidan protesters and, later, Ukraine's new government as 'fascist' (see, e.g., Gaufman 2017: 103-123).

The shrinking of the public sphere and a dramatic increase in restrictions on the freedom of expression and the freedom of press in recent years mean that there is now less room for alternative voices in memory politics to be heard. With regard to the Second World War in particular, the peak in the political mobilisation of the memory has gone hand in hand with restriction of public debate on the topic. In a clear break with previous practices, the state has moved from a reliance on self-censorship to the implementation of legal measures to curb undesirable interpretations of history. In April 2014, for instance, the Duma passed a law criminalising the 'rehabilitation' of 
Nazism as well as the spreading of 'false information' about the conduct of the Soviet Union during the Second World War.

The importance the Russian government continues to attribute to cinema is clear from one of the Kremlin's first measures to 'reintegrate' Crimea following its annexation: to invest in its film industry and organise local film festivals ('Russia Will Revive Crimean Film Industry' 2014). Since the appointment of Vladimir Medinskii as Minister of Culture in 2012, there has been an overall increase in government meddling in cinema production. On the one hand, the state is more outspoken about the types of films it seeks to finance, and its preferences are more politically motivated than before. For example, whereas in 2011 the annual call of the Ministry of Culture for films to compete for funding included the rather general theme of 'films of historical, military and patriotic content, developing a sense of pride in one's country' (Ministry of Culture of the Russian Federation 2011), the calls from 2013 to 2016 formulate multiple specific historical themes. The call for 2015, for instance, welcomes submissions for films on 'Crimea and Ukraine in the thousand-year history of the Russian state' (Ministry of Culture of the Russian Federation 2015). On the other hand, Medinskii himself harshly criticises films he deems 'anti-historical', 'anti-Russian' or 'anti-patriotic'. For example, he publicly denounced the film My Good Hans (Milyi Khans, dorogoi Petr, 2015, Aleksandr Mindadze), about the friendship between a German and a Soviet man on the eve of the Second World War, and 'tried (unsuccessfully) to shut down its funding' (Muchnik 2015). Foreign films thought to present an 'incorrect' rendering of history have been banned from Russian cinemas. For instance, the distribution of Child 44 (2015, Espinosa) was prohibited on grounds that it was Russophobic. In January 2018, the Ministry of Culture revoked the distribution license of the British-French comedy The Death of Stalin (Iannucci, 2017) shortly before its scheduled release for containing 'extremist materials'. With regard to television, a parallel development has taken place to obstruct those oppositional media outlets that remain. Most notably, the oppositional TV station Dozhd' was targeted for an opinion poll it conducted about the siege of Leningrad. The poll asked whether the Soviet Union should have surrendered Leningrad to the German army to save the lives of the city's inhabitants. As a result of the political backlash created by the poll, all major Russian television providers discontinued their broadcasting of the channel, and Dozhd' was forced to move online.

The aim of this study has been to look beyond the Kremlin walls and explore how various groups in Russian society, including the state, have mobilised cultural memory to legitimise, question or challenge the political regime and propagate their vision of Russian statehood. In my analysis I have paid particular attention to: 1) which cultural memories have been employed, by whom and to what end; and 2) how these actors have drawn upon existing interpretations and representations of various cultural memories to shape their contributions to the debate on history and political legitimacy. Based on the evidence provided by the case studies, the answer to these questions falls 


\section{2}

\section{Conclusion}

into four parts. First, the state has quite successfully relied on memories with rich histories of cultural representation and political instrumentalisation to portray itself as traditional. The government actively aimed to support and expand its legitimacy by stimulating the development of a type of patriotism connected to the state. While this state patriotism is essentially present-oriented, the historical dimension is vital to its strengthening, showing it to rise above ideological breakpoints and to emphasise, instead, the unity of the historical development of the Russian state.

The guiding logic of state-sponsored memory politics in the period 20002012 was to claim the existence of a typically 'Russian' type of governance. In his Address to the Federal Assembly in December 2012, Vladimir Putin, in fact, literally stated that 'Russia is characterised by a tradition of a strong state' (Putin 2012b). Russian memory politics was shaped, furthermore, by the purported reclaiming of lost commemorative traditions dating back to both tsarist and Soviet times. Within this unitary concept of the Russian state, the regime departed from the premise that Russian history is characterised by, first, cycles of stability and revolution and, second, a continuous threat emanating from groups in society that seek to undermine the stability of the state, typically supported or guided by external, and in particular Western, forces. The institutionalisation of the memory of Petr Stolypin forms an exception to the rule since it could only draw upon cultural representations from recent years, most notably Stolypin's inclusion among the finalists of The Name Is Russia. The case study in that instance made it evidently clear why this is a disadvantageous circumstance. Despite substantial symbolic investment on the part of Vladimir Putin and cultural heavyweight Nikita Mikhalkov, it has proved difficult beyond certain political circles to counter the negative image of Stolypin that had been established by Soviet historiography.

Second, I have found that the regime's memory politics should in some cases be characterised as reactive rather than proactive - it co-opts existing societal and cultural initiatives - and that it is adaptive rather than static that is, it is continually revised in response to changing (geo)political circumstances and domestic needs. All acts involving memory politics by the state, however, give evidence of the same strategy: to keep popularity ratings up while also keeping the general public passive. The anti-mobilisational purport of the political mobilisation of memory has gone hand in hand with an increasing reliance on conspiracy theories in state-aligned media and other strategies of inducing fear, uncertainty and overall confusion.

Third, my analyses have shown that the state is far from the only player involved in the circulation of political claims through historical narratives. Instead, we can speak of a complex, interactive process of memory negotiation that takes place on multiple levels - from the state to social and religious organisations, and from state-aligned and (semi-)independent media to cultural actors and individuals who have access to public discourse and succeed in generating national media exposure for themselves. Opposing and alternative voices existed and continue to exist. For most of the period under discussion in this 
study, these voices could also be heard, albeit mainly through channels outside of the mainstream. Although the subject of the Soviet past has not been directly covered in this study, I want to emphasise here that the relative freedom to express divergent opinions did not apply to efforts to examine and commemorate the crimes committed by the Soviet state (e.g. there has been a continuous obstruction of the work of the human rights group Memorial).

With regard to the representations of the selected memories in state-aligned television and cinema productions, I have found a considerable measure of deviation. The variety in interpretations should not be mistaken as a sign of full authorial freedom, however. Such deviations from the official line tend to be more extreme, conspirational and propagandistic, which has a double effect and a clear function. First, they suggest a greater measure of authorial freedom than is actually the case. And second, such sensational and at times absurd narratives actually make the regime's uses of history come across as unassuming and sensible. By allowing these extremes to exist, the government actually reinforces the credibility of its claims.

Fourth, it is evident from all the case studies that remediation - including the particular forms of remediation that I have named memory chains and memory clusters - is both a ubiquitous and highly significant element of the strategies employed in Russian memory politics. In particular, the remediation of (iconic) visual elements plays a vital role in framing historical analogies and facilitating the circulation and transfer of preferred interpretations. Recognisability is key, as it helps to bridge the gap between collective and individual memory. Therefore, it is fair to argue that the lack of remediation history is one of the primary reasons why the government's efforts to sponsor the memory of Stolypin failed to catch on with the general public. On the other hand, as I have demonstrated on the basis of the example of Vladimir Mirzoev's Boris Godunov, the accumulated meanings of these memories also greatly increase their potential to be used in politically subversive ways. To appreciate why this is the case, it is important to remember that memory politics in many ways resembles mythologisation. If we follow Roland Barthes' classic definition of myth, the aim of mythologisation is to normalise and eternalise history through simplification (Barthes 1973). Remediation, memory chains and memory clusters interfere with this process of simplification. They thus provide access points for formulating historically framed political critique. As in the example of Boris Godunov, a simple transposition of memory frames can serve to challenge the official line and undercut the purported naturalness and timelessness of the regime's mythical claims.

As mentioned in the Introduction, the combination of case studies has also allowed me to reflect specifically on the relevance of Soviet preconfiguration. Already in 2006, Kevin Platt and David Brandenberger made the following observation:

Many of the watchwords and catch phrases of present-day mythmaking were last deployed as politically significant symbols under Stalin. Today's 
enthusiasts of the pre-revolutionary past no doubt imagine themselves reaching back to the roots of the Russian political tradition - to a 'true' wellspring of Russian national pride that predates the Soviet era. Yet in reality, this dialogue with the past - ostensibly conducted 'over the heads' of seven decades of Soviet history - borrows heavily from the cultural norms of the Stalin period. [...] Clearly, the Stalinist celebration of the Russian national past must be seen as an important link in the genealogy of current nationalist rhetoric.

(Platt \& Brandenberger 2006: 8)

My study adds a nuance to this argument by demonstrating that the reappropriation of elements of Stalinist propaganda was by no means complete for example, the relative absence of Peter the Great - nor was it unproblematic. The holiday commemorating the end of the Time of Troubles, for instance, was soon co-opted by nationalists and steadily lost symbolic ground, while the memory of Ivan continues to be so volatile that only those on the margins of the political debate dare employ it.

The case studies have also shed light on the extent to which state-dependent film and television productions about history reiterate state-sponsored lines of interpretation; in other words, whether it is appropriate to speak of systemic 'patriotic propaganda' with regard to this period. I agree with Stephen Hutchings and Vera Tolz that, despite evident pressure from the government, state-aligned television demonstrates 'a level of dialogic exchange which, although tame by western standards, belies [its] image as a mere purveyor of Kremlin propaganda' (Hutchings \& Tolz 2015: 4). In an opinion piece for Vedomosti, Russian journalist Andrei Babitsky has suggested that television should rather be seen as an 'open market for patriotic trash than a factory for propaganda':

National television creates something like a stock exchange, where different persons and businesses can sell timely patriotic content to the state. [...] The system is perfectly liberal in its contours: it's not central planning, but a stock exchange open to anyone to come sell their goods and earn a paycheck. [...] It's undeniable that this market's structure, despite the high price, has many advantages. The buying and selling all happens in one place, you don't have to pay for anything before it's ready, and most importantly you don't need to try all that hard. Because Russian television deals in price tags, not placards.

(Babitsky 2015)

In other words, the state has 'outsourced' part of its patriotism campaign. While I strongly disagree with Babitsky's characterisation of this 'patriotic market' as 'open to anyone', he is correct to point out how self-interest and self-censorship have long been sufficient means to control the medium, including its role in memory politics. 
The film The Descendants (Nasledniki, Vladimir Khotinenko, 2015) can be seen as a reflection on how the societal system of memory politics I have described in this study works. The apparent paradox is that, although the film appears to uncover the truth behind the 'patriotic propaganda machine', the production was financially supported by the Ministry of Culture and directed by Kremlin loyalist Vladimir Khotinenko (director of, e.g., 1612). The setting for the film is a TV show about the memory of Sergii of Radonezh, one of the most venerated saints of the Russian Orthodox Church, who pronounced his blessing on Dmitrii Donskoi before the fourteenth-century Battle of Kulikovo Field. Unmistakably modelled on The Name Is Russia and similar programmes, Khotinenko uses the television format as a microcosmos to explore the intersection of politics, religion and history in contemporary Russia. The guests on the show represent the leading actors of memory politics: the state politician (rumoured to be based on Medinskii), the patriotic publicist, the Orthodox cleric, the historian, the celebrity (a look-alike of singer Alla Pugachova) and, of course, the popular television host himself. Two young brothers in the audience personify the general public at the receiving end of it all. When the host discovers that his show will be cancelled, he sets out on an act of sabotage aimed at exposing the truth behind the spectacle of primetime patriotism. His plan backfires, though, which makes it all the more painfully clear that, at the end of the day, each of the groups represented on stage has to resign themselves to the role it has been assigned to play.

The alternative approach to memory politics that I have developed in this study has demonstrated the importance of non-state actors in memory politics. Nevertheless, there are a number of related issues that my approach has not been able to fully address. First, I have taken only modest steps towards assessing the reception of memory politics in Russia. The impact and effectiveness of the political uses of the past, however, remains an understudied but vital aspect of memory politics. In addition to assessing the ways that memory politics affects popular perceptions of governance, further research in this direction could also shed light on whether state-produced memory narratives work differently in this respect to those circulated in the media and/or as entertainment. Also, such reception studies - employing, for instance, focus groups - can provide a better understanding of the extent to which certain (entertainment) genres are more or less likely to affect political preferences, as well as how state-aligned media take advantage of these differences.

Second, further research is needed into online memory discourses. The internet is the most significant remaining platform where alternative and opposing views on memory politics can be expressed. At the same time, the state increasingly interferes in these online debates and in recent years has rapidly expanded its body of legislative restrictions on online freedom of expression. The dynamics of these online memory discourses, how they relate to offline discourses, who the various actors of online memory politics are and how they interact with one another: these questions have yet to be addressed in a satisfactory manner. 


\section{6}

\section{Conclusion}

More than twenty-five years has passed since the Soviet Union ceased to exist. For the 15 former republics that (re)gained their independence, the collapse of the Soviet state necessitated the rewriting of their respective collective histories. In retrospect, we can see that, at the same time, it had been precisely such a critical revisiting of the past that contributed to the Soviet Union's demise. Indeed, the experience of Perestroika testifies to how, in authoritarian states, 'change often starts when the past is challenged' (Johnson 2016). For the Putin regime, having founded its legitimacy on historical narratives, controlling the past has become vital to its survival. In fact, a clear pattern emerges if we look back on the development of governmental memory politics since 2000: the intensity of the regime's efforts in the memory domain peak whenever it feels that its legitimacy is threatened. It relied on the mobilisation of history to strengthen its position and discredit its opponents following both the wave of colour revolutions of the early 2000s and the Russian protest movement that developed in response to the rampant electoral fraud in the Duma elections of December 2011. With the presidential elections of March 2018 approaching, and the resurfacing of mass street protests in the year preceding, the state has once again turned to the familiar remedy to mitigate the perceived political threat: it has intensified its memory politics, simultaneously restricting public debate. Evidently, it believes that if the past cannot be challenged, regime change will also be averted. But the severity of the legal measures it has now put in place demonstrates that the regime fears the subversive potential of its citizens more than ever. 


\section{List of interviews}

All interviews were conducted in Moscow in the fall and winter of 2014/15. None of the interviewees requested anonymity. However, I have decided against identifying them by name to prevent them from encountering any possible negative consequences from their participation in this study.

\section{Interviewee A}

Former editor of video archives for a state television channel

\section{Interviewee B}

Video-editor for television productions

\section{Interviewee C}

Camera operator for national and regional television

\section{Interviewee D}

Independent documentary maker, high-ranking position in an industry representational body

\section{Interviewee $\mathbf{E}$}

Former governmental advisor on film policy and state funding

\section{Interviewee F}

Camera operator for national television

\section{Interviewee G}

Employee at a major film festival 
228 List of interviews

\section{Interviewee $\mathbf{H}$}

Documentary producer at a state television channel

\section{Interviewee I}

Documentary director at a state television channel 


\section{References}

Alekseev, Aleksei. 2008. 'VIP-parad. Ezhegodnyi reiting rossiiskoi elity'. Kommersant', 26 December. Accessed 17 November 2015, www.kommersant.ru/doc/1099719.

Amelina, Anna. 2008. 'Asymmetrie der Verhältnisse. Aktuelle Entwicklungen im Fernsehen der Russischen Föderation'. Publizistik 53: 25-47.

Anderson, John. 2007. 'Putin and the Russian Orthodox Church: Asymmetric Symphonia?' Journal of International Affairs 61, no. 1: 185-201.

Anemone, Anthony. 2010. 'Vladimir Khotinenko: The Priest (Pop, 2009)'. KinoKultura 30. Accessed 29 June 2015, www.kinokultura.com/2010/30r-pop-aa.shtml.

Aptekar', Pavel. 2011. 'Pochemu Putin ne Stolypin'. 21 April. Accessed 13 December 2012, www.vedomosti.ru/blogs/aptekar/1515.

Arbatskii, Aleksei. 2008. 'XIII vek: Rusich'. Strana igr 17. Accessed 8 July 2015, www. gameland.ru/post/43271/.

Arkhangel'skii, Andrei. 2013. 'Pusto mesto sviato ne byvaet. Goszakaz v SSSR i v sovremennoi Rossii'. Iskusstvo kino, no. 9. Accessed 15 February 2016, http://kinoa rt.ru/archive/2013/09/pusto-mesto-svyato-ne-byvaet-goszakaz-v-sssr-i-v-sovrem ennoj-rossii.

Arutunyan, Anna. 2009. The Media in Russia. Maidenhead and New York: Open University Press.

Ascher, Abraham. 2001. P.A. Stolypin: The Search for Stability in Late Imperial Russia. Stanford: Stanford University Press.

Assmann, Aleida. 2008. 'Canon and Archive'. In Cultural Memory Studies: An International and Interdisciplinary Handbook, edited by Astrid Erll and Ansgar Nünning, 97-107. Berlin [etc.]: Walter de Gruyter.

Assmann, Jan. 2008. 'Communicative and Cultural Memory'. In Cultural Memory Studies: An International and Interdisciplinary Handbook, edited by Astrid Erll and Ansgar Nünning, 109-118. Berlin [etc.]: Walter de Gruyter.

Babalova, Mariia. 2007. 'Rezhisser Aleksandr Sokurov: "Boris Godonov" - eto istoriia schastlivykh liudei'. Izvestiia, 20 April.

Babitsky, Andrei. 2015. 'Opinion: Who Are You Calling "Propaganda"?' Meduza, 8 December. Accessed 1 June 2016, https://meduza.io/en/feature/2015/12/08/opinionwho-are-you-calling-propaganda. Originally published as 'Respublika: Magazin na divane'. Vedomosti, 4 December 2015.

Baïdine, Irène Semenoff-Tian-Chansky. 2011. 'Le film de l'archimandrite Tikhon (Chevkounov), La chute d'un empire: la leçon de Byzance (2008). Une double manipulation des images de Byzance et de la Russie d'aujourd'hui'. Revue Russe 37: 99-111. 
Balandina, N. 2007. 'Eduard Volodarskii. Neliubovnyi treugol'nik'. Iskusstvo kino, no. 2. Accessed 20 December 2012, http://kinoart.ru/archive/2007/02/n2-article15.

Bandenko, Andrei. 2008. 'Imennoi schet'. Itogi 31, 29 July. Accessed 24 September 2015, www.itogi.ru/tv/2008/31/42215.html.

Barthes, Roland. 1973. Mythologies. Translated by A. Lavers. London: Paladin Books.

Bartig, Kevin. 2013. Composing for the Red Screen: Prokofiev and Soviet Film. New York: Oxford University Press.

Bashkatova, Anastasiia. 2016. 'Iz krizisa - v novuiu stabil'nost'. Nezavisimaia gazeta, 26 May. Accessed 31 May 2016, www.ng.ru/economics/2016-05-26/1_crisis.html.

Baudrillard, Jean. 2009. 'History: A Retro Scenario'. In The History on Film Reader, edited by M. Hughes-Warrington, 189-192. London and New York: Routledge. Originally published in Simulacra and Simulations, edited by M. Poster, 43-48. Stanford: Stanford University Press, 1998.

Beam Eggers, Susan. 2006. 'The Villains of Glinka's Opera Ivan Susanin on the Soviet Stage'. In Epic Revisionism: Russian History and Literature as Stalinist Propaganda, edited by Kevin M. F. Platt and David Brandenburger, 262-275. Madison: University of Wisconsin Press.

Beard, Nadia. 2015. 'Candid Camera: Leviathan Director Andrey Zvyagintsev Opens Up about Politics in Russia'. The Calvert Journal, 20 February. Accessed 20 June 2016, http://calvertjournal.com/articles/show/3694/leviathan-andrey-zvyagintsev-russiapussy-riot-oscars.

Beumers, Birgit, Stephen Hutchings and Natalia Rulyova (eds). 2009. The Post-Soviet Russian Media: Conflicting Signals. London and New York: Routledge.

Blakkisrud, H. 2016. 'Blurring the Boundary between Civic and Ethnic: The Kremlin's New Approach to National Identity under Putin's Third Term'. In The New Russian Nationalism: Imperialism, Ethnicity and Authoritarianism 2000-15, edited by P. Kolstø and H. Blakkisrud, 249-274. Edinburgh: Edinburgh University Press.

Bocharova, Svetlana, and Igor' Bacharev. 2011. 'Piatomy kanaly pokazali, kto tut Pervyi'. Gazeta.ru, 13 January. Accessed 10 December 2015, www.gazeta.ru/politics/ 2011/01/13_a_3490222.shtml.

Bodin, Per-Arne. 2009. Language, Canonization and Holy Foolishness: Studies in Postsoviet Russian Culture and the Orthodox Tradition. Stockholm: Stockholm University.

Boiko-Velikii, Vasilii. 2010. 'Kto govorit lozh' - ne spasetsia'. Izvestiia, 13 January.

Bolter, Jay David, and Richard Grusin. 1999. Remediation: Understanding New Media. Cambridge: MIT Press.

Borusiak, Liubov'. 2008. 'Proekt “Imia Rossiia” kak novyi uchebnik istorii'. Vestnik obshchestvennogo mneniia, no. 5: 58-66. Accessed 3 June 2015, www.levada.ru/ books/vestnik-obshchestvennogo-mneniya-597-za-2008-god.

Boym, Svetlana. 2001. The Future of Nostalgia. New York: Basic Books.

Brandenberger, David, and Kevin M. F. Platt. 2006. 'Terribly Pragmatic: Rewriting the History of Ivan IV's Reign, 1937-1956'. In Epic Revisionism: Russian History and Literature as Stalinist Propaganda, edited by Kevin M. F. Platt and David Brandenberger, 157-178. Madison: University of Wisconsin Press.

Brouwer, Sander (ed.). 2016a. Contested Interpretations of the Past in Polish, Russian, and Ukrainian Film. Leiden: Brill Rodopi.

Brouwer, Sander. 2016b. 'From Empire to Smuta and Back. The Mythopoetics of Cyclical History in Russian Film and TV-Documentaries'. In Contested Interpretations of the Past in Polish, Russian, and Ukrainian Film, edited by Sander Brouwer, 123-142. Leiden: Brill Rodopi. 
Brown, David. 1974. Mikhail Glinka: A Biographical and Critical Study. London: Oxford University Press.

Bruggemann, K., and A. Kasekamp. 2008. 'The Politics of History and the "War of Monuments" in Estonia'. Nationalities Papers 36, no. 3: 425-448.

Buller, Rachel Epp. 2010. 'Controlled Chaos: A Case Study of Photomontage in Weimar'. In Reworking the German Past: Adaptations in Film, the Arts, and Popular Culture, edited by Susan Figge and Jenifer Ward, 39-56. Rochester: Camden House.

Buntman, Sergei. 2009. 'Diagnoz Rossiia'. Iskusstvo kino, no. 1. Accessed 3 June 2015, http://kinoart.ru/archive/2009/01/n1-article3.

Burrett, Tina. 2011. Television and Presidential Power in Putin's Russia. London: Routledge.

Chilikova, Liubov'. 2012. 'Pamiatniki Karamzinu i Stolypinu poiaviatsia v Ul'ianovske'. Ria Novosti, 19 November. Accessed 24 February 2013, http://ria.ru/cul ture/20121119/911332389.html.

Clay, Eugene. 2015. 'Multiculturalism and Religious Education in the Russian Federation: The Fundamentals of Religious Cultures and Secular Ethics'. State, Religion and Church 2, no. 1: 44-74.

Condee, Nancy. 2008. 'Mediation, Imagination, and Time: Speculative Remarks on Russian Culture'. Ab Imperio, no. 1: 177-192.

Condee, Nancy. 2009. 'The State Face: The Empire's Televisual Imagination'. In The Post-Soviet Russian Media: Conflicting Signals, edited by Birgit Beumers, Stephen Hutchings and Natalia Rulyova, 178-187. London and New York: Routledge.

Dobrenko, Evgeny. 2008. Stalinist Cinema and the Production of History: Museum of the Revolution. New Haven and London: Yale University Press.

Doerry, Martin, and Matthias Schepp. 2014. "Russia is Slipping Back into an Authoritarian Empire". Spiegel Interview with Vladimir Sorokin'. In Late and PostSoviet Russian Literature: A Reader. Book 1: Perestroika and the Post-Soviet Period, edited by Mark Lipovetsky and Lisa Ryoko Wakamiya, 278-284. Translated by Christopher Sultan. Boston: Academic Studies Press.

Dolgopolov, Greg. 2008. 'Liquidating the Happy End of the Putin Era'. KinoKultura 21. Accessed 29 January 2018, www.kinokultura.com/2008/21-dolgopolov.shtml.

Dugin, Aleksandr. 1998. 'My tserkov' poslednikh vremen'. Zavtra, no. 1.

Dugin, Aleksandr. 2000. 'Zaria v sapogakh (Ideal'naia spetssluzhba)'. Zavtra, no. 13.

Dugin, Aleksandr. 2005a. 'Russkii orden. Sovremennoi Rossii nuzhna oprichnina'. Ogonek, no. 11.

Dugin, Aleksandr. 2005b. 'Metafizika Oprichniny. Tezisy vystupleniia Aleksandra Dugina v ramkakh "Novogo Universiteta". 25 February. Accessed 21 April 2016, www.arcto.ru/article/1252.

Dunning, Chester. 2001. Russia's First Civil War: The Time of Troubles and the Founding of the Romanov Dynasty. University Park: Pennsylvania State University Press.

Dunning, Chester. 2010. 'The Tsar's Red Pencil: Nicholas I and Censorship of Pushkin's Boris Godunov'. Slavic \& Eastern European Journal 54, no. 2: 238-254.

Dvorkina, Aleksandra. 2004. 'Psevdopravoslavnaia sekta "Oprichnoe bratstvo" i ee rukovoditel' N. Kozlov (A.A. Shchedrin)'. 25 April. Accessed 18 April 2016, http:// iriney.ru/iskazhenie-pravoslaviya-i-okolopravoslavnyie-sektyi/oprichnoe-bratstvo/p sevdopravoslavnaya-sekta- $\% \mathrm{C} 2 \% \mathrm{AB}$ oprichnoe-bratstvo $\% \mathrm{C} 2 \% \mathrm{BB}-\mathrm{i}-\mathrm{ee}-\mathrm{r}$ ukovoditel-n.-kozlov-(a.a.-shhedrin).html.

Dykhovichnyi, Aleksei. 2010. 'Stenogrammy press-konferentsii radio "Ekho Moskvy"'. Ekho Moskvy, 16 July. Transcript accessed via Integrum World Wide database. 
Dymarskii, Vitalii, and Kseniia Larina. 2012. 'V efire radiostantsii "Ekho Moskvy" Oleg Kashin, spetsial'nyi correspondent izdatel'skogo doma "Kommersant"'. Ekho Moskvy, 9 November. Transcript accessed via Integrum World Wide database.

Edgerton, Gary R. 2001. 'Introduction: Television as Historian: A Different Kind of History Altogether'. In Television Histories: Shaping Collective Memory in the Media Age, edited by Gary R. Edgerton and Peter C. Rollins, 1-18. Lexington: University Press of Kentucky.

Emerson, Caryl. 1992. 'Glasnost' in Russian Music: The Musorgsky Jubilee during a Time of Trouble'. Slavic Review 51, no. 3: 544-556.

Engström, Maria. 2014. 'Contemporary Russian Messianism and New Foreign Policy'. Contemporary Security Policy 35, no. 3: 356-379.

Epanchina, Ol'ga. 2006. 'Serial "Stolypin": Itogi s Iuriem Kuzinym'. Accessed 20 December 2012, http://isjuminka.narod.ru/fan2.html.

Epshtein, Alek D. 2011. 'Ot oprichniny - k dvortsovomu perevorotu: natsional'nye i antisovetskie motivy v aktsiiakh art-gruppy "Voina"'. Neprikosnovennyi zapas, no. 6.

Erll, Astrid, and Ann Rigney. 2009. 'Introduction: Cultural Memory and its Dynamics'. In Mediation, Remediation, and the Dynamics of Cultural Memory, edited by Astrid Erll and Ann Rigney, 1-11. Berlin and New York: Walter de Gruyter.

Etkind, Alexander. 2009. 'Post-Soviet Hauntology: Cultural Memory of the Soviet Terror'. Constellations 16, no. 1: 182-200.

Etkind, Alexander, Rory Finnin, Uilleam Blacker, Julie Fedor, Simon Lewis, Maria Mälksoo and Matilda Mroz. 2012. Remembering Katyn. Cambridge [etc.]: Polity.

Etkind, Alexander. 2017. 'Foreword'. In War and Memory in Russia, Ukraine and Belarus, edited by J. Fedor, M. Kangaspuro, J. Lassila and T. Zhurzhenko, v-xi. Palgrave Macmillan Memory Studies. Cham: Springer.

Fedor, J. 2014. 'Setting the Soviet Past in Stone: The Iconography of the New Martyrs of the Russian Orthodox Church'. Australian Slavonic and East European Studies 28, no. 1-2: 121-153.

Fedor, J., M. Kangaspuro, J. Lassila and T. Zhurzhenko (eds). 2017. War and Memory in Russia, Ukraine and Belarus. Palgrave Macmillan Memory Studies. Cham: Springer.

Fedor, J. 2017. 'Memory, Kinship, and the Mobilization of the Dead: The Russian State and the 'Immortal Regiment' Movement'. In War and Memory in Russia, Ukraine and Belarus, edited by J. Fedor, M. Kangaspuro, J. Lassila and T. Zhurzhenko307-346. Palgrave Macmillan Memory Studies. Cham: Springer.

Figge, Susan G., and Jenifer K. Ward. 2010. 'Introduction: Adapting the Past for the Present'. In Reworking the German Past. Adaptations in Film, the Arts, and Popular Culture, edited by Susan Figge and Jenifer Ward, 1-12. Rochester: Camden House.

Filaticheskii Obzor. 2012. 'Anons marok. ROSSIIA 2012. Aprel'. Accessed 27 February 2013, http://philatelic-shop.com/?page_id=2549.

Fisher, Burton. 2002. Boris Godunov. Opera Journeys Mini Guide Series. Coral Gables: Opera Journeys Publishing.

Fond Izucheniia Naslediia P.A. Stolypina. 2006a. 'Iubilei reform P.A. Stolypina'. Accessed 27 February 2013, www.stolypin.ru/press-tsentr/arkhiv-novostey/?SEC TION_ID=1\&ELEMENT_ID=138.

Fond Izucheniia Naslediia P.A. Stolypina. 2006b. 'Zasedanie orgkomiteta po podgotovke i provedeniu 100-letnego iubileia reform P.A. Stolypina'. Accessed 27 February 2013, www.stolypin.ru/press-tsentr/arkhiv-novostey/?SECTION_ID $=1 \&$ ELEMENT_ID=136. 
Fond Izucheniia Naslediia P.A. Stolypina. N.d. 'Istoriia sozdaniia Fonda izucheniia naslediia P.A. Stolypina'. Accessed 27 February 2013, www.stolypin.ru/o-fonde/ istoriya-sozdaniya-fonda/.

Froianov, Igor'. 2011. 'Velikan Stalin i pigmei Stolypin'. 14 July. Accessed 4 March 2013, http://ruskline.ru/news_rl/2011/07/14/velikan_stalin_i_pigmej_stolypin/.

Frolova-Walker, Marina. 2006. 'The Soviet Opera Project: Ivan Dzerzhinsky vs. Ivan Susanin'. Cambridge Opera Journal 18, no. 2: 181-216.

Frolova-Walker, Marina. 2007. Russian Music and Nationalism: From Glinka to Stalin. New Haven: Yale University Press.

Fursov, Andrei, Maksim Kalashnikov and Vitalii Aver'ianov. 2011. Novaia oprichnina, ili Modernizatsiia po-russki. Moscow: FOLIO.

Gaikovich, Marina. 2007. 'Musorgskomy - s liubov'iu. Vash Aleksandr Sokurov'. Nezavisimaia gazeta, 24 April.

Garrard, John, and Carol Garrard. 2008. Russian Orthodoxy Resurgent: Faith and Power in the New Russia. Princeton and Oxford: Princeton University Press.

Gaufman, E. 2017. Security Threats and Public Perception: Digital Russia and the Ukraine Crisis. Cham: Palgrave Macmillan.

Gavrilova, Mariia. 2008. 'Aleksandr. Nevskaia bitva: Domashnee zadanie'. Kinokadr, 3 May. Accessed 2 September 2015, www.kinokadr.ru/articles/2008/05/03/ nevsky.shtml.

Gill, Graeme. 2011. Symbols and Legitimacy in Soviet Politics. Cambridge: Cambridge University Press.

Gill, Graeme. 2013. Symbolism and Regime Change in Russia. Cambridge: Cambridge University Press.

Golev, Nikolay D., and Olga E. Yakovleva. 2012. 'Manipulative Strategies and Tactics of Mass Media Communication (on the example of "The Name of Russia" television project)'. Journal of Siberian Federal University. Humanities and Social Sciences 12: 1834-1842.

Golubovskii, Anatolii. 2009. 'Identichnost' kak format'. Iskusstvo kino, no. 1. Accessed 3 June 2015, http://kinoart.ru/archive/2009/01/n1-article4.

Goncharenko, Roman. 2013. 'Direktor "Levada-Tsentra": "Russkii marsh" vytesnil Den' narodnogo edinstva'. Deutsche Welle, 3 November. Accessed 5 February 2016, www.dw.com/ru/директор-левада-центрарусский-марш-вытеснил-день-народногоединства/а-17196431.

Goodwin, James. 1993. Eisenstein, Cinema, and History. Urbana and Chicago: University of Illinois Press.

Gorp, Baldwin van. 2007. 'The Constructionist Approach to Framing: Bringing Culture Back In'. Journal of Communication 57: 60-78.

Gorp, Jasmijn van. 2011. 'Inverting Film Policy: Film as Nation Builder in Post-Soviet Russia, 1991-2005'. Media, Culture \& Society 33, no. 2: 243-258.

Goscilo, Helena. 2011. 'Zurab Tsereteli's Exegi Monumentum, Luzhkov's Largesse, and the Collateral Rewards of Animosity'. In Celebrity and Glamour in Contemporary Russia. Shocking Chic, edited by Helena Goscilo and Vlad Strukov, 221-254. London and New York: Routledge.

Gudkov, Lev. 2000. 'K probleme negativnoi identifikatsii'. Monitoring obshchestvennogo mneniia: ekonomicheskie $i$ sotsial'nye peremeny, no. 5.

Gudkov, Lev. 2010. 'Vremia i istoriia v soznanii rossiian (Chast' II)'. Vestnik obshchestvennogo mneniia, no. 2: 13-61. 


\section{References}

Halperin, Charles J. 2011. False Identity and Multiple Identities in Russian History: The Mongol Empire and Ivan the Terrible. Carl Beck Papers in Russian and East European Studies, no. 2103. Pittsburgh: University of Pittsburgh.

Halperin, Charles J. 2013. 'Ivan the Terrible Returns to the Silver Screen: Pavel Lungin's Film Tsar'. Studies in Russian \& Soviet Cinema 7, no. 1: 61-72.

Hemment, Julie. 2015. Youth Politics in Putin's Russia: Producing Patriots and Entrepreneurs. Bloomington and Indianapolis: Indiana University Press.

Hill, Fiona, and Clifford Gaddy. 2012. 'Putin and the Uses of History'. The National Interest, no. 117, January/February: 21-31.

Horvath, R. 2013. Putin's Preventive Counter-Revolution. Post-Soviet Authoritarianism and the Spectre of Velvet Revolution. London and New York: Routledge.

Hughes-Warrington, M. (ed.) 2009. The History on Film Reader. London and New York: Routledge.

Human Rights Watch. 2008. 'Choking on Bureaucracy: State Curbs on Independent Civil Society Activism'. Accessed 28 January 2013, www.hrw.org/sites/default/files/ reports/russia 0208_1.pdf.

Humphrey, C. 2009. 'Historical Analogies and the Commune: The Case of Putin/Stolypin'. In Enduring Socialism. Explorations of Revolution and Transformation, Restoration and Continuation, edited by Harry G. West and Parvathi Raman, 231249. New York and Oxford: Berghahn Books.

Hutcheon, Linda. 2010. 'Adapting (to) History'. In Reworking the German Past. Adaptations in Film, the Arts, and Popular Culture, edited by Susan Figge and Jenifer Ward, vii-ix. Rochester: Camden House.

Hutchings, Stephen, and Natalia Rulyova. 2009. Television and Culture in Putin's Russia: Remote Control. London [etc.]: Routledge.

Hutchings, Stephen, and Vera Tolz. 2015. Nation, Ethnicity and Race on Russian Television: Mediating Post-Soviet Difference. London and New York: Routledge.

IA REGNUM. 2005. 'Iaroslavskaia eparkhiia: "Ustanovka pamiatnika Groznomu ukhudshit kriminogennuiu situatsiiu v raione"'. 26 August. Accessed 18 April 2016, http://regnum.ru/news/cultura/503074.html.

IA REGNUM. 2012. "Aktivist belolentochnogo dvizheniia i "etnicheskii pomor" otkryli v Arkhangel'ske plitu tsariu-demokratu'. 2 July. Accessed 18 April 2016, http:// regnum.ru/news/polit/1547347.html.

InterMedia. 2008a. '20 DVD liderov prodazh v magazinakh "Soiuz"'. 26 May. Accessed via Integrum World Wide database.

InterMedia. 2008b. '20 DVD liderov prodazh v magazinakh "Soiuz"'. 2 June. Accessed via Integrum World Wide database.

InterMedia. 2008c. '20 DVD liderov prodazh v magazinakh "Soiuz"'. 9 June. Accessed via Integrum World Wide database.

Johnson, Ian. 2016. 'China's Memory Manipulators'. The Guardian, 8 June. Accessed 21 June 2016, www.theguardian.com/world/2016/jun/08/chinas-memory-manipula tors\#comments.

JoyReactor. 2010. 'Il'ia Repin Ivan Groznyi ubivaet Marata Maslo, kholst, 1866 Il'ia Repin Ivan Groznyi ybivaet neizve / ivan groznyi: zhivopis': fotozhaby'. 16 November. Accessed 28 March 2016, http://joyreactor.cc/post/101699.

JoyReactor. 2014. 'na zlobu dnia'. 17 August. Accessed 28 March 2016, http://joyrea ctor.cc/post/1496982.

Kachkaeva, Anna. 2006. 'Stolypin na NTV: uroki neokonchennogo serial'. Radio Svoboda, 31 July. Accessed 16 April 2014, www.svoboda.org/content/transcript/259067.html. 
Kachkaeva, Anna. 2010. 'Prem'ery "Piatogo": Iuliia Larina i Sergei Varshavchik v programme Anny Kachkaevoi obsuzhdaiut izmenivshiisia oblik i status Piatogo federal'nogo kanala'. 22 March. Accessed 10 December 2015, www.svoboda.org/ content/transcript/1991110.html.

Kalashnikov, Maksim. 2010. 'Segodnia nuzhen Beriia'. Zavtra, no. 27.

Kalinin, Il'ia. 2013. 'Future-in-the-past/Past-in-the-future: sovetskoe budushee postsovetskogo proshlogo'. Seans, 14 May. Accessed 24 May 2016, http://seance.ru/blog/ esse/future_in_the_past/.

Kalinina, Ekaterina. 2017. 'Beyond Nostalgia for the Soviet Past: Interpreting Documentaries on Russian Television'. European Journal of Cultural Studies 20, no. 3: 285-306.

Karas', Alena. 2007. 'Pol'skoe prochtenie. V Teatre.doc sygrali svoiu versiiu 1612 goda'. Rossiiskaia gazeta, 7 November. Accessed 15 February 2016, www.rg.ru/ 2007/11/07/taetr.html.

Khapaeva, Dina. 2016. 'Triumphant Memory of the Perpretrators: Putin's Politics of Re-Stalinization'. Communist and Post-Communist Studies 49: 61-73.

Khlobystova, Liudmila. 2009. 'S'emki "Ivana Groznogo" stali adom'. Accessed 14 February 2016, http://russia.tv/article/show/article_id/5881/brand_id/15711/type_id/1/.

Khromov, Mikhail. 2010. 'Obzor igry Real Warfare: 1242'. Absolute Games, 3 January. Accessed 8 July 2015, www.ag.ru/games/real-warfare-1242/review.

Knoppe, Boris. 2006. "Oprichnyi mistitsizm" v religioznykh praktikakh "tsarebozhnichestva"”. In Religioznye praktiki v sovremennoi Rossii: Sbornik statei, edited by K. Russele and A. Agadzhaniana, 384-397. Moscow: Novoe izdatel'stvo. Accessed 19 April 2016, www.anti-raskol.ru/pages/1936.

Kolesnikov, Andrei. 2014. 'Glavnaia noch' v Sochi. Kak gotovilis' i nachinalas' tseremoniia otkrytiia Zimnikh Igr-2014'. Kommersant', 7 February. Accessed 27 May 2016, www.kommersant.ru/doc/2403751.

Koposov, N. 2011a. Pamiat' strogogo rezhima: Istoriia i politika v Rossii. Moscow: Novoe literaturnoe obozrenie.

Koposov, N. 2011b. "The Armored Train of Memory": The Politics of History in Post-Soviet Russia'. Perspectives on History 49, no. 1.

Korzhavin, Naum. 1991. 'Pravda KPSS i svoboda'. Nezavisimaia gazeta 112, 19 September.

Kozenko, Andrei. 2007. 'Voinstvenno voskrese. "Evraziiskii soiuz molodezhi” provel paskhal'nyi imperskii marsh'. Kommersant', 9 April. Accessed 21 April 2016, www. kommersant.ru/doc/757091.

Krasnov, Pavel. 2011. 'Zaversheno narodnoe golosovanie za luchshii proekt pamiatnika Petru Stolypinu'. Pervyi kanal, 1 December. Accessed 7 March 2013, www.1tv. $\mathrm{ru} /$ news/culture/192481.

Kuzin, Iurii. 2006. 'IVAN GROZNYI - BASTARD NA TRONE!?' LiveJournal, 9 November. Accessed 20 December 2012, http://kuzin-yurii.livejournal.com/4343. html.

Kuzin, Iurii. 2007a. 'Zachem lukavit dramaturg Volodarskii?' LiveJournal, 20 August. Accessed 20 December 2012, http://kuzin-yurii.livejournal.com/12420.html.

Kuzin, Iurii. 2007b. 'Ne smeshno...' LiveJournal, 3 November. Accessed 20 December 2012, http://kuzin-yurii.livejournal.com/14448.html.

Kuzin, Iurii. 2009. 'Serial "Ivan Groznyi” Andreia Eshpaia i Vladimira Dostalia'. LiveJournal, 20 May. Accessed 20 December 2012, http://kuzin-yurii.livejournal. com/28370.html. 


\section{6}

\section{References}

Kvasha, Semen. 2008. 'Aleksandr. Nevskaia bitva. "V nashem kinomatografe zvezd net"'. Film.ru, 29 April. Accessed 14 December 2015, www.film.ru/articles/v-nashemkinematografe-zvezd-net.

Langenohl, Andreas. 2000. Erinnerung und Modernisierung: Die öffentliche Rekonstruktion politischer Kollektivität am Beispiel des Neuen Rußland. Göttingen: Vandenhoeck und Ruprecht.

Larina, Kseniia. 2011. 'Stenogrammy press-konferentsii radio "Ekho Moskvy". Ekho Moskvy, 3 September. Transcript accessed via Integrum World Wide database.

Laruelle, Marlène. 2009. In the Name of the Nation: Nationalism and Politics in Contemporary Russia. Basingstoke: Palgrave Macmillan.

Lassila, Jussi. 2014. The Quest for an Ideal Youth in Putin's Russia II: The Search for Distinctive Conformism in the Political Communication of Nashi, 2005-2009. Stuttgart: Ibidem Verlag.

Lesk, M. 2007. 'The New Front Line. Estonia under Cyberassault'. IEEE Security \& Privacy 5, no. 4: 76-79.

Levada Centre. 2011. 'TV-shou "Istoricheskii protsess"'. 16 November. Accessed 12 April 2016, www.levada.ru/2011/11/16/tv-shou-istoricheskij-protsess/.

Levada Centre. 2012. Obshchestvennoe mnenie - 2011. Moscow: Levada-Tsentr. Accessed 20 May 2016, www.levada.ru/sites/default/files/levada_2011_0.pdf.

Levada Centre. 2015. Obshchestvennoe mnenie - 2014. Moscow: Levada-Tsentr. Accessed 20 May 2016, www.levada.ru/sites/default/files/om14.pdf.

Levada Centre. 2016. Obshchestvennoe mnenie - 2015. Moscow: Levada-Tsentr. Accessed 20 May 2016, www.levada.ru/cp/wp-content/uploads/2016/02/OM20151. pdf.

Liakin, Aleksandr. 2012. 'Na etoi nedele Vladimir Putin vstretilsia s predstaviteliami vsekh traditsionnykh religioznykh konfessii'. Pervyi kanal, 12 February. Accessed 12 April 2013, www.1tv.ru/news/social/198884.

Liashchenko, Vladimir. 2008. 'Aleksandr. Nevskaia bitva - retsenzii'. Afisha, 3 May. Accessed 7 September 2015, www.afisha.ru/movie/181133/review/220539/.

Liderman, Iuliia. 2007. 'Kurs na patriotism i otvet rossiiskogo kinematografa v 2000-e gody. Novye biudzhety, novye zhanry, novye fil'my o voine'. In Sovremennye interpretatsii russkogo natsionalizma, edited by Marlène Laruelle, 289-317. Stuttgart: Ibidem Verlag.

Lipovetsky, M., and A. Etkind. 2008. 'Vozvrashchenie triton: Sovetskaia katastrofa i postsovetskii roman'. $N L O$, no. 94: 174-206.

Lipovetsky, M., and L. Ryoko Wakamiya (eds). 2014. Late and Post-Soviet Russian Literature: A Reader. Book 1: Perestroika and the Post-Soviet Period. Boston: Academic Studies Press.

Loginov, V.T. 2004 [2001]. 'Stolypin as a Reformer'. Russian Studies in History 42, no. 4: $22-28$

Logos. 2011. 'Smuta: Ozhivshie mertvetsy (1997/RUS)'. 3 September. Accessed 1 March 2016, www.syper-games.ru/shoter/37517-smuta-ozhivshie-mertvecy-1997rus. html.

Lutomin, Oleg, and Dmitrii Sergeev. 2002. 'Partiinaia zona'. Russkii predprinimatel', no. 8. Accessed 21 June 2016, www.ruspred.ru/arh/06/10rr.html.

Lutz-Auras, Ludmila. 2012. 'Auf Stalin, Sieg und Vaterland!': Politisierung der kollektiven Erinnerung und den Zweiten Weltkrieg in Russland. Heidelberg: Springer.

Maetnaia, Elizaveta. 2012. 'Poiushii tadzhik pishet novuiu pesniu k inauguratsii Putina'. Izvestiia, 1 March. 
Makarychev, Andrey, and Alexandra Yatsyk. 2014. 'A New Russian Conservatism: Domestic Roots and Repercussions for Europe'. Notes Internacionals, no. 93: 1-6.

Maler, Arkadii. 2007. 'Goszakaz \#1612 provalen'. Russkii Zhurnal. Accessed 16 February 2016, www.russ.ru/pole/Goszakaz-1612-provalen.

Malinova, O. 2017. 'Political Uses of the Great Patriotic War in Post-Soviet Russia from Yeltsin to Putin'. In War and Memory in Russia, Ukraine and Belarus, edited by J. Fedor, M. Kangaspuro, J. Lassila and T. Zhurzhenko, 43-70. Palgrave Macmillan Memory Studies. Cham: Springer.

Maliukova, Larisa. 2010. 'Vosslavim perestavshikh vrat'. O khudozhestvennoi pravde i fal'sifikatsii istorii'. Novaia gazeta, 27 January.

Marchenia, P. P., and S. Iu. Razina (eds). 2010. Narod $i$ vlast'v rossiiskoi smute: Sbornik nauchnykh statei uchastnikov Mezhdunarodnogo kruglogo stola 'Narod $i$ vlast' v rossiiskoi smute'. Moscow: Izd. VVA im. prof. N.E. Zhukovskogo i Iu.A. Gagarina.

Maslova, Lidiia. 2007. 'Idet voina nariadnaia'. Kommersant' Vlast' 43, 5 November. Accessed 20 February 2016, www.kommersant.ru/doc/821761.

Maslova, Lidiia. 2008. 'Aleksandr Iaroslavich ne meniaet konfessiiu'. Kommersant' 72, 26 April. Accessed 2 September 2015, www.kommersant.ru/doc/886997.

Matvienko, Kristina. 2013. 'Mirzoev Vladimir. "Tolstoi - Stolypin. Chastnaia perepiska". Teatr, no. 13-14: 94-97.

Mediascope. 2017. 'Auditoriia pol'zovatelei interneta v Rossii v 2017 godu sostavila 87 mln. chelovek'. 21 April. Accessed 30 January 2018, http://mediascope.net/press/ news/744498/.

Medvedev, Dmitry. 2008. 'Address to the Federal Assembly of the Russian Federation'. 5 November. Accessed 21 June 2016, http://en.kremlin.ru/events/president/transcrip ts/1968.

Mel'nikov, Andrei, and Vladislav Mal'tsev. 2013. 'Russkii mir dobralsia do Kremlia'. Nezavisimaia gazeta, 6 November.

Mickiewicz, Ellen. 2008. Television, Power, and the Public in Russia. Cambridge [etc.]: Cambridge University Press.

Mijnsen, Ivo. 2014. The Quest for an Ideal Youth in Putin's Russia I: Back to Our Future! History, Modernity, and Patriotism According to Nashi, 2005-2013. Second, revised and expanded edition. Stuttgart: Ibidem Verlag.

Mikhalkov, Nikita. 2010. 'Pravo i pravda. Manifest Prosveshchennogo Konzervatizma'. Polit.ru, 26 October. Accessed 28 May 2015, http://polit.ru/article/2010/10/ 26/manifest/.

Mikhalkov, Nikita. 2012. 'Petr Stolypin protiv "norkovykh vorotnichkov"'. Kul'tura, no. 1. Accessed 30 June 2016, www.culture.ru/ru/uploads/media/paper_archive/0001/ 08/00c22b52bf96a3b35a5cd74ba288223a1bb6bdc7.pdf.

Miller, Alexei. 2012. 'The Turns of Russian Historical Politics, from Perestroika to 2011'. In The Convolutions of Historical Politics, edited by Alexei Miller and Maria Lipman, 253-278. Budapest: Central European University Press.

Miller, Alexei and Maria Lipman (eds). 2012. The Convolutions of Historical Politics. Budapest: Central European University Press.

Mil'shtein, Il'ia. 2013. 'Oklevatannyi Groznyi. Zhivopisets Repin oskorbil chuvstva veruiushchikh'. Novaia gazeta 112, 7 October.

Mink, Georges, and Laure Neumayer (eds). 2013. History, Memory and Politics in Central and Eastern Europe: Memory Games. Basingstoke: Palgrave Macmillan. 


\section{8}

\section{References}

Ministry of Culture of the Russian Federation. 2010. 'Prikaz No. 272. O prioritetnykh temakh natsional'nykh fil'mov v 2010 godu'. 17 May.

Ministry of Culture of the Russian Federation. 2011. 'Prikaz No. 45. O prioritetnykh temakh natsional'nykh fil'mov v 2011 gody'. 3 February.

Ministry of Culture of the Russian Federation. 2015. 'Prikaz No. 275. O prioritetnykh temakh gosudarstvennoi finansovoi podderzhki kinoproizvodstva v 2015 godu'. 19 February.

Ministry of Education and Science of the Russian Federation. 2012. 'O meropriiatiiakh po prazdnovaniiu 150-letiia so dnia rozhdeniia P.A. Stolypina'. 15 February.

Mitrokhin, Nikolay. 2009. 'The Russian Orthodox Church in Contemporary Russia: Structural Problems and Contradictory Relations with the Government, 2000 2008'. Social Research 76, no. 1: 289-320.

Mordvinov, B. A. 2006. 'Ivan Susanin on the Stage of the Bolshoi Theater'. Pravda, 7 February 1939. Reproduced in translation in Epic Revisionism: Russian History and Literature as Stalinist Propaganda, edited by Kevin M. F. Platt and David Brandenburger, 276-280. Madison: University of Wisconsin Press.

Morozov, Mikhail. 2009. 'Istoriia v stile "pop"'. Iskusstvo kino, no. 1. Accessed 3 June 2015, http://kinoart.ru/archive/2009/01/n1-article2.

Morrison, Simon. 2009. The People's Artist: Prokofiev's Soviet Years. Oxford and New York: Oxford University Press.

Mosigra. N.d. 'Nastol'naia igra Smuta 1605-1612 gg'. Accessed 1 March 2016, www. mosigra.ru/Face/Show/smuta_1605_1612/.

Muchnik, Andrei. 2015. 'Red Carpets, Chaos and Great Movies: The 37th Moscow International Film Festival'. The Moscow Times, 28 June. Accessed 1 June 2016, www.themoscowtimes.com/article.php?id=524541.

Muratov, Sergei. 2011. 'Dal'novidenie dlia radiozritelei. Zametki rovesnika televideniia'. Iskusstvo kino, no. 7. Accessed 8 December 2015, http://kinoart.ru/a rchive/2011/07/n7-article16.

Nadein, Vladimir. 2012a. 'Stolypin, Putin, Mikhalkov. Chast' pervaia. Ideal'nyi silovik'. 21 May. Accessed 13 December 2012, www.ej.ru/?a=note\&id=11782.

Nadein, Vladimir. 2012b. 'Stolypin, Putin, Mikhalkov. Chast' tret'ia. Aktual'nyi kozel v serebrianykh stremenakh'. 30 May. Accessed 3 December 2015, www.ej.ru/?a= note\&id=11824.

Naumova, Marina. 2011. 'Channel No. 5: novyi aroma ot Konstantina Ernsta. Zachem iz televizionnogo "Piatogo kanala" delaiut analog "Pervogo". Slon, 17 January. Accessed 10 December 2015, http://slon.ru/russia/channel_5_novyy_aroma t_ot_konstantina_ernsta-522164.xhtml.

Nikolaeva, Dar'ia. 2015. 'Ekonomicheskii rost vopreki vsemu. "Stolypinskii klub" mechtaet o NEPe'. Kommersant' 194, 21 October. Accessed 29 May 2016, http:// www.kommersant.ru/doc/2836500.

Norris, Stephen M. 2012. Blockbuster History in the New Russia: Movies, Memory, and Patriotism. Bloomington: Indiana University Press.

Norris, Stephen M. 2013. 'Blessed Films: The Russian Orthodox Church and Patriotic Culture in the 2000s'. In Iconic Turns. Nation and Religion in Eastern European Cinema since 1989, edited by Liliya Berezhnaya and Christian Schmitt, 65-79. Leiden and Boston: Brill.

Novikova, Anna. 2014. 'Myths about Soviet Values and Contemporary Russian Television'. Russian Journal of Communication 3, no. 3-4: 280-294. 
Novoselova, Elena. 2010. 'Ne venchan? Uvolen! Prezident krupnoi kompanii po proizvodstvu moloka dal bezbozhnikam srok do Pokrova'. Rossiiskaia gazeta 180, 13 August.

Oates, Sarah. 2006. Television, Democracy and Elections in Russia. London and New York: Routledge.

O’Mahony, Mike. 2008. Sergei Eisenstein. London: Reaktion Books.

Oushakine, Serguei. 2009. The Patriotism of Despair. Nation, War, and Loss in Russia. Ithaca: Cornell University Press.

Oushakine, Serguei. 2013. 'Remembering in Public: On the Affective Management of History'. Ab Imperio, no. 1: 269-302.

Papkova, Irina. 2011. The Orthodox Church and Russian Politics. Washington: Woodrow Wilson Center Press; New York: Oxford University Press.

Pavlov, D., and Z. Peregudova. 1994. Pis'ma Azefa: 1893-1917. Moscow: Terra.

Payne, Daniel. 2010. 'Spiritual Security, the Russian Orthodox Church, and the Russian Foreign Ministry: Collaboration'. Journal of Church and State 52, no. 4: 712-727.

Penzin, A., and I. Budraitskis. 2013. 'The Catastrophes of "Real Capitalism"'. In PostPost-Soviet? Art, Politics and Society in Russia at the Turn of the Decade, edited by M. Dziewanska, E. Degot and I. Budraitskis, 115-127. Warsaw: Museum of Modern Art.

Perrie, Maureen. 1987. The Image of Ivan the Terrible in Russian Folklore. Cambridge [etc.]: Cambridge University Press.

Perrie, Maureen. 2001. The Cult of Ivan the Terrible in Stalin's Russia. New York: Palgrave Macmillan.

Perrie, Maureen. 2006, 'The Time of Troubles (1603-1613)'. In The Cambridge History of Russia, edited by Maureen Perrie, 409-432. Cambridge: Cambridge University Press.

Petersson, Bo. 2013. 'The Eternal Great Power Meets the Recurring Time of Troubles: Twin Political Myths in Contemporary Russian Politics'. European Studies 30: 301-326.

Platt, Kevin M. F., and David Brandenberger. 2006. 'Introduction: Tsarist-Era Heroes in Stalinist Mass Culture and Propaganda'. In Epic Revisionism: Russian History and Literature as Stalinist Propaganda, edited by Kevin M. F. Platt and David Brandenberger, 3-14. Madison: University of Wisconsin Press.

Platt, Kevin M.F. 2010. 'Pavel Lungin: Tsar (2009)'. KinoKultura, no. 28. Accessed 29 January 2018, www.kinokultura.com/2010/28r-tsar-kp.shtml.

Platt, Kevin M.F. 2011. Terror and Greatness. Ivan and Peter as Russian Myths. Ithaca: Cornell University Press.

plucer. 2008. 'Daesh' zheleznyi zanaves!, ili Slava Zolotoi rybke! Novaia skandal'naia aktsiia gruppy Voina'. 31 December. Accessed 19 April 2016, http://plucer.live journal.com/128862.html.

Pomerantsev, Peter. 2014. Nothing is True and Everything is Possible: The Surreal Heart of the New Russia. New York: Public Affairs.

Ponomariov, Alexander. 2013. 'The Pussy Riot Case in Russia: Orthodox Canon Law and the Sentence of the Secular Court'. Ab Imperio, no. 4: 187-216.

President of the Russian Federation. 2010. 'Ukaz no. 565. O prazdnovaniia 150-letiia so dnia rozhdeniia P.A. Stolypina'. 10 May. Accessed 21 June 2016, http://www.gara nt.ru/products/ipo/prime/doc/6636691/.

President of the Russian Federation. 2014. 'Ukaz no. 488. O prazdnovaniia 800-letiia so dnia rozhdeniia kniazia Aleksandra Nevskogo'. 23 June. Accessed 14 December 2015, http://kremlin.ru/acts/news/46050. 
President of the Russian Federation. 2015. 'Ukaz no. 330. O nagrazhdenii gosudarstvennymi nagradami Rossiiskoi Federatsii'. 29 June. Accessed 28 June 2016, http://publication.pravo.gov.ru/Document/View/0001201506300058?index=9\&range Size $=1$.

Prosvirnin, Egor. 2010. 'Imperiia: Smutnoe vremia'. Igromaniia, no. 2. Accessed 1 March 2016, www.igromania.ru/articles/108561/Imperiya_Smutnoe_vremya.htm.

Prozorov, Sergei. 2008. 'Russian Postcommunism and the End of History'. Studies in Eastern European Thought, no. 60: 207-230.

Putin, Vladimir. 2000. 'Annual Address to the Federal Assembly of the Russian Federation'. 8 July. Accessed 21 June 2016, http://en.kremlin.ru/events/president/ transcripts/21480.

Putin, Vladimir. 2006. 'Uchastnikam i gostiam vystavka-foruma "Pravoslavnaia Rus' k Dniu narodnogo edinstva"”. 1 November. Accessed 1 April 2015, www.kremlin. $\mathrm{ru} / \mathrm{letters} / 26194$.

Putin, Vladimir. 2007. 'Uchastnikam i gostiam vystavka-foruma "Pravoslavnaia Rus"”. 1 November. Accessed 1 April 2015, www.kremlin.ru/letters/26526.

Putin, Vladimir. 2012a. 'Rossiia sosredotachivaetsia - vyzovy, na kotorye my dolzhny otvetit”. Izvestiia, 16 January. Accessed 29 June 2016, http://izvestia.ru/news/511884.

Putin, Vladimir. 2012b. 'Address to the Federal Assembly'. 12 December. Accessed 21 June 2016, http://eng.kremlin.ru/transcripts/4739.

Radulova, Natal'ia. 2005. 'Groznyi Liubim'. Ogonek, 25 September. Accessed 18 April 2016, www.kommersant.ru/doc/2295787.

Ramm, Vita. 2007. 'Kinorezhisser Vladimir Khotinenko: "Ia ne poluchal goszakaza snimat" pro to, "kak liakhov gnali iz Kremlia"'. Izvestiia, 30 October. Accessed 16 February 2016, http://izvestia.ru/news/330245.

Ramm, Vita. 2008. 'Rezhisser fil'ma "Aleksandr. Nevskaia bitva” Igor' Kalenov: "Eto fil'm o mal'chike, kotoryi vstupaet v rukovodstvo stranoi"'. Izvestiia, 11 April. Accessed 1 September 2015, http://izvestia.ru/news/335388.

Richters, Katja. 2013. The Post-Soviet Russian Orthodox Church: Politics, Culture and Greater Russia. London and New York: Routledge.

Rigney, Ann. 2005. 'Plenitude, Scarcity and the Circulation of Cultural Memory'. Journal of European Studies 35, no. 1: 11-28.

Roberts, Graham. 1999. Forward Soviet! History and Non-fiction Film in the USSR. London and New York: I.B. Tauris.

Rock, Sheila. 2014. 'Rebuilding the Chain: Tradition, Continuity, and Processions of the Cross in Post-Soviet Russia'. In Orthodox Paradoxes: Heterogeneities and Complexities in Contemporary Russian Orthodoxy, edited by Katya Tolstaya, 275301. Leiden: Brill.

Rollberg, Peter. 2014. 'Peter the Great, Statism, and Axiological Continuity in Contemporary Russian Television'. Demokratizatsiya 22, no. 2: 335-355.

Romanenkova, Veronika. 2005. 'Putin v Den' narodnogo edinstva priznal vozrodit' traditsii rossiiskoi blagotvoritel'nosti'. ITAR-TASS, 4 November. Accessed via Integrum World Wide database.

Rosen, Philip. 2001. Change Mummified: Cinema, Historicity, Theory. Minneapolis: University of Minnesota Press.

Rousselet, Kathy. 2015. 'The Church in the Service of the Fatherland'. Europe-Asia Studies 67, no. 1: 49-67.

Russian Central Bank. 2012. 'Seriia: Vydaiushchiesia lichnosti Rossii. Gosudarstvennyi deiatel' P.A. Stolypin - k 150-letiiu so dnia rozhdeniia'. Accessed 27 
February 2013, http://cbr.ru/bank-notes_coins/base_of_memorable_coins/Show Coins.aspx?cat_num $=5110-0112$.

Russian Government. 2006. 'Rasporiazhenie no. 1457-r. O provedenii v 2006 godu meropriiatii, posviashchennykh 100-letiiu reform P.A. Stolyina'. 20 October. Accessed 21 June 2016, http://lawru.info/dok/2006/10/20/n303375.htm.

Russian Government. 2008. 'Postanovlenie no. 388. O medali Stolypina P.A.'. 26 May. Accessed 21 June 2016, http://uristu.com/library/pravitelstvo-rf/postanovleniya/pra vpost_8143/.

Rzhevsky, Nicholas. 2009. The Modern Russian Theater: A Literary and Cultural History. Armonk and London: M.E. Sharpe.

Samsonova, Ol'ga. 2013. 'Patriarkh Kirill nazval vossozdanie Romanovskogo obelisk ispravleniem oshibok proshlogo'. RIA Novosti, 4 November. Accessed via Integrum World Wide database.

Schenk, Frithjof Benjamin. 2004. Aleksandr Nevskij: Heiliger - Fürst - Nationalheld: eine Erinnerungsfigur im russischen kulturellen Gedächtnis (1263-2000). Cologne [etc.]: Böhlau.

Schimpfossl, E., and I. Yablokov. 2014. 'Coercion or Conformism? Censorship and Self-Censorship among Russian Media Personalities and Reporters in the 2010s'. Democratizatsiya 20, no. 2: 295-312.

Shamanska, A. 2016. 'Bloody Stake: "Alternative" Monument to Ivan the Terrible Unveiled in Russia'. RFE/RL, 24 October. Accessed 19 March 2018, www.rferl. org/a/russia-ivan-terrible-statue-oryol-alternative-monument/28072311.html.

Shcherbakova, Irina. 2014. 'Vret, kak ochevidets'. Iskusstvo kino, no. 2. Accessed 25 March 2014, http://kinoart.ru/ru/archive/2014/02/vret-kak-ochevidets.

Sherlock, Thomas. 2007. Historical Narratives in the Soviet Union and Post-Soviet Russia: Destroying the Settled Past, Creating an Uncertain Future. New York and Basingstoke: Palgrave Macmillan.

Sherlock, Thomas. 2011. 'Confronting the Stalinist Past: The Politics of Memory in Russia'. Washington Quarterly 34, no. 2: 93-109.

Sherlock, Thomas. 2016. 'Russian Politics and the Soviet Past: Reassessing Stalin and Stalinism under Vladimir Putin'. Communist and Post-Communist Studies 49: 45-59.

Shigareva, Iuliia. 2008. 'Pavel Lungin: "Ivan Groznyi - vechnoe iskyshenie Rossii"'. Argumenty i Fakty, no. 16. Accessed 3 May 2016, www.aif.ru/culture/3110.

Skoibeda, Ul'iana. 2013. 'Nash pap stal sektantom'. Komsomol'skaia pravda, 17 May. Accessed 18 April 2016, www.kp.ru/daily/26076/2982094/.

Smith, Kathleen. 2002. Mythmaking in the New Russia: Politics and Memory during the Yeltsin Era. Ithaca: Cornell University Press.

Sobakin, Ivan. 2012. 'Zhanna Bichevskaia v Ul'ianovske: o Putine, vere, tsare i Otchestve'. 73online, 12 October. Accessed 8 June 2016, http://73online.ru/readnews/20574.

Stähle, Hanna, and Mariëlle Wijermars. 2014. 'Forget Memory: Aleksei Navalnyi's LiveJournal and the Memory Discourse of the Protest Movement (2011-2012)' Digital Icons: Studies in Russian, Eurasian and Central European New Media, no. 12: $105-128$.

Stepnova, Svetlana. 2008. 'Patrioticheskii kinokomiks'. Ruskino.ru, 4 May. Accessed 15 January 2018, https://ruskino.ru/item/2008/5/4/patrioticheskij-kinokomiks.

Stolypin. Petr. 1991. Petr Arkad'evich Stolypin. Nam nuzhna Velikaia Rossiia. Moscow: Molodaia Gvardiia.

Strukov, Vlad. 2009. 'Possessive and Superlative: On the Simulation of Democracy and Nationhood in Russia'. Russian Cyberspace 1, no. 1: 31-39. 


\section{2}

References

Suslov, M. 2013. 'Proshloe v budushchee v istoricheskom voobrazhenii sovremennoi russkoi pravoslavnoi tserkvi'. In Proshlyi vek, edited by Aleksei Miller, 133-157. Moscow: Inion Ran.

Suslov, M. 2014. 'Holy Rus': The Geopolitical Imagination in the Contemporary Russian Orthodox Church'. Russian Politics and Law 52, no. 3: 67-86.

Suslov, M. 2015. 'The Medium for Demonic Energies: "Digital Anxiety" in the Russian Orthodox Church'. Digital Icons: Studies in Russian, Eurasian and Central European New Media, no. 14: 1-25.

Suslov, M. 2018. "Russian World” Concept: Post-Soviet Geopolitical Ideology and the Logic of "Spheres of Influence". Geopolitics. Published online first.

TASS. 2015. 'Eksperty instituta Likhacheva raskritikovali radikal'nykh rezhisserov za spektakli po Pushkinu'. 31 March. Accessed 1 April 2015, http://tass.ru/kultura/ 1869677.

Taylor, Richard. 1998. Film Propaganda. Soviet Russia and Nazi Germany. London and New York: I.B. Tauris.

Taylor, Richard, and Derek Spring (eds). 1993. Stalinism and Soviet Cinema. London and New York: Routledge.

Tolstaya, Katya. 2014. 'Orthodox Paradoxes: Introduction'. In Orthodox Paradoxes: Heterogeneities and Complexities in Contemporary Russian Orthodoxy, edited by Katya Tolstaya, 1-20. Leiden: Brill.

Tolz, Vera. 2001. Russia: Inventing the Nation. London: Hodder Education.

Torbakov, Igor. 2011. 'History, Memory and National Identity: Understanding the Politics of History and Memory Wars in Post-Soviet Lands'. Demokratizatsiya 19, no. 3: 209-232.

Tsvetkova, Vera. 2010. 'Poedinok nachalsia. V novom sezone "iashchik" ozabotilsia nashim zdorov'em - fizicheskim i matrimonial'nym'. Nezavisimaia gazeta, 3 September.

Tsyrkun, Sergei. 2006. 'Stolypin bez "galstuka". "Stolypin ... Nevyuchennye uroki," rezhisser Iurii Kuzin'. Iskusstvo kino, no. 8. Accessed 3 January 2013, http://kinoart. ru/archive/2006/08/n8-article18.

Tsyrkun, Sergei. 2009. 'Ochen' priiatno, tsar' ... Ivan Groznyi, rezhisser Andrei Eshpai'. Iskusstvo kino, no. 5. Accessed 21 June 2016, http://kinoart.ru/archive/2009/ 05/n5-article9.

Ulybin, Viacheslav. 2006. 'Otkrytoe Pis'mo Prezidentu RF V.V. Putinu'. Russkaia narodnaia liniia, 1 August. Accessed 17 August 2015, http://ruskline.ru/analitika/ 2006/08/01/otkrytoe_pis_mo_prezidentu_rf_v_v_putinu/.

Ul'ianovsk Public Chamber. 2017. 'Startoval opros obshchestvennogo mneniia po voprosu vybora mesta ustanovki biusta P.A. Stolypina v Ul'ianovske'. 20 February. Accessed 23 January 2018, https://opuo.ru/blog/2017/02/20/startoval-opros-obshhestven nogo-mneniya-po-voprosu-vybora-mesta-ustanovki-byusta-p-a-stolypina-v-ulyanovske/.

Uskov, Nikolai. 2009. 'Tvoe moe otechestvo'. Nezavisimaia gazeta, 14 December. Accessed 9 March 2016, http://www.ng.ru/people_regulations/2009-12-04/9_uskov. html.

Varshavchik, Sergei. 2005. 'Minin i Pozharskii kak Marks i Engel's'. Nezavisimaia gazeta, 11 November.

Vázquez Liñán, Miguel. 2010. 'History as a Propaganda Tool in Putin's Russia'. Communist and Post-Communist Studies 43: 167-178.

Vinogradov, M., N. Konygina, P. Kiseleva and E. Rotkevich. 2005. 'Natsionalisty privatizirovali prazdnik'. Izvestiia, 6 November. 
Vinokurov, Oleg. 2007. 'Dramaturg Elena Gremina o Dne narodnogo edinstva: "Seichas takoi moment, chto my dolzhny sochinit' novye mify ili pereotsenit starye". Radio Svoboda, 2 November. Accessed 15 February 2016, www.svoboda.org/content/ transcript/419418.html.

Volchkova, Marina. 2010. 'Premiia bez skandal'chika. V Kremle vruchili "Personu goda". Nezavisimaia gazeta, 5 March.

Volkov, Denis, and Stepan Goncharov. 2017. 'Rossiiskii media-landshaft: osnovnye tendentsii ispol'zovaniia SMI - 2017'. Levada Centre, 22 August. Accessed 29 January 2018, www.levada.ru/2017/08/22/16440/.

Voronin, S. A., B. G. Iakemenko, P. A. Sadovnikov, A. Bkhandari and Iu. M. Sechina. 2014 [2045]. Istoriia Rossii 2014-2045: Uchebnik dlia srednoi shkoly. Moscow: Kryg'.

Vremena i Epokhi. N.d. 'Strategicheskaia nastol'naia igra "Vremena i epokhi: Smuta". Accessed 1 March 2016, http://historyfest.ru/news/120627-show.html.

Wood, Elizabeth A. 2011. 'Performing Memory: Vladimir Putin and the Celebration of World War II in Russia'. The Soviet and Post-Soviet Review 38: 172-200.

Youngblood, Denise J. 2007. Russian War Films. On the Cinema Front, 1914-2005. Lawrence: University Press of Kansas.

Yurchak, Alexei. 2006. Everything Was Forever, Until It Was No More: The Last Soviet Generation. Princeton: Princeton University Press.

Zhelenin, Aleksandr. 1998. 'Molodye agrarii ob'edinilis'. Nezavisimaia gazeta, 26 February.

Ziborova, Ol'ga. 2013. 'Trend istoricheskogo sezona: prigovor proshlomy - opravdatel'nyi'. In Khroniki kinoprotsessa, edited by S. M. Ishevskaia, 72-124. Moscow: VGIK.

Zorin, Andrei. 2001. Kormia dvuglavogo orla...Literatura i gosudarstvennaia ideologiia $v$ Rossii v poslednei treti XVIII - pervoi treti XIX veka. Moscow: Novoe literaturnoe obozrenie.

Zuev, Denis. 2013. 'The Russian March: Investigating the Symbolic Dimension of Political Performance in Modern Russia'. Europe-Asia Studies 65, no. 1: 102-126.

Zvereva, Vera. 2004. 'Istoriia na TV: konstruirovanie proshlogo'. Otechestvennye zapiski 20, no. 5. Accessed 17 November 2015, www.strana-oz.ru/2004/5/istoriya-na -tv-konstruirovanie-proshlogo.

'16\% rossiian otprazdnuiut Den' narodnogo edinstva'. 2012. Levada Centre, 31 October. Accessed 5 February 2016, www.levada.ru/old/31-10-2012/16-rossiyan-otpra zdnuyut-den-narodnogo-edinstva-4-oktyabrya.

'Aleksandr. Nevskaia bitva'. N.d. Kinopoisk.ru. Accessed 6 September 2015, www. kinopoisk.ru/film/395684/.

'Anti imia Rossii'. N.d. Accessed 1 October 2015, www.antinameofrussia.ru/.

'Chuev: Siuzhety "Gorodka" o "Ledovom poboishche" nado dat' pravovuiu otsenky'. 2006. Rosbalt.ru, 30 March. Accessed 17 August 2015, http://m.rosbalt.ru/main/ 2006/03/30/248863.html.

'Evgeniiu Primakovu vruchena premiia Aleksandra Nevskogo'. 2009. Vesti.ru, 28 January. Accessed 24 August 2015, http://www.vesti.ru/doc.html?id=246895.

'Evraziiskaia oprichnina vosstanovit v Rossii sakral'nuiu vlast'. 2005. Evraziia, 27 February. Accessed 20 April 2016, www.evrazia.org/modules.php?name=News\& file $=$ article $\&$ sid $=2255$.

'Imia Rossii'. N.d. Accessed 30 September 2015, http://nameofrussia.org/.

'Imia Rossiia. FLOOD ATTACK'. 2008. 10 July. Accessed 29 September 2015, www. nameofrussia.ru/doc.html?id=1982. 


\section{References}

'IMIA ROSSIIA. "TOP 22 NEGODIAIA", 2008. 17 July. Accessed 29 September 2015, www.nameofrussia.ru/doc.html?id=2106.

'Istoriia Kinosoiuza'. N.d. Kinosoiuz. Accessed 24 May 2016, http://kinosoyuz.com/ about/history/.

'Istoriia premii'. N.d. Natsional'naia Premiia imeni Petra Stolypina. Accessed 26 February 2013, www.stolypin-premium.ru/.

'Kiev ne khochet prinimat' ot RF v dar pamiatnik Stolypinu'. 2012. RIA Novosti, 30 January. Accessed 7 March 2013, http://ria.ru/world/20120130/552585221.html\# ixzz2MrMJCL58.

'Kto dolzhen stoiat' na Lublianke?' 2011. Gazeta.ru, 25 May. Accessed 28 May 2015, www.gazeta.ru/infographics/politics/pamyatnik_dzerzhinskomu.shtml.

'Luchshie lozungi narodnogo protesta na Manezhke: "Churov, prokati menia na karuseli!", “1612, 1812, 2012!", galereia karikatur na Putina-Medvedeva "Lysyi-volosatyi"'. 2011. KPRF, 19 December. Accessed 19 March 2013, http://kprf.ru/actions/ 100521.html.

'Manifest'. N.d. Antimaidan. Accessed 31 May 2016, https://antimaidan.ru/page/9.

'Mikhalkov "zamakhnulsia" na gubernatora'. 2012. TVSAR.ru, 20 March. Accessed 3 December 2015, www.tvsar.ru/news/mihalkov-zamahnylsya-na-gybernatora.

"Moskvichi progolosovali protiv pereimenovaniia "Voikovskoi"'. 2015. Lenta.ru, 23 November. Accessed 26 February 2016, https://lenta.ru/news/2015/11/23/voykovskaya/.

'Nachalis' s'emki fil'ma o molodykh godakh Aleksandra Nevskogo'. 2007. Film.ru, 1 August. Accessed 21 June 2016, www.film.ru/news/nachalis-semki-filma-o-molodyhgodah-aleksandra-nevskogo

"Natal'ia Nikonova s "Pervogo kanala" stala general'nym prodiuserom "Piatogo". 2009. Gazeta.SPb, 12 October. Accessed 9 December 2015, www.gazeta.spb.ru/ 206333-0/.

"Na vystavke "Moia istoriia. Riurikovichi" prodolzhaetsia programma pokazov rossiiskogo kino'. 2014. Pravoslavie.ru, 19 November. Accessed 9 July 2015, www.pra voslavie.ru/75248.html.

'Novaia oprichnina Putina'. 2007. RBK Daily, 16 October. Accessed via Integrum World Wide database.

'O khrame'. N.d. Khram sviatogo blagovernogo kniazia Aleksandra Nevskogo pri MGIMO. Accessed 8 July 2015, www.hramnevskogo.ru/o-khrame.

'Otets Ioann Okhlobystin khochet ostavit' sluzhenie sviashchennika'. 2009. Interfaks religiia, 26 November. Accessed 8 March 2016, www.interfax-religion.ru/?act= news\&div $=33081$.

'Otets Vsevolod Chaplin: Rossii nuzhna Antidiffamatsionnaia liga'. 2006. Rosbalt, 30 March. Accessed 18 August 2015, http://m.rosbalt.ru/main/2006/03/30/248878.html.

'Otkrytie pamiatnika Aleksandru I'. 2014. Kremlin.ru, 20 November. Accessed 13 March 2016, www.kremlin.ru/events/president/news/47044.

'Pamiatnik Sviatomy Blagovernomu Velikomu kniaziu Aleksandru Nevskomu'. N.d. Sviato-Troitskaia Aleksandro-Nevskaia Lavra. Accessed 13 July 2015, http://lavra. spb.ru/about/aleksandr-nevskij/963-pamjatnik-svjatomu-blagovernomu-velikom u-knjazju-aleksandru-nevskomu.html.

"Patriarkh Kirill: "Aleksandr Nevskii - primer dlia budushchikh diplomatov"”. 2010. MGIMO, 23 March. Accessed 24 August 2015, www.mgimo.ru/news/university/ document147562.phtml.

'Patriarkh Kirill nagradil Ziuganova Tserkovnym ordenom'. 2014. Interfaks, 12 September. Accessed 26 August 2015, http://www.interfax.ru/russia/396440. 
'Patriarkh Kirill otkryl mul'timediinuiu vystavku "Moia istoriia. Riurikovichi” v Manezhe'. 2014. Pervyi kanal, 4 November. Accessed 5 May 2015, www.1tv.ru/ news/culture/271119.

"Piatyi kanal" vozglavil top-menedzher "Pervogo". 2010. Delovoi Peterburg, 29 December. Accessed 9 December 2015, www.dp.ru/a/2010/12/29/Pjatij_kanal_vozgla vil_t/.

“"Postizhenie Rossii, ili Otkrytyi urok grazhdanstvennosti'. Interv'iu mitropolita Smolenskogo i Kaliningradskogo Kirilla zhurnalu "Foma". 2008. Patriarchia.ru, 29 December. Accessed 2 April 2015, www.patriarchia.ru/db/text/517260.html.

'Proekt "Moia istoriia"'. N.d. Accessed 20 August 2015, www.expohistory.ru/?page= content\&id $=84$.

'Programma "Aleksandr Nevskii'". 2014. Tsentr natsional'noi slavy, 16 June. Accessed 24 August 2015, www.cnsr.ru/o-fonde/proekty/programma-aleksandr-nevskiy/.

'Putin dolzhen uiti'. 2010. 3 March. Accessed 28 April 2016, www.putinavotstavku. org/.

'Putin: Istoriia Rossii svidetel'stvuet - tol'ko soobshcha, ob'edniniaia usiliia, my mozhem dostoina otvechat' na vyzovy vremeni'. 2005. ITAR-TASS, 4 November. Accessed via Integrum World Wide database.

'Putin otvetil na kritiku Stolypinu i ego reform'. 2011. RIA Novosti, 15 November. Accessed 3 January 2013, http://ria.ru/society/20111115/489623390.html\#ixzz2GvLo3Jn3.

'Putin predlozhil chlenam kabmina vnesti den'gi na pamiatnik Stolypinu'. 2011. RIA Novosti, 13 July. Accessed 31 May 2015, http://ria.ru/politics/20110713/401083427. html.

'Putin vozglavil komitet po podgatovke prazdnovaniia iubileia Stolypina'. 2011. RIA Novosti, 18 October. Accessed 26 February 2013, http://ria.ru/society/20101018/ 286866406.html.

'Putin zagovoril iazykom Stolypina'. 2011. RIA Novosti, 7 October. Accessed 3 January 2013, http://ria.ru/society/20111115/489623390.html.

'Rasistskii intsident na khokkeinom matche v Magnitogorske'. 2007. SOVA, 11 April. Accessed 11 April 2016, www.sova-center.ru/racism-xenophobia/news/racism-na tionalism/2007/04/d10605/.

'Rezhisser Nikita Mikhalkov otvechaet na voprosy zritelei proekta "Imia Rossiia". 2008. Accessed 13 September 2012, www.nameofrussia.ru/interview.html?id=140.

'Rossiiane nazvali predstavitelei elity strany'. 2012. Levada Centre, 23 January. Accessed 17 November 2015, www.levada.ru/old/23-01-2012/rossiyane-nazvalipredstavitelei-elity-strany.

'Rossiiskie diplomaty budut udostaivat'sia znaka sv. kniazia Aleksandra Nevskogo'. 2007. MGIMO, 5 December. Accessed 14 December 2015, www.mgimo.ru/news/ press/document31728.phtml.

'Russia Will Revive Crimean Film Industry'. 2014. Moscow Times, 6 April.

'Sostoialsia Popechitel'skii sovet programmy "Aleksandr Nevskii"'. 2007. MGIMO, 5 December. Accessed 14 December 2015, www.mgimo.ru/news/press/docum ent31728.phtml.

'Stenogramma vstrechi predsedatel'ia Pravitel'stva RF V.V. Putina so Sviateishim Patriarkhom Kirillom i liderami traditsionnykh religioznykh obshchin Rossii'. 2012. Patriarchia.ru, 8 February. Accessed 31 May 2013, www.patriarchia.ru/db/text/ 2005767.html.

'Stenogrammy suda vremeni. 24. Sud nad Sudom vremeni'. N.d. kurginyan.ru. Accessed 17 August 2015, www.kurginyan.ru/publ.shtml?cmd=add\&cat=3\&id=134\#top. 
"Telereitingi kanaly sorevnuiutsia v oblasti tsvetogo "tiuninga". 2009a. NEWSru.com, 21 May. Accessed via Integrum World Wide database.

'Telereitingi: Aleksandr Lykov vernulsia na ekran v novoi roli sledovatelia'. 2009b. NEWSru.com, 4 June. Accessed via Integrum World Wide database.

'Tsereteli podaril Ul'ianovsku pamiatnik Stolypinu, ot kotorogo otkazalis' v Kieve'. 2012. Argumenty i Fakty, 28 August. Accessed 24 February 2013, www.aif.ru/cul ture/news/193160.

'Tsereteli poobeshchal produblirovat' Stolypina'. 2012. 27 September. Accessed 24 February 2013, http://uliyanovsk.bezformata.ru/listnews/tcereteli-poobeshal-produ blirovat/6816296/.

'TOP-100 reiting saita "Imena Rossii” za 2009 god'. N.d. Imena Rossii. Accessed 30 September 2015, www.nameofrussia.su/2009.html.

'Torzhestva po sluchaiu 200-letiia Borodinskogo strazheniia'. 2012. Kremlin.ru, 2 September. Accessed 1 April 2015, http://kremlin.ru/events/president/news/16346.

'Veruiushchie vorvalis' v "Gorodok"'. 2005. Gazeta.ru, 30 March. Accessed 17 August 2015, www.gazeta.ru/2006/03/30/oa_194130.shtml.

'V Krasnodare otkryli pamiatnik Stolypinu'. 2011. Rossiiskaia gazeta, 6 September. Accessed 27 February 2013, www.rg.ru/2011/09/06/reg-kuban/stolypin.html.

'Vladimir Medinskii: “Leviafan” zapredel'no kon'iunkturen'. 2015. Izvestiia, 15 January. Accessed 26 May 2016, http://izvestia.ru/news/581814\#ixzz3XUBR3xkd.

'Vladimir Mirzoev: "Borisa Godunova" nikto ne zapreshchal'. 2011. Dozhd', 9 November. Accessed 13 February 2015, http://tvrain.ru/articles/vladimir_mirzoev_ borisa_godunova_nikto_ne_zapreshchal-72729/.

'Vladimir Putin: Do 2020 goda v sostav flota voidut vosem' podvodnykh kreiserov i vosem' mnogotselevykh atomnykh podlodok'. 2013. RT, 23 December. Accessed 1 September 2015, http://russian.rt.com/article/20100.

'V Kremle vrucheny gosudarstvennye nagrady'. 2012. Kremlin.ru, 29 August. Accessed 27 May 2013, http://kremlin.ru/news/16316.

'V MGIMO proshlo otkrytie fotovystavki “Aleksandr Nevskii - imia Rossii”. 2011. MGIMO, 6 December. Accessed 24 August 2015, www.mgimo.ru/news/university/ document213781.phtml.

'V Moskve osviashchena chasovnia v chest' sv. blgv. Tsaria Ioanna Groznogo'. 2011. Russkaia narodnaia liniia, 20 December. Accessed 7 March 2016, http://ruskline.ru/a nalitika/2011/12/21/v_moskve_osvyawena_chasovnya_v_chest_sv_blgv_carya_ioa nna_groznogo/.

'V Moskve ustanoviat pamiatnik Stolypinu'. 2011. Lenta.ru, 16 March. Accessed 27 February 2013, http://lenta.ru/news/2011/03/16/stolypin/.

'V Moskve ustanovili pamiatnik Petru Stolypinu'. 2012. RBK, 27 December. Accessed 20 March 2018, http://top.rbc.ru/society/27/12/2012/838839.shtml.

'V preddverii Novoletiia i Rozhdestva Khristova Mestobliustitel' Patriarshego Prestola vstretilsia s radiozhurnalistami i predstaviteliami informatsionnykh agentstv'. 2008. Patriarchia.ru, 29 December. Accessed 2 April 2015, www.patriarchia.ru/db/text/ 517822.html.

'V Rossii otmechaiut Den' narodnogo edinstva'. 2011. Kremlin.ru, 4 November. Accessed 1 April 2015, http://news.kremlin.ru/news/13340/print.

'V Saratove otkryt pamiatnik P.A. Stolypinu'. 2002. Saratov Oblast Government, 14 April. Accessed 27 February 2013, www.saratov.gov.ru/news/events/detail.php?ID=9496.

'Vse kandidaty'. N.d. Pozor Rossii. Accessed 30 September 2015, www.badnameofrus sia.ru/all.php?order $=$ votes $\&$ direction $=$ desc $\&$ page $=1$. 
'V Tserkvi napominaiut o nekanonichnosti klirika, "osviativshego" v Moskve chasovniu Ivana Groznogo'. 2012. Interfaks religiia, 24 February. Accessed 7 March 2016, www.interfax-religion.ru/estonia/?act=news\&div $=44318$.

'V Ul'ianovskoi oblasti otkryli pamiatnik, izgotovlennyi Zurabom Tsereteli'. 2012. Ul'ianovskii portal, 26 September. Accessed 3 June 2015, www.ulyanovsk-portal.ru/ novosti/ulyanovsk/1058/.

'Vystavka "Riurikovichi”: ekspozitsiia, fotografii, otzyvy'. 2014. Pravoslavie.ru, 4 November. Accessed 5 May 2015, http://www.pravoslavie.ru/74861.html.

'Vystavochnyi proekt "Aleksandr Nevskii - Imia Rossii" startoval v Sankt-Peterburge'. 2009. Patriarchia.ru, 19 February. Accessed 20 August 2015, www.patriarchia.ru/db/ text/562853.html.

'Zurab Tsereteli otkryvaet v Ul'ianovske vystavku i pamiatnik Petru Stolypinu'. 2012. 26 September. Accessed 24 February 2013, www.artrussia.ru/russian/artnews.php? $\mathrm{id}=1769$.

\section{User comments}

0987655. 'O Stolypine P.A., Mikhalkove N.S. i ne tol'ko'. 2008. LiveJournal, 26 December. Accessed 23 November 2015, http://nameofrussia-ru.livejournal.com/ 41348.html\#comments.

akini. 'A vot eto vse v odnom ...'. 2009. Imkhonet, 16 November. Accessed 3 September 2015, http://serials.imhonet.ru/element/1081195/opinions/.

Andrei. 'Opiat' nas schitaiut za bydlo'. 2013. Megacritic.ru, 27 April. Accessed 2 September 2015, www.megacritic.ru/film/152.html.

Diadia Patrik. 'Otlichnye [sic] serial'. 2010. Imkhonet, 12 March. Accessed 3 September 2015, http://serials.imhonet.ru/element/1081195/opinions/.

Frigirifico. 'Posmotrel poka tri serii'. 2009. Imkhonet, 14 July. Accessed 21 June 2016, http://serials.imhonet.ru/element/1081195/based/.

Gost'_Vladimir Panteleev. 'Kinoshniki sdelali gnysnyi paskvil' na russkuiu istoriiu'. 2009. Ruskino.ru, 16 June. Accessed 3 September 2015, http://ruskino.ru/mov/ forum/10849/2.

Mario Puso. 'Khoroshee kino'. 2008. Imkhonet, 8 June. Accessed 2 September 2015, http://films.imhonet.ru/element/257540/opinions/?page $=3$.

meus. 'Durak ty baten'ka i tochka'. 2008. Imkhonet, 4 November. Accessed 2 September 2015, http://films.imhonet.ru/element/257540/opinions/?page $=3$.

mig-24. 'Neplokho'. 2008. Imkhonet, 30 December. Accessed 2 September 2015, http:// films.inhonet.ru/element/257540/opinions/?page $=3$.

Panteleev, Vladimir. 'Kinoshniki sdelali gnusnyi paskvil' na russkuiu istoriiu'. 2009. Kino-teatr.ru, 1 June. Accessed 8 April 2016, www.kino-teatr.ru/kino/movie/ros/ser/ 14097/forum/f5/.

ratnik07. 'Stolypin'. 2008. LiveJournal, 26 December. Accessed 23 November 2015, http://nameofrussia-ru.livejournal.com/41348.html\#comments.

Taiso4ka. 'Potriasaiushchii fil'm!' 2010. Imkhonet, 11 January. Accessed 2 September 2015, http://films.imhonet.ru/element/25754.

tourmate. 'Unylaia ura-patrioticheskaia agitka'. 2008. Imkhonet, 7 July. Accessed 2 September 2015, http://films.inhonet.ru/element/257540/opinions/?page=3.

tsenitel' istorii. 'Nesuraznostei i domyslov v filme, konechno, khvataet'. 2011. Megacritic.ru, 20 April. Accessed 2 September 2015, www.megacritic.ru/film/152.html. 


\section{References}

vitalyklichko. 'Nastoiashchii fil'm'. 2009. Imkhonet, 22 May. Accessed 3 September 2015, http://serials.imhonet.ru/element/1081195/opinions.

zlo. 'Dlia podniatiia natsional'nogo samosoznaniia nuzhny takie fil'my'. 2008. Imkhonet, 26 May. Accessed 2 September 2015, http://films.imhonet/element/ 257540/opinions/?page $=4$. 


\section{Index}

Headings in italics indicate a Russian language term, a film/book title or an event. Page numbers in bold refer to tables and those containing $\mathrm{n}$ refer to notes.

1612 (play, 2007) 135

1612: Chronicles of the Time of Troubles (2007) 101, 148-53

Ad Spectatores 135

agricultural reforms 45-6, 48, 53, 56, 66-70

Akunin, Boris 17n11, 143

Aleksandr I 126, 138, 217-18

Aleksandr II 8, 68, 108, 167

Aleksandr III 82n11, 167

Aleksandr Nevskii - The Name of Russia (exhibition) 95, 99

Aleksandr Nevskii (1938) 32, 88, 100-1, 105,107 ; Ice, Battle on the (1242) 102, 113,128

Aleksandr Nevskii Monastery 85, 87,113

Aleksandr Nevskii programme 97, 98

Aleksandr Nevskii (submarine) 99

Aleksandr: The Neva Battle (2008) 32, 88, 100-7, 119, 150, 189

Aleksei, Tsarevich 156

Aleksii II, Patriarch 92, 95, 99, 116; film industry $112,121 \mathrm{n} 18,193-4$

All-Russia State Television and Radio Broadcasting Company (VGTRK) 12-13, 108

Anatomy of a Protest (2012) 74

Anemone, Antony 94

Anti-Maidan Movement 219, 220

anti-Semitism 59, 180-1, 183

Antokol'skii, Mark 164, 166-7

Archangel'skii, Andrei 152

archives 20-1, 125; visual images 148, 156-7 audiences $33,36-7,140$; feedback 116-17, 190-2; scepticism 26, 31, 105-6; voting 199, 202, 204, 209-12, 214

authoritarianism 46, 54-5, 64, 195, 199, 201

Aver'ianov, Aleksei 183

Aver'ianov, Vitalii 175-7

awards 37n7, 45, 93-4, 136-7; Order of Aleksandr Nevskii 86-7, 97-8, 99

Azef, Evno 53, 58-9, 60, 82n7

Babitsky, Andrei 224

Baltic states 94, 104, 130, 189

Berezovskii, Boris 158, 189

Beriia, Lavrentii 175, 192

Bichevskaia, Zhanna 181-2

Bogomolov, Konstantin 158

Bogrov, Dmitrii 41, 53, 59, 63, 73

Boiko-Velikii (Vasilii Boiko) 182-3, 197, 199

Bolsheviks 59, 63-4

Boris Godunov (Bondarchuk, 1986) 129, 146, 157

Boris Godunov (Mirzoev, 2011) 13, 29, 153-9, 223

Boris Godunov (Musorgskii, 1868-73) 126-7, 129, 154

Boris Godunov (Pushkin, 1831) 126, 129 , 155-9

Borodino, Battles of $(1812,1941)$ 137-8

boyars: and Nevskii 103-5; Time of Troubles 124, 141, 145, 149, 165-6, 187-9, 195

Brezhnev era 15

Brodskii, Aleksei 212 
Burtsev, Vladimir 60

Bykov, Dmitrii 212

Byzantium 56, 95, 186

canon $20-1$

canonisation 92-3; Ivan the Terrible 169, 171, 179-80, 182-3; Patriarch

Germogen 217; Stalin 180

Catherine the Great 14, 108, 110

Catholicism see Roman Catholic Church

centralisation 57, 130

Centre of National Glory 98

Channel Five 199, 207-8, 210, 212-14; The Trial of Time (2010) 207, 212-14

Channel One 12, 112, 139, 140, 157, 220; The Name is Russia (2008) 119

Chaplin, Vsevolod 96

Cherkasov, Nikolai 190

Chernomyrdin, Viktor 68-9, 108, 111

Child 44 (2015) 221

Chuev, Aleksandr 96

church construction 92, 95-6, 98, 219; see also Russian Orthodox Church

cinema see film industry; films

City of Military Honour award 137, 139

civil rights 44, 66, 205

civil society 44, 130, 137, 211

civil war 63-4, 142

colour revolutions $130,173,176-7$, 219, 226

Combat Organisation, Socialist Revolutionary Party (CO) 52, 57-8, 60-1, 62-3

commemorations 5, 6, 8, 19-21, 220-1; Nevskii 85-6; see also Day of National Unity; memorials

Commission against the Falsification of History 196

communicative memory 19-20

Communist Party 6, 172

conformity $21-3$

conservatism $55,175,183,200$; enlightened conservatism 71,72 , 79,81

continuity of history $1-2,4,153$, 160,220

corruption 77, 103-5, 171, 176-7, 178

Crimea 221; annexation 90, 183, 217-18, 219

cultural memories 7, 19-21, 24, 147-8; creation 81, 116; dynamics 13, 20, 22-3, 29-33; Russian Orthodox Church 91-6; subversive potential
153-4; Time of Troubles 124-9;

see also memories

cyberattacks 104

cyclical patterns in history $34-5,123-4$, 141, 159, 198-9

Danilov, Aleksandr 7

Day of National Unity 1, 129-36, 160-1; TV programming $140,148-9,152$

Day of the Oprichnik (2006) 169-70, 192, 195

The Death of Stalin (2017) 221

Death of the Empire (2005) 153

decollectivisation 45-6

Defender of the Fatherland Day 152

Deliagin, Mikhail 206n7

democratisation 47, 57, 64, 145, 210

The Descendants (2015) 225

diplomacy $85,97,114$

directors 148

Dmitrii, Prince 124-5, 141

Dmitrii, Tsarevich 156

documentaries 5, 10, 24, 72-9, $140-8,152$

Dondurei, Daniil 210

Donskoi, Dmitrii 225

Dostal', Vladimir 184, 192

Dostoevskii, Fedor 108

Dozhd' (TV channel) 155, 162, 221

Dugin, Aleksandr 172-7, 183, 192

Duma 41, 55, 64, 76, 82n6

Dymarskii, Vitalii 210

East and West relationships 84, 97, 114, 166, 174, 189-90; see also The West

Edgerton, Gary 23-4, 26, 28

editors 148

Eisenstein, Sergei: Aleksandr Nevskii (1938) 32-3, 88, 100-1, 102, 105, 107, 113; Ivan the Terrible (1945) 143, 167-8, 188, 190, 194

Ekho Moskvy radio 210, 215

Empire: The Time of Troubles (game) 133-4

Empire Under Fire (2000) 52

The End of the Time of Troubles (2005) 142-4

enlightened conservatism 71, 72, 79, 81

Erll, Astrid 30-1

Ernst, Konstantin 213, 220

Erofeev, Viktor 111

Eshpai, Andrei 184-5, 190

The Essence of Time (2012) 200

ethnic groups $60,64,90-1$ 
Etkind, Alexander 156

Eurasian Youth Union 131, 174

European Union, enlargement (2004) 130

The Fall of an Empire: The Lesson of Byzantium (2008) 95

False Dmitriis 124-5, 141

falsification: of history 7, 168-9, 176, 196-7; of votes (The Name is Russia) 109, 115-16

fantasy genre 149, 151

Federal Agency for Culture and Cinema (Roskul'tura) 101

Federal Agency for Culture and Cinematography 149

Federal Fund for Social and Economic Support to National Cinematography (Fond Kino) 12, 218

Federal Security Services (FSB) 93, 172

Fedorov, Ivan 188

Fedortsov, Andrei 153

Feofan, Hieromonk 142

Filipp, Metropolitan 180, 188, 193-5

Filippov, Aleksandr 7

film industry 10-11, 13; funding 11-13, $17 \mathrm{n} 14,94,101,149,218$

films $3,23,221$; foreign films $17 \mathrm{n} 12,221$; representations of the past $5,27-9,88$; see also names of individual films

Finland $60-1$

First World War 63, 69

Fokina, Marina 216n3

Fomenko, Anatolii 168

Fond Kino (Federal Fund for Social and Economic Support to National

Cinematography) 12, 218

The Fortress: With Shield and Sword (2015) 218

Fradkov, Mikhail 45

Free Society of Lovers of Literature, Science and the Arts 126

freedom of the press 3, 220-1

Freemasons 61, 62-3, 65

Froianov, Igor' 51

FSB (Federal Security Services) 93, 172

Fund for the Study of P.A. Stolypin's Legacy $45,49,67,80$

fundamentalists $14,88-9$

funding: film industry 11-13, 17n14, 94, 101, 149, 218; Stolypin year 49

Fursov, Andrei 175-7

Gaidai, Leonid 168

games $88,133-4$ genealogy of cultural memories 31,34 , 36

Georgia 7, 52, 115

Gerasimov, Aleksandr 62

German, Aleksei 13

Germany 61, 107, 189; Nazis 35, 94, $128,167-8$

Germogen, Patriarch 143, 217-18

ghostware 156

Gill, Graeme 14-15

Glaz'ev, Sergei 220

Glazunov, Il'ia 69, 108, 111, 143-4, 201

Glinskaia, Elena 165

Godunov, Boris 124-5, 145, 161; Boris Godunov (Bondarchuk, 1986) 129, 146, 157; Boris Godunov (Mirzoev, 2011) 13, 29, 153-9, 223; Boris

Godunov (Musorgskii, 1868-73) 126-7, 129, 154; Boris Godunov (Pushkin, 1831) 126, 129, 155-9

Godunov, Kseniia 149-50

Golden Horde 56, 85, 113, 114, 174

Gorbachev, Mikhail 109

Gordon, Aleksandr 157

Gorodok (TV show) 96

goszakaz 11, 102, 149, 152

government: funding of films/TV 11-13, $17 \mathrm{n} 14,94,101,149,218$; primacy of state 153, 160; repression 172, 174-5, 200; and Russian Orthodox Church 14, 89, 91, 119, 194-5; television programming 26-7, 207; see also memory politics

Great Patriotic War see World War II

Gremina, Elena 135, 136

Gudkov, Lev 134

Gulag 146-7, 156

Gumilev, Lev $12 \ln 26$

hackers 109, 116

Hammer and Sickle (1926) 127

Historical Chronicles with Nikolai Svanidze (2003-13) 10

The Historical Trial (2011-12) 10, 214 historiography 112, 133; Soviet Union $36,42,79,127-9,164-5$

history: continuity $1-2,4,153,160$, 220; cyclical patterns 9, 34-5, 123-4, 141, 159, 198-9; falsification 7, 168-9, 176, 196-7; interpretation 5, 7-8, 22, 35, 220-1, 223; representations 3, 25-9, 37n6; see also memory chains

History of Russia: 1945-2006 (2007) 7 


\section{Index}

The History of Russia 2014-2045 (2014) 159-60

history politics see memory politics

Humphrey, Caroline 45-6

Hutchings, Stephen 25-7, 37n3, $131-2,224$

hypermediacy $30-1$

Iakunin, Vladimir 98

Iankovskii, Oleg 193

Iaroslav the Wise 107

Ice, Battle on the (1242) 85, 87, 88, 102, 113,128

Ilarion, Metropolitan 183

immediacy 30-1

Immortal Regiment parade 220

imperial traditions $6,51,87,100,153$

individual's rights $44,47,62,81$

Institute of Dynamic Conservatism 175

institutionalisation: Stolypin 41-51, 222;

Time of Troubles 123, 129-36

intelligentsia 76, 77, 210

internet 10, 105-6, 155, 200, 225-6;

feedback from 116-17, 190-2

interpretation of history $5,7-8,22,35$, $220-1,223$

Ivan Susanin (1939) 127, 128

Ivan the Terrible (1945) 143, 167-8, 188, 190, 194

Ivan the Terrible (2009) 184-92

Ivan the Terrible and His Son Ivan, 16 November 1581 (1885) 166-7, 182, 204

Ivan the Terrible (Ivan IV) 84, 108, 164-7, 176; canonisation 169,171 , 179-80, 182-3; character 181-2, 185, 190, 193, 195, 201-2, 204; The Name is Russia (2008) 110-12; oprichnina 14, 165; Russian Orthodox Church 179-83; Stalin 158, 164, 167-8, 175-6, 185, 201, 204-5; statues 166-7, 181, 205n1, 218; Time of Troubles 124, 146-7; The Trial of Time (2010) 199-205, 207-16; Tsar (2009) 192-9

Ivan Vasil'evich Changes Profession (1973) 168-9

Ivanov, Aleksei 197

Ivanov, Sergei 2, 47, 193

Izborsk Club 175

Jews 53, 59-60

journalism 9, 27

Kalashnikov, Maksim (Kucherenko) 175-8
Kalenov, Igor' 100-2, 104

Kapitsa, Sergei 69, 70, 108, 110, $111-12$

Karamzin, Nikolai 126, 166, 176, 186, 191

Karelin, Aleksei 101

Kashin, Oleg 172

Kavelin, Konstantin 166

Khamynia, Vladimir 208

Khlebnikov, Boris 13

Khordorkovskii, Mikhail 170, 189, 214-15

Khotinenko, Vladimir 94, 149, 151, 153,225

Khrushchev era 145

Kiev 42, 50

Kinosoiuz 13

Kirill, Patriarch (previously Metropolitan) 1, 4, 90, 92-3, 98, 217; memory chains 138-9, 143; $M y$ History: Riurikids exhibition (2014) 84; The Name is Russia (2008) 68, 95, 108, 112-16, 118; Putin 139

Kiselev, Dmitrii 216n5

Kislov, Petr 149

Klishin, Oleg 53-4, 76

Kozitsyn, Andrei 98

Kremlin 141; ceremonies 130, 136, 140; memorials 138; see also government

Kublanovskii, Iurii 69, 108

Kucherenko, Vladimir (Kalashnikov) 175-8

Kudrin, Aleksei 47, 220

Kulikovo Field, Battle of (1380) 183,225

Kul'tura channel 10, 12, 100, 148

Kurbankhanov, Tolibzhon 122

Kurbskii, Prince Andrei 158, 165, 188-9, 197

Kurginian, Sergei 178, 183; The Trial of Time (2010) 199-204, 207-8, 212, 214-16

Kurlov, Pavel 61, 63

Kuzin, Iurii 53-4, 59-60, 184

Larina, Kseniia 215

Lavrov, Sergei 84-5, 97, 99

Lazar, Berl 116

Lebedeva, Irina 182

legitimacy (political) 2, 93, 123-4, 160,226

Lenin, Vladimir 33, 69, 108, 141, 154; popularity 110,116

Leont'ev, Mikhail 144, 146-7, 178-9 
Levada Centre: holidays 134; Ivan the Terrible 170-1; Stolypin 43, 70; television viewing 9-11, 25, 216n6

Leviathan (2014) 17n14

\section{A Life for the Tsar (Glinka, 1836) 127, 129}

Likhachev Research Institute of Cultural and Natural Heritage 158

literature 3,17n11, 169-70, 178

Liubimov, Aleksandr 66, 67, 69, 108, 113

Liubimov, Iurii 129

Lukashenko, Aleksandr 117

Lungin, Pavel 176, 182, 192-8, 202

Luzhkov, Iurii 50

Makarii, Metropolitan 186, 187

Maliuta (Skuratov) 169, 187, 192, 194-5, 218

Mamonov, Petr 193, 197

Maniagin, Viacheslav 196-7

Mariia Fedorovna (Empress) 53, 63

Matvienko, Valentina 108

media 211-12, 222; combination of 22-3, 29

mediation 30-1, 161; see also remediation

Medinskii, Vladimir 221

Medvedev, Dmitrii 7, 70, 133, 139, 179, 196; Stolypin 41, 45, 46-7, 48, 80

Memorial human rights group 223

memorials 137, 138, 217-18; Ivan the Terrible 164; Nevskii 99; Romanov dynasty 1-2, 16n1, 20, 92-3, 217; Stolypin 50; see also commemorations; memory artefacts; statues

memories 19-20; layers 4, 32, 34, 38n7, 156; recirculation $20-1,23,29,32-5$, 88; triggers 150; see also cultural memories

memory artefacts 20, 30, 32-3; see also memorials; statues

memory chains $34-5,144-5,205,223$;

1612-1812-1942 linkage 34, 92, 128, 136-40, 144, 217; see also history

memory clusters $33-4,43,125$, $153-4,223$

memory politics $2,4,21-3,119,210$, 221-6; state involvement 6-9, 80, 99, 160-1, 178; television 23-9, 25, 81, 199-200; see also government

memory texts $22,32-3,123,125,144$; visual 146,156
Mendeleev, Dmitrii 108

Menshov, Vladimir 141, 142

messianism 174, 200

MGIMO (Moscow State Institute of International Relations) 95, 97, 99

Mikhailova, Ol'ga 159

Mikhalkov, Nikita 13, 17n17, 49-50, 80, 83n14, 222; 1612: Chronicles of the

Time of Troubles (2007) 149, 151; The Name is Russia (2008) 67-8, 70-2, 108, 111-12, 114, 116; Petr Stolypin: A Shot at Russia (2012) 72-9, 81

Mikhalkov, Sergei 7

Minin (1937) 127

Minin, Kuzma 124-6, 128, 149-50, 153; statues 126, 131, 141, 144, 217

Minin and Pozharskii (1939) 128, 143, 145,150

Mironov, Sergei 108, 115

Mirzoev, Vladimir 29, 154-9, 223

Mlechin, Leonid 199, 201, 203-4, 207-8, 212, 214

Mlynnik, Cheslav 117

Mnishek, Marina 141

modernisation 9, 171, 174-5, 178, 201-3

Moloch (1999) 154

Molodaia Gvardiia 42

Mongol (film) 101

Mongols 103, 107

The Monk (Inok) (comic) 88

Moscow 41, 125-6, 130, 155

Moscow State Institute of International Relations (MGIMO) 95, 97, 99

Movement Against Illegal Migration 131

Mstislavets, Petr 188

multinational state 133, 144, 150, 160

Muratov, Sergei 208

Musorgskii, Modest 126-7, 129, 154

My Good Hans (2015) 221

My History (exhibition series) 94, 133, 219; Riurikids (2014) 84, 94

mythmaking 194, 223; Godunov 159; Ivan the Terrible 166-7; Nevskii 88; post-Soviet Russia 130, 153; Putin 122-3, 186; Soviet Union 6, 110, 119; Stolypin 41, 43, 80; Time of Troubles $160-1,218$

Nadein, Vladimir 78

The Name is Russia (2008) 25, 107-11, 119, 208, 225; falsification of votes 109, 115-16; Ivan the Terrible 110-12, 171; Nevskii 65-6, 95, 112-18; Stolypin 43, 65-72, 76-80 


\section{Index}

The Names of Russia - The Historical Choice of ... 116-17

Napoleon 126, 136, 137-8

narratives 8-9, 152, 226; anti-fascist

128; critical 9, 153-4; integrated 2, 22 , $34-5,125$; periodic collapse $9,81,123$, $138,145,153,160$

Nashi 131, 163n17

National Guard 218

national identity $6-8,21-2,87,100,114$

National Media Group Television

(NMG) 208, 212, 213

nationalism 28-9; nationalist movements $14,135,161,171,172-8,183$; Stalinism $127-8$

Naval'nyi, Aleksei 78

Near Abroad 90, 97, 119

negative memory chains 138

negotiation of meaning 3-4, 96, 222

Nemtsov, Boris 78

Neva, Battle of the (1240) 85, 87, 114-15

Nevskii, Aleksandr 84-8, 118-20, 219; 800th anniversary (2021) 99, 219; Aleksandr Nevskii (1938) 32, 88, 100-2, 105, 107, 113, 128; Aleksandr: The Neva Battle (2008) 100-7; diplomacy 97-100, 114, 189-90; as military hero 86, 100, 115, 119; The Name is Russia (2008) 65-6, 95, 112-18; portrayal 102-5, 114-15; The Priest (2009) 94; sanctity 85, 87, 95, 103, 113, 115; statues 87-8; video games 88

New Chronology 168-9

New Martyrs and Confessors of Russia 93

Nicholas I 127

Nicholas II 33, 82n6; canonisation 92-3; portrayal $53,55,57,61,62,75$; Stolypin 46, 66, 73

Night Wolves 219

Nika Award 206n16

Nikola Film 100

Nikonova, Natal'ia 208, 212-13, 214

NKVD (People's Commissariat for Internal Affairs) 172

NMG (National Media Group

Television) 208, 212, 213

non-state actors 3-4, 22-3, 225

Norris, Stephen 28-9

Nosovskii, Gleb 168

Novaia Oprichnina 171-9

Novgorod 85, 124, 165

Novikova, Anna 26-7
Novodvorskaia, Valeriia 78

NTV 10, 52, 74, 141

Oil Painting (TV show) 212

Okhlobytsin, Ivan 197-8

Okhrana 52, 58, 60, 62, 63, 64

oligarchs 145, 149, 162n11

opinion polls $69,161,211,221$; Levada

Centre 10, 25, 134, 170, 216n6

opposition to the state $9,73-4,135$, 169-70, 194, 222-3, 225-6

oprichnina 14, 165, 169-71, 197, 201-3, 205; Ivan the Terrible (2009) 186, 188;

Novaia Oprichnina 171-9, 218; Tsar (2009) 192-6

Oprichnoe Brotherhood 180-1

Orthodox brotherhoods 89, 180-1

Orthodox Church see Russian Orthodox Church

Orthodox Encyclopedia project 120n14

Orthodox Rus' (exhibition) 132-3

The Other Day 1961-2003: Our Era (1997-2003) 10

Our Lady of Kazan 125, 132, 162n3

palimpsestic layering see memories, layers

Pampushnyi, Anton 102

parades 8,220

Parfenov, Leonid 10, 76

The Pastor's Word (TV show) 112

Patriotic War (1812) 128, 136, 137-8, 217-18

patriotism 85, 106, 196, 224-5; nationalist movements 173,177 ;

Orthodox fundamentalists 180 ; state $9,98,119,133,136-7,152-3$, 160-1, 222; symbols $37 \mathrm{n} 7$

Pavlovskii, Igor' 203

People's Commissariat for Internal Affairs (NKVD) 172

People's Movement 'Holy Rus" 183

Perestroika period 9, 42, 87, 129, 226

performance art 178-9

personal freedoms 44, 47, 62, 81

Peter the First: The Testament (2011) 153

Peter the Great 18n19, 108, 125, 224; Nevskii 85, 86; as reformer 8,14

Petr Stolypin: A Shot at Russia (2012) 72-9

Petrovskaia, Irina 212, 215

Platt, Kevin 166-7, 194-6, 223-4

Poland 104, 176; theatre 135-6; Time of Troubles 124-5, 132, 149-50, 165 
Poliakov, Iurii 210

Polish-Lithuanian forces 130, 141, 150

political elites 171, 174, 200

politics of memory see memory politics

Porechenkov, Mikhail 153

positive memory chains 138

power: centralisation $46,57,130$; personalisation 65 ; vertical of power $28,65,73,77,81,171$

Pozharskii, Prince Dmitrii 124-6, 128, 149-50, 153; statues 126, 131, 141, 144, 217

Pozhigailo, Pavel 45, 49

Presidential Commission to Counter Attempts to Falsify History 7, 196 press freedom 3, 220-1

The Priest (2009) 94

Primakov, Evgenii 99

Private Screening (TV show) 157

Programme 200 92, 96

protest movement (2011/12) 73-4, 78, 81,161

Pskov Spiritual Mission 94

Pudovkin, Sergei 128

Pushkin, Aleksandr 108, 126, 155-9

Pussy Riot 91, 178

Putin, Vladimir 44, 50, 74-5, 158; Day of National Unity 129-30, 160-1; film industry $12,28-9$; memory chains $6-7$, 136-7; myth 122-3, 186; Nevskii 104; popularity 70, 116-17; recycling Soviet myths 26; Russian Orthodox Church $89,132,139$; Russian traditions 222, 226; Stolypin 13, 41, 44, 46, 48-9, 55, $57,69,77,79-80$

quotations 32

Rasputin, Grigorii 33, 63, 180

recirculation of memories 20-1, 23, 29, $32-5,88$

reformers 8-9, 66-7, 69-70; see also

Stolypin, Petr

religious education 91

remediation 13, 30-7, 223; Ivan the

Terrible 183-4, 205; Nevskii 118-19; oprichnina myth 169-70; Stolypin 66, 79, 81; Time of Troubles 123; visual images 144-8, 158-9, 223; see also mediation

Repin, Il'ia 166-7, 182, 204

revolutions 145; 1905 revolution 41, 52, $66,68,75$; October $63-4,69,130,134$, 138,141
Riurik dynasty 84, 85, 94, 124

ROC see Russian Orthodox Church

Rodichev, Fedor 42, 54

Rodnianskii, Aleksandr 113, 216

Rogozin, Dmitrii 69, 70, 108

Roman Catholic Church 85, 103, 150, 176, 189, 197

Romanov, Mikhail 124-5, 149

Romanov dynasty $34,51-2,94,124-5$, 156; memorials 1-2, 16n1, 20, 92-3, 217; oprichnina 168-9; Stolypin...The Undrawn Lessons (2006) 53; see also Aleksandr I to III; Nicholas I and II

Romanova, Anastasiia 124, 166, 187, 190

The Romanovs: An Imperial Family (2000) 51

Rosen, Baron Egor 128

Rossiia channels 10, 12-13, 107, 184

Rossiia Molodaia 131

RTR 96

The Rider Named Death (2004) 52

Ruskino.ru 105

Russia - My History (exhibition) see My History (exhibition series)

The Russia That We Lost (1992) 51

Russian Agrarian Youth Union 171

Russian Alarm (2005) 140-1, 144

The Russian Empire (2000-03) 76

Russian Entrepreneur (journal) 172

Russian heritage 56-7, 71, 160, 163n16; folklore 165-6; see also traditions

Russian identity see national identity

Russian March 131, 135

Russian Orthodox Church 64, 85, 88-91, 96-7, 115, 217; church construction 92, 95-6, 98, 219; factions 88, 120n11; fundamentalists 14, 88-9; Ivan the Terrible 179-83, 186; The Name is Russia (2008) 112; Nevskii 14, 84, 107, 118-19; relationship with the state 14 , 89, 91, 119, 194-5; Stolypin 68; symbolism 89, 99-100; Time of Troubles 132-3, 142-4; traditional identity $71,73,91-6,138,144,150$

Russian people 127, 130; ethnic Russians 60, 64, 90-1

Saakashvili, Mikheil 115

Saint Andrew Foundation 98

St Petersburg 87-8

Sakharov, Andrei N. 69, 108

Savinkov, Boris 53, 60, 82n5

Schenck, Frithjof Benjamin 85-6, 87

The Searchers (TV series) 10 
Second World War see World War II self-censorship 27, 220, 224

Seliger camp 159-60, 163n17

separatism 77, 97, 202

Sergeii of Radonezh 225

Shakurov, Sergei 140

Shchedrin, Andrei 180-1

Shcherbakov, Salavat 41

Shoigu, Sergei 99, 116

Shuiskii, Ivan 187

Siberia 69-70, 165

The Sins of Our Fathers (2004) 52

Sipiagin, Dmitrii 75

Skumin, Viktor 117

Skuratov, Maliuta 169, 187, 192, 194-5, 218

Smolianinov, Artur 149

smutasee Time of Troubles

Sobchak, Kseniia 78, 207

Sochi Winter Olympic Games (2014) 220

Social Democrats 56, 59

Socialist Revolutionaries (SR) 33, 52, $57-8,60$

Sokolov, Nikita 65

Sokurov, Aleksandr 13, 154

Solov'ev, Arkadii 212

Sorokin, Vladimir 169-70, 176, 178, 192, 195

Sorokina, Svetlana 212-13

Soviet Union: collapse 5-6, 91, 129, 138, $142,169,202$; historiography 15,36 , $42,79,127-9,164-5$; legacy $15,25-6$; memory chains 34,36 ; mythmaking 6 , 110, 119; portrayal 141; repression 15, 93, 121n17, 156, 164; Soviet Union 2.0 $175,200,205$

stability 41, 48, 81, 178, 200, 202; Time of Troubles 153, 160-2

Stalin, Iosif 183; Ivan the Terrible 158, 164, 167-8, 175-6, 185, 201, 204-5; The Name is Russia (2008) 108, 109-11, 116; Nevskii 85, 86; popularity $7-8,51,71,117,180$, 193; Time of Troubles 123, 127-8, $138,145,146-7$

Starikov, Nikolai 219

state see government

statues: Ivan the Terrible 166-7, 181, 205n1; Minin and Pozharskii 126, 131, 141, 144, 217; Nevskii 87-8; Patriarch Germogen 217; Putin 50; Stolypin 41, 42, 48-50, 80, 219; see also memorials; memory artefacts
Stolypin, Petr 13-14, 33, 108, 159, 219; assassination 41, 53, 63-4, 76; characterisation 53-4, 68-9; commemorative year (2006) 45, 48-51, 79; institutionalisation 41-51, 222; legacy 42-3, 64-5, 75-6; The Name is Russia (2008) 43, 65-72, 76-80; National Prize for the Agrarian Elite 45; Petr Stolypin: A Shot at Russia (2012) 72-9; Putin 13, 44, 48-9, 55, $57,69,77,79-80$; speeches $42,55-6$, 76-7; statues 41, 42, 48-50, 80, 219; symbolism 41, 46, 77, 79-81;

Tolstoi-Stolypin: Private correspondence (2013) 159

Stolypin Club 219-20

Stolypin medal 47, 80

Stolypin...The Undrawn Lessons (2006) $52-65,67,184$

Stolypin's necktie 42, 54, 58

Strizhak, Nika 209

Stroev, Aleksandr 58

Stroeva, Vera 129

Sukhanov, Maxim 155

Susanin, Ivan 125, 127

Suslov, Mikhail 92

Suvorov, Aleksandr 108

Svanidze, Nikolai 10, 199, 201-2, 204, 207, 213-15

Sweden: Nevskii 85, 102-4, 107; Time of Troubles 124, 176, 189

symbolism: foreign aggression 125 ;

Russian Orthodox Church 89, 99-100; state 4-7, 21-2, 79-81, 217; Stolypin $41,46,77,79-81$

symphonic model 89, 91

talk shows 117-18, 152, 199-200

Targamadze, Givi 74

Tatars 85, 103-4, 107, 114, 189

Taurus (2001) 154

Teatr.doc 135, 159, 161

television 210, 211-12; channels 12, 14, 17n10, 23, 25-6; documentaries 5, 10, 72-9, 140-8; historical dramas 51-65, 185 , 186-92; programming 131-2,

207; representation of the past 5, 23-9, 81, 152; state intervention 3, 9-11; viewing figures $9-11,190$

terrorism 33, 64, 202; Romanov Russia $42,54,57-8,60,61,63-4$

Teutonic Knights 85, 103, 128, 165, 176 theatre $129,135-6,158-9$ 
Tikhon, Archimandrite 84, 94, 120n1, 178

Time of Troubles 13, 48, 80, 224; 1612: Chronicles of the Time of Troubles (2007) 101, 148-53; cultural memory 124-9; Empire: The Time of Troubles (2009) 133-4; The End of the Time of Troubles (2005) 142-4; institutionalisation 123, 129-36; A Life for the Tsar (Glinka, 1836) 127, 129; memory chains 136-40; remediation 123-4, 160-2, 218; television documentaries 141-5; Yeltsin era 160

Time of Troubles (2005) 141-2

The Time of Troubles (2006) 144-6

Time of Troubles: The Living Dead (1997) 134

Timofeev, Aleksandr 168

Tkachev, Aleksandr 108, 115

Tolstoi, Aleksei 167

Tolstoi, Lev 69, 159

Tolstoi - Stolypin: Private correspondence (2013) 159

Torkunov, Anatolii 97

Traditionalists (within Russian Orthodox Church) 88

traditions 21, 71, 90, 119-20;

reclamation $5,45,137-8$,

$160-1,222 ;$ see also

Russian heritage

Trepov, Vladimir 55, 61

Tret'iakov Gallery 182

The Trial of The Trial (2010) 199, 209-12

The Trial of Time (2010) 10, 199-200, 207-16

TriTe 79, 149

Troepol'skii, Vladimir 213, 216n3

Tsar (2009) 176, 182, 190, 192-9

Tsereteli, Zurab 50, 131, 181,218

Tsvetkova, Vera 208

Tsyrkun, Sergei 190

tyranny 166, 201, 204

Ukraine 8, 84, 107, 204-5; Crimea 90, 217-18; Orange Revolution 7, 52, 74, 173-4, 176-7

Ulianovsk State Agrarian Academy 50

Ulybin, Viacheslav 96, 97

Unicorn Games Studio 88

Unified Energy System of Russia 149
Union of Cinematographers of the Russian Federation 13, 23, 79

United Russia party 172

United States 178, 203

Ural Mining and Metallurgical Company (UGMK) 98

Uskov, Nikolai 198-9

USSR see Soviet Union

Uzhankov, Aleksandr 158

Varennikov, Valentin 108, 109

Varshavchik, Sergei 65, 131-2

Vasil'ev, Oleg 179

Veksel'berg, Viktor 149

Vereshchagin, Leonid 149

vertical of power $28,65,73$, 81,171

VGTRK (All-Russia State Television and Radio Broadcasting Company) $12-13,108$

Victory Day 8, 87-8, 220

video games $88,133-4$

violence 15, 147, 180; Ivan the Terrible 193, 195, 204; Ivan the Terrible (2009) 185-6; state 200-1, 205

visual images: archives 148, 156-7; buildings metaphor 62,67 ; remediation 144-8, 158-9, 223

Vitte, Sergei 70

Vkontakte 155, 173

Vladimir, Prince 219

Voikov, Petr 156

Voina 178-9

Volodarskii, Eduard 52, 59

Von Pleve, V. 58, 59

voting: audiences 199, 202, 204, 214; falsification (The Name is Russia) 109, 115-16; The Trial of The Trial (2010) 209-12

VTB 149

V.V.P. (song) 122

The Wall of Grief $12 \ln 17$

websites 116-17, 190-2, 225-6

The West 7-8, 130; anti-Western sentiments $119,124-5,178$; Nevskii 103, 107, 114; threat to Russia 57, 60-1, 64, 74, 92, 189-90; Time of Troubles 141, 145, 150, 176; see also East and West relationships

Who Are We? Russian Reforms (documentary) 100

Wladislaw, Prince (of Poland) 124 


\section{Index}

World War I 63, 69

World War II 109, 126, 167-8, 205; commemoration $6,8,37 \mathrm{n} 7,220-1$; films $28-9$; memory chains $137,139,143-4$

Year of Russian History (2012) 136, 161,217

Yeltsin, Boris 116, 162n11

Yeltsin era 25-6, 123, 129, 203; break with Soviet past 4, 6-7, 139 ; memory chains $34,68,77$, 123, 144, 149, 160; Russian Orthodox Church 89; television 51

youth movements $7,131,159-60$, $163 \mathrm{n} 17,171$
YouTube 155, 173

Zaldostanov, Aleksandr 'the Surgeon' 219

Zavtra 173, 175

Zbruev, Aleksandr 159

zemshchina (the land) 165, 177

Zemskii sobor 124, 126

Zhirinovskii, Vladimir 47

Zhukovskii, Vasilii 127

Ziuganov, Gennadii 69-70, 93, 108, 110

Zlatopol'skii, Anton 108, 109

Zolotov, Viktor 218

Zvereva, Vera 24-6

Zviagintsev, Andrei 17n14 